\title{
Platelets, from sample to big data
}

\author{
Citation for published version (APA):
}

Van Poucke, S. (2017). Platelets, from sample to big data: exploring granularity in platelet research . [Doctoral Thesis, Maastricht University]. Datawyse / Universitaire Pers Maastricht.

https://doi.org/10.26481/dis.20170705svp

Document status and date:

Published: 01/01/2017

DOI:

10.26481/dis.20170705svp

Document Version:

Publisher's PDF, also known as Version of record

\section{Please check the document version of this publication:}

- A submitted manuscript is the version of the article upon submission and before peer-review. There can be important differences between the submitted version and the official published version of record.

People interested in the research are advised to contact the author for the final version of the publication, or visit the DOI to the publisher's website.

- The final author version and the galley proof are versions of the publication after peer review.

- The final published version features the final layout of the paper including the volume, issue and page numbers.

Link to publication

\footnotetext{
General rights rights.

- You may freely distribute the URL identifying the publication in the public portal. please follow below link for the End User Agreement:

www.umlib.nl/taverne-license

Take down policy

If you believe that this document breaches copyright please contact us at:

repository@maastrichtuniversity.nl

providing details and we will investigate your claim.
}

Copyright and moral rights for the publications made accessible in the public portal are retained by the authors and/or other copyright owners and it is a condition of accessing publications that users recognise and abide by the legal requirements associated with these

- Users may download and print one copy of any publication from the public portal for the purpose of private study or research.

- You may not further distribute the material or use it for any profit-making activity or commercial gain

If the publication is distributed under the terms of Article $25 \mathrm{fa}$ of the Dutch Copyright Act, indicated by the "Taverne" license above, 


\section{Platelets, \\ from sample \\ to big data}

EXPLORING GRANULARITY IN PLATELET RESEARCH

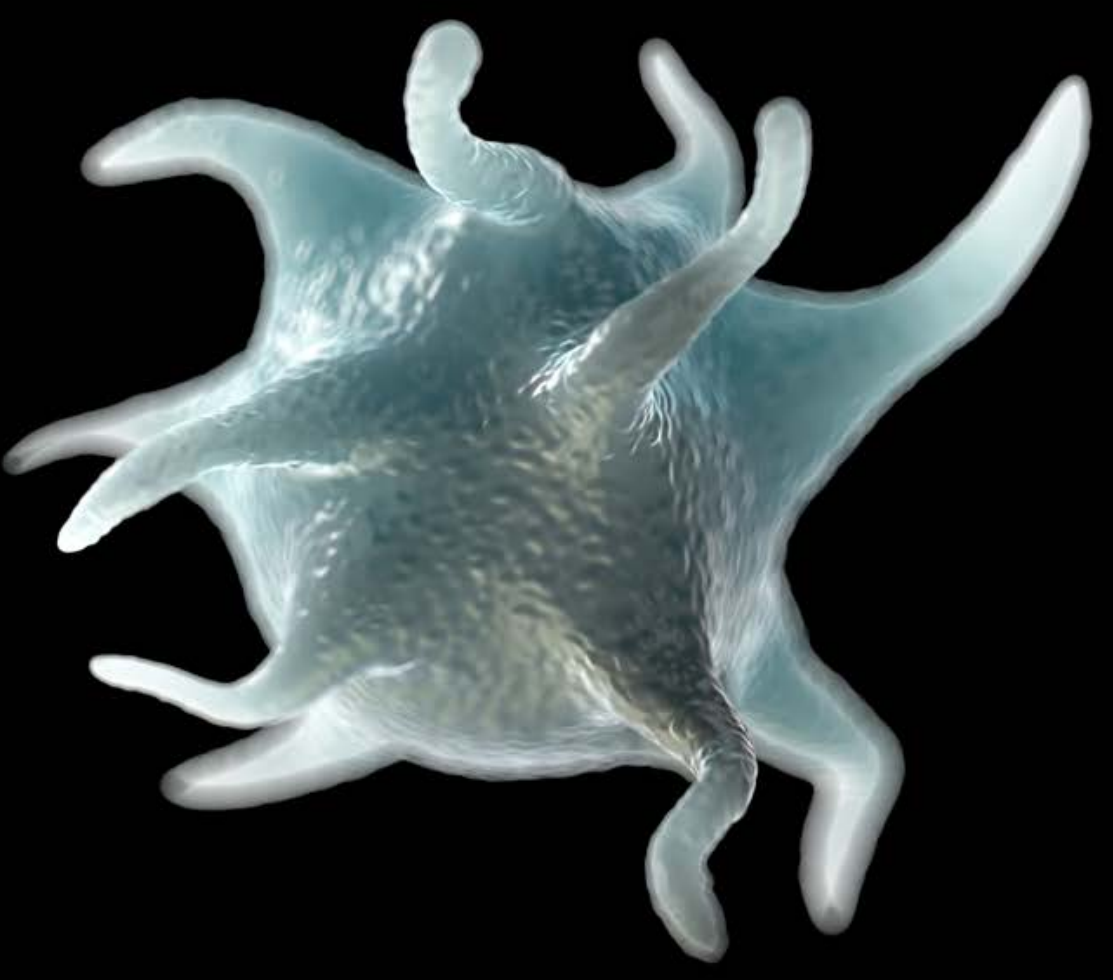

Sven Van Poucke 
(c) copyright Sven Van Poucke, Maastricht 2017

Printing: Datawyse | Universitaire Pers Maastricht

ISBN 9789461597137

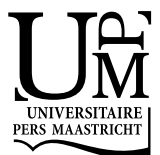




\title{
Platelets, from sample to big data
}

\author{
EXPLORING GRANULARITY IN PLATELET RESEARCH
}

\section{PROEFSCHRIFT}

ter verkrijging van de graad van doctor aan de Universiteit Maastricht, op gezag van de Rector Magnificus, Prof. dr. Rianne M. Letschert volgens het besluit van het College van Decanen in het openbaar te verdedigen op woensdag 5 juli 2017 om 16.00 uur door

\section{SVEN VAN POUCKE}

Geboren op 18 maart 1969 te St. Amandsberg 


\section{PROMOTORES}

Prof. dr. Marco A.E. Marcus

Prof. dr. Wolfgang Buhre

\section{COPROMOTOR}

Dr. Marcus Lancé

\section{BEOORDELINGSCOMMISSIE}

Prof. dr. Hugo te Cate (voorzitter)

Prof. dr. Christa Boer (VUmc, Amsterdam)

Dr. Bas de Laat

Prof. dr. Dieter Mesotten (UHasselt, Hasselt, B)

Prof. dr. Steven Olde Damink 
To my loved ones

\section{'WE CANNOT SOLVE OUR PROBLEMS WITH THE SAME THINKING WE USED WHEN WE CREATED THEM."}

Albert Einstein 



\section{TABLE OF CONTENTS}

$\begin{array}{lll}\text { CHAPTER } 1 & \text { Introduction }\end{array}$

CHAPTER 2 Hypothermia: effects on platelet function and hemostasis 15

CHAPTER 3 Response of platelet concentrates to pressure and temperature 27 changes without impairment of the in vitro function

CHAPTER 4 Platelet function during hypothermia in experimental mock circulation 39

CHAPTER 5 Early platelet recovery following cardiac surgery with cardiopulmonary 51 bypass

CHAPTER 6 Thrombin generation and platelet activation in cytoreductive surgery combined with hyperthermic intra-peritoneal chemotherapy

CHAPTER 7 Normalization methods in time series of platelet function assays.

CHAPTER 8 From sample to big data

$\begin{array}{lll}\text { CHAPTER } 9 & \text { Discussion and valorization } & 145\end{array}$

$\begin{array}{ll}\text { Nederlandse samenvatting } & 159\end{array}$

$\begin{array}{ll}\text { English summary } & 165\end{array}$

$\begin{array}{ll}\text { Publications } & 171\end{array}$

$\begin{array}{ll}\text { Biography } & 177\end{array}$

Thanks and acknowledgements 181 



\section{CHAPTER 1}

INTRODUCTION

\section{$a_{1}^{2}$ (1)}




\subsection{BACKGROUND}

For computationally managing the various levels of detail in biomedical data, biological granularity is indispensable for both dealing effectively with large amounts of data and for structuring the knowledge to analyze and vertically integrate, across the different levels of granularity. Managing granularities of data in the field of platelet research requires specific methodologies to evolve to new knowledge applicable for clinical practice. In this thesis, the author attempted to find inflection points for innovation. Current inflection points in biomedical research are related with the capacity for description and collecting data, the efficiency of compiling, organizing, manipulating these data and extracting true understanding of fundamental biological processes, and insights into human health and disease, from them.

\subsubsection{PLATELET BIOLOGY}

Platelets (2 4 microns in diameter) are essential effectors of cellular hemostasis in humans and other mammals. Although the relevance of platelets in hemostasis and thrombosis is well established, platelets also contribute to host inflammatory and immune responses in infections or injury [1]. Suggested by comparative biology of the innate antibacterial and primitive hemostatic systems of invertebrates, the anucleate human platelet is a specialized cell fragment unique to mammals. Nonmammalian vertebrates, such as fish and birds, have nucleated platelets. Fig. 1.

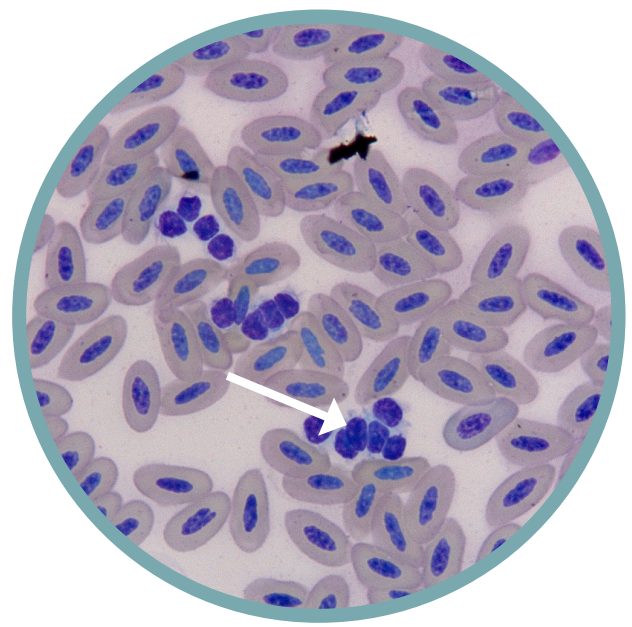

Fig.1. Photomicrographs of avian thrombocytes. Hemacolor stained (Merck), magnification 100x. Kindly provided by Prof. Tom Hellebuyck, DVM, PhD, Dipl ECZM (Herpetology). Department of Pathology, Bacteriology and Avian Diseases.

Division of Poultry, Exotic Companion Animals, Wildlife and Experimental Animal, Salisburylaan 133, 9820 Merelbeke, Belgium

Invertebrates have an even more primitive blood cell, the amebocyte.

The amebocyte is the single blood cell of invertebrates with a multitude of functions. The presence of platelets in fetal blood by 12 weeks of gestation suggests that platelet functions are useful to the fetus [2]. 
Platelets lack nuclei, but perform various vital functions of nucleated cells. Platelets can generate new cell bodies packed with respiring mitochondria and a-granules [3]. Whereas platelets were once considered to function exclusively during hemostasis and thrombosis, they are now considered to function as circulating sentinels in the activation and modulation of the host immune response [4-6].

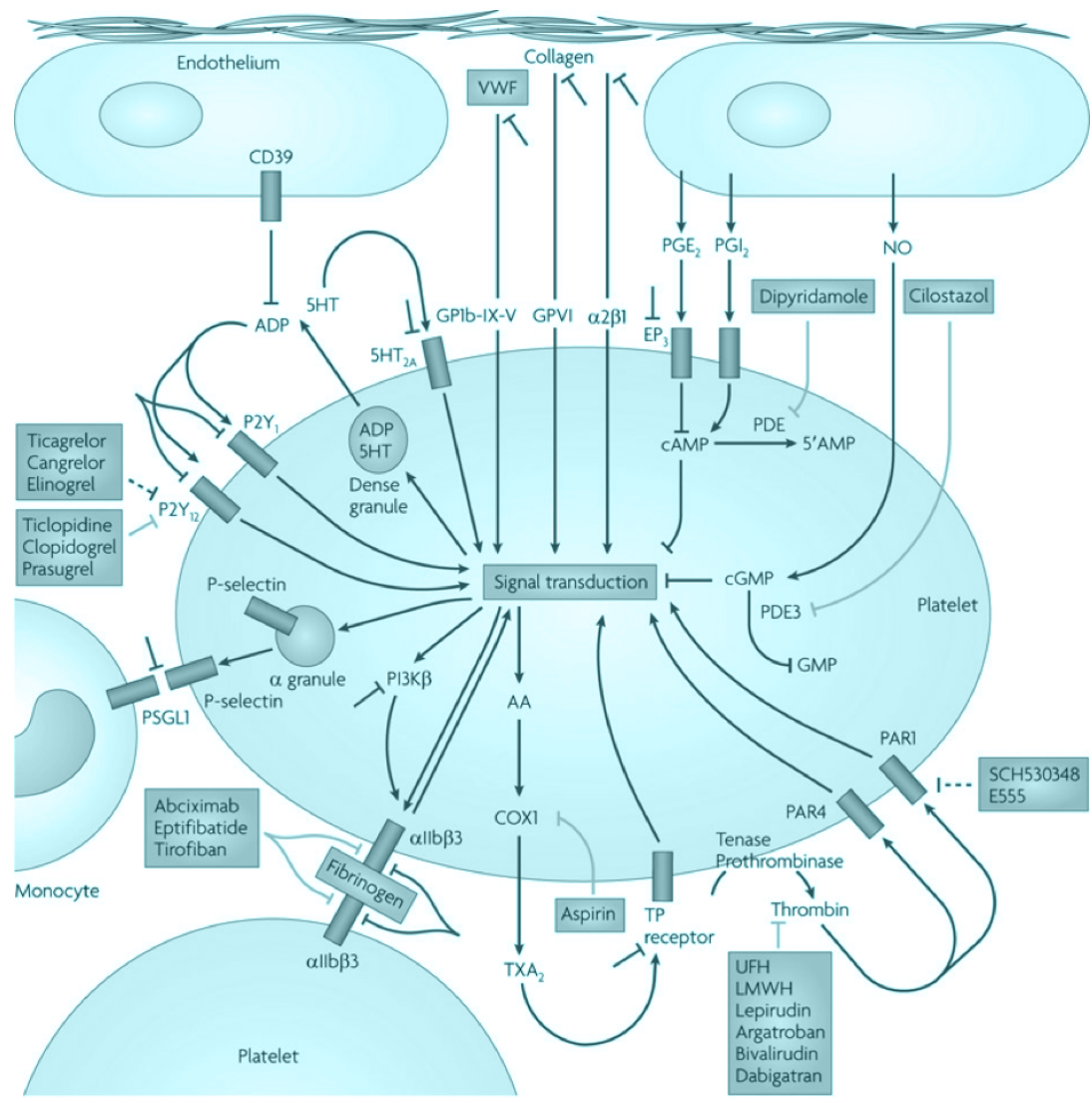

Nature Reviews | Drug Discovery

Fig.2. Platelet function and molecular targets of antiplatelet agents.

Copyright to Antiplatelet therapies for the treatment of cardiovascular disease. Alan D. Michelson Nature Reviews Drug Discovery 2010; 9: 154-169

Copyright License Number: 4038090975816 
In the process of thrombus formation, a crucial participation of platelet receptors and signaling processes is essential. Initial tethering and firm adhesion of platelets to the exposed subendothelium is mediated by the glycoprotein (GP) Ib/IX/V complex and collagen receptors, GP VI and a2 $\beta 1$ integrin, on the platelet surface and by the Von Willebrand factor ( $V W F$ ) and fibrillar collagen at the vascular site. Thereafter, soluble agonists, ADP, thrombin, thromboxane A2, produced and released at the site of the vascular injury act in autocrine and paracrine mode in order to amplify platelet activation and to recruit circulating platelets to the developing thrombus. (Fig. 2.) Specific interactions of these agonists with their G-protein coupled receptors generate inside-out signaling leading to conformational activation of integrins, in particular by allbß3 increasing their ligand activity.

\subsubsection{CLINICAL ASSAYS}

Routine laboratory assays such as activated clotting time, activated partial thromboplastin time, prothrombin time, or platelet count do not provide sufficient specificity and/or sensitivity to assess coagulation and platelet disorders in the majority of clinical conditions. Different assays have been developed in the previous years aiming to quantify coagulation and platelet disorders by more reflecting the invivo context of hemostasis. Additionally, novel tests are able to quantify the effect of specific agonists enabling to quantify the pharmacodynamic impact of certain drugs.

Viscoelastic tests such as rotational thromboelastometry (ROTEM)-performed on whole blood-elucidate the contribution of platelets, intrinsic and extrinsic coagulation pathways [7]. The gold standard for platelet function (PF) testing is light transmission aggregometry (LTA), described as first by Born et al. The need for centrifugation, and consequently longer turn-around times, makes LTA less applicable in perioperative bleeding management. Multiple electrode impedance aggregometry (MEIA) using whole blood and similar agonists as LTA has the potential as point-of-care PF test, although MEIA seems more sensitive to variations in platelet count $[8,9]$. Additionally for the purpose of this thesis, thrombin generation was quantitatively analyzed by means of the calibrated automated thrombogram assay (CAT) and platelet function was quantitatively assessed by the PAC-t-UB assay $[10,11]$. Except fibrin formation and clot firmness (which can be measured by viscoelastic measurements), the CAT assay is able to provide an overall function of the coagulation status. 


\subsubsection{FROM SAMPLE TO BIG DATA}

Despite the accelerating pace of scientific discovery, the current clinical research enterprise does not fully address daily clinical questions such as "what is the most adequate course of action for a particular patient (e.g. 'Is platelet transfusion required?'), under certain conditions, in this phase of the disease?" [12]. From a clinician's perspective, the most abundant information available for decision making is based on observations and experience [13]. With the accumulation of large amounts of health-related data, the methods for therapeutic effect quantification have been rapidly evolving and are driven by recent innovations in statistics, machine learning, and big data analytics [14].

Despite the abundance of available data, fitting data in to a model in order to explain observations might be plausible and appears to be in agreement with clinical experiences, the derivation of natural laws or theories cannot be justified. From an epistemological point of view (Karl Popper), science should strive to describe simple and logical theoretical systems that are testable, before enabling any predictions [15]. Classically, deductive science begins with a hypothesis or theory and proceeds in order to derive possible conclusions and statements. With the introduction of precision medicine, as an emerging approach for disease treatment and prevention, the question arises whether simple and logical theoretical systems are the only choice for predictive analysis of complex, high-dimensional data from a multimorbidity patient population [16]?

Various methods have been presented to predict future outcomes or to forecast trends using observational data [17]. Observational data research might seem attractive because of lower cost and time consumption, but it is mostly considered inferior compared to prospective research. In the big data and internet of things (IOT) era, "observational" data are abundant and could be considered as a historical clinical footprint, valuable for training and testing models from which performance can be quantitatively assessed using new data input [18].

The value of any kind of data is greatly enhanced when it exists in a form that allows integration with other data. One approach for integration is through the annotation of multiple bodies of data using common controlled vocabularies or 'ontologies'. The domain of molecular biology is marked by the availability of large amounts of well defined data that can be used without restriction as inputs to algorithmic processing. In the clinical domain, by contrast, only limited amounts of structured data are available for research purposes, and this data still consist primarily in the form of natural language text [19].

Data collections from patients can be characterized by a large cardinality and dimensionality, variable data distribution and inherent sparseness. In addition, in order to model different aspects within the targeted domain, heterogeneous data types should be processed in the data analysis process. 


\subsection{JUSTIFICATIONS FOR THE RESEARCH}

The justification of this research was based on the FINER criteria applicable for the development of a research question. The "Feasibility" of the experiments as presented in this thesis was guaranteed. The problem of adequate number of subjects was addressed in particular in the context of transition from small samples to big data. Adequate technical expertise was accessible thanks to the Synapse laboratory and the input of the (co)promotores. Affordability in terms of time and money was only possible thanks to the investment and support of the Department of Anesthesia of the University of Maastricht, the Department of Anesthesiology, Intensive Care, Emergency Medicine and Pain Therapy of the Ziekenhuis OostLimburg Genk and the laboratories of Synapse and Genk. The research project could be managed within scope.

The subject was considered "Interesting" in particular in terms of data availability which was considered as both wide (from large populations, big data) and deep (large amount of data per patient). The combination of various innovative tests as provided by the Synapse laboratory enabled deep investigation in terms of data availability. Wide data was available from the MIMIC database and allowed for analytics (e.g. feature selection) of various trends which are suited for epidemiological studies, the development of quality indicators for departments (eg, readmission rates, optimization of the choice of lab tests), the introduction of drugs, the development of early warning systems. In other words, the secondary use of wide data provides essential raw material for key operations in health care. Plans and priorities of governmental health departments and clinical decision making based on historical disease characteristics both depend on secondary data.

The research of this thesis was considered "Novel" in the sense that the results confirmed, refuted or extended previous findings. Innovative technology by means of assays and analytical algorithms were used and implemented in this research.

All research was approved by "Ethical "Committees as mentioned in the manuscripts. The thesis was "Relevant" to scientific knowledge, to clinical and health policy, and to future research.

\subsection{RESEARCH QUESTIONS}

$\mathrm{RQ1}$ :

What is the measurable impact of temperature and/or pressure changes on platelet function (Ch2, Ch6), in in-vitro context (Ch3), during experimental mock circulation (Ch4) and during two different in-vivo extracorporeal circulation techniques? (Ch5, Ch6)

RQ2:

Which technological, computational and epistemological (the study of knowledge and justiffed belief) challenges are faced by studying platelets in a big data context? (Ch7, Ch8) 


\subsection{REFERENCES}

1. Ware J, Corken A, Khetpal R. Platelet function beyond hemostasis and thrombosis. Curr Opin Hematol 2013;20:451-6.

2. Wiedmeier S, Henry E, Sola-Visner M, Christensen R. Platelet reference ranges for neonates, defined using data from over 47000 patients in a multihospital healthcare system. J Perinatol Off J Calfornia Perinat Assoc 2009;29:130-6.

3. Schwertz H, Rowley JW, Tolley ND, Campbell RA, Weyrich AS: Assessing protein synthesis by platelets . Methods Mol Biol 2012,788:141-153.

4. Jenne CN, Urrutia R, Kubes P: Platelets: bridging hemostasis, inflammation,and immunity. Int J Lab Hematol 2013,35:254-261.

5. Horstman LL, Jy W, Ahn YS, Zivadinov R, Maghzi AH, Etemadifar M, Steven Alexander J, Minagar A: Role of platelets in neuroinflammation:a wide-angle perspective. J Neuroinflammation 2010,7:10

6. Jurk K, Kehrel BE: Platelets: physiology and biochemistry. Semin Thromb Hemost 2005, 31:381-392

7. Romlin BS, Wåhlander H, Synnergren, Baghaei F, Jeppsson A. Earlier detection of coagulopathy with thromboelastometry during pediatric cardiac surgery: a prospective observational study. Pediatric Anesthesia 2013;23(3):222-227.

8. Tóth $\mathrm{O}$, Calatzis A, Penz S, Losonczy H, Siess W. Multiple electrode aggregometry: a new device to measure platelet aggregation in whole blood. Thrombosis and Haemostasis 2006;96(6):781-788.

9. Femia EA, Scavone M, Lecchi A, Cattaneo M. Effect of platelet count on platelet aggregation measured by impedance aggregometry (Multiplate ${ }^{\mathrm{TM}}$ analyser) and by light transmission aggregometry. Journal of Thrombosis and Haemostasis 2013;11(12):2193-2196.

10. Hemker HC. Thrombin generation : biochemical possibilities and clinical reality. Blood 2015;126:288-9.

11. Roest M, van Holten TC, Fleurke G-J et al. Platelet Activation Test in Unprocessed Blood (Pac-t-UB) to monitor platelet concentrates and whole blood of thrombocytopenic patients. Transfus Med Hemother. 2013;40(2):117-25.

12. Van Poucke S, Thomeer M, Hadzic A. 2015, big data in healthcare: for whom the bell tolls? Critical Care 2015;19:171.

13. Greenhalgh T, Howick J, Maskrey N. Evidence based medicine: a movement in crisis? BMJ 2014;348:g3725-g3725.

14. Jager LR, Leek JT.An estimate of the science-wise false discovery rate and application to the top medical literature. Biostatistics 2014;15:1-12

15. Winkler R. Popper and the Omics. Front Plant Sci 2016;7:1-3.

16. McCarthy M. Obama promises to defend health law and promote "precision medicine". BMJ 2015;350:h385.

17. Dinov ID. Methodological challenges and analytic opportunities for modelling and interpreting Big Healthcare Data. Gigascience 2016;5:12.

18. Zigler CM, Dominici F. Uncertainty in Propensity Score Estimation: Bayesian Methods for Variable Selection and Model Averaged Causal Effects. J Am Stat Assoc 2014;109:95-107.

19. Smith B, Ceusters W, Klagges B, Köhler J, Kumar A, Lomax J, Mungall C, Neuhaus F, Rector AL, Rosse C. Relations in biomedical ontologies. Genome Biol 2005;6:R46. 


\section{CHAPTER 2}

\section{EFFECT OF HYPOTHERMIA ON PLATELET FUNCTION AND HEMOSTASIS}

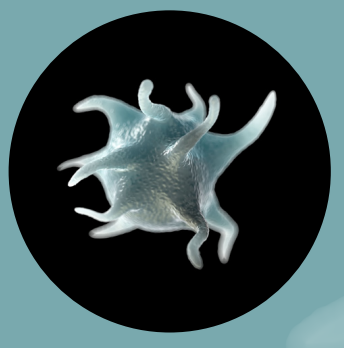

Sven Van Poucke, Kris Stevens, Abraham Emanuel Marcus and Marcus Lancé.

Thrombosis Journal 2014;12:31 


\begin{abstract}
Mild therapeutic hypothermia is considered standard care in the treatment of patients resuscitated from cardiac arrest. With increasingly more frequent concomitant use of platelet-inhibiting drugs, clinicians must be cognizant of the ramifications of hypothermia on platelet function as part of the hemostasis. The effects of hypothermia on platelet function have been studied for more than 50 years, but the results are inconsistent and may be related to the circumstances during which hypothermia is achieved. This review summarizes current knowledge of platelet function during hypothermia and the impact on hemostasis.
\end{abstract}

\title{
2.1 INTRODUCTION
}

Although humans are homeothermic, significant body-temperature changes can result in life-threatening situations (including bleeding and thrombosis), particularly in association with certain medical conditions [1-10].

Platelets lack nuclei, but perform multiple vital functions of nucleated cells. Platelets can generate new cell bodies packed with respiring mitochondria and a-granules [11]. Whereas platelets were once considered to function exclusively during hemostasis and thrombosis, they are now considered to function as circulating sentinels in the activation, modulation of the host immune response [12-14].

This review summarizes current knowledge of platelet function during hemostasis under various hypothermic conditions. The review will not discuss the effect of systemic hypothermia on the pharmacokinetics and pharmacodynamics of antiplatelet drugs [15-19]. 


\subsection{REVIEW}

\subsubsection{FUNDAMENTAL ASPECTS OF HYPOTHERMIA}

The research on hemostasis in the setting of hypothermic reveals inconsistent, even conflicting results, ranging from seasonal increase in thromboembolic disease in winter to excessive surgical bleeding in hypothermic patients.

The effects of hypothermia on coagulation and platelet function is influenced by [20]:

$>$ the actual body temperature during sampling,

$>\quad$ the pre-analytical and analytical temperature and sample type (in-vivo, ex-vivo, in-vitro; whole blood, washed platelet preparation)

$>$ temperature changes during the sampling time (induction, maintenance, and rewarming)

$>$ the moment of sampling in relation to agonist stimulation

$>\quad$ the duration of hypothermia

$>\quad$ the cause of hypothermia (induced externally or internally)

$>$ coexisting factors (extracorporeal circulation [21], comorbidity, drugs)

$>\quad$ the modality of induced hypothermia (local, regional, or general) [2]

Hypothermia can be caused by metabolic dysfunction in association with decreased heat production (hypothyroidism, hypoglycemia, or hypoadrenalism) or disturbed thermoregulation (intracranial tumor or degenerative neurological disorders). Accidental hypothermia is an unintentional decrease of core temperature caused by prolonged exposure to cold [22]. Hypothermia acts as a natural survival strategy in some animals that hibernate, and actively suppresses metabolism $[4,23,24]$.

In trauma patients, extra precautions are required based on inherent bias due to absolute or relative hypovolemia and acidosis [25].

Since the early 1950 s, active therapeutic cooling has been used during specific surgical procedures to reduce oxygen requirements of organs such as the brain, heart, and kidney $[26,27]$. The use of hypothermia has recently been extended to post-resuscitation care based on results from more intensive and innovative monitoring techniques [28-31]. While precluding the current guidelines for platelet storage, research on chilled platelets (at $4^{\circ} \mathrm{C}$, ex-vivo) should be differentiated from research on deep hypothermic circulatory arrest at in-vivo temperatures of $15-18^{\circ} \mathrm{C}$ and from research on cardiopulmonary bypass and post-resuscitation at temperatures $>=28^{\circ} \mathrm{C}$. 
Hypothermia has been shown to result in hemoconcentration, leukopenia and thrombocytopenia, slowing down of coagulation enzymes, disordered fibrinolysis, and disruption of platelet function [6,32-34]. Some hematologic diseases are directly influenced by temperature changes; for example, cold agglutination disease exhibits an increase in cold agglutinin titers [35].

With more frequent use of hypothermia in clinical practice and concomitant use of platelet-inhibiting drugs, there is a growing need to understand the ramifications of platelet-inhibiting drugs on coagulation and platelet function [36,37].

\subsubsection{EFFECT OF HYPOTHERMIA ON PLATELETS}

\section{PLATELET MORPHOLOGY}

Chilling platelets $\left(4^{\circ} \mathrm{C}\right)$ in vitro results in volume increase, spherical deformation, and the formation of lose marginal microtubules and pseudopods [38,39] (Fig. 1. ). The chilling-induced $\left(\mathrm{O}^{\circ} \mathrm{C}\right.$, ice water), reversible shape-change in platelets correlates with phosphorylation of myosin, subsequent interaction on actin filaments and free cytosolic calcium increase [40]. Human platelets can be maintained in a discoid shape in the cold, in vitro, using a cell-permeable calcium chelator to attenuate calcium mobilization and cytochalasin B to prevent barbed-end actin assembly [39]. FTIR spectroscopy in northern elephant seals confirms three different thermotropic membrane phase transitions [39]. The microtubules of hibernating mammals are more tolerant to cold, which facilitates the rapid shift from a thrombocytopenic, anticoagulant state during torpor to a normal state $[3,4]$.
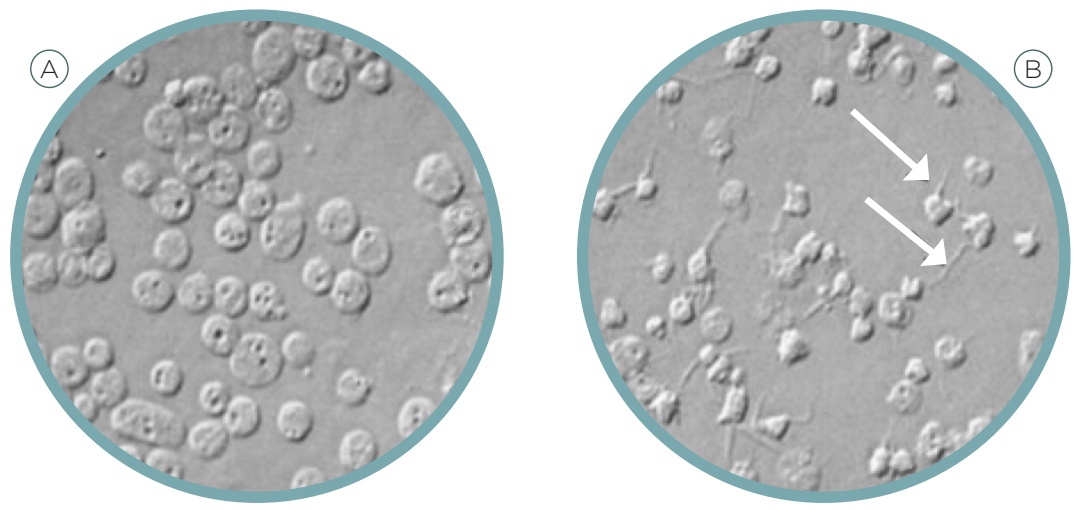

Fig.1. Differential interference microscopy (DIC) micrographs comparing control (A: $37^{\circ} \mathrm{C}$ ) and chilled (B: $4^{\circ} \mathrm{C}$ ) Northern Elephant Seal platelets. A: At $37^{\circ} \mathrm{C}$, the platelets generally maintain a resting, discoid shape with occasional filopodia. B: After chilling to $4{ }^{\circ} \mathrm{C}$ for one h, most elephant seal platelets show a condensed and spherical phenotype with multiple filopodia (arrows). Copyright to Response of Northern Elephant Seal platelets to pressure and temperature changes: A comparison with human platelets. Cara L. Field,Fern Tablin. Comparative Biochemistry and Physiology Part A: Molecular \& Integrative Physiology. Copyright (c) 2012 Elsevier Inc. Copyright Clearance: 4051800720272 


\section{PLATELET FUNCTION}

Platelet adhesion and activation leads to their aggregation and ultimately to the formation of a fibrin-rich hemostatic plug [41]. Hypothermia promotes platelet margination by increasing hematocrit, changing platelet shape, lowering blood flow rate, and increasing the expression of adhesion molecules.

\section{Low temperature enhances shear-induced platelet aggregation}

Platelets interacting with the vessel wall are influenced by the small-scale motions of neighboring erythrocytes, which allows platelets to move across flow streamlines in a form of enhanced diffusion. Platelets contact each other via collisions driven by blood-flow velocity gradients [42]. Adhesive interactions between platelets and the extracellular matrix are strongly influenced by local rheological conditions. Blood is considered a two-phase liquid with a solid-liquid suspension. The viscosity of a liquid is temperature-dependent, and blood viscosity increases with decreasing temperature [43]. Thus low temperature may enhance shear-induced platelet aggregation by increasing blood viscosity [44].

\section{Hypothermia and life span of platelets}

Chilled platelets subjected to refrigeration before transfusion rapidly leave circulation. Therefore, blood banks store platelets at room temperature $[32,45]$. The normal in vivo lifespan of platelets (7-10 days) does not appear to be affected by hypothermia. A surface-induced deep hypothermia study $\left(20^{\circ} \mathrm{C}\right)$ on dogs reported that the mean survival of platelets ( 4.9 days) is slightly but significantly longer in the hypothermic group compared to that in the control group (4.2 days) [46].

\section{Storage, clearance and release underlies the (reversible) thrombocytopenia}

The decrease in platelet count observed in vivo during hypothermia is reversible as normal body temperature is restored. This change in platelet count is explained by hepatic and splenic sequestration, and possibly margination of platelets, relative to hypothermic depth and duration, and with a maximum decline between $25-30^{\circ} \mathrm{C}$ [47-49]. Under mild hypothermia, the reduction in platelet count is modest and remains within the normal range [45]. As core body temperature drops below $37^{\circ} \mathrm{C}$, platelets become more susceptible to activation by thrombotic stimuli, a phenomenon known as priming. Therefore, platelets can act as thermosensors. The ability for priming at peripheral body sites, where temperatures are lower and chances for trauma higher evolved as a protective effect against bleeding, whereas more central body sites (brain and coronary vessels) are more protected against thrombosis [39].

Subjecting platelets to chilling changes its surface configuration. In response to cooling, the GPIba subunit of the $\mathrm{vWf}$ receptor complex undergoes clustering and becomes a target for recognition by hepatic macrophage complement receptor type 3 (CR3), which is strongly expressed in liver macrophages, and leads to platelet phagocytosis and clearance. Compared to mice that are CR3-deficient, mice overexpressing CR3 demonstrate a rapid reduction in platelets counts when exposed to cold leading to platelet phagocytosis and clearance in the liver [47]. 


\section{vWF retention is prolonged on the cell surface at low temperatures}

VWF is a protein that circulates in a globular form under conditions of low shear-stress, but changes into an elongated form under the influence of stronger hydrodynamic shear forces [50,51]. Expression of VWF in endothelial cells is higher at low temperature than at normal temperature [52]. The kinetics of VWF proteolysis by the cleaving metalloprotease ADAMTS-13 is temperature-dependent, with slower but complete activity at $4^{\circ} \mathrm{C}$ and at $22^{\circ} \mathrm{C}$. A sub-physiological temperature might influence the proteolysis kinetics due to minor variations in ADAMTS-13 structure, or further modification of the VWF substrate [53]. The failure of secreted VWF to form long cellsurface strings following its secretion at low temperatures $\left(\leq 17^{\circ} \mathrm{C}\right)$ results in formation of predominantly globular deposits. This failure of VWF to unfurl at lower temperatures, combined with its reduced thermal motions, may interfere with the prolonged retention of this protein on the cell surface, and may result in hemostatic disorders [54].

\section{The recognition of VWF with factor VIII is sensitive to temperature changes}

Closely related to VWF is factor VIII which, after its extracellular release, forms a complex with $v W F$ [51]. Thermodynamic analysis reveals that the recognition process of factor VIII with VWF is very sensitive to temperature changes. Generally, interactions between proteins with pre-optimized binding sites are stimulated by increases in the system kinetic energy (temperature). By contrast, interactions between proteins driven by conformational changes are generally reduced by temperature increases. The stimulatory effect of higher temperatures on the association kinetics and affinity of factor VIII for VWF suggests that this interaction does not require significant conformational changes [55]. The impact of body temperature changes on the recognition process of factor VIII with VWF is currently unknown.

\section{Hypothermia increases the ability of platelets to respond to activating stimuli}

Moderate hypothermia results in a minor increase in spontaneous platelet activation but a significant rise in agonist- induced responsiveness. In-vitro research in mice demonstrates that with incubation at temperatures of $34^{\circ} \mathrm{C}$ and $31^{\circ} \mathrm{C}$, spontaneous expression of P-selectin and the activated conformation of GPIllb-IIla does not change markedly. A small yet statistically significant increase in PAC-1 binding in unstimulated samples at $31^{\circ} \mathrm{C}$ suggested spontaneous hypothermia-induced activation. TRAP exposure during hypothermia causes an increase of PAC-1 binding with increased activation during hypothermia. In line with this, binding of fluorescent-labeled fibrinogen increases at $34^{\circ} \mathrm{C}$ and $31^{\circ} \mathrm{C}$ after TRAP exposure [56].

Although early research only referred to cold effects on platelets as "activation," chilled platelets do not resemble platelets activated by classical agonists such as thrombin, ADP, or collagen. Whole blood aggregation assays demonstrated that platelet aggregation and P-selectin expression are enhanced under hypothermic temperatures but the effect depends on the agonist used. The potency of the agonist does not seem to be related to the susceptibility of platelets to the effects of temperature [57-68].

Interestingly, the platelet intrinsic function is maintained throughout torpor/arousal in hibernators as well as throughout cooling/rewarming and pharmacological induced torpor, as demonstrated by P-selectin expression and platelet aggregometry. P-selectin expression on circulating platelets, however, are significantly decreased in torpid hamsters, but restores to normal euthermic levels shortly after arousal [49]. 


\section{Factors regulating thrombus formation may be tissue and temperature dependent}

Mechanisms that limit or prevent the process of thrombus growth are essential in the balance between prothrombotic and antithrombotic forces. Cold-induced vasodilatation mediates cyclic regulation of blood flow during prolonged cooling of protruding limbs, reducing localized cold injury [69]. The protective effect of $\mathrm{NO}$ and prostacyclin on platelet aggregation during temperature-dependent vasoconstriction and vasodilation, is currently unknown but might be tissue and temperature dependent [70].

\section{The machinery for executing platelet apoptosis is temperature dependent}

Studies on the effects of chemotherapeutic drugs revealed that apoptosis in platelets, as determined by mitochondrial inner membrane potential depolarization is much more efficient at $37^{\circ} \mathrm{C}$ than at room temperature [71]. Cold-storage of platelets followed by rewarming has been shown to trigger apoptosis through a GN-sensitive GPIba-change indicative of receptor clustering [72].

\subsection{CONCLUSION}

The impact of hypothermia on platelet function and its effect on hemostasis has been studied for more than 50 years, yet its effects and the mechanisms behind the observed phenomena have not been fully elucidated. Studies differ in the circumstances under which hypothermia is achieved, and in the duration and extent of temperature decrease. Comparative studies are challenging as the parameters defining sufficient platelet function have not been clearly identified, and experimental studies have not used standardized techniques and platelet-stimulating agents. Conflicting results suggest that the heterogeneous techniques do not accurately reflect in vivo hemostatic function, which involves platelets, coagulation factors, plasma proteins, endothelial and other cells and flow characteristics. Animal models may not be directly translatable to humans as demonstrated in hibernating mammals. The hypothermia-associated coagulopathy is more likely related to a reduced availability of platelet activators, rather than a consequence of an intrinsic defect in platelet function. More research is required to elucidate the activation of platelets, the interaction of platelets and leukocytes and the production of proinflammatory cytokines at different temperatures are required.

\footnotetext{
Abbreviations

o: Degrees, C: Celsius, F: Fahrenheit, L: Liter, kDa: kilodalton, GP: Glycoprotein, vWF: von Willebrand factor, a: alpha, $\beta$ : beta, FTIR: Fourier transform infrared spectroscopy, CR3: Complement receptor type 3, ADAMTS: A disintegrin and metalloproteinase with thrombospondin motifs, TRAP: Thrombin receptor activating peptide, ADP: Adenosine diphosphate, FeCl3: Ferric chloride, CPA: Cone and platelet analyzer, NO: Nitric oxide, PAF: Platelet-activating factor, BH: Bcl-2 homology domain, PT: Prothrombin time, APTT: Activated partial thromboplastin time, ACT: Activated clotting time, TEG: Thromboelastography, ROTEM: Rotational thromboelastometry, MA: Maximal amplitude, MCF: Maximum clot firmness, PFA: Platelet function analysis, PAC-1: Monoclonal antibody against GP IIb-IIla
} 


\subsection{REFERENCES}

1. Field CL, Tablin F: Response of Northern Elephant Seal platelets to pressure and temperature changes: a comparison with human platelets. Comp Biochem Physiol A Mol Integr Physiol 2012;162:289-295.

2. Hurd PL, van Anders SM: Latitude, digit ratios, and Allen's and Bergmann's rules: a comment on Loehlin, McFadden, Medland, and Martin (2006). Arch Sex Behav 2007;36:139-141. author reply 143.

3. Cooper ST, Richters KE, Melin TE, Liu Z, Hordyk PJ, Benrud RR, Geiser LR, Cash SE, Shelley CS, Howard DR, Ereth MH, Sola-Visner MC: The hibernating 13-lined ground squirrel as a model organism for potential cold storage of platelets. Am J Physiol Regul Integr Comp Physiol 2012; 302:R1202-R1208.

4. Britton SW: Extreme hypothermia in various animals and in man. Can Med Assoc J 1930; 22:257-261.

5. Lee S, Alston T: A little hypothermia goes a long way. Crit Care Med 2012; 40:1369-1370.

6. Díaz M, Becker DE: Thermoregulation: physiological and clinical considerations during sedation and general anesthesia. Anesth Prog 2010; 57:25-32. quiz 33-4.

7. Guly H: History of accidental hypothermia. Resuscitation 2011; 82:122-125.

8. Horosz B, Malec-Milewska M: Inadvertent intraoperative hypothermia. Anaesthesiol Intensive Ther 2013; 45:38-43.

9. Bratincsák A, Palkovits M: Activation of brain areas in rat following warm and cold ambient exposure. Neuroscience 200; 127:385-397.

10. Kurz A: Physiology of thermoregulation. Best Pract Res Clin Anaesthesiol 2008; 22:627-644.

11. Schwertz H, Rowley JW, Tolley ND, Campbell RA, Weyrich AS: Assessing protein synthesis by platelets. Methods Mol Biol 2012; 788:141-153.

12. Jenne CN, Urrutia R, Kubes P: Platelets: bridging hemostasis, inflammation, and immunity. Int J Lab Hematol 2013; 35:254-261.

13. Horstman LL, Jy W, Ahn YS, Zivadinov R, Maghzi AH, Etemadifar M, Steven Alexander J, Minagar A: Role of platelets in neuroinflammation: a wide-angle perspective. J Neuroinflammation 2010; 7:10.

14. Jurk K, Kehrel BE: Platelets: physiology and biochemistry. Semin Thromb Hemost 2005; 31:381-392.

15. Gawaz M: Intelligent platelet inhibitors are on the horizon. Arterioscler Thromb Vasc Biol 2011; 31:1949-1950.

16. Topcic D, Kim W, Holien JK, Jia F, Armstrong PC, Hohmann JD, Straub A, Krippner G, Haller CA, Domeij H, Hagemeyer CE, Parker MW, Chaikof EL, Peter K: An activationspecific platelet inhibitor that can be turned on/off by medically used hypothermia. Arter Thromb Vasc Biol 201; 31:2015-2023.

17. Han HS, Park J, Kim J-H, Suk K: Molecular and cellular pathways as a target of therapeutic hypothermia: pharmacological aspect. Curr Neuropharmacol 2012; 10:80-87.

18. Hall R, Mazer CD: Antiplatelet drugs: a review of their pharmacology and management in the perioperative period. Anesth Analg 2011; 112:292-318.

19. Johansson BW: Drugs affect and are affected by body temperature. Lakartidningen 2001; 98:2178-2181.

20. Mackowiak PA, Wasserman SS, Levine MM: A critical appraisal of $98.6^{\circ} \mathrm{F}$, the upper limit of the normal body temperature, and other legacies of Carl Reinhold August Wunderlich. JAMA 1992; 268:1578-1580. 
21. Krajewski S, Kurz J, Geisler T, Peter K, Wendel HP, Straub A: Combined blockade of ADP receptors and PI3-kinase p110beta fully prevents platelet and leukocyte activation during hypothermic extracorporeal circulation. PLoS One 2012; 7:e38455.

22. Marx J: Rosen's emergency medicine: concepts and clinical practice. Mosby/ Elsevier; 2006:2239.

23. Fröbert O, Christensen K, Fahlman A, Brunberg S, Josefsson J, Särndahl E, Swenson JE, Arnemo JM: Platelet function in brown bear (Ursus arctos) compared to man. Thromb J 2010; 8:11.

24. Storey KB: Out cold: biochemical regulation of mammalian hibernation - a mini-review. Gerontology 2010; 56:220-230.

25. Morrison JJ, Ross JD, Poon H, Midwinter MJ, Jansen JO: Intra-operative correction of acidosis, coagulopathy and hypothermia in combat casualties with severe haemorrhagic shock. Anaesthesia 2013; 68:846-850.

26. Mohr J, Ruchholtz S, Hildebrand F, Flohé S, Frink M, Witte I, Weuster M, Fröhlich M, van Griensven M, Keibl C, Mommsen P: Induced hypothermia does not impair coagulation system in a swine multiple trauma model. J Trauma Acute Care Surg 2013; 74:1014-1020.

27. Kheirbek T, Kochanek AR, Alam HB: Hypothermia in bleeding trauma: a friend or a foe? Scand J Trauma Resusc Emerg Med 2009; 17:1-15.

28. Meex I, Dens J, Jans F, Boer W, Vanhengel K, Vundelinckx G, Heylen R, De Deyne C: Cerebral tissue oxygen saturation during therapeutic hypothermia in post-cardiac arrest patients. Resuscitation 2013; 84:788-793.

29. Absalom AR, Scheeren TWL: NIRS during therapeutic hypothermia: cool or hot? Resuscitation 2013; 2013:95-96.

30. Frink M, Flohé S, Van Griensven M, Mommsen P, Hildebrand F: Facts and fiction: the impact of hypothermia on molecular mechanisms following major challenge. Mediat Inflamm 2012, 2012:762840.

31. Broessner G, Fisher M, Schubert G, Metzler B, Schmutzhard E: Update on therapeutic temperature management. Crit Care 2012; 16(Suppl 2):1-42.

32. Palmiere C, Bardy D, Letovanec I, Mangin P, Augsburger M, Ventura F, Iglesias K, Werner D: Biochemical markers of fatal hypothermia. Forensic Sci Int 2013; 226:54-61.

33. Brändström H, Eriksson A, Giesbrecht G, Angquist K-A, Haney M: Fatal hypothermia: an analysis from a sub-arctic region. Int J Circumpolar Health 2012; 71:1-7.

34. Escalda A, Marques M, Silva-Carvalho L, Barradas MA, Silva-Carvalho J, Cruz JM, Mikhailidis DP: Hypothermia-induced haemostatic and biochemical phenomena. An experimental model. Platelets 1993; 4:17-22.

35. Heni M, Saur SJ: Blood clotting at room temperature in cold agglutinin disease. Blood 2013; 121:4975-4975.

36. Penela D, Magaldi M, Fontanals J, Martin V, Regueiro A, Ortiz JT, Bosch X,

Sabaté M, Heras M: Hypothermia in acute coronary syndrome: brain salvage versus stent thrombosis? J Am Coll Cardiol 2013; 61:686-687.

37. Polderman KH: Hypothermia and coagulation. Crit Care 2012; 16(Suppl 2):A2O.

38. Andrews RK, Berndt MC: Platelet physiology: in cold blood. Curr Biol 2003;13:R282-R284.

39. Winokur R, Hartwig JH: Mechanism of shape change in chilled human platelets. Blood 1995; 85:1796-1804. 
40. Kawakami H, Higashihara M, Ohsaka M, Miyazaki K, Ikebe M, Hirano H: Myosin light chain phosphorylation is correlated with cold-induced changes in platelet shape. J Smooth Muscle Res 2001; 37:113-122.

41. Broos K, Feys HB, De Meyer SF, Vanhoorelbeke K, Deckmyn H: Platelets at work in primary hemostasis. Blood Rev 2011; 25:155-167.

42. Grabowski EF, Yam K, Gerace M: Evaluation of hemostasis in flowing blood. Am J Hematol 2012; 87(Suppl 1):S51-S55.

43. Baskurt OK, Meiselman HJ: Blood rheology and hemodynamics. Semin Thromb Hemost 2003; 29:435-450.

44. Zhang J, Wood J, Bergeron AL, McBride L, Ball C, Yu Q, Pusiteri AE, Holcomb JB, Dong J: Effects of low temperature on shear-induced platelet aggregation and activation. J Trauma Inj Infect Crit Care 2004; 57:216-223.

45. Egidi MG, D’Alessandro A, Mandarello G, Zolla L: Troubleshooting in platelet storage temperature and new perspectives through proteomics. Blood Transfus 2010; 8(Suppl 3):s73-s81.

46. Hessel EA, Schmer G, Dillard DH: Kinetics during Deep Hypothermia. J Surg Res 1980; 34:23-34.

47. Hoffmeister KM, Felbinger TW, Denis V, Bergmeier W, Mayadas TN, Von Andrian UH, Wagner DD, Stossel TP, Hartwig JH: The clearance mechanism of chilled blood platelets Brigham and women's hospital. Cell 2003; 112:87-97.

48. Ao H, Moon JK, Tashiro M, Terasaki H: Delayed platelet dysfunction in prolonged induced canine hypothermia. Resuscitation 2001; 51:83-90.

49. De Vrij EL, Vogelaar PC, Goris M, Houwertjes MC, Herwig A, Dugbartey GJ, Boerema AS, Strijkstra AM, Bouma HR, Henning RH: Platelet dynamics during natural and pharmacologically induced torpor and forced hypothermia. PLoS One 2014; 9:e93218.

50. Tanaka KA, Key NS, Levy JH: Blood coagulation: hemostasis and thrombin regulation. Anesth Analg 2009; 108:1433-1446.

51. Lenting PJ, Casari C, Christophe OD, Denis CV: von Willebrand factor: the old, the new and the unknown. J Thromb Haemost 2012; 10:2428-2437.

52. Ai X, Gu Y: The effect of low temperature on von Willbrand factor expression of cultured human umbilical vein endothelial cells. Chin J Surg 1997; 35:597-599.

53. Perutelli P, Amato S, Molinari AC: Cleavage of von Willebrand factor by ADAMTS-13 in vitro: effect of temperature and barium ions on the proteolysis kinetics. Blood Coagul Fibrinolysis 2005; 16:607-611.

54. Carter T, Mashanov G, Ogden D, Zupančič G, Hannah MJ, Hewlett L, Knipe L: Temperature-dependence of weibel-palade body exocytosis and cell surface dispersal of von Willebrand factor and its propolypeptide. PLoS One 2011; 6:e27314.

55. Dimitrov JD, Christophe OD, Kang J, Repessé Y, Delignat S, Kaveri SV, Lacroix-Desmazes S: Thermodynamic analysis of the interaction of factor VIII with von Willebrand factor. Biochemistry 2012; 51:4108-4116.

56. Lindenblatt N, Menger MD, Klar E, Vollmar B: Sustained hypothermia accelerates microvascular thrombus formation in mice. Am J Physiol Heart Circ Physiol 2005; 289:H2680-H2687. 
57. Berger G, Hartwell DW, Wagner DD: P-Selectin and platelet clearance. Blood 1998; 92:4446-4452.

58. Michelson AD, MacGregor H, Barnard MR, Kestin AS, Rohrer MJ, Valeri CR: Reversible inhibition of human platelet activation by hypothermia in vivo and in vitro. Thromb Haemost 1994; 71:633-640.

59. Faraday N, Rosenfeld B: In vitro hypothermia enhances platelet GPIIb-IIla activation and P-selectin expression. Anesthesiology 1998; 88:1579-1585.

60. Scharbert G, Kalb ML, Essmeister R, Kozek-Langenecker SA: Mild and moderate hypothermia increases platelet aggregation induced by various agonists: a whole blood in vitro study. Platelets 2010; 21:44-48.

61. Frelinger AL, Furman MI, Barnard MR, Krueger LA, Dae MW, Michelson AD: Combined effects of mild hypothermia and glycoprotein IIb/IIla antagonists on platelet-platelet and leukocyte-platelet aggregation. Am J Cardiol 2003; 92:1099-1101.

62. Högberg C, Erlinge D, Braun OÖ: Mild hypothermia does not attenuate platelet aggregation and may even increase ADP-stimulated platelet aggregation after clopidogrel treatment. Thromb J 2009; 7:2.

63. Lantz N, Hechler B, Ravanat C, Cazenave J-P, Gachet C: A high concentration of ADP induces weak platelet granule secretion independently of aggregation and thromboxane A2 production. Thromb Haemost 2007; 98:1145-1147.

64. Xavier RG, White AE, Fox SC, Wilcox RG, Heptinstall S: Enhanced platelet aggregation and activation under conditions of hypothermia. Throb Haemost 2007;998:1266-1275.

65. Straub A, Krajewski S, Hohmann JD, Westein E, Jia F, Bassler N, Selan C, Kurz J, Wendel HP, Dezfouli S, Yuan Y, Nandurkar H, Jackson S, Hickey MJ, Peter K: Evidence of platelet activation at medically used hypothermia and mechanistic data indicating ADP as a key mediator and therapeutic target. Arter Thromb Vasc Biol 2011; 31:1607-1616.

66. Scharbert G, Kalb M, Marschalek C, Kozek-Langenecker SA: The effects of test temperature and storage temperature on platelet aggregation: a whole blood in vitro study. Anesth Analg 2006; 102:1280-1284.

67. Wang $\mathrm{X}$ : Comparative analysis of various platelet glycoprotein Ilb/IIla antagonists on shear-induced platelet activation and adhesion. Blood 2002; 100:61B.

68. Wolberg AS, Meng ZH, Monroe DM, Hoffman M: A systematic evaluation of the effect of temperature on coagulation enzyme activity and platelet function. J Trauma Inj Infect Crit Care 2004; 56:1221-1228.

69. Wallin BG: Neural control of human skin blood flow. J Auton Nerv Syst 1990; 30(Suppl):S185-S190.

70. Evora PRB, Cable DG, Chua YL, Rodrigues AJ, Pearson PJ, Schaff HV: Nitric oxide and prostacyclin-dependent pathways involvement on in vitro induced hypothermia. Cryobiology 2007; 54:106-113.

71. Gyulkhandanyan AV, Mutlu A, Freedman J, Leytin V: Selective triggering of platelet apoptosis, platelet activation or both. Br J Haematol 2013; 161:245-254.

72. van der Wal DE, Du VX, Lo KSL, Rasmussen JT, Verhoef S, Akkerman JWN: Platelet apoptosis by cold-induced glycoprotein Iba clustering. J Thromb Haemost 2010;8(11):2554-2562. 
CHAPTER 3

RESPONSE OF PLATELET CONCENTRATES

TO PRESSURE AND

TEMPERATURE CHANGES

WITHOUT IMPAIRMENT OF

THE IN VITRO FUNCTION.

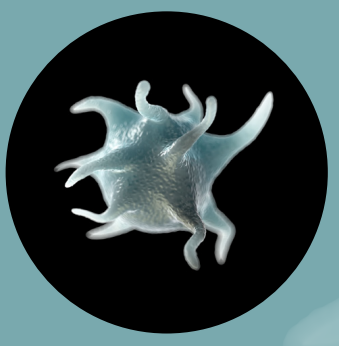

Cécile Kicken, Sven Van Poucke, Abraham Emanuel Marcus, Marcus D. Lancé,

Yvonne Henskens Thrombosis Research 2015;135:1-5. 


\subsection{INTRODUCTION}

Massive hemorrhage requires early transfusion of intravenous fluids and blood components for circulatory resuscitation and hemostasis [1]. This treatment ultimately results in thrombocytopenia and platelet function deterioration. The resulting coagulopathy is amplified by hypothermia and/or acidosis, and is designated as the lethal triad [2,3]. Transfusions with higher ratios of plasma and platelets to red blood cells have improved outcomes in trauma patients, although randomized controlled trials evaluating the efficacy of liberal platelet transfusion are required [4].

Platelet concentrate (PC) bags can be stored at $22^{\circ} \mathrm{C} \pm 2^{\circ} \mathrm{C}$ with continuous gentle agitation for up to 7 days (Sanquin Blood Services, Amsterdam, The Netherlands). Generally, PC should be administered during a 30-minute period [5]. Warming platelets before transfusion is not recommended, but could prevent a core body temperature drop [6].

The need for rapid replacement of blood components and fluids triggered the development of more efficient transportation and administration techniques. A popular technique uses an external pressure sleeve with an inflatable airbag that raises pressure up to $300 \mathrm{~mm} \mathrm{Hg}$ [7]. Possible mechanical alteration effects during pressurized transfusion remain unclear, but platelets are hypothezised to become activated by high-shear stress or destroyed by pressure. Thromboelastography (TEG) analysis indicates that pressure-aided platelet transfusion does not significantly affect the maximal amplitude of clot formation [7].

Many facilities use a pneumatic tube system (PTS) for transport of patient samples to reduce turnaround time. However the use of PTS to deliver PC from the laboratory to the patient is not common practice. PTS is suggested to exert shear stress and change platelet activity during accelerations, decelerations, and sudden changes in air pressure, but this remains controversial and different PTS may differently afflict platelet function [8-11]. We showed previously that PTS transport of PC does not significantly affect platelet function [12]. The current study quantitatively assesses platelet function after storage for 7 days compared with that of fresh PCs, and platelet function from PCs (aged 2 and 7 days) subjected to PTS transport followed by warming and/or pressure-aided mock transfusion. 


\subsection{METHODS}

This study was approved by the Medical Ethics Committee of Maastricht University Medical Centre (Reference Number METC 13-4-087) and registered in the Dutch Trial Register (NTR4235; www.trialregister.nl/trialreg/admin/rctview.asp?TC=4235). Written informed consent to use the donations for scientific purposes was obtained from anonymous blood donors. The local blood bank (Sanquin Blood Services, Amsterdam, The Netherlands) provided 10 fresh platelet concentrates (PCs), each consisting of randomly pooled buffy-coat platelets from five healthy donors (approximate volume 300 $\mathrm{ml}$, platelet count $250-350 \cdot 10^{9} / \mathrm{L}$, leucocytes $<1 \cdot 10^{6}$ unit-1). PC bags were stored at $22^{\circ} \mathrm{C} \pm$ $2^{\circ} \mathrm{C}$ with continuous gentle agitation until testing for maximal 7 days after donation.

At $48 \mathrm{~h}$ after donation, PCs were aliquoted into smaller units for sampling and testing using a closed sterile system. PVC CompoflexTM bags, which are permeable for $\mathrm{O}_{2}$ and $\mathrm{CO}_{2}$ (Fresenius Kabi, Bad Homburg, Germany), were docked to the 300-ml PC bag using a sterile tube welder (TSCD ${ }^{\oplus}$ II, Terumo). Bags were sealed with a bloodbag tube sealer (CompoSeal ${ }^{\circledR}$ Mobilea, Fresenius Kabi). The first $150 \mathrm{ml}$ (Part A) was analyzed on the day of aliquoting (day 2); the remaining $150 \mathrm{ml}$ (Part B) was stored as two $75-\mathrm{ml} \mathrm{samples,} \mathrm{to} \mathrm{ensure} \mathrm{adequate} \mathrm{gas} \mathrm{exchange} \mathrm{during} \mathrm{storage,} \mathrm{for} \mathrm{another}$ 5 days in a gently shaking incubator at $22^{\circ} \mathrm{C}$. These two samples were gently mixed three times and reconstituted before further testing on day 7 after donation (Fig. 1).

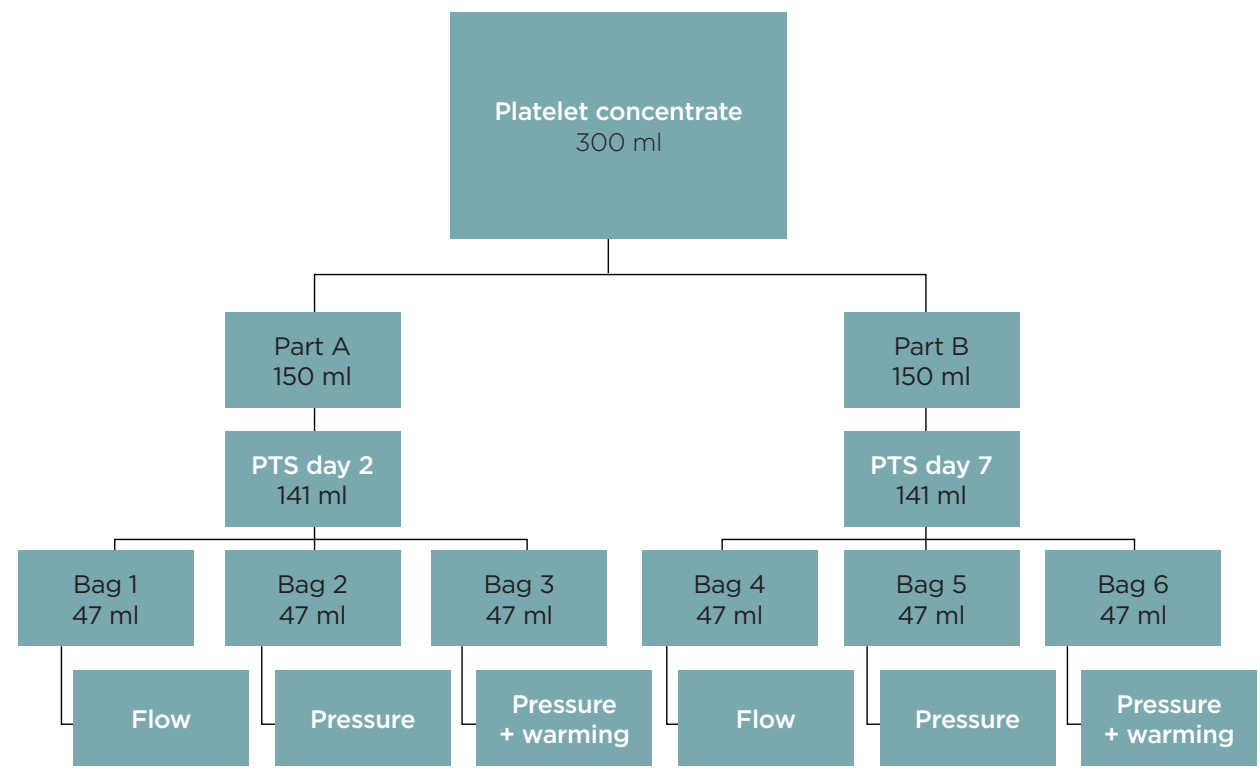

Figure 1: Sample preparation flow chart.

Sample preparation flow chart for testing platelet concentrate $(P C)(N=10)$. The sample in each 300-ml collection bag was aliquoted on day 2. Part A was tested the same day; Part B was stored as two 75-ml aliquots for an additional 5 days. A baseline sample was collected before PTS transport. Samples were transported by pneumatic tube system (PTS) and then aliquoted into 3 samples to test the following conditions: flow, pressure, and pressure + warming. 
A baseline sample was collected before PTS transport. Subsequently, half of the PC volume was placed in a PTS carrier (PTS-Swisslog, ErgoTrans, Apeldoorn, The Netherlands). After sealing the carrier and placing it into the system, the carrier ran a fixed route between two predefined hospital departments. The transport parameters were as follows: 109 s average duration, 364 m distance, two switching stations, $3.3 \mathrm{~m} \mathrm{~s}^{-1}$ average speed, and $6.6 \mathrm{~m} \mathrm{~s}^{-1}$ maximum speed. An air cushion slowed the carrier down at arrival to reduce deceleration. All PCs were subsequently transported manually to the sending station, where another sample was taken for testing.

After completion of the experimental test, each PC sample was aliquoted into three 47- $\mathrm{ml} \mathrm{samples} \mathrm{in} \mathrm{smaller} \mathrm{bags,} \mathrm{and} \mathrm{were} \mathrm{left} \mathrm{to} \mathrm{rest} \mathrm{for} \mathrm{2-3} \mathrm{hours} \mathrm{in} \mathrm{a} \mathrm{gently} \mathrm{shaking}$ incubator (Fig. 1). Then, the following three conditions were tested:

(i) Flow: PC infusion through an i.v. line and blood warmer circuit for 2 minutes without warming.

(ii) Pressure: $300 \mathrm{~mm} \mathrm{Hg}$ was applied to PC for 2 minutes, followed by the conditions described in (i).

\section{(iii)Pressure + warming: PC infusion, pressurization for 2 minutes, and warming to $37^{\circ} \mathrm{C}$ for 2 minutes.}

A 40-cm infusion line with spike and Luer lock (Braun Medical, Melsungen, Germany) and a pressure infusion bag with manometer (Medisize BV, Hillegom, The Netherlands). The PC was warmed using a RangerTM blood/fluid warming system (Model 245; Arizant Healthcare, Eden Prairie, US). A pediatric disposable cassette (RangerTM Paediatric/Neonate disposable set \#24450) with a priming volume of 20 $\mathrm{ml}$ was used. The bubble trap was removed to limit air contact and heat loss during sampling. Temperature was measured immediately after sampling with an infrared thermometer with $0.5^{\circ} \mathrm{C}$ accuracy (Testo 830-T3, Almere, The Netherlands).

\section{Metabolic parameters}

The $\mathrm{pH}, \mathrm{pCO}_{2}$, glucose, and lactate were determined with a Gem Premier 4000 blood-gas analyzer (Instrumentation Laboratory, Zaventem, Belgium). Platelet count and mean platelet volume (MPV) were measured with an automated XN-9000 whole-blood analyser (Sysmex America, Lincolnshire, IL, US).

\section{Light-transmission aggregometry}

Light-transmission aggregometry (LTA) was performed on a PAR-4 platelet aggregometer (Hart Biologicals, Hartlepool, UK) according to the manufacturer's instructions [13-14]. Unaltered PC was used as platelet-rich plasma (PRP). The basic optical density was set using platelet-poor plasma (PPP). Aggregation was measured in response to ADP (Chronolog, Havertown, US), Na-arachidonic acid (Bio/Data, Horsham, US), collagen (Chronolog), and thrombin-receptor activating peptide (TRAP-Bachem, Bubendorf, Germany), with final concentrations of $10 \mu \mathrm{M}, 1 \mathrm{mM}, 4 \mu \mathrm{g} /$ $\mathrm{ml}$, and $30 \mu \mathrm{M}$, respectively. Optical density changes were expressed as percentage (\%) maximum aggregation compared with that of PPP. 


\section{Multiple-electrode aggregometry}

Multiple-electrode aggregometry (MEA) was performed with a Multiplate ${ }^{\circledast}$ aggregometer (Dynabyte Medical, Munich, Germany) according to the manufacturer's instructions [15-16]. Platelet function was determined by testing ADP, arachidonic-acid-induced aggregation (ASPI), collagen, and thrombin-receptor activating peptide (TRAP), with final concentrations of $6.5 \mu \mathrm{M}, 1 \mathrm{mM}, 3.2 \mu \mathrm{g} / \mathrm{ml}$, and $32 \mu \mathrm{M}$, respectively. Collagen was obtained from Chronolog; the other agonists were obtained from Roche Diagnostics International (Rotkreuz, Switzerland). Aggregation was expressed as the area under the aggregation curve (AUC) in arbitrary units $(U)$.

Data entries were double-checked by a co-researcher. Collected data were analyzed using SPSS version 20 (SPSS Inc., Chicago, IL, USA). Differences among the PC samples were compared with paired non-parametric testing (Wilcoxon signed ranks test). Non-parametric tests were used due to the small sample size. Exact $p$-values were used and were not adjusted for multiple testing to avoid an increase of type II error [17]. A p-value <0.05 was considered statistically significant. Figures were generated using Prism version 6 (GraphPad Software Inc., La Jolla, CA, USA). 


\subsection{RESULTS}

\subsubsection{METABOLIC PARAMETERS}

Metabolic parameters were expressed as median and interquartile range (IQR) in Table 1 and 2. All metabolic parameters except for $\mathrm{pCO}_{2}$ were significantly changed after 7 days of storage. In fresh PCs, the pH was significantly lower after PTS transport compared with that of baseline (one-sided P=0.001) without an accompanying lactate elevation; $\mathrm{pCO}_{2}$ was significantly higher in these samples (one-sided $\mathrm{P}=0.0029$ ). Pressure-aided mock transfusion caused a small but significant $\mathrm{pH}$ decrease in fresh PCs (one-sided P=0.007). MPV was significantly altered after warmed plus pressure-aided mock transfusion in both fresh and stored PCs (two-sided P=0.014 and 0.004 , respectively).

\begin{tabular}{|c|c|c|c|c|c|}
\hline Day 2 & 0 & 1 & 2 & 3 & 4 \\
\hline $\begin{array}{l}\text { Platelet count } \\
\left(\cdot 10^{9} / \mathrm{L}\right)\end{array}$ & $\begin{array}{l}985.5 \\
{[789-1118]}\end{array}$ & $\begin{array}{l}993 \\
{[744-1069]}\end{array}$ & $\begin{array}{l}982 \\
{[783-1101]}\end{array}$ & $\begin{array}{l}1011 \\
{[772-1122]}\end{array}$ & $\begin{array}{l}1003 \\
{[786-1107]}\end{array}$ \\
\hline $\begin{array}{l}\text { Platelet count } \\
\text { (\% from PTS) }\end{array}$ & & 100 & 98.9 & 101.8 & 101.0 \\
\hline $\mathrm{pH}$ & $\begin{array}{l}7.41 \\
{[7.40-7.46]}\end{array}$ & $\begin{array}{l}7.32 \\
{[7.31-7.37]^{*}}\end{array}$ & $\begin{array}{l}7.40 \\
{[7.36-7.42]}\end{array}$ & $\begin{array}{l}7.37 \\
[7.33-7.41]\rangle\end{array}$ & $\begin{array}{l}7.39 \\
{[7.34-7.43]}\end{array}$ \\
\hline $\mathrm{pCO}_{2}(\mathrm{kPa})$ & $\begin{array}{l}3.2 \\
{[2.8-3.5]}\end{array}$ & $\begin{array}{l}4.2 \\
{[4.0-4.4]^{*}}\end{array}$ & $\begin{array}{l}3.45 \\
{[3.2-3.6]}\end{array}$ & $\begin{array}{l}3.7 \\
{[3.3-4.1]}\end{array}$ & $\begin{array}{l}3.3 \\
{[3.2-3.7]}\end{array}$ \\
\hline Glucose (mM) & $\begin{array}{l}17.9 \\
{[17.3-19]}\end{array}$ & $\begin{array}{l}17.7 \\
{[17-18.8]}\end{array}$ & $\begin{array}{l}17.8 \\
{[17.1-19.2]}\end{array}$ & $\begin{array}{l}17.9 \\
{[17.3-19]}\end{array}$ & $\begin{array}{l}17.7 \\
{[17.1-18.48]}\end{array}$ \\
\hline Lactate (mM) & $\begin{array}{l}7.2 \\
{[6.5-7.5]}\end{array}$ & $\begin{array}{l}7.15 \\
{[6.1-7.4]}\end{array}$ & $\begin{array}{l}7.45 \\
{[7-7.7]}\end{array}$ & $\begin{array}{l}7.4 \\
{[6.9-7.8]}\end{array}$ & $\begin{array}{l}7.4 \\
{[6.7-7.7]}\end{array}$ \\
\hline
\end{tabular}

Table 1: Metabolic parameters of platelet concentrates day 2 after donation.

Metabolic parameters of platelet concentrates day 2 after donation $(N=10)$, expressed as median and interquartile range [IQR]. Legend: $\mathrm{O}=$ baseline; 1 = PTS (pneumatic tube system); 2 = PTS + flow; 3 = PTS + pressure; 4 = PTS + pressure \& warming. Measuring units: platelet count $\left(\cdot 10^{9} / \mathrm{l}\right), \mathrm{pH}, \mathrm{pCO}_{2}(\mathrm{kPa})$, glucose $(\mathrm{mM})$ and lactate $(\mathrm{mM}){ }^{*}{ }^{*}=\mathrm{p}<0.05$ compared to 0 (baseline); $\diamond=p<0.05$ compared to 2 (PTS + flow) 


\begin{tabular}{|c|c|c|c|c|c|}
\hline Day 7 & 0 & 1 & 2 & 3 & 4 \\
\hline $\begin{array}{l}\text { Platelet count } \\
\left(\cdot 10^{9} / \mathrm{L}\right)\end{array}$ & $\begin{array}{l}956 \\
{[773-1109]^{*}}\end{array}$ & $\begin{array}{l}963 \\
{[780-1086]}\end{array}$ & $\begin{array}{l}960 \\
{[747-1096]}\end{array}$ & $\begin{array}{l}967 \\
{[782-1102]}\end{array}$ & $\begin{array}{l}966 \\
{[773-1133]}\end{array}$ \\
\hline $\begin{array}{l}\text { Platelet count } \\
\text { (\% from PTS) }\end{array}$ & & 100 & 99.7 & 100.4 & 100.3 \\
\hline $\mathrm{pH}$ & $\begin{array}{l}7.14 \\
{[7.00-7.19]^{*}}\end{array}$ & $\begin{array}{l}7.15 \\
{[7.01-7.19]}\end{array}$ & $\begin{array}{l}7.18 \\
{[7.03-7.22]}\end{array}$ & $\begin{array}{l}7.16 \\
{[7.02-7.21]}\end{array}$ & $\begin{array}{l}7.18 \\
{[7.01-7.20]}\end{array}$ \\
\hline $\mathrm{pCO}_{2}(\mathrm{kPa})$ & $\begin{array}{l}3.2 \\
{[2.7-3.8]}\end{array}$ & $\begin{array}{l}3.1 \\
{[2.7-3.6]}\end{array}$ & $\begin{array}{l}2.6 \\
{[2.35-3.2]}\end{array}$ & $\begin{array}{l}2.7 \\
{[2.4-3.2]}\end{array}$ & $\begin{array}{l}2.6 \\
{[2.4-3.1]}\end{array}$ \\
\hline Glucose (mM) & $\begin{array}{l}12.4 \\
{[9.7-13.3]^{*}}\end{array}$ & $\begin{array}{l}11.9 \\
{[9.9-13.1]}\end{array}$ & $\begin{array}{l}11.7 \\
{[9.8-13.4]}\end{array}$ & $\begin{array}{l}12.1 \\
{[9.8-13.1]}\end{array}$ & $\begin{array}{l}11.7 \\
{[9.7-13.1]}\end{array}$ \\
\hline Lactate (mM) & $\begin{array}{l}17.1 \\
{[15.8-19.6]^{*}}\end{array}$ & $\begin{array}{l}16.3 \\
{[15.9-19.4]}\end{array}$ & $\begin{array}{l}17.1 \\
{[15.9-20]}\end{array}$ & $\begin{array}{l}17 \\
{[16-20]}\end{array}$ & $\begin{array}{l}16.8 \\
{[16.2-20]}\end{array}$ \\
\hline
\end{tabular}

Table 2: Metabolic parameters of platelet concentrates day 7 after donation.

Metabolic parameters of platelet concentrates day 7 after donation $(N=10)$, expressed as median and interquartile range [IQR]. Legend: $\mathrm{O}=$ baseline; 1 = PTS (pneumatic tube system); 2 = PTS + flow; 3 = PTS + pressure; $4=$ PTS + pressure \& warming. Measuring units: platelet count $\left(\cdot 10^{9} / \mathrm{l}\right), \mathrm{pH}, \mathrm{pCO}_{2}(\mathrm{kPa})$, glucose $(\mathrm{mM})$ and lactate $(\mathrm{mM}){ }^{*}{ }^{*}=\mathrm{p}<0.05$ compared to 0 day 2 (baseline); $\diamond=p<0.05$ compared to 2 (PTS + flow)

\subsubsection{PLATELET AGGREGATION TESTS}

Percentage maximum aggregation for LTA and AUC for multiple-electrode aggregometry (MEA) were expressed as median and IQR (Fig. 2). Single PTS transport markedly reduced ADP response in fresh PCs compared with that of baseline (MEA 53 to $16 \mathrm{U}$, one-sided P=0.001; LTA 45.5 to 28.5\%, one-sided $P=0.002$ ). Seven-day storage had a greater impact on platelet response to ADP (MEA 53 to $1 \mathrm{U}$, one-sided $\mathrm{P}=0.001$; LTA 45.5 to $20.1 \%$, one-sided $\mathrm{P}=0.001$ ) and collagen (MEA 98 to $43 \mathrm{U}$, one-sided $\mathrm{P}=0.001$; LTA 81.4 to $42.4 \%$, one-sided $\mathrm{P}=0.001$ ), compared with that of baseline. Additional pressurizing slightly decreased LTA ADP (20.1 to 18.9\%, one-sided $\mathrm{P}=0.003$ ) and LTA collagen (42.4 to $28.3 \%$, one-sided $\mathrm{P}=0.001$ ) in stored PCs compared with that of baseline, but not in fresh samples. Additional pressurizing combined with warming slightly decreased MEA ASPI (92 to $83 \mathrm{U}$, onesided $P=0.013$ ) and MEA collagen (98 to $80 \mathrm{U}$, one-sided $\mathrm{P}=0.003$ ) in fresh $\mathrm{PCs}$, and MEA collagen ( 43 to $33 \mathrm{U}$, one-sided $\mathrm{P}=0.003$ ) in stored $\mathrm{PCs}$, compared with that of baseline. Other platelet responses were not affected. 

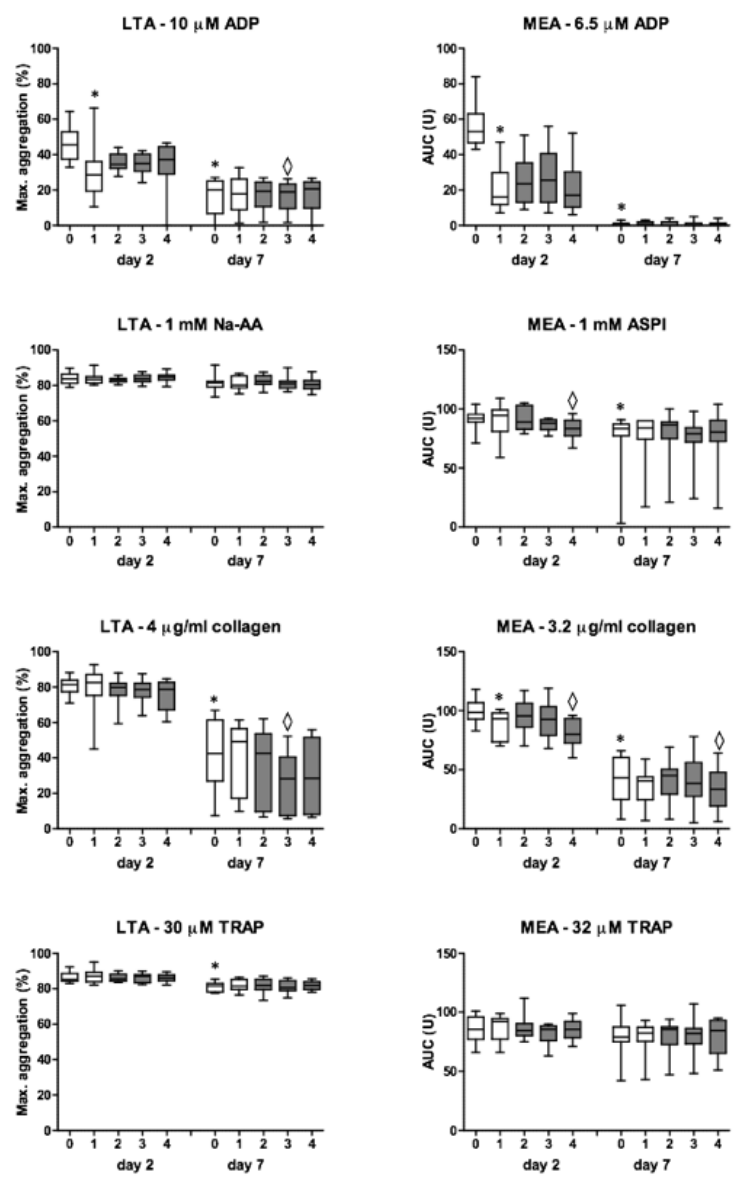

Fig 2: LTA and MEA analysis of platelet concentrate function.

Light-transmission aggregation (LTA) and multiple-electrode aggregation (MEA) analysis of platelet concentrate function for different testing conditions ( $\mathrm{O}-4)$ and on two storage days (day 2 and 7).

Legend: $\mathrm{O}$, = baseline; 1 = pneumatic tube system (PTS); 2 = PTS + flow; 3 = PTS + pressure; 4 = PTS + pressure and warming.

AUC (area under the aggregation curve); ADP (adenosine diphosphate); AA (arachidonic acid); ASPI (cyclooxygenase dependent aggregation); TRAP (thrombin-receptor activating peptide) * $\mathrm{P}<0.05$ compared with baseline on day $2(0) ; \diamond \mathrm{P}<0.05$ compared with $\mathrm{PTS}+$ flow (2). 


\subsection{DISCUSSION}

\subsubsection{METABOLIC PARAMETERS}

Recommended hemostatic resuscitation protocols favor liberal platelet transfusion using higher ratios of platelets to red blood cells. With concomitant use of plateletinhibiting drugs, the search for optimized platelet conservation, transportation, and transfusion is more relevant than ever. The present study is the first to demonstrate that exposure of PC to the PTS, warming and pressure is unlikely to decrease the hemostatic efficacy of PC by multiple surrogate (in vitro) markers. Applying a pressure of $300 \mathrm{~mm} \mathrm{Hg}$ for mock transfusion caused a significant but small decrease in ADP-induced and collagen-induced aggregation in stored platelets measured by LTA, which might not be clinically relevant. All other agonist responses were preserved. The combination of pressurized and warmed transfusion caused a significant yet small decrease in collagen and ASPI-induced aggregation measured by MEA in both fresh and stored PCs. All other agonist responses measured by LTA and MEA were unaffected in this study. These results are in contrast with two previous studies on pressurization or warming which did not report negative effects on platelet function, although those studies did not use the gold-standard technique of aggregometry $[6,7]$. The first study analyzed the effect of warming on platelet function [6]. The second study used a pressure inducer which decreased transfusion time by approximately $50 \%$. Platelet function in this study was assessed by flow cytometry and thromboelastography which is considered a global test for hemostasis and platelet function [7].

Storage had a considerable effect on metabolic features and platelet function. Platelet counts decreased significantly during storage. Platelets were metabolically active resulting in lowered glucose and elevated lactate concentrations after 7 days of storage, as shown in Table 2. Storage also reduced ADP-induced and collageninduced aggregation measured by LTA and MEA, and caused a minor decrease in the MEA-TRAP response. These results are consistent with previous work $[12,18]$. Arachidonic acid-induced aggregation measured by LTA and MEA remained stable after 7 days of storage.

PTS transport significantly reduced ADP-induced aggregation measured by both MEA and LTA. This reduced ADP response may be caused by ADP-receptor desensitization. Platelet ADP receptors become desensitized to ADP stimulation after autocrine ADP release from granules $[19,20]$. This effect was demonstrated in PCs stored in plasma or plasma additive solution for 4 days [18]. The acceleration/ deceleration forces and sudden directional changes that occur during PTS may cause granular ADP release, which subsequently desensitizes ADP receptors and possibly explains the ADP response demonstrated in this study [18]. Yet, the sensitivity of platelets to ADP stimulation is dependent of a receptor desensitization. However there is the possibility of subsequent re-sensitization which might ameliorate platelet in vivo function after transfusion [21]. PTS also significantly reduces the MEA-collagen response in fresh PCs, but to a much lesser extent. All other agonist responses were preserved after single PTS transport. 
There are two main limitations of this study. Firstly, all samples except baseline samples were transported by PTS. Therefore, this study did not provide exclusive information on the influence of pressure or pressure combined with warming on platelet function. However we attempted to simulate a realistic clinical situation with maximal platelet stress. Secondly, the pH of fresh PCs was significantly lower after transport by PTS compared with that of baseline, accompanied by $\mathrm{PCO}_{2}$ elevation. Sample handling may have caused this difference. PRP emits $\mathrm{CO}_{2}$ when left in contact with air, which causes a pH increase [22]. The $\mathrm{pH}$ of PC samples is influenced by the sample volume and the number of platelets; a smaller volume and lower platelet count leads to higher $\mathrm{pH}$ values caused by $\mathrm{CO}_{2}$ escape. In the baseline and post-PTS samples, pH values could be higher due to $\mathrm{CO}_{2}$ escape. This process could be overcome by replacing the air over PRP with $\mathrm{CO}_{2}$ [23]. The $\mathrm{pH}$ remained within transfusable criteria set for platelet concentrates defined by the FDA Regulation in the USA (21 CFR 640.25(b))

\subsection{CONCLUSION}

This study shows that platelet concentrate transport by PTS and pressure-aided/ warmed transfusion may be allowable (or not-prohibited) for patients requiring rapid PC transfusion. However, single PTS transport markedly reduces the ADP response in fresh PCs. Storage for 7 days has an even more pronounced effect on the ADP and collagen response. The relevance of these alterations from a clinical perspective remains to be determined in different patient populations. Subsequent application of pressure or pressure and warming does not further compromise platelet function. Future research should focus on validating the proposed route of rapid platelet concentrate supply in a clinical setting. 


\subsection{REFERENCES}

1. Johansson P, Ostrowski S, Oliveri R. Hemostatic resuscitation with plasma and platelets in trauma. J Emerg Trauma Shock 2012;5:120-5.

2. Jansen JO, Thomas R, Loudon MA, Brooks A. Damage control resuscitation for patients with major trauma. BMJ 2009;338:b1778.

3. Davenport R. Pathogenesis of acute traumatic coagulopathy. Transfusion 2013;53 Suppl $1: 23 S-27 S$.

4. Hallet J, Lauzier F, Mailloux O, et al. The Use of Higher Platelet: RBC Transfusion Ratio in the Acute Phase of Trauma Resuscitation: A Systematic Review. Crit Care Med 2013;41:2800-11.

5. British Committee for Standards in Haematology and Blood Transfusion Task Force (Chairman P. Kelsey). Guidelines for the use of platelet transfusions. Br J Haematol 2003;122:10-23.

6. Konig G, Yazer MH, Waters JH. Stored platelet functionality is not decreased after warming with a fluid warmer. Anesth Analg 2013;117:575-8.

7. Fischer-Nielsen A, Stissing T, Maansson C, Joergensen BG. Pressure-aided transfusion of platelets: does it affect the platelets? Transfusion 2010;50:361-5.

8. Bolliger D, Seeberger MD, Tanaka KA, et al. Pre-analytical effects of pneumatic tube transport on impedance platelet aggregometry. Platelets 2009;20:458-65.

9. Sari I, Arslan A, Ozlu C, et al. The effect of pneumatic tube system on complete blood count parameters and thrombocyte donation in healthy donors. Transfus Apher Sci 2012;47:81-3.

10. Glas M, Mauer D, Kassas H, Volk T, Kreuer S. Sample transport by pneumatic tube system alters results of multiple electrode aggregometry but not rotational thromboelastometry. Platelets 2013;24:454-61.

11. Thalén S, Forsling I, Eintrei J, Söderblom L, Antovic JP. Pneumatic tube transport affects platelet function measured by multiplate electrode aggregometry. Thromb Res 2013;132:77-80.

12. Lancé MD, Marcus M a E, van Oerle R, Theunissen HMS, Henskens YMC. Platelet concentrate transport in pneumatic tube systems--does it work? Vox Sang 2012;103:79-82.

13. Panzer S, Jilma P. Methods for testing platelet function for transfusion medicine. Vox Sang 2011;101:1-9.

14. Cattaneo M. Light transmission aggregometry and ATP release for the diagnostic assessment of platelet function. Semin Thromb Hemost 2009;35:158-67.

15. Cardinal DC, Flower RJ. The electronic aggregometer: A novel device for assessing platelet behavior in blood. J Pharmacol Methods 1980;3:135-58.

16. Tóth $\mathrm{O}$, Calatzis A, Penz S, Losonczy H, Siess W. Multiple electrode aggregometry: a new device to measure platelet aggregation in whole blood. Thromb Haemost 2006;96:781-8.

17. Perneger T V. What's wrong with Bonferroni adjustments. BMJ 1998;316:1236-8.

18. Keuren JFW, Cauwenberghs S, Heeremans J, de Kort W, Heemskerk JWM, Curvers J. Platelet ADP response deteriorates in synthetic storage media. Transfusion 2006;46:204-12.

19. Baurand A, Eckly A, Bari N, et al. Desensitization of the platelet aggregation response to ADP: differential down-regulation of the P2Y1 and P2cyc receptors. Thromb Haemost 2000;84:484-91.

20. Hardy AR, Conley PB, Luo J, Benovic JL, Poole AW, Mundell SJ. P2Y1 and P2Y12 receptors for ADP desensitize by distinct kinase-dependent mechanisms. Blood 2005;105:3552-60. 
21. Kanamarlapudi V, Owens SE, Saha K, Pope RJ, Mundell SJ. ARF6-dependent regulation of P2Y receptor traffic and function in human platelets. Schulz C, editor. PLoS One 2012;7:e43532.

22. Murphy S, Gardner FH. Platelet storage at 22 degrees C: role of gas transport across plastic containers in maintenance of viability. Blood 1975;46:209-18.

23. Rogers AB, Des Prez RM. The effect of $\mathrm{pH}$ on human platelet aggregation induced by epinephrine and ADP. Proc Soc Exp Biol Med 1972;139:1100-3. 
CHAPTER 4

\section{PLATELET FUNCTION DURING HYPOTHERMIA IN EXPERIMENTAL MOCK CIRCULATION.}

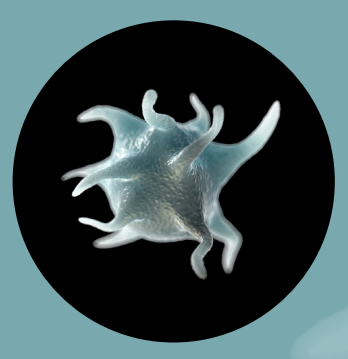

Sven Van Poucke, Kris Stevens, Cécile Kicken, Antoine Simons, Abraham Marcus, Marcus Lancé. Artif Organs 2016;40:288-93. 


\subsection{INTRODUCTION}

Patients undergoing cardiac surgery with cardiopulmonary bypass (CPB) are at risk for activation of the hemostatic system creating both coagulopathic and thrombotic complications [1].

Mock circulation loops (MCLs) are used to mimic the vascular system in the development and improvement of cardiovascular devices (e.g. ventricular assist devices, heart valves) [2-4]. They are designed from simple non-pulsatile loops to high-tech systems imitating normal and pathologic human circulation. More advanced MCLs are able to adjust for systemic and pulmonic circulation parameters, left/right ventricle function and vascular parameters (compliance resistance, flow, volume) [5]. MCLs might additionally be attractive as in-vitro flow model for research on coagulation and platelet function [6].

Hypothermia has been shown to result in hemoconcentration, leukopenia and thrombocytopenia, slowing down of coagulation enzymes, disordered fibrinolysis, and disruption of platelet function [7-10]. The decrease in platelet count observed in vivo during hypothermia is reversible as normal body temperature is restored. The change in platelet count is related to hypothermic depth and duration with a maximum decline between $25-30^{\circ} \mathrm{C}[11,12]$. Currently, mild therapeutic hypothermia is considered standard care in the treatment of patients resuscitated from cardiac arrest who are often treated with a myriad of anticoagulation drugs and platelet inhibitors [14].

Platelet activation and or desensitization during surgery with CPB contribute substantially to the development of hemostatic abnormalities in this setting $[15,16]$. Inhibition of platelet activation during CPB might, in this context, result in a better preservation of platelet function [17, 18].

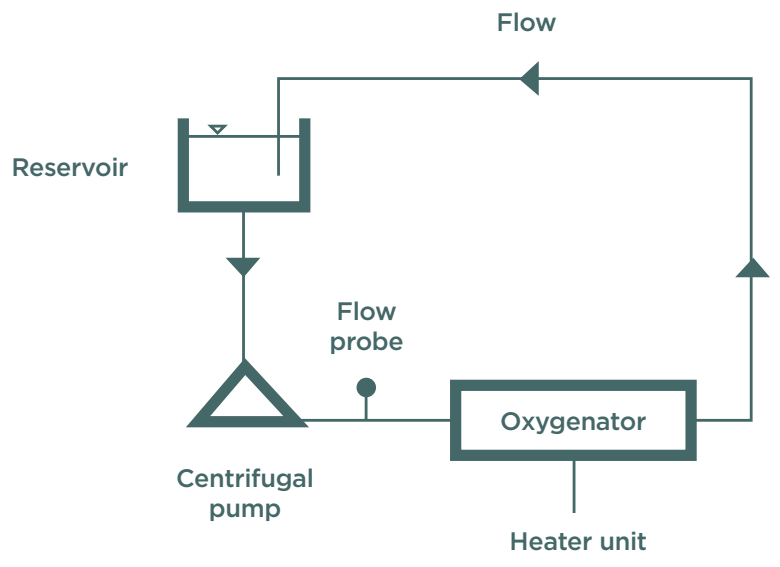

Figure 1: Schematic representation of the mock circulation consisting of a reservoir, pump, flow probe, and an oxygenator with integrated heat exchanger connected to a heater unit. 
Routine laboratory assays such as activated clotting time, activated partial thromboplastin time, prothrombin time or platelet count do not provide sufficient specificity and or sensitivity to assess coagulation and platelet disorders during surgical trauma, CPB and hypothermia [19].

It seems relevant to investigate the influence of cooling and rewarming of whole blood on platelet function using an in-vitro CPB set-up (mock circulation loop) (Fig. 1.)

The aim of this in-vitro pilot study was to evaluate the usability of an experimental mock circulation loop to study the impact of hypothermia for platelet related hemostatic changes. This setting could in the future lead to research for consistent measurement of thermic influences on platelet function using minimal sample volumes.

\subsection{METHODS}

\section{Study population}

Venous blood was collected from healthy male adult volunteers $(n=3)$ immediately before the start of each experiment. The volunteers gave full informed consent according to the Helsinki declaration and had no previous intake of medication that interfered with hemostasis. Each experiment was performed with blood from a single donor. Blood was collected in Compoflex Basic Conventional blood bag systems including CPDA (citrate phosphate dextrose adenine) as anticoagulant (T2118, Fresenius Kabi, Bad Homburg, Germany).

\section{Mock circulation loop}

The closed MCL is shown in Fig. 1. and consisted of a cardiotomy reservoir (D100, Sorin S.p.A., Milan, Italy), a centrifugal pump with drive unit and integrated flow probe (Rotaflow 32, Maquet Cardiopulmonary AG, Hirrlingen, Germany), and an oxygenator with integrated heat exchanger (D100, Sorin S.p.A., Milan, Italy). All connections were made using $1 / 4$ inch PVC tubing. All components were coated based on phosphorylcholine, mimicking biological membranes aiming to minimize platelet activation. Circuit temperature was controlled using a heater unit (BioCal 370, Medtronic Inc., Minneapolis, MN, USA) connected to the heat exchanger. In each $M C L$ the centrifugal pump drained from the reservoir and blood was pumped via the oxygenator back into the reservoir. The circuit was primed using $125 \mathrm{ml}$ of priming solution (100.3 ml Gelofusine ( $40 \mathrm{~g} / \mathrm{l}$ succinylated gelatine, B. Braun, Melsungen AG, Germany; final concentration in priming solution: 32.10 mg/ml); 13.4 $\mathrm{ml}$ mannitol 15\% (Baxter B.V., Utrecht, NL; final concentration in priming solution: $16.08 \mathrm{mg} / \mathrm{ml}$ ), $6.7 \mathrm{ml}$ albumin ( $40 \mathrm{~g} / \mathrm{l}$ human albumin, Sanquin, Amsterdam, The Netherlands; final concentration in priming solution: $2.14 \mathrm{mg} / \mathrm{ml}$ ), $1.3 \mathrm{ml} \mathrm{NaHCO}$ 8.4\% (Fresenius Kabi, Zeist, NL; final concentration in priming solution: $0.87 \mathrm{mg} /$ $\mathrm{ml}$ ) and $1.3 \mathrm{ml}$ Calcium-gluconate 10\% (B. Braun, Melsungen AG, Germany; final concentration in priming solution: $1.04 \mathrm{mg} / \mathrm{ml})$ ). Just prior to the start of the experiment $250 \mathrm{ml}$ of venous whole blood, collected from a single donor was added to the MCL via the venous reservoir. This resulted in a total circulating volume of $375 \mathrm{ml}$. The pump speed was set to induce a constant flow of $0.6 \mathrm{l} / \mathrm{min}$. 


\section{Timeline}

The mock circulation was run for a period of +32 hours from start. The experiment was subdivided in 4 time frames in correlation with instituted temperature changes. The experiment started with the mock circulation temperature set at $37^{\circ} \mathrm{C}(\mathrm{TO}(\mathrm{Oh}))$. After reaching stabile flow conditions cooling was initiated at $\boldsymbol{T 1}(+2 \mathrm{~h})$, where temperature was adjusted from $37^{\circ} \mathrm{C}$ to $32^{\circ} \mathrm{C}$. Hypothermia was maintained from $\mathbf{T} 2(+4 \mathrm{~h})$ to $\mathbf{T 3}(+28 \mathrm{~h})$. From that point in time, rewarming from $32^{\circ} \mathrm{C}$ to $37^{\circ} \mathrm{C}$ was started with similar speed as the cooling procedure. From time point $T 4(+30 \mathrm{~h})$, normothermia $\left(37^{\circ} \mathrm{C}\right)$ was maintained until the experiment ended at $T 5(+32 h)$.

\section{Blood sampling}

A baseline blood sample was collected from the blood collection bag (containing $63 \mathrm{~mL}$ CPDA-1) directly. Consequently, blood samples were collected from the MCL at different time points: $T O$ (directly after addition of the blood to the MCL and start of the centrifugal pump); $\boldsymbol{T} \mathbf{1}$ (at $+2 \mathrm{~h}) ; \boldsymbol{T} \mathbf{2}(+4 \mathrm{~h}) ; \boldsymbol{T} \mathbf{3}$ (at $+28 \mathrm{~h}) ; \boldsymbol{T} \mathbf{4}$ (at $+30 \mathrm{~h}$ ); T5 (at $+32 \mathrm{~h}$ ).

Blood sampling from the MCL was obtained using a venoject quickfit luer adapter (XX-MN2000Q, Terumo Medical, Europe) and vacuum blood collection tubes: BD Vacutainer 7.2 mg K 2 EDTA (ref.: 368861; Becton Dickinson, Plymouth, UK); BD Vacutainer 3.2\% sodium citrate (ref.: 367714; Becton Dickinson, Plymouth, UK); BD Vacutainer $15 \mu \mathrm{g} / \mathrm{ml}$ hirudin (ref.: MP0600; Verum Diagnostica GmbH, Munich, Germany).

\section{Laboratory analysis}

All blood samples were analysed within 2 hours by the following technologies:

\section{STANDARD HEMATOLOGICAL ANALYSES:}

Platelet counts, hematocrit and hemoglobin levels were measured via cytometric analysis in the whole blood counter Sysmex XE 2100 ${ }^{\circledR}$ (Sysmex, Kobe, Japan) using EDTA-anticoagulated blood.

\section{LIGHT TRANSMISSION AGGREGOMETRY:}

Citrate-anticoagulated whole blood was centrifuged at $170 \mathrm{~g}$ for $10 \mathrm{~min}$ to obtain platelet-rich plasma (PRP). The remaining blood was centrifuged twice more at $2500 \mathrm{~g}$ for $5 \mathrm{~min}$ followed by $10 \mathrm{~min}$ at $10000 \mathrm{~g}$, to obtain platelet-poor plasma (PPP) as reference. Platelet aggregation was subsequently measured in test cuvettes (ref.: HB-5538-FG, Hart Biologicals Ltd., Hartlepool, UK) filled with non-adjusted PRP, using the Platelet Aggregometer PAR-4 (ref.: 50.000.1070, Hart Biologicals Ltd., Hartlepool, UK), after addition of the following platelet agonists: AA (ref.: LS101297, Bio/Data Corporation, Pennsylvania, USA), ADP (ref.: HB-5502-FG, Hart BiologicalsLtd., Hartlepool, UK), COL (ref.: CH 385, Chrono-Log Corporation, Pennsylvania, USA) and TRAP (ref.: H-8105.0001, Bachem, Bubendorf, Switzerland) in final concentrations of $1 \mathrm{mM}$ AA, $5 \mu \mathrm{M}$ ADP, $2 \mu \mathrm{g} / \mathrm{ml} \mathrm{COL}$ and $20 \mu \mathrm{M}$ TRAP. Optical density changes were expressed as \% maximum aggregation compared to PPP. 


\section{MULTIPLE ELECTRODE AGGREGOMETRY:}

Platelet aggregation was measured using multiple electrode aggregometer (Roche Diagnostics Nederland BV, Almere, The Netherlands) according to the manufacturer's protocol [28]. Analogous to the LTA measurements platelet aggregation was measured using the following agonists: AA at a final concentration of 0.5 mM (ASPI-Test; ref.: MPO210, Dynabyte Medical, Munich, Germany), ADP at a final concentration of $6.4 \mu \mathrm{M}$ (ADP-Test; ref.: MP0220, Dynabyte Medical, Munich, Germany), COL at a final concentration of $3.2 \mu \mathrm{g} / \mathrm{ml}$ (ref.: 385, Chronolog-Par, Stago BNL, Leiden, The Netherlands) and TRAP at a

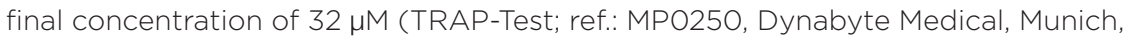
Germany). All samples were measured after a resting period of 30 min following blood collection. Aggregation was expressed as area under the aggregation curve $(A \cup C)$ in units $(U)$.

\section{ROTATIONAL THROMBOELASTOMETRY:}

Viscoelastic changes during clot formation and subsequent fibrinolysis were measured using ROTEM-device (Tem International GmbH c/o Dutch Affiliate, Tilburg, The Netherlands). To differentiate between the contributions of different hemostatic components to the eventual thrombus formation, the following standard assays according to the manufacturer's recommendations were used: EXTEM (ROTEM in presence of added tissue factor; ref.: 503-05, Tem International $\mathrm{GmbH}$ c/o Dutch Affiliate, Tilburg, The Netherlands) to study contribution of the extrinsic coagulation pathway, and FIBTEM (ROTEM in presence of added tissue factor and cytochalasin D; ref.: 503-06, Tem International GmbH c/o Dutch Affiliate, Tilburg, The Netherlands) to study contribution of fibrinogen. Finally, after obtaining our results for the EXTEM and FIBTEM analyses, the contribution of platelet action to the eventual thrombus formation was calculated for each blood sample as a dimensionless number, by subtracting the FIBTEM results for maximum clot firmness (MCF) from the complementary EXTEM results of the same blood sample. Further throughout this paper we refer to this parameter as PLTEM.

\section{Statistical analysis}

Values measured at different time points are expressed as median and IQR (Table 1). Data was imported into the data-mining application. 


\begin{tabular}{|c|c|c|c|c|c|c|}
\hline & Baseline & $\begin{array}{l}\text { Start mock } \\
\text { circulation } \\
\text { TO }\end{array}$ & $\begin{array}{l}\text { Start cooling } \\
\mathrm{T} 1(+2 \mathrm{~h})\end{array}$ & $\begin{array}{l}\text { Start } \\
\text { hypothermia } \\
\text { T2(+4h) }\end{array}$ & $\begin{array}{l}\text { Start } \\
\text { rewarming } \\
\text { T3(+28h) }\end{array}$ & $\begin{array}{l}\text { Maintenance } \\
\text { normothermia } \\
\mathrm{T} 4(+30 \mathrm{~h})\end{array}$ \\
\hline & $37^{\circ} \mathrm{C}$ & $37^{\circ} \mathrm{C}$ & $37^{\circ} \mathrm{C}->32^{\circ} \mathrm{C}$ & $32^{\circ} \mathrm{C}$ & $32^{\circ} \mathrm{C}->37^{\circ} \mathrm{C}$ & $37^{\circ} \mathrm{C}$ \\
\hline & $\begin{array}{l}\text { Median } \\
{[\mathrm{IQR}]}\end{array}$ & $\begin{array}{l}\text { Median } \\
\text { [IQR] }\end{array}$ & $\begin{array}{l}\text { Median } \\
\text { [IQR] }\end{array}$ & $\begin{array}{l}\text { Median } \\
{[\mathrm{IQR}]}\end{array}$ & $\begin{array}{l}\text { Median } \\
\text { [IQR] }\end{array}$ & $\begin{array}{l}\text { Median } \\
{[\text { IQR }]}\end{array}$ \\
\hline $\mathrm{Hb}(\mathrm{mmol} / \mathrm{L})$ & $\begin{array}{l}8.9 \\
{[8.2-9.35]}\end{array}$ & $\begin{array}{l}6.7 \\
{[6.2-6.75]}\end{array}$ & $\begin{array}{l}6.9 \\
{[6.65-7.45]}\end{array}$ & $\begin{array}{l}6.3 \\
{[5.8-7.45]}\end{array}$ & $\begin{array}{l}5.6 \\
{[5.2-6.75]}\end{array}$ & $\begin{array}{l}5.3 \\
{[5.05-6.3]}\end{array}$ \\
\hline Hct (\%) & $\begin{array}{l}41.6 \\
{[38.1-43.4]}\end{array}$ & $\begin{array}{l}30.9 \\
{[28.55-30.9]}\end{array}$ & $\begin{array}{l}31.5 \\
{[30.55-34.1]}\end{array}$ & $\begin{array}{l}27.9 \\
{[26.5-33.6]}\end{array}$ & $\begin{array}{l}25.9 \\
{[23.8-31.4]}\end{array}$ & $\begin{array}{l}24.8 \\
{[23.05-29.85]}\end{array}$ \\
\hline $\mathrm{PC}\left(\mathrm{x} 10^{\%} / \mathrm{L}\right)$ & $\begin{array}{l}186 \\
\text { [155-215] }\end{array}$ & $\begin{array}{l}108 \\
{[94-122.5]}\end{array}$ & $\begin{array}{l}94 \\
{[83.5 .96]}\end{array}$ & $\begin{array}{l}90 \\
{[77-94]}\end{array}$ & $\begin{array}{l}77 \\
{[73.5-84.5]}\end{array}$ & $\begin{array}{l}81 \\
{[73.5-82.5]}\end{array}$ \\
\hline $\begin{array}{r}\text { LTA MA (\%) } \\
\text { AA }\end{array}$ & & $\begin{array}{l}83.03 \\
{[70.55-86.07]}\end{array}$ & $\begin{array}{l}68.07 \\
{[63.87-72.09]}\end{array}$ & $\begin{array}{l}59.62 \\
{[53.44-65.97]}\end{array}$ & $\begin{array}{l}3.2 \\
{[3.22-20.31]}\end{array}$ & $\begin{array}{l}4.56 \\
{[4.66-21.54]}\end{array}$ \\
\hline $\begin{array}{r}\text { LTA MA (\%) } \\
\text { ADP }\end{array}$ & & $\begin{array}{l}77.53 \\
{[70.22-80.01]}\end{array}$ & $\begin{array}{l}60.99 \\
{[55.32-66.24]}\end{array}$ & $\begin{array}{l}48.23 \\
{[41.61-50.81]}\end{array}$ & $\begin{array}{l}4.47 \\
{[2.38-4.74]}\end{array}$ & $\begin{array}{l}0.11 \\
{[0.06-18.45]}\end{array}$ \\
\hline $\begin{array}{r}\text { LTA MA (\%) } \\
\text { COL }\end{array}$ & & $\begin{array}{l}78.8 \\
{[51.66-82.46]}\end{array}$ & $\begin{array}{l}28.03 \\
{[24.51-40.55]}\end{array}$ & $\begin{array}{l}57.23 \\
{[36.87-62.43]}\end{array}$ & $\begin{array}{l}6.87 \\
{[6-6.96]}\end{array}$ & $\begin{array}{l}5.3 \\
{[4.86-5.57]}\end{array}$ \\
\hline $\begin{array}{r}\text { LTA MA (\%) } \\
\text { TRAP }\end{array}$ & & $\begin{array}{l}80.61 \\
{[79.2-82.94]}\end{array}$ & $\begin{array}{l}73.7 \\
{[70.51-74.62}\end{array}$ & $\begin{array}{l}61.71 \\
{[58.04-68.41]}\end{array}$ & $\begin{array}{l}42.79 \\
{[32.41-52.04]}\end{array}$ & $\begin{array}{l}43.09 \\
{[42.27-49.44]}\end{array}$ \\
\hline $\begin{array}{r}\text { MEA AUC (U) } \\
\text { ASP }\end{array}$ & & $\begin{array}{l}21 \\
{[20.5-30]}\end{array}$ & $\begin{array}{l}18 \\
{[14.5-25]}\end{array}$ & $\begin{array}{l}17 \\
{[14-25.5]}\end{array}$ & $\begin{array}{l}7 \\
{[4-11]}\end{array}$ & $\begin{array}{l}8 \\
{[4-8]}\end{array}$ \\
\hline $\begin{array}{r}\text { MEA AUC (U) } \\
\text { ADP }\end{array}$ & & $\begin{array}{l}29 \\
{[24.5-31]}\end{array}$ & $\begin{array}{l}22 \\
{[19-25.5]}\end{array}$ & $\begin{array}{l}18 \\
{[14-21.5]}\end{array}$ & $\begin{array}{l}8 \\
{[4-13]}\end{array}$ & $\begin{array}{l}8 \\
{[0-1.5]}\end{array}$ \\
\hline $\begin{array}{r}\text { MEA AUC (U) } \\
\text { COL }\end{array}$ & & $\begin{array}{l}46 \\
{[33-46.5]}\end{array}$ & $\begin{array}{l}34 \\
{[25-36]}\end{array}$ & $\begin{array}{l}29 \\
{[19.5-32]}\end{array}$ & $\begin{array}{l}4 \\
{[2-7.5]}\end{array}$ & $\begin{array}{l}0 \\
{[0-1.5]}\end{array}$ \\
\hline $\begin{array}{r}\text { MEA AUC (U) } \\
\text { TRAP }\end{array}$ & & $\begin{array}{l}45 \\
{[38-49]}\end{array}$ & $\begin{array}{l}35 \\
{[32.5-40.5]}\end{array}$ & $\begin{array}{l}37 \\
{[25.5-40.5]}\end{array}$ & $\begin{array}{l}19 \\
{[11-21]}\end{array}$ & $\begin{array}{l}12 \\
{[6.5-15.5]}\end{array}$ \\
\hline $\begin{array}{l}\text { ROTEM MCF } \\
(\mathrm{mm}) \text { EXTEM }\end{array}$ & & $\begin{array}{l}55 \\
{[53-56.5]}\end{array}$ & $\begin{array}{l}47 \\
{[45.5-48.5]}\end{array}$ & $\begin{array}{l}44 \\
{[44-47]}\end{array}$ & $\begin{array}{l}48 \\
{[47-49]}\end{array}$ & $\begin{array}{l}47 \\
{[46-47.5]}\end{array}$ \\
\hline $\begin{array}{l}\text { ROTEM MCF } \\
(\mathrm{mm}) \text { FIBTEM }\end{array}$ & & $\begin{array}{l}9 \\
\text { [7-9.5] }\end{array}$ & $\begin{array}{l}6 \\
{[6-6.5]}\end{array}$ & $\begin{array}{l}7 \\
{[6-7]}\end{array}$ & $\begin{array}{l}8 \\
{[5.5-9.5]}\end{array}$ & $\begin{array}{l}8 \\
{[7.5-9]}\end{array}$ \\
\hline $\begin{array}{l}\text { ROTEM MCF } \\
(\mathrm{mm}) \text { PLTEM }\end{array}$ & & $\begin{array}{l}48 \\
{[45-49]}\end{array}$ & $\begin{array}{l}41 \\
{[39-42.5]}\end{array}$ & $\begin{array}{l}39 \\
{[34.5-41]}\end{array}$ & $\begin{array}{l}42 \\
{[39.5-42.5]}\end{array}$ & $\begin{array}{l}38 \\
{[37.5-39]}\end{array}$ \\
\hline
\end{tabular}

Table 1: Measurement results of hemoglobin concentration, hematocrit, platelet count, LTA, MEA and ROTEM Values of samples ( $N=3$ ), expressed as median and IQR. Legend: Baseline: blood collection bag. Mock circulation set at $37^{\circ} \mathrm{C}$ ( $T O$ O (Oh)). Cooling initiated at $\boldsymbol{T}(+2 \mathrm{~h})$, where temperature was adjusted from $37^{\circ} \mathrm{C}$ to $32^{\circ} \mathrm{C}$. Hypothermia maintained from $T 2(+4 h)$ to $T 3(+28 \mathrm{~h})$. Rewarming from $32^{\circ} \mathrm{C}$ to $37^{\circ} \mathrm{C}$ at time point $T 4(+30 h)$. Normothermia $\left(37^{\circ} \mathrm{C}\right)$ maintained until end experiment (T5). 


\subsection{RESULTS}

All samples are obtained from healthy male adults $(n=3)$. Representative results of measurements of hemoglobin concentration, hematocrit, platelet count, LTA, MEA and ROTEM are summarized in Table 1.

Hemoglobin concentration, hematocrit and median platelet count decrease more substantially during temperature drop from $37^{\circ} \mathrm{C}$ to $32^{\circ} \mathrm{C}$ than during hypothermia maintenance. Hemoglobin concentration and hematocrit continue to follow this trend during active rewarming $\left(32^{\circ} \mathrm{C}\right.$ to $\left.37^{\circ} \mathrm{C}\right)$. Platelet count increase from the moment active rewarming was initiated. None of the values return to the initial values in the time frame measured. (Table 1)

With respect to LTA, similar decrease in aggregation after stimulation with the platelet agonists are shown between the start of the mock circulation and the start of cooling (arachidonic acid (AA), adenosine diphosphate (ADP), collagen $(\mathrm{COL})$ and thrombin-receptor-activating-peptide-14 (TRAP)). Except for platelet stimulation using $\mathrm{COL}$, this trend continues during temperature drop from $37^{\circ} \mathrm{C}$ to $32^{\circ} \mathrm{C}$. Agonist-stimulated platelet aggregation using $1 \mathrm{mM}$ AA and $20 \mu \mathrm{M}$ TRAP demonstrates a considerable decline in platelet function (expressed as $\%$ maximum platelet aggregation (MA)) throughout the experiment which was most pronounced after $24 \mathrm{~h}$ of circulation at $32^{\circ} \mathrm{C}$. For platelet stimulation using $10 \mu \mathrm{M}$ ADP and $2 \mu \mathrm{g} / \mathrm{ml} \mathrm{COL}$, further decline in platelet function is observed after rewarming the circulating blood from $32^{\circ} \mathrm{C}$ to $37^{\circ} \mathrm{C}$. (Table 1)

Platelet function determined by MEA in terms of ADP test, arachidonic-acidinduced aggregation (ASPI) test, collagen test (COL) and thrombin receptor activating peptide (TRAP) test (end concentrations of respectively $6.5 \mu \mathrm{M}, 1 \mathrm{mM}$, $3.2 \mu \mathrm{g} / \mathrm{ml}$ and $32 \mu \mathrm{M}$ ) identifies platelet dysfunction patterns analogous with LTA, between the start of the mock circulation and the start of cooling. Except for platelet stimulation using TRAP, this trend continues during temperature drop from $37^{\circ} \mathrm{C}$ to $32^{\circ} \mathrm{C}$. Agonist-stimulated platelet aggregation by ASPI and ADP test demonstrate a considerable decline in platelet function (expressed as \% maximum platelet aggregation (MA)) throughout the experiment which was most pronounced after $24 \mathrm{~h}$ of circulation at $32^{\circ} \mathrm{C}$. For platelet stimulation using $\mathrm{COL}$ and TRAP, further decline in platelet function is observed after rewarming the circulating blood from $32^{\circ} \mathrm{C}$ to $37^{\circ} \mathrm{C}$. (Table 1)

Platelet dysfunction detected by LTA and MEA did not result in a uniform decreased thrombus formation as measured by ROTEM (EXTEM, FIBTEM, PLTEM) in terms of maximum clot firmness (MCF, mm). (Table 1) 


\subsection{DISCUSSION}

The aim of this in vitro pilot study was to evaluate the usability of a mock circulation loop for the investigation of the impact of hypothermia on platelet related hemostasis.

This study demonstrates that platelet aggregation analysis (with agonists stimulating different pathways), both LTA and MEA are able to show reduced platelet aggregation during hypothermic mock circulation. Additionally, both assays demonstrate only partial recovery during rewarming. These findings confirm results published by others $[20,21]$. None of the measurements return to the precooling values in the time frame studied.

The remarkable decline in platelet count observed during CPB and hypothermia might be related with platelet binding to the artificial surface of the mock circulation system as with hemodilution, aggregation with other platelets and blood cells, shear stress and platelet destruction [1, 17].

This decline in platelet counts might also account for the observed strong decline in platelet function as measured by LTA and MEA. In our study LTA demonstrates, similar decrease in aggregation between the start of the mock circulation and the start of cooling. Except for platelet stimulation using COL, this trend continues during temperature drop from $37^{\circ} \mathrm{C}$ to $32^{\circ} \mathrm{C}$. Agonist-stimulated platelet aggregation using $1 \mathrm{mM} A \mathrm{~A}$ and $20 \mu \mathrm{M}$ TRAP demonstrates a considerable decline in platelet function throughout the experiment which was most pronounced after $24 \mathrm{~h}$ of circulation at $32^{\circ} \mathrm{C}$. For platelet stimulation using $10 \mu \mathrm{M}$ ADP and $2 \mu \mathrm{g} / \mathrm{ml}$ $\mathrm{COL}$, further decline in platelet function is observed after rewarming the circulating blood from $32^{\circ} \mathrm{C}$ to $37^{\circ} \mathrm{C}$. (Table 1)

Platelet function determined by MEA in terms of ADP test, ASPI test, COL test and TRAP test identifies platelet dysfunction patterns analogous with LTA, between the start of the mock circulation and the start of cooling. Except for platelet stimulation using TRAP, this trend continues during temperature drop from $37^{\circ} \mathrm{C}$ to $32^{\circ} \mathrm{C}$. Agonist-stimulated platelet aggregation by ASPI and ADP test demonstrate a considerable decline in platelet function throughout the experiment which was most pronounced after $24 \mathrm{~h}$ of circulation at $32^{\circ} \mathrm{C}$. For platelet stimulation using $\mathrm{COL}$ and TRAP, further decline in platelet function is observed after rewarming the circulating blood from $32^{\circ} \mathrm{C}$ to $37^{\circ} \mathrm{C}$ (Table 1) [21, 22].

ROTEM (EXTEM, FIBTEM, PLTEM) during hypothermia and CPB reflected a uniform decreased thrombus formation as measured in terms of maximum clot firmness (MCF, mm). This confirms previous findings stating that CPB-induced clotting factor depletion and platelet dysfunction measured by ROTEM persisted after CPB and heparin neutralisation [23]. Others however stated that ROTEM revealed a hypocoagulative response to in vitro-applied hypothermia in blood reflected in the prolonged clot initiation and decreased clot propagation without affecting clot firmness [24]. Changes of thromboelastometry parameters need to be interpreted with caution with respect to variations in hematocrit and platelet counts $[25,26]$. 
Ideally, hemostatic activation during CPB (and hypothermia) should be as low as possible, with maximal recuperation after termination of CPB, strongly resembling hibernation in animals [27]. As such platelet anesthesia, the temporary pharmacologic inhibition of platelet reactivity by prostaglandin E1, NO, glycoprotein Ilb/IIla inhibitors, ADP receptor antagonists has been proposed as strategy during CPB to preserve platelet numbers and function in order to prevent bleeding disorders and inflammatory reactions post-CPB [15, 17, 18, 28]. The most optimal modality for time-limited inhibition of platelet activation at the initiation of CPB in order to preserve functional platelet activity potential after CPB is a subject for future research.

Hypothermia as result of active therapeutic cooling has been used during specific therapeutic procedures to reduce oxygen requirements of organs such as the brain, heart, and kidney. Hypothermia exerts multiple effects on platelet function by inhibiting platelet aggregation, augmenting eptifibatide- and tirofiban-induced inhibition of platelet aggregation, increasing the formation of ADP-induced leukocyte-platelet aggregates and by diminishing the glycoprotein IIb/IIla antagonist-induced decrease in leukocyte-platelet aggregates [29].

Our study confirms these findings that hypothermia negatively affects platelet function and that spontaneous recovery of platelet function does not start immediately after rewarming.

A limitation of our in vitro model is however the small number of volunteers included (3). Additionally this study is limited by the absence of an endothelial layer in the circulating system altering the likelihood of our experimental representation [6]. In comparison with the Chandler loop model there is no blood-air contact inducing leukocyte and platelet aggregation and protein denaturation. In comparison with the roller pump less blood damage is expected when extrapolated to a clinical setting [6]. In our experiment, CPDA-1 was used instead of heparin. The authors question the fact if this more closely resembles with the in vivo conditions. The results however demonstrate the capability of the $\mathrm{MCL}$ as testing environment for consistent measurement of platelet function using minimal sample volumes of fresh human blood. Although mock circulation testing systems cannot replace in vivo models, this configuration should be well suited for developing experimental protocols to study platelet thermophysiology.

More efforts are required to confirm the results and to establish the role of of this mock circulation loop in hemostasis research.

The authors further suggest to closely monitor platelet function during and after hypothermia especially if in combination with extracorporeal circulation. Platelet anesthesia might be interesting to be re-evaluated. 


\subsection{REFERENCES}

1. Sniecinski RM, Chandler WL: Activation of the hemostatic system during cardiopulmonary bypass. Anesth Analg 2011; 113(6):1319-1333.

2. AAMI. Biological evaluation of medical devices-Part 4: ANSI/AAMI/ISO 10993-4:2002/(R)2013.

3. Ganushchak YM, Ševerdija EE, Simons a P, van Garsse L, Weerwind PW: Can minimized cardiopulmonary bypass systems be safer? Perfusion 2012; 27:176-82.

4. Timms DL, Gregory SD, Stevens MC, Fraser JF: Haemodynamic modeling of the cardiovascular system using mock circulation loops to test cardiovascular devices. Annu Int Conf IEEE Eng Med Biol Soc 2011:4301-4304.

5. Slee JB, Alferiev IS, Levy RJ, Stachelek SJ. The use of the ex vivo Chandler Loop Apparatus to assess the biocompatibility of modified polymeric blood conduits. JoVE 2014; 90:e51871.

6. van Oeveren W, Tielliu IF, de Hart J. Comparison of modified chandler, roller pump, and ball valve circulation models for in vitro testing in high blood flow conditions: Application in thrombogenicity testing of different materials for vascular applications. International Journal of Biomaterials 2012:Article ID 673163.

7. Díaz M, Becker DE: Thermoregulation: physiological and clinical considerations during sedation and general anesthesia. Anesth Prog 2010; 57:25-32; quiz 33-4.

8. Dirkmann D, Hanke AA, Görlinger K, Peters J: Hypothermia and acidosis synergistically impair coagulation in human whole blood. Anesth Analg 2008, 106:1627-1632.

9. Escalda A, Marques M, Silva-Carvalho L, Barradas MA, Silva-Carvalho J, Cruz JM, Mikhailidis DP: Hypothermia-induced Haemostatic and Biochemical Phenomena. An Experimental Model. Platelets 1993; 4:17-22.

10. Frith D, Brohi K: The pathophysiology of trauma-induced coagulopathy. Curr Opin Crit Care 2012; 18:631-6.

11. Hoffmeister KM, Felbinger TW, Denis V, Bergmeier W, Mayadas TN, Andrian UH Von, Wagner DD, Stossel TP, Hartwig JH: The Clearance Mechanism of Chilled Blood Platelets Brigham and Women 's Hospital. Cell 2003; 72:87-97.

12. Ao H, Moon JK, Tashiro M, Terasaki H: Delayed platelet dysfunction in prolonged induced canine hypothermia. Resuscitation 2001; 51:83-90.

13. Straub A, Breuer M, Wendel HP, Peter, Dietz K, Ziemer G. Critical temperature ranges of hypothermia-induced platelet activation: Possible implications for cooling patients in cardiac surgery. Thromb Haemost 2007; 97: 608-616.

14. Nielsen N, Wetterslev J, Cronberg T, Erlinge D, Gasche Y, Hassager C, et al. Targeted Temperature Management at $33^{\circ} \mathrm{C}$ versus $36^{\circ} \mathrm{C}$ after Cardiac Arrest. N Engl J Med 2013:131117131833001.

15. Despotis G, Eby C, Lublin D. Perioperative Bleeding With Cardiac Surgery. Transfusion 2008;48:1-30.

16. Jenne CN, Urrutia R, Kubes P: Platelets: bridging hemostasis, inflammation, and immunity. Int J Lab Hematol 2013;35:254-61.

17. Suzuki Y, Malekan R, Hanson C W, Niewiarowski S, Sun L, Rao a K, Edmunds LH: Platelet anesthesia with nitric oxide with or without eptifibatide during cardiopulmonary bypass in baboons. J Thorac Cardiovasc Surg 1999;117: 987-93.

18. Kanemitsu S, Nishikawa M, Onoda K, Shimono T, Shimpo H, Yazaki A, Tanaka, K, 
Shiku H, Yada I. Pharmacologic platelet anesthesia by glycoprotein IIb/IIla complex antagonist and argatroban during in vitro extracorporeal circulation.

J Thorac Cardiovasc Surg 2003;126:428-35.

19. Martini WZ, Cortez DS, Dubick MA, Park MS, Holcomb JB: Thrombelastography is better than PT, aPTT, and activated clotting time in detecting clinically relevant clotting abnormalities after hypothermia, hemorrhagic shock and resuscitation in pigs. J Trauma 2008; 65:535-43.

20. Reece MJ, Klein AA, Salviz EA, Hastings A, Ashworth A, Freeman R, Luddington RJ, Nair S and Besser MW. Near-patient platelet function testing in patients undergoing coronary artery surgery: a pilot study. Anaesthesia 2011;66, 97-103.

21. Ortmann E, Klein A a, Sharples LD, Walsh R, Jenkins DP, Luddington RJ, Besser MW: Point-of-care assessment of hypothermia and protamine-induced platelet dysfunction with multiple electrode aggregometry (Multiplate ${ }^{\circledast}$ ) in patients undergoing cardiopulmonary bypass. Anesth Analg 2013;116:533-40.

22. Hanke AA, Dellweg C, Kienbaum P, Weber CF, Görlinger K, Rahe-Meyer N: Effects of desmopressin on platelet function under conditions of hypothermia and acidosis: an in vitro study using multiple electrode aggregometry. Anaesthesia 2010; 65:688-91.

23. Straub A, Schiebold D, Wendel HP, Hamilton C, Wagner T, Schmid E, Dietz K, Ziemer G: Using reagent-supported thromboelastometry (ROTEM) to monitor haemostatic changes in congenital heart surgery employing deep hypothermic circulatory arrest. Eur J Cardiothorac Surg 2008; 34:641-647.

24. Kander T, Brokopp J, Friberg H, Schött U.Wide temperature range testing with ROTEM coagulation analyses. Ther Hypothermia Temp Manag 2014; 4(3): 125-30.

25. Nagler M, Kathriner S, Bachmann LM, Wuillemin WA. Impact of changes in haematocrit level and platelet count on thromboelastometry parameters. Thrombosis Research 2013;131: 249-253.

26. Ninivaggi M, Feijge M, Baaten C, Kuiper G, Marcus MEA, Ten Cate H, Lancé MD, Heemskerk JWM, van der Meijden, PEJ. Additive roles of platelets and fibrinogen in whole-blood fibrin clot formation upon dilution as assessed by thromboelastometry. Thrombosis and Haemostasis 2014;111: 447-457.

27. De Vrij EL, Vogelaar PC, Goris M, Houwertjes MC, Herwig A, Dugbartey GJ, Boerema AS, Strijkstra AM, Bouma HR, Henning RH: Platelet Dynamics during Natural and Pharmacologically Induced Torpor and Forced Hypothermia. PLoSOne 2014; 9:e93218.

28. Topcic D, Kim W, Holien JK, Jia F, Armstrong PC, Hohmann JD, Straub A, Krippner G, Haller C, Domeij H, Hagemeyer CE, Parker MW, Chaikof, EL, Peter, K. An activation-specific platelet inhibitor that can be turned on/off by medically used hypothermia. Arterioscler Thromb Vasc Biol 2011;31:2015-2023.

29. Frelinger AL, Furman MI, Barnard MR, Krueger LA, Dae MW, Michelson AD. Combined effects of mild hypothermia and glycoprotein IIb/IIla antagonists on plateletplatelet and leukocyte-platelet aggregation. Am J Cardiol 2003;92:1099-1101.

30. Hardy AR, Conley PB, Luo J, Benovic JL, Poole AW, Mundell SJ. P2Y1 and P2Y12 receptors for ADP desensitize by distinct kinase-dependent mechanisms. Blood 2005;105:3552-60. 
CHAPTER 5

EARLY PLATELET

RECOVERY FOLLOWING

CARDIAC SURGERY

WITH CARDIOPULMONARY BYPASS.

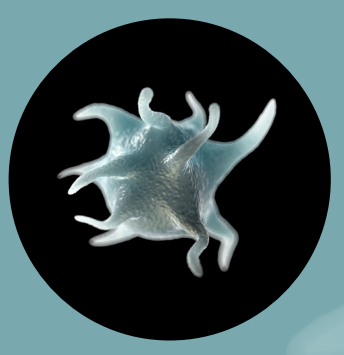

Sven Van Poucke, Kris Stevens, Rick Wetzels, Cécile Kicken, Paul Verhezen, Maurice Theunissen, Gerhardus Kuiper, Rene van Oerle, Yvonne Henskens \& Marcus Lancé Platelets 2016;7104:1-7. 


\begin{abstract}
Coronary artery bypass grafting (CABG) with cardiopulmonary bypass (CPB) is frequently associated with low platelet count (PC) and disturbed platelet function (PF). While PC is easy to measure, PF is more difficult to assess. Moreover the time related platelet dysfunction and recovery after CPB are not fully elucidated. Platelet dysfunction could lead to bleeding but also to coronary graft failure. Laboratory tests could provide more insights into platelet function after CABG. The aim of the current study was to investigate the time related platelet function induced by CPB. Blood samples of 20 patients with a preoperative PC of more than $250 \times 10^{9} / \mathrm{L}$ were collected before incision, after weaning from CPB and $24 \mathrm{~h}$ postoperative. Platelet contribution to coagulation was quantified by PLTEM (calculated by means of EXTEM and FIBTEM results). Platelet function was assessed by multiple electrode impedance aggregrometry (MEIA) in whole blood and by light transmission aggregrometry (LTA) in platelet rich plasma after stimulation with arachidonic acid, adenosine diphosphate, collagen and thrombinreceptor-activating-peptide. LTA and MEIA analysis demonstrated significant platelet dysfunction after CPB, with partial recovery within $24 \mathrm{~h}$ after surgery. AA-induced platelet aggregation increased to higher levels within $24 \mathrm{~h}$ after surgery compared to baseline values as measured by LTA. PLTEM MCF remained unchanged throughout the study. Correlation analyses revealed that MEIA and ROTEM, but not LTA, were dependent on platelet count and haematocrit. No correlations were found between LTA, MEIA, ROTEM, platelet count and clinical outcome parameters. Our results demonstrate a reversible platelet dysfunction recovering within 24 hours after CPB. Interestingly, AA-induced platelet aggregation increases to higher levels during the first $24 \mathrm{~h}$ postoperatively, which might be important for early initiation of anti-platelet therapy after CABG. MEIA as POC test is able to detect platelet dysfunction during cardiac surgery with a platelet count of $\geq 150 \times 10^{9} / \mathrm{L}$.
\end{abstract}




\subsection{INTRODUCTION}

Coronary artery bypass grafting (CABG) with cardiopulmonary bypass (CPB) is frequently associated with low platelet count $(P C)$ and disturbed platelet function (PF) [1-5]. Both contribute to bleeding with an incidence after CABG surgery between 15 and $90 \%[4,5]$. The noticeable variation of peri-operative bleeding strategies implicate over- and under-correction of transfusion with blood products. Excessive correction of coagulation and platelet function facilitate the risk of early coronary bypass failure that could be prevented by timely and adequate anti-platelet therapy. This justifies close monitoring of coagulation and platelet function during CABG surgery [1-9]. Additionally, increasing evidence confirms that availability and effective use of point of care haemostatic assays improves haemostatic management by decreasing blood product consumption without increased risk for bleeding or thrombosis [3, 10-15]. Viscoelastic tests such as rotational thromboelastometry (ROTEM) -performed with whole blood-elucidate the contribution of platelets, intrinsic and extrinsic coagulation pathways in postoperative bleeding [16]. However ROTEM does not enable specific discrimination between PC and PF disturbances, even in the presence of a high PC [17]. The gold standard for PF testing is light transmission aggregometry (LTA) as first described by Born et al. The need for centrifugation, and consequently longer turnaround times makes LTA less applicable in peri-operative bleeding management. Multiple electrode impedance aggregometry (MEIA) using whole blood and similar agonists as LTA has the potential as an alternative point of care PF test, although MEIA seems more sensitive to variations in platelet count $[18,19]$. The most optimal choice of PF point of care test, based on current evidence, is inconclusive [3]. The protocol for administrating RBC, FFP and PC was based on a ROTEM algorithm. The authors did not have the intension to test the algorithm on efficiency and efficacy.

The aim of this study was to quantitatively assess platelet dysfunction induced by CPB focusing on the early postoperative period. As a secondary outcome measure, we investigated the correlation of LTA, MEIA, ROTEM and PC with postoperative blood loss, quantitatively assessed by chest tube output (CTO), blood product consumption and need for re-exploration. 


\subsection{MATERIALS AND METHODS}

\section{Study design and patients}

This prospective observational pilot study, scheduled between January 2013 and January 2014, included 20 patients at the Maastricht University Medical Centre, after approval by the local medical ethics committee (NTR 4238). The eligible patients during the period of this study consisted of 142 patients. 122 patients were not included in this study related to refusal by informed consent, inclusion in other trials at that moment or a platelet count below $250 \times 10^{9} / \mathrm{L}$. Inclusion was additionally restricted to 20 patients because of logistic limitations to perform the laboratory tests required for this trial. Adult patients scheduled for elective CABG with CPB, and a preoperative $\mathrm{PC}$ of $\geq 250 \times 10^{9} / \mathrm{L}$ were included. The latter was decided, because platelet function tests are prone for platelet count dependency, and we intended to anticipate a low platelet count due to haemodilution.

Chronic acetylsalicylic acid (ASA) (or ASA derivatives) anti-platelet therapy (APT) could not be discontinued prior to surgery, because of its proven benefit in the preoperative period. ASA was taken until the day before surgery. Exclusion criteria consisted of emergency surgery, chronic thienopyridine APT, not discontinued at least 5 days prior to surgery, patients under P2Y12 receptor inhibitors, the use of any other anticoagulation drug other than prophylactic low-molecular-weight-heparins, congenital disorders of the haemostatic system, and detection of an infection prior to surgery. Eligible patients were recruited on the medical ward the day prior to surgery where they provided written informed consent. Data collection was covered for three consecutive days, starting on the day prior to surgery until $24 \mathrm{~h}$ postoperatively.

\section{Routine patient care}

On arrival at the operating theatre, standard monitoring (i.e. electrocardiography, non-invasive blood pressure measurement, plethysmographic oxymetry, nasal temperature) was initiated. Hereafter a venous line (Vasofix ${ }^{\circledR}$ Safety, 14 G or 16G, B. Braun Melsungen, Germany) was placed in the forearm and an arterial line (Radial Artery Catheterization set, 20 G, Arrow International, Reading, MA, USA) was positioned in the radial artery using subcutaneous local anaesthesia ( $1 \mathrm{ml}$ of lidocaïne 1\% solution). After induction of general anaesthesia and intubation, a large bore central venous line (Arrow-Flex ${ }^{\circledR}$ polyurethane sheath 8.5Fr, Arrow International, Reading, MA, USA) was placed in the right internal jugular vein. Immediately before initiation of normothermic cardiopulmonary bypass, patients were anticoagulated by $250-400 \mathrm{lU} / \mathrm{kg}$ intravenous unfractionated heparin aiming for an activated coagulation time $>480 \mathrm{~s}$. Anticoagulation was maintained throughout CPB by means of additional heparin boluses when necessary. After weaning from CPB, anticoagulation was reversed by intravenous protamine sulphate at a $1: 1$ ratio relative to the administered heparin dose. Patients received 2 doses tranexamic acid during the surgical procedure ( $2 \mathrm{~g}$ intravenous at induction of anaesthesia and $1 \mathrm{~g}$ added to the priming volume of the CPB). After surgery, patients were transferred to the intensive care unit (ICU). The radial artery line was kept in place until $24 \mathrm{~h}$ postoperative for blood sampling and monitoring of blood pressures. In this study, the physicians were unaware of the ROTEM, MEIA and LTA findings. They did however have access to the PC and HCT values. Also, even if LTA values could be accessed in other trials, the delay of results that could influence decisions would be too extensive. 


\section{Blood collection \& laboratory analyses}

Blood samples were collected in vacuum tubes via the arterial line, using a VenoJect ${ }^{\circledR}$ Quick Fit luer adapter (XX-MN2000Q, Terumo Medical, Europe), at 3 different time points: directly after placement of the arterial line (baseline), 15 min after protamine infusion at the end of CPB (post-CPB) and 24h after surgery (24h postoperative). Following discarding $10 \mathrm{~mL}$ of blood at each time point, $4 \mathrm{ml}$ whole blood was collected in a $\mathrm{K}_{2}$ EDTA 7.2 mg BD Vacutainer ${ }^{\oplus}$ (Ref.: 368861, Becton, Dickinson \& Company, Plymouth, UK), 4,5 ml whole blood in a sodium citrate 3.2\% BD Vacutainer ${ }^{\circledast}$ (Ref.: 367714, Becton, Dickinson \& Company, Plymouth, UK), and $3 \mathrm{ml}$ whole blood in a hirudin 15 rg/mL vacutainer (Ref.: MP0600, Verum Diagnostica GmbH, Munich, Germany). Blood samples were directly transported to the laboratory and analyzed within 2-4 $\mathrm{h}$ after collection to allow for minimal necessary resting time for PF tests.

Standard haematological analyses. EDTA-anticoagulated blood was used for cytometric analysis using a whole blood counter Sysmex XE $2100^{\circledR}$ (Sysmex, Kobe, Japan) to obtain a whole blood count.

Light transmission aggregometry (LTA). Citrate-anticoagulated whole blood was centrifuged $10 \mathrm{~min}$ at $170 \mathrm{~g}$ to obtain PRP. The remaining blood was centrifuged twice more, $5 \mathrm{~min}$ at $2.500 \mathrm{~g}$ followed by $10 \mathrm{~min}$ at $10.000 \mathrm{~g}$, providing platelet-poor plasma (PPP) as reference material. Platelet aggregation was subsequently measured in test cuvettes (ref.: HB-5538-FG, Hart Biologicals Ltd., Hartlepool, UK) filled with nonadjusted PRP, using the Platelet Aggregometer PAR-4 (ref.: 50.000.1070, Hart Biologicals Ltd., Hartlepool, UK), after addition of platelet agonists: AA (ref.: LS101297, Bio/Data Corporation, Pennsylvania, USA), ADP (ref.: HB-5502-FG, Hart Biologicals Ltd., Hartlepool, UK), COL (ref.: CH 385, CHRONO-LOG Corporation, Pennsylvania, USA) and TRAP (ref.: H-8105.0001, BACHEM, Bubendorf, Switzerland) in final concentrations of $1 \mathrm{mM}$ AA, $5 \mu \mathrm{M}$ ADP, $2 \mu \mathrm{g} / \mathrm{ml} \mathrm{COL}$ and $20 \mu \mathrm{M}$ TRAP respectively.

Multiple electrode impedance aggregometry (MEIA). Platelet aggregation was measured by MEIA principle using the Multiplate ${ }^{\circledast}$ multiple electrode aggregometer (Roche Diagnostics, Almere, The Netherlands). Similar to LTA measurements, platelet aggregation was analyzed using the following agonists: AA at a final concentration of 0.5 mM (ASPI-Test; ref:. MPO210, Dynabyte Medical, Munich, Germany), ADP at a final concentration of 6.4 MM (ADP-Test; Ref.: MPO22O, Dynabyte Medical, Munich, Germany), $\mathrm{COL}$ at a final concentration of $3.2 \mu \mathrm{g} / \mathrm{ml}$ (ref.: 385, Chronolog-PAR, Stago BNL, Leiden, The Netherlands) and TRAP at a final concentration of $32 \mu \mathrm{M}$ (TRAP-Test; ref.: MPO250, Dynabyte Medical, Munich, Germany). All samples were measured after a resting period of 30 min following blood collection.

Rotational thromboelastometry (ROTEM). Thrombus formation was measured by ROTEM (Tem International GmbH c/o Dutch Affiliate, Tilburg, The Netherlands). Standard assays were used according to the manufacturer's recommendations: EXTEM (ref.: 503-05, Tem International GmbH c/o Dutch Affiliate, Tilburg, The Netherlands), FIBTEM (ref.: 503-06, Tem International GmbH c/o Dutch Affiliate, Tilburg, The Netherlands), and HEPTEM (ref:.503-09, Tem International GmbH c/o Dutch Affiliate, Tilburg, The Netherlands). All samples were measured within $1 \mathrm{~h}$ after blood collection. Furthermore, by means of EXTEM and FIBTEM results, the contribution of platelet count to the thrombus formation was calculated as the PLTEM parameter [2O, 21]. 


\section{Clinical data collection}

Clinical data was collected during the entire study period and consisted of: demographic parameters (age, weight, height, body mass index, gender, operative risk status according to the American Society of Anesthesiologists guidelines; preoperative drug use, times and dates of thienopyridine and/or non-steroidal anti-inflammatory drug discontinuation; temperature at blood collection; preoperative laboratory parameters (PC, haemoglobin, haematocrit (Hct), fibrinogen, activated partial thromboplastin time (aPTT), prothrombin time (PT)), international normalized ratio, creatinine clearance); medication use; blood product consumption (packed red blood cells (PRBC), fresh frozen plasma (FFP), platelet concentrate); fluid consumption; intraoperative laboratory parameters (haemoglobin, Hct, PC, fibrinogen, aPTT, PT, blood gas); CPB parameters (priming volume, use of haemocompatible coatings, CPB duration); duration of aortic cross clamping; duration of surgery; graft number; cell saver use; chest tube output (CTO) (first hour, second hour, total volume), re-exploration rate and motivation.

\section{Statistical analysis}

All data was entered in SPSS 20 for Windows (SPSS Inc. Chicago, IL, USA) for statistical analyses. Graphical data is displayed as box plots (minimum, third quartile, median, first quartile, maximum and outliers extending more than $2(\bullet)$ or 3 ( times the standard deviation). Wilcoxon matched-pairs signed-ranks test for nonparametric variables was used to compare baseline values relative to postCPB values, post-CPB values relative to $24 \mathrm{~h}$ postoperative values, and baseline values relative to $24 \mathrm{~h}$ postoperative values within subgroups of different laboratory analyses, using a confidence level of $99 \%$. For comparisons a $p$ value of $<0.01$ was considered statistically significant. Correlations between LTA/MEIA/ROTEM and PC or Hct, LTA/MEIA/ROTEM/PC and postoperative blood loss or blood product use were analyzed using Spearman's correlation test.

\subsection{RESULTS}

\section{Study population}

20 patients (17 men, 3 women) were included after written informed consent. Characteristics of the included patient group are illustrated in Table I. 3 patients required re-exploration for severe postoperative bleeding due to surgical bleeding as the underlying cause (based on surgical reports noticed as arterial bleedings). Therefore, re-exploration was not investigated as a relevant clinical outcome parameter in our correlation analyses. These patients did not receive PC or any other pro-coagulant treatment. 


\begin{tabular}{lll}
\hline \multicolumn{1}{c}{ Mean } & Standard deviation \\
\hline Gender & 17 men, 3 women & - \\
\hline Age (years) & 65 & 12 \\
\hline Body Mass Index (kg/m2) & 27 & 5 \\
\hline $\begin{array}{l}\text { Preoperative platelet count } \\
\text { X 10 } / \text { L) }\end{array}$ & 319 & 106 \\
\hline Graft number & 3 & 1 \\
\hline Cardiopulmonary bypass time (min) & 92 & 35 \\
\hline Aortic cross clamp time (min) & 59 & 22 \\
\hline
\end{tabular}

Table 1: Patient characteristics of the included patient group $n=20$.

Peri- and postoperative evolution of standard haematological parameters PC and Hct.

Compared to baseline, cytometric analysis revealed a significant decrease in both PC $(p<0.01)$ and Hct $(p<0.01)$ following CPB (Figure 1). During the first $24 \mathrm{~h}$ after surgery both parameters partially increased compared to post-CPB, which was significant for PC ( $p<0.01)$. PC and Hct levels remained, however, significantly lower at $24 \mathrm{~h}$ postoperative compared to baseline $(\mathrm{p}<0.01)$.
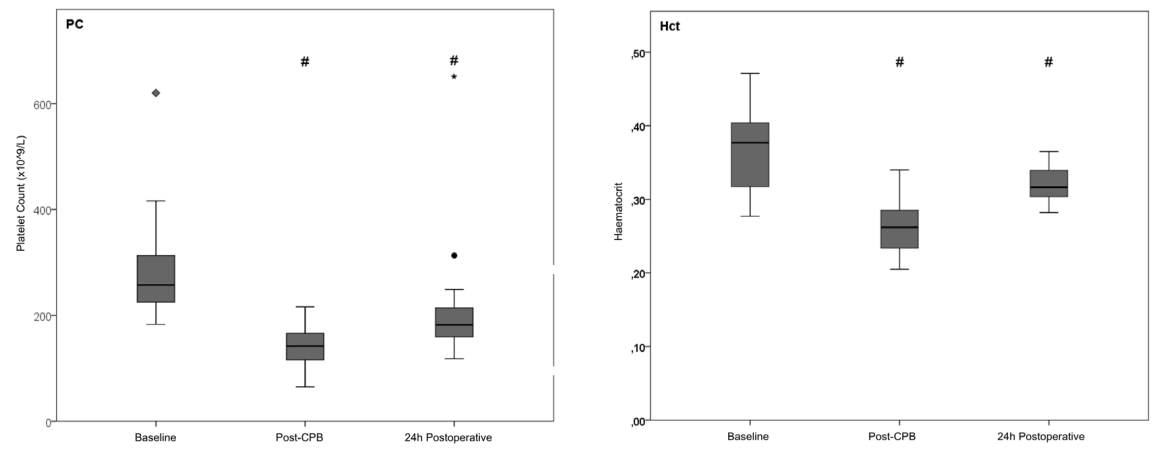

Figure 1 Results of the cytometric analyses of PC and Hct. ${ }^{*} \mathrm{p}<0.01$ compared to baseline. ${ }^{*} \mathrm{p}<0.01$ compared to post-CPB. $n=20$ (PC platelet count; Hct Haematocrit; CPB cardiopulmonary bypass) 


\section{Peri- and postoperative evolution of PF.}

LTA analysis, using AA, ADP, COL and TRAP as platelet agonists, identified a common, pattern in PF changes over the peri- and early postoperative period (Figure 2). Platelet aggregation levels decreased significantly following CPB compared to baseline $(p<0.01)$ for all activation routes tested. During the first $24 \mathrm{~h}$ postoperative, platelet aggregation levels significantly recovered compared to postCPB ( $p<0.01)$ for all activation routes tested. TRAP-induced LTA demonstrated the same trend in platelet function changes as the other platelet agonists, however the data displayed considerable spreading. Interestingly, although all study participants continued their chronic ASA therapy throughout the peri-operative period, platelet aggregation via the AA route increased to levels significantly $(p<0.01)$ higher compared to baseline levels during the first $24 \mathrm{~h}$ after surgery.
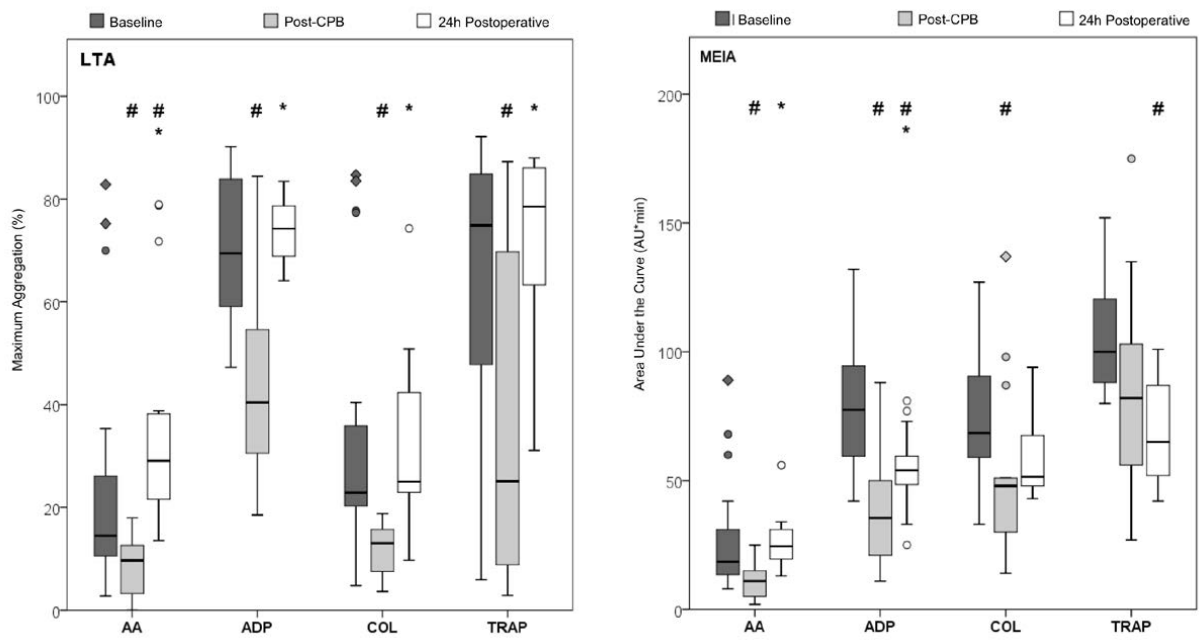

Figure 2: Results of LTA and MEIA analysis assessed with AA-ADP-COL and TRAP agonists. $\# p<0.01$ compared to baseline. ${ }^{*} p<0.01$ compared to post-CPB. $n=20$

(LTA light transmission aggregometry; MEIA multiple electrode impedance aggregometry; AA arachidonic acid; ADP adenosine diphosphate; TRAP thrombin-receptor activating peptide; COL collagen; ROTEM rotational thromboelastometry; MCF maximum clot firmness)

MEIA analysis, using similar platelet agonists as LTA, demonstrated a comparable pattern of PF changes over the peri- and early postoperative period, except for TRAP-induced platelet aggregation (Figure 2). AA-, ADP- and COL-induced platelet aggregation following CPB demonstrated a decrease compared to baseline. The decrease in PF was significant for AA $(p<0.01)$, ADP $(p<0.01)$ and COL $(p<0.01)$ platelet activation routes. LTA analysis with AA-, ADP- and COL-induced platelet aggregation recovered during the first $24 \mathrm{~h}$ postoperative as compared to post-CPB. This was significant for AA ( $p<0.01)$ and ADP $(p<0.01)$, but not for $C O L$. Remarkably, MEIA results for TRAP-induced platelet aggregation followed a different pattern than LTA. Similar to LTA, TRAP-induced platelet aggregation via MEIA demonstrated a decrease following CPB as compared to baseline. At $24 \mathrm{~h}$ postoperative, however, TRAP-induced platelet aggregation via MEIA significantly decreased further as compared to both baseline and post-CPB levels $(p<0.01)$. 
Peri-

and postoperative thrombus formation.

Compared to baseline levels, platelet-specific contribution to thrombus formation, throughout this study defined as PLTEM clot firmness, remained unchanged, both after CPB and at $24 \mathrm{~h}$ postoperative (values not shown).

\section{Analyses of correlation between PC or Hct and LTA, MEIA or ROTEM.}

Correlation analysis using Spearman's correlation coefficients (Table II) identified a strong ( $r>0.40$ or $r<-0.40$ ) correlation between MEIA results and PC for respectively ADP- $(r=0.741, p<0.01), C O L-(r=0.494, p<0.01)$ and TRAP-induced $(r=0.551, p<0.01)$ platelet aggregation. With respect to ROTEM measurement, EXTEM MCF $(r=0.749, p<0.01)$ demonstrated a strong correlation with PC. No, moderate $(0.30<r<0.39$ or $-0.30>r>-0.39)$ or strong correlations were found between LTA measurement and PC intrinsic to LTA methodology.

Correlation analysis using Spearman's correlation coefficients (Table II) identified a strong ( $r>0.40$ or $r<-0.40)$ correlation between MEIA results and Hct for respectively AA- $(r=0.492, p<0.01$ and ADP-induced $(r=0.405, p<0.01)$ platelet aggregation. Additionally, ROTEM values were correlated with Hct results (FIBTEM MCF $r=0.374, p<0.01$ ). Correlation analysis between LTA and Hct was not performed since this assay is performed in PRP.

\begin{tabular}{llllll} 
& \multicolumn{3}{c}{ PC } & & Hct \\
& $r$ & $p$ value & $r$ & $p$ value \\
LTA - AA & 0.135 & 0.338 & $a$ & $a$ \\
LTA - ADP & 0.317 & ${ }^{*} 0.022$ & $a$ & $a$ \\
LTA - COL & 0.338 & ${ }^{*} 0.014$ & $a$ & $a$ \\
LTA - TRAP & 0.359 & ${ }^{* *} 0.009$ & $a$ & $a$ \\
\hline MEIA - AA & 0.318 & ${ }^{*} 0.019$ & 0.492 & ${ }^{* *} 0.000$ \\
MEIA - ADP & 0.741 & ${ }^{* *} 0.000$ & 0.405 & ${ }^{* *} 0.003$ \\
MEIA - COL & 0.494 & ${ }^{* *} 0.000$ & 0.301 & ${ }^{*} 0.030$ \\
MEIA - TRAP & 0.551 & ${ }^{* *} 0.000$ & 0.328 & ${ }^{*} 0.018$ \\
\hline ROTEM - PLTEM MCF & 0.067 & 0.629 & -0.066 & 0.640 \\
ROTEM - EXTEM MCF & 0.749 & ${ }^{* *} 0.000$ & 0.302 & ${ }^{*} 0.030$ \\
ROTEM - FIBTEM MCF & b & b & 0.374 & ${ }^{* *} 0.006$
\end{tabular}

Table 2: Spearman rank test and p-values of correlation analyses between LTA, MEIA and ROTEM versus PC and Hct $n=20$. 
${ }^{*}$ p value $<0.05 ;{ }^{* *}$ p value $<0.01$

${ }^{a}$ Correlation analysis was not performed for LTA versus Hct because the assay is performed in PRP.

${ }^{b}$ Correlation analysis was not performed for FIBTEM versus PC because the assay is performed in presence of cytochalasin $\mathrm{D}$, which completely inhibits platelet action.

(LTA light transmission aggregometry; MEIA multiple electrode impedance aggregometry; AA arachidonic acid; ADP adenosine diphosphate; TRAP thrombin-receptor activating peptide; COL collagen; ROTEM rotational thromboelastometry; PC platelet count; Hct haematocrit; PRP platelet rich plasma; MCF maximum clot firmness)

\section{Analyses of correlation between laboratory assays and clinical outcome parameters.}

Both baseline and post-CPB values for LTA, MEIA, ROTEM and PC demonstrated no correlation with chest tube output (CTO) (first hour, second hour, total). Baseline measurements also revealed no correlation with postoperative blood product consumption. However postoperative consumption of PRBC (packed red blood cells) was strongly correlated with post-CPB values of PLTEM MCF $(r=-0.485 ; p<0.05)$ and EXTEM MCF $(r=-0.493 ; p<0.05)$; postoperative consumption of FFP was strongly correlated with EXTEM MCF $(r=-0.484 ; p<0.05)$ and FIBTEM MCF ( $r=-0.470 ; p<0.05$ ) and postoperative consumption of platelet concentrate was strongly correlated with EXTEM MCF $(r=-0.495 ; p<0.05)$ and FIBTEM MCF $(r=-0.488 ; p<0.05)$.

\subsection{DISCUSSION}

The current study describes the time course of CPB induced platelet dysfunction, using LTA as a reference and multiple electrode impedance aggregometry (MEIA) and rotational thromboelastometry (ROTEM). Results from this study clearly demonstrate that platelet function recovered within 24 hours after surgery in adult, elective CABG patients. This is in accordance with the observation that platelet function but not platelet count recovers within 24 hours after pediatric cardiac surgery [16]. LTA analysis revealed a significant platelet aggregation decrease following CPB compared to baseline $(p<0.01)$ for all activation routes tested. During the first $24 \mathrm{~h}$ postoperative, platelet aggregation significantly restored compared to post-CPB ( $p<0.01)$ for all activation routes tested. MEIA analysis with similar platelet agonists as LTA, demonstrated a comparable pattern in platelet aggregation over the peri- and early postoperative period except for TRAP-induced platelet aggregation (Figure 2). MEIA is able to pick up platelet function changes of LTA, although to a lesser extent, with AA and ADP considered as most useful parameters in this respect. Velick-Salchner et al. also reported ADP and COL, but not AA as the most useful parameters for detection of platelet function changes demonstrating different results between authors [22]. Probably, the difference of time points used for platelet function analysis (LTA at 15 min and 3 hours after CPB) compared to our protocol (directly after weaning from CPB and 24 hours postoperatively) may account for the 
variation in observed postoperative restoration of platelet function. The time point used by Velick-Salchner et al. might have been too close to weaning from CPB when platelet restoration is not maximally effective yet, explaining differences in the extent to which restoration has taken place for the different platelet activation routes. It would have been interesting to observe how function improves more than 24 hours post-op ahead of both HCT and PC. Unfortunately the patients were discharged to the general ward after this time, some of them even to peripheral hospitals.

Early platelet recovery might be considered an advantage from the perspective of postoperative bleeding, but excessive platelet recovery as demonstrated by LTA and MEIA might lead to hypersensitivity questioning the need for earlier initiating of anti-platelet therapy after CABG to prevent graft occlusion [23]. The enhanced AA response postoperative compared to baseline values is an interesting finding. One could speculate that a burst of reticulated, and perhaps uninhibited, platelets into the circulation could explain this finding. Although similar findings are mentioned during hibernation where a rapid restoration of platelet count and coagulative function could unlikely to be due to increased platelet production from the bone marrow (platelet synthesis from megakaryocytes takes 24-48 hours to restore circulating platelet counts after an induced thrombocytopenia).

Secondly, as expected, platelet aggregation measured with LTA was independent of platelet count [25]. In contrast, correlation analysis clearly demonstrates the influence of platelet count on platelet aggregation using MEIA analysis (Table II). A similar correlation has been found in earlier studies, revealing that a platelet count $<150 \times$ $10^{\%} / \mathrm{L}$ resulted in decreased platelet aggregation results $[26,27]$. The platelet count dependency challenges the applicability of MEIA in the peri-operative period where the platelet count frequently is below the above mentioned limit. For that reason we included a study population with high preoperative PC, i.e. $\geq 250 \times 10^{9} / \mathrm{L}$ which could end up in a platelet count of $\geq 150 \times 10^{9} / \mathrm{L}$ after surgery. The correlation of MEIA results and platelet count are illustrated by the observed difference between TRAPinduced platelet aggregation using LTA and MEIA 24h after surgery. Since platelet count increased only marginally in the $24 \mathrm{~h}$ postoperative period, this could have masked detection of TRAP-induced platelet aggregation by MEIA.

Another parameter of interest in this respect is haematocrit. Platelet function analysis using Platelet Function Analyser-100, already demonstrated to rely heavily on haematocrit levels [28]. During cardiac surgery with CPB, haematocrit values decrease due to haemodilution. Therefore, if MEIA results are correlated with haematocrit and platelet count levels, the use of MEIA in a cardiac surgery setting could lead to misinterpretation of true platelet function.

Because of labour intensive analysis and longer turnaround times, LTA is less suited for use preoperative. More importantly, LTA is analyzed using PRP (platelet rich plasma). That means making correlation studies of LTA and HCT seems irrelevant because there are no red cells and the amount of platelets is concentrated.

Additionally, although the absolute magnitude of aggregation in non-adjusted PRP is clearly dependent on platelet number, no moderate or strong correlation was found in this study. With MEIA being dependent on HCT and PC, Iow values of HCT and PC 
might be related with inaccurate platelet function analysis.

ROTEM analyses in this study included EXTEM and FIBTEM parameters. This allowed analysis of platelet-specific contribution to thrombus formation by means of the PLTEM parameter. Compared to baseline, the PLTEM MCF remained unchanged both after CPB and at $24 \mathrm{~h}$ postoperative, suggesting that the contribution of platelets in the thrombus formation process remained unchanged over the study period. This finding is most interesting since LTA and cytometric analysis demonstrated profound decreases in both platelet function and count following CPB, respectively. Furthermore, EXTEM results seemed to be correlated with platelet count. Although the platelet count showed a significant decrease after CPB, our patients had a relatively high baseline platelet count $\left(>=250 \times 10^{\%} / \mathrm{L}\right.$ ) (only 1 patient platelet count decreased below $100 \times 10^{\%} / \mathrm{L}$ throughout the study period). If speculated that thrombus formation remains unaffected by platelet dysfunction, as long as platelet count remains above a certain critical level, it must be remarked, that in vitro ROTEM analysis of thrombus formation differs markedly from reality. Analysis of EXTEM and FIBTEM parameters via ROTEM involves triggering of coagulation via artificial addition of tissue factor. These conditions could have artificially overruled decreased thrombus formation caused by platelet dysfunction. In perspective of future development of new transfusion triggers based on platelet function assays, these findings need further investigating. Interestingly, this study demonstrated only moderate correlation between FIBTEM results and hematocrit. This is in contrast with others demonstrating a correlation between haematocrit and EXTEM or FIBTEM [29, 30].

Petricevic, et al. recently conducted an observational study in 148 adult patients undergoing elective cardiac surgery revealing an inverse correlation between chest tube output at 24h postoperative and results from MEIA (measured before induction of anesthesia, after release of aortic clamp, and $15 \mathrm{~min}$ after heparin neutralization) (AA- and ADP-induced platelet aggregation) and ROTEM analysis (EXTEM, FIBTEM and HEPTEM MCF). In the excessive "bleeding" subgroup, higher proportion of patients were transfused with fresh frozen plasma, fibrinogen concentrate, and platelet concentrate [31]. Others found a correlation between results of MEIA analysis preoperatively and platelet transfusions [32]. Our correlation analysis revealed no correlations between MEIA results and chest tube output or postoperative use of blood products. We observed inverse correlations between the ROTEM parameters PLTEM MCF, EXTEM MCF and FIBTEM MCF with postoperative use of blood products. This implicates that the PLTEM, EXTEM and FIBTEM MCF parameters, when determined directly after CPB, could be indicative for the need of blood products.

The present study had some limitations. First, the authors are aware that the current study population is small resulting in a lack of power with regard to clinical findings, which were our secondary endpoints only. Secondly, our study population contained an unequal gender distribution. During screening far less women appeared eligible than men based on preoperative platelet count. The fact that the female population admitted for CABG with CPB displayed lower preoperative PC may suggest that haemostasis will be differently affected in this population as compared to men. Indeed, female gender is a well-known risk factor for blood product consumption during CS, but this is frequently associated with preoperative anemia [3]. Analysis 
for gender differences in changes of platelet function and thrombus formation is therefore interesting for future studies.

Various triggers such as contact activation, anesthesia, surgery, dilution, temperature changes have different effects on platelet function. Contact activation can not be avoided when collecting blood, but apparently this does not influence platelet function test outcomes as previously published [33]. Even though it does not seem relevant whether a vacuum system (direct) or a syringe (indirect) method is used, one should always consider collecting blood in compliance with a standardized method. Contact activation was independent of the collection method. Only the MEA ASPI test revealed significant differences between the two collection methods. The influence of temperature change on platelet function was reviewed recently [34]. Platelet changes by therapeutic intervention related to surgery and anesthesia have been extensively published [35].

Additionally, blood loss and dilution have a considerable impact on coagulation and platelet physiology. Although the authors are aware that measuring Hct and PC not fully and definitely quantify these changes, they were taken into consideration in this paper.

In this study, thromboxane A2 production was not measured but could have provided a definitive characterisation of the platelet COX inhibition.

Recently, the importance of platelet function assays before, during and after CABG surgery received an increasing interest in the literature [36, 37].

Finally, our study population consisted only elective procedures, with lower risk for postoperative blood product consumption compared to more complex, urgent combined cardiac surgery procedures. Our results may therefore underestimate the value of MEIA and ROTEM as POC tests for identification of platelet function abnormalities in bleeding patients.

\subsection{CONCLUSIONS}

In conclusion, the data from this pilot study clearly demonstrate a reversible CPB induced platelet dysfunction. Additionally, AA-induced platelet aggregation increases to higher levels during the first $24 \mathrm{~h}$ postoperatively which might be important in the context of more aggressive anti-platelet therapy.

If our findings can be generalized, the authors suggest to prescribe aspirin earlier in the postoperative process and associate it with an ADP receptor inhibitor. MEIA and ROTEM at low platelet count $<=150 \times 10^{\%} / \mathrm{L}$ should be interpreted with caution regarding platelet contribution to coagulation. 


\subsection{REFERENCES}

1. Johansson PI, Sølbeck S, Genet G, Stensballe J, Ostrowski SR. Coagulopathy and hemostatic monitoring in cardiac surgery: an update. Scand Cardiovasc J 2012;46(4):194-202.

2. Hartmann M, Sucker C, Boehm O, Koch A, Loer S, Zacharowski K. Effects of cardiac surgery on hemostasis. Transfus Med Rev 2006;20(3):230-41.

3. Ferraris VF, Brown JR, Despotis GJ, Hammon, JW, Reece TB, Saha SP, Song HK, Clough ER, Shore-Lesserson LJ, Goodnough LT, Mazer CD · Shander A, Stafford-Smith M, Waters J, Baker RA, Dickinson TA, FitzGerald DJ, Likosky DS, Shann KG. 2011 update to the Society of Thoracic Surgeons and the Society of Cardiovascular Anesthesiologists blood conservation clinical practice guidelines. Ann Thorac Surg 2011;91:944-82.

4. Despotis G, Eby C, Lublin DM. A review of transfusion risk and optimal management of perioperative bleeding with cardiac surgery. Transfusion 2008;48(1 Suppl):2S-30S.

5. Shander A, Rijhwani TS. Clinical outcomes in cardiac surgery: conventional versus bloodless surgery. Anesthesiol Clin North America 2005;23(2):327-45.

6. Vivacqua A, Koch CG, Yousuf AM, Nowicki ER, Houghtaling PL, Blackstone EH, Sabik JF 3rd. Morbidity of bleeding after cardiac surgery: is it blood transfusion, reoperation for bleeding, or both? Ann Thorac Surg 2011;91(6):1780-90.

7. Kristensen KL, Rauer LJ, Mortensen PE, Kieldsen BJ. Reoperation for bleeding in cardiac surgery. Interact Cardiovasc Thorac Surg 2012;14(6):709-13.

8. Biancari F, Mikkola R, Heikkinen J, Lahtinen J, Airaksinen KE, Juvonen T. Estimating the risk of complications related to re-exploration for bleeding after adult cardiac surgery: a systematic review and meta-analysis. Eur J Cardiothorac Surg 2012;41(1):50-5.

9. Enriquez LJ, Shore-Lesserson L. Point-of-care coagulation testing and transfusion algorithms. Br J Anaesth 2009;103 (Suppl 1):i14-22.

10. Xydas S, Magovern CJ, Slater JP, Brown JM 3rd, Bustami R, Parr GV, Thurer RL. Implementation of a comprehensive blood conservation program can reduce blood use in a community cardiac surgery program. J Thorac Cardiovasc Surg 2012;143(4):926-35.

11. Weber CF, Klages M, Zacharowski K. Perioperative coagulation management during cardiac surgery. Curr Opin Anaesthesiol 2013;26(1):60-4.

12. Görlinger K, Fries D, Dirkmann D, Weber CF, Hanke AA, Schöchl H. Reduction of fresh frozen plasma requirements by perioperative point-of-care coagulation management with early calculated goal-directed therapy. Transfus Med Hemother 2012;39(2):104-113.

13. Weber CF, Görlinger K, Meiniger D, Herrmann E, Bingold T, Moritz A, Cohn LH, Zacharowski K. Point-of-care testing: a prospective, randomized clinical trial of efficacy in coagulopathic cardiac surgery patients. Anesthesiology 2012;117(3):531-47.

14. Zaffar N, Joseph A, Mazer CD, Nisenbaum R, Karkouti K, Tinmouth A, Peterson MD, Pavenski K, Callum J, Cserti-Gazdewich C, Shehata N. The rationale for platelet transfusion during cardiopulmonary bypass: an observational study. Can J Anaesth 2013;60(4):345-54.

15. Harrison P, Mackie I, Mumford A, Briggs C, Liesner R, Winter M, Machin S; British Committee for Standards in Haematology. Guidelines for the laboratory investigation of heritable disorders of platelet function. Br J Haematol 2011;155(1):30-44.

16. Romlin BS, Wåhlander H, Synnergren, Baghaei F, Jeppsson A. Earlier detection of coagulopathy with thromboelastometry during pediatric cardiac surgery: a prospective observational study. Pediatric Anesthesia 2013;23(3):222-7. 
17. Ninivaggi M, Feijge M, Baaten C, Kuiper GJ, Marcus MA, Ten Cate H, Lancé MD, Heemskerk JW, van der Meijden PE. Additive roles of platelets and fibrinogen in wholeblood fibrin clot formation upon dilution as assessed by thromboelastometry. Thromb and Haemost 2014;111:447-457.

18. Tóth $\mathrm{O}$, Calatzis A, Penz S, Losonczy H, Siess W.Multiple electrode aggregometry: a new device to measure platelet aggregation in whole blood. Thromb Haemost 2006;96(6):781-8.

19. Femia EA, Scavone M, Lecchi A, Cattaneo M. Effect of platelet count on platelet aggregation measured by impedance aggregometry (Multiplate ${ }^{\mathrm{TM}}$ analyser) and by light transmission aggregometry. J Thromb and Haemost 2013;11(12):2193-6.

20. Olde Engberink R, Kuiper G, Wetzels R, Nelemans PJ, Lance MD, Beckers EA, Henskens YM. Rapid and correct prediction of thrombocytopenia and hypofibrinogenemia with rotational thromboelastometry in cardiac surgery. J Cardiothorac Vasc Anesth 2014;28(2):210-6.

21. Lang T. Johanning K, Metzler H, Piepenbrock S, Solomon C, Rahe-Meyer N, Tanaka KA. The effects of fibrinogen levels on thromboelastometric variables in the presence of thrombocytopenia. Anesth Analg 2009;108(3):751-8.

22. Velik-Salchner C, Maier S, Innerhofer P, Kolbitsch C, Streif W, Mittermayr M, Praxmarer M, Fries D. An assessment of cardiopulmonary bypass-induced changes in platelet function using whole blood and classical light transmission aggregometry: the results of a pilot study. Anesth Analg 2009;108(6):1747-54.

23. Arazi HC, Doiny DG, Torcivia RS, Grancelli H, Waldman SV, Nojek C, Fornari MC, Badimon JJ. Interact Cardiovasc Thorac Surg. 2010; 10(6):863-7.

24. de Vrij EL, Vogelaar PC, Goris M, Houwertjes MC, Herwig A, Dugbartey GJ, Berea AS, Strijkstra AM, Bouma HR, Henning RH. Platelet Dynamics during Natural and Pharmacologically Induced Torpor and Forced Hypothermia. PLoS ONE 2014; 9(4): e93218. doi:10.1371/journal.pone.0093218.

25. Breet NJ, Van Werkum JW, Bouman HJ, Kelder JC, Ten Berg JM, Hackeng CM. Do not adjust the platelet count in light transmittance aggregometry when predicting thrombotic events after percutaneous coronary intervention. J Thromb and Haemost 2010;8:2326-2328.

26. Hanke AA, Roberg K, Monaca E, Sellmann T, Weber CF, Rahe-Meyer N, Görlinger K. Impact of platelet count on results obtained from multiple electrode platelet aggregometry (Multiplate). Eur J Med Res 2010;15(5):214-9.

27. Görlinger K, Kozek-Langenecker SA. Economic Aspects and Organisation. In Marcucci CE, Schoettker P, editor. Perioperative Hemostasis: Coagulation for Anesthesiologists. Springer, Berlin, Heidelberg 2015: 421-445.

28. Mischke R, Keidel A. Influence of platelet count, acetylsalicylic acid, von Willebrand's disease, coagulopathies, and haematocrit on results obtained using a platelet function analyser in dogs. Vet J 2003;165(1):43-52.

29. Nagler M, Kathriner S, Bachmann LM, Wuillemin WA. Impact of changes in haematocrit level and platelet count on thromboelastometry parameters. Thromb Res 2013;131(3):249-53.

30. Solomon C, Ranucci M, Hochleitner G, Schöchl H, Schlimp CJ. Assessing the Methodology for Calculating Platelet Contribution to Clot Strength (Platelet Component) in Thromboelastometry and Thrombelastography. Anesth Analg 2015;121(4):868-78.

31. Petricevic M, Biocina B, Milicic D, Konosic S, Svetina L, Lekić A, Zdilar B, Burcar I, Milosevic M, Brahimaj R, Samardzic J, Gasparovic H. Bleeding risk assessment using 
whole blood impedance aggregometry and rotational thromboelastometry in patients following cardiac surgery. J Thromb Thrombolysis 2013; 36:514-526.

32. Rahe-Meyer N, Winterhalter M, Boden A, Froemke C, Piepenbrock S, Calatzis A, Solomon C. Platelet concentrates transfusion in cardiac surgery and platelet function assessment by multiple electrode aggregometry. Acta Anaesthesiol Scand 2009;53(2):168-75.

33. Lance MD, Henskens YM, Nelemans P, Theunissen MH, Oerle R V, Spronk HM, Marcus MA. Do blood collection methods influence whole-blood platelet function analysis? Platelets 2013;24:275-81.

34. Poucke S Van, Stevens K, Marcus AE, Lancé M. Hypothermia : effects on platelet function and hemostasis. Thromb J 2014;12:31.

35. Kozek-Langenecker SA. The effects of drugs used in anaesthesia on platelet membrane receptors and on platelet function. Curr Drug Targets 2002;3:247-58.

36. Agarwal S, Johnson RI, Shaw M. Preoperative point-of-care platelet function testing in cardiac surgery. J Cardiothorac Vasc Anesth. 2015 Apr;29(2):333-41.

37. Mutlak H, Reyher C, Meybohm P, Papadopoulos N, Hanke AA, Zacharowski K, Weber CF. Multiple electrode aggregometry for the assessment of acquired platelet dysfunctions during extracorporeal circulation. Thorac Cardiovasc Surg. 2015 Feb;63(1):21-7. 


\section{CHAPTER 6}

\section{THROMBIN GENERATION AND PLATELET ACTIVATION IN CRS/HIPEC.}

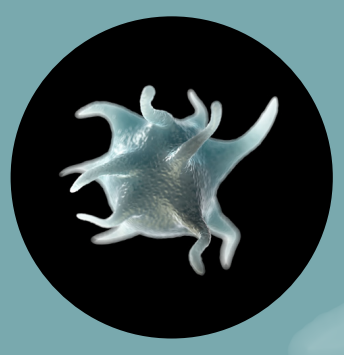

Sven Van Poucke, Dana Huskens, Kurt Van der Speeten, Mark Roest, MD, Bart Lauwereins, Ming-Hua Zheng, Seppe Dehaene, Joris Penders, Abraham Marcus, Marcus Lancé. PLOSOne, submitted 


\section{THROMBIN GENERATION, PLATELET ACTIVATION IN HIPEC.}

\subsection{ABSTRACT}

Background and Objectives: Cytoreductive surgery (CRS) with hyperthermic intraperitoneal peroperative chemotherapy (HIPEC), indicated for patients with peritoneal metastases from digestive or gynecological malignancies alike, demonstrates a considerable impact on hemostatic metabolism, both on platelet and on coagulation level. The potential hemostatic interference in CRS and HIPEC is phase dependent.

Methods: This study demonstrates the combined use of ROTEM (rotational thromboelastometry), PACT (platelet activation test) and CAT (thrombin generation test) assays during CRS and HIPEC with a follow-up of 7 days postoperative.

Results: Platelet reactivity (relative to before incision values) to CRP and TRAP seems to be slightly reduced during CRS and HIPEC with regard to allbB3 activation, while P-selectin expression is not affected. During surgery, CAT demonstrates that, the LT and TTP values decrease while and the TP and ETP increase. Subsequently, after surgery, the LT and TTP increase and ETP and TP decrease in time. ROTEM EXTEM MCF, INTEM MCF and FIBTEM MCF decreased during CRS. At day 7 INTEM and FIBTEM MCF values were significantly higher than before surgery. No considerable changes in platelet count and hemoglobin concentration and absence of leukopenia are noticed.

Conclusion: This approach detects changes in coagulation much earlier than noticed by standard coagulation tests (PT and aPTT)

\section{Keywords:}

cytoreductive surgery, hyperthermia, intraperitoneal chemotherapy, thrombin generation, platelet activation, thromboelastometry 


\subsection{INTRODUCTION}

Cytoreductive surgery (CRS) with hyperthermic intraperitoneal peroperative chemotherapy (HIPEC) is a therapeutic modality for patients with abdominal malignancies and peritoneal dissemination (quantified by the peritoneal cancer index (PCI) $[1,2]$. CRS and HIPEC was introduced in 2001 in our facility. Since then, over 620 CRS/HIPEC procedures have been accomplished. The procedure consists of surgical removal of macroscopic tumor tissue, combined with intraperitoneal/IV, heated chemotherapy perfusate administered during surgery in the abdomen with the aim of annihilating the microscopic residual tumor volume [2]. The thermal enhancement and pharmacokinetics of chemotherapeutic agents have been extensively described [3-6]. CRS and HIPEC potentially exerts a substantial impact on the patients' respiratory, cardiovascular, renal, and metabolic status [7-10]. Additionally, the procedure has been depicted as a high risk with significant levels of comorbidity (22-39\%), mortality (5\%) and prolonged hospital stays [11]. Although cytoreductive surgery (CRS) and hyperthermic intraperitoneal peroperative chemotherapy (HIPEC) has established its therapeutic role in selected patient populations with peritoneal carcinomatosis (PC), multiple factors can disrupt the patient metabolism during and after surgery [12-14].

Complications are related to the disease burden $(\mathrm{PCl})$ and the experience of the surgical team $[2,15,16]$. In general, the majority of complications are situated in three groups: one third of the patients develop digestive fistulas, one third pulmonary complications, and one third hematological complications [17]. The multifactorial impact of surgery (open abdomen or Coliseum technique), hyperthermia and chemotherapy on hemostatic physiology of oncologic patients remains to be quantitatively elucidated, although both a potential bleeding risk as a potential thrombotic risk have been related with CRS-HIPEC [17]. The purpose of this study was to quantitatively assess the impact of CRS and HIPEC, on various components of hemostasis. Routine laboratory assays such as activated clotting time, activated partial thromboplastin time, prothrombin time, or platelet count might, as demonstrated previously, insufficiently provide specificity and/or sensitivity to assess coagulation and platelet disorders. Therefore, additionally thrombin generation (TG) was analyzed by the calibrated automated thrombogram assay (CAT) [18-20]. Also, platelet function was quantitatively assessed by the PAC-t-UB assay and rotational thromboelastometry (ROTEM) was used to elucidate the contribution of platelets, intrinsic and extrinsic coagulation pathways in peri-operative bleeding [21-24]. The hypothesis of this study was that the procedure exposed an increased thrombotic risk, resulting in a faster and increased TG and hyper platelet function? 


\subsection{METHODS \& MATERIALS}

\section{Study design and patients}

This prospective observational pilot study, recruited patients scheduled for CRSHIPEC between April 2015 and July 2016, finally included 27 patients from the Ziekenhuis Oost-Limburg, Genk, Belgium. One patient refused enrollment. The study was approved by the local medical ethics committee (B371201524199), written informed consent was obtained from the enrolled patients. ClinicalTrials.gov Protocol Registration ClinicalTrials.gov ID: NCT03034850. (Figure 1.)

Eligibility criteria included: a confirmed histological diagnosis of peritoneal disease (e.g., mesothelioma; pseudomyxoma peritonei; colorectal, ovarian, or gastric peritoneal carcinomatosis of colorectal, ovarian, or gastric cancer origin; or abdominal sarcomatosis); age <80 years; a cardiac, renal, hepatic, and bone marrow function compatible with surgery; and informed written consent to participate in the study. Exclusion criteria were: inherited coagulation abnormalities, active systemic infections, interstitial lung disease, serious cardiac dysrhythmia or condition, New York Heart Association classification of III or IV, uncontrolled hypertension (diastolic blood pressure constantly $>100 \mathrm{~mm} \mathrm{Hg}$, systolic blood pressure constantly $>180 \mathrm{~mm} \mathrm{Hg}$ ). Inadequate bone marrow function at the beginning of the trial, defined as platelet count less than $<150 \mathrm{GPT} / \mathrm{L}$ or neutrophil granulocyte count less than $<1.5 \mathrm{GPT} / \mathrm{L}$. Inadequate renal function at the beginning of the trial, defined as GFR less than $<60$ $\mathrm{ml} / \mathrm{min}$, inadequate liver function at the beginning of the trial, defined as Bilirubin $>1.5$ times ULN (upper limit of normal), active hepatitis B or C infection, female patients who are pregnant or breast feeding and participation in another therapeutic clinical trial.

Data were collected from inclusion, the day before surgery and consisted of the patient characteristics, anesthesia procedure, perioperative fluid administration, transfusion and coagulation management and body temperature. Laboratory values and blood gas analysis were recorded before incision, before start chemotherapy, at 30 (and if relevant at 60-90) minutes after the start of chemotherapy depending on the cycle length, at the 1st and 7th day postoperative. At the end of the surgical procedure, all patients were admitted to a postoperative intensive care unit for at least 24 h. Postoperative data included pain management, surgical drainage, immediate complications were additionally recorded. Primary outcome measure was peroperative blood loss, secondary outcome measures were parameters as further described by standard hematological analyses, thrombin generation assay, platelet activation test, rotational thromboelastometry.

\section{Surgical technique and anesthesia}

On arrival at the operating theater, standard monitoring (i.e. electrocardiography, noninvasive blood pressure measurement, plethysmographic oximetry, rectal temperature) was initiated. Hereafter, a venous line (Vasofix ${ }^{\circledR}$ Safety, 14G or 16G, B.Braun Melsungen, Germany) was placed in the forearm and an arterial line (Radial Artery Catheterization set, 20 G, Arrow International, Reading, MA, USA) was positioned in the radial artery using subcutaneous local anesthesia ( $1 \mathrm{ml}$ of lidocaine $1 \%$ solution). An epidural catheter was introduced at the levels of L1-L3 before the induction of anesthesia unless otherwise contra-indicated. Anesthesia was induced intravenously, with remifentanyl $0.25-1 \mathrm{mcg} / \mathrm{kg} / \mathrm{min}$ and propofol TCl (target- 
controlled infusion) 4 to $6 \mathrm{ng} / \mathrm{mL}$ given intravenously, and intubation was facilitated with rocuronium $0.5 \mathrm{mg} / \mathrm{kg}$. All patients received $2 \mathrm{~g}$ cephazolin and $1500 \mathrm{mg}$ metronidazol at the end of the induction. Ventilation was set to achieve normal values of blood gases; anesthesia was maintained with air/oxygen mixture, maintenance shot doses of relaxant and supplemented with fentanyl 50-100 $\mu \mathrm{g}$ shots, or epidural marcaine $0.25 \% 10-15 \mathrm{ml}$ bolus and $5 \mathrm{ml}$ shot doses throughout the surgery.

The generic surgical approach involved peritonectomy procedures and visceral resections called CRS as described by Sugarbaker (1995). Peritoneal disease burden was assessed using the peritoneal cancer index (PCI), which scores 13 intraabdominal sites on a scale of $\mathrm{O}$ (no disease) to 3 (lesion size $>5 \mathrm{~cm}$ ), thus giving a range of possible scores from $\mathrm{O}$ to 39. The same team performed the surgical procedure of all included patients. Before connection to the patient, the circuit was filled with dextrose $5 \%\left(2 \mathrm{~L} / \mathrm{m}^{2}\right.$ body surface area) and warmed to $37^{\circ} \mathrm{C}$.

Normovolemia was maintained by ensuring appropriate intravenous fluid and blood replacement for insensible fluid and blood losses that may be gradual and may accumulate over the long duration of surgery. End points such as the maintenance of blood pressure within $20 \%$ of the patient's baseline and urine output $>0.5 \mathrm{~mL} / \mathrm{kg} /$ hour were targeted. Blood product replacement was guided by clinical estimation of blood loss and targeted hemoglobin levels of 8-10 mg/dL. Fresh frozen plasma was given in an effort to stabilize prothrombin time (PT)/international normalized ratio (INR) below 1.2. Base excess and $\mathrm{pH}$ measured intraoperatively also gave indications of the adequacy of tissue perfusion. Normothermia was sustained by forced air warming or underbody thermal blanket, bearing in mind that the subsequent HIPEC tended to increase patient's body temperature.

\section{Chemotherapeutic agents}

The intraperitoneal temperature was maintained at $41.5-42.5^{\circ} \mathrm{C}$ during the perfusion. Different chemotherapeutic agents were used for bidirectional chemotherapy, depending on the tumor's histological characteristics. Colon and appendix cancer: oxaliplatinum $460 \mathrm{mg} / \mathrm{m}^{2}$ intraperitoneal for 30 minutes plus a fast central IV bolus of 5-fluorouracil $400 \mathrm{mg} / \mathrm{m}^{2}$ in $250 \mathrm{ml} \mathrm{NaCl} 0.9 \%$ and a fast peripheral IV bolus of leukovorin (folinic acid) $20 \mathrm{mg} / \mathrm{m}^{2}$ in $250 \mathrm{ml} \mathrm{NaCl} \mathrm{0.9 \%}$. Gastric, ovarian cancer and mesothelioma: cisplatinum $50 \mathrm{mg} / \mathrm{m}^{2}$ and doxorubicin $15 \mathrm{mg} / \mathrm{m}^{2}$ for 90 minutes intraperitoneal associated with IV ifosfamide $1300 \mathrm{mg} / \mathrm{m}^{2}$ over 90 minutes. Mesna (sodium-2mercaptoethane sulfonate) was used to protect against hemorrhagic cystitis.

\section{Blood collection and laboratory analyses}

Blood samples were collected in vacuum tubes via the arterial line, using a VenoJect ${ }^{\oplus}$ Quick Fit luer adapter (XX-MN2000Q,Terumo Medical, Europe), at different time points: before incision (baseline), before chemotherapy, after 30, 60, 90 minutes of chemotherapy and on day 1,3 and 7. Following discarding $10 \mathrm{~mL}$ of blood at each time point, $4 \mathrm{~mL}$ whole blood was collected in a $\mathrm{K}_{2}$ EDTA $7.2 \mathrm{mg}$ BD Vacutainer ${ }^{\circledast}$ (Ref.: 368861, Becton, Dickinson \& Company, Plymouth, UK), $4.5 \mathrm{~mL}$ whole blood in a sodium citrate 3.2\% BD Vacutainer ${ }^{\oplus}$ (Ref.: 367714, Becton, Dickinson \& Company, Plymouth, UK), and 3 $\mathrm{mL}$ whole blood in a hirudin $15 \mathrm{\mu g} / \mathrm{mL}$ vacutainer (Ref.: MP0600, Verum Diagnostica $\mathrm{GmbH}$, Munich, Germany). Blood samples were directly transported to the laboratory 
and analyzed within 2-4 $\mathrm{h}$ after collection to allow for minimal necessary resting time. ROTEM, PACT and thrombin generation assays were performed as further described.

\section{Standard hematological analyses}

EDTA-anticoagulated blood was used for cytometric analysis using a whole blood counter Sysmex XE 2100 (Sysmex,Kobe, Japan) to obtain a whole blood count. Fibrinogen levels were determined with an ACL-9000 (Diamond Diagnostics, Holliston, MA) coagulation analyser, using a PT-fibrinogen high sensitivity reagent, which is a highsensitivity calcium thromboplastin that allows the simultaneous determination of PT and fibrinogen levels. aPTT was measured using an ACL-9000 coagulation analyser and INR was calculated by the formula INR (PT patient/PT normal).

\section{Thrombin generation assay (CAT)}

TG in plasma was measured with the calibrated automated thrombogram (CAT) assay as developed by Hemker and co-workers [18-20]. Briefly, $80 \mu l$ platelet poor plasma (PPP) was mixed with $20 \mu \mathrm{l}$ of a mixture containing tissue factor (DadeBehring) at a final concentration of 1 pM and phospholipid vesicles (f.c. 4 MM 20 mol\% phosphatidylserine, 60 mol\% phosphatidylcholine and 20 mol\% phosphatidylethanolamine, Avanti). To calibrator wells, $20 \mu$ of calibrator (a2macroglobulin-thrombin complex, [19]) was added instead of TF and PL. After 10 minutes of incubation at $37^{\circ} \mathrm{C}$, thrombin generation was initiated by the addition of $20 \mu$ of the thrombin specific substrate, Z-Gly-Gly-Arg-7-amino-4-methylcoumarin (f.c. $416 \mu \mathrm{M}$, Bachem) and $\mathrm{CaCl}_{2}$ (f.c. $16.7 \mathrm{mM}$ ). Fluorescence was measured with a Fluoroscan Ascent reader (Thermo Labsystems) and data were analyzed with dedicated software (Thrombinoscope, Stago) [20]. Thrombin generation was expressed based on endogenous thrombin potential (ETP); lagtime (LT); thrombin peak (TP), time-to-thrombin peak (TTP).

\section{Platelet activation test (PACT)}

Platelet activation was quantitatively assessed on a randomly selected subgroup of 10 patients (not treated with acetylsalicylic acid) in unprocessed blood by the PACT (Platelet activation test, adjusted from Roest 2013). The PACT is based on platelet activation induced by addition of a specific agonist to whole blood and gives specific insight in the granule release capacity and in the aggregation potential of platelets. The test contains three agonists to activate the platelets: (1) the protease activated receptor (PAR-1) agonist thrombin receptor activator peptide (TRAP f.c. $30 \mu \mathrm{M}, \mathrm{SFLLRN}$, H-2936; Bachem, Germany), (2) the glycoprotein VI (GPVI) agonist collagen-related peptide (CRP f.c. $5 \mu \mathrm{g} / \mathrm{ml}$, Professor Farndale, university of Cambridge, UK), and (3) the P2Y12 agonist ADP (f.c. $30 \mu \mathrm{M}$, 01897, Sigma-Aldrich, Zwijndrecht, the Netherlands) in HEPES-buffered saline (HBS, $10 \mathrm{mmol} / \mathrm{L} \mathrm{HEPES,} 150 \mathrm{mmol} / \mathrm{L} \mathrm{NaCl}, 1 \mathrm{mmol} / \mathrm{L}$ MgSO4, $5 \mathrm{mmol} / \mathrm{L} \mathrm{KCL}, \mathrm{pH}$ 7.4). The reaction mixtures also contain three antibodies directed against GPIb (APC-conjugated CD42b, BD Bioscience), activated allbß33 (FITC-conjugated PAC-1) and P-selectin (PE-conjugated CD62P) purchased from BD Pharmingen (Franklin Lakes, USA). Whole blood was heated at $37^{\circ} \mathrm{C}$ for $10 \mathrm{~min}$ and the tests were performed at $37^{\circ} \mathrm{C}$. Whole blood was diluted 1:4 in HEPES-buffered saline and $5 \mu \mathrm{l}$ of this diluted blood was added to each reaction mixture. Reactions were stopped by adding $250 \mu \mathrm{l}$ fixation solution $(137 \mathrm{mmol} / \mathrm{L} \mathrm{NaCl}, 2.7 \mathrm{mmol} / \mathrm{L} \mathrm{KCl}, 1.12$ $\mathrm{mmol} / \mathrm{L} \mathrm{NaH} \mathrm{PO}_{4}, 1.15 \mathrm{mmol} / \mathrm{L} \mathrm{KH}_{2} \mathrm{PO}_{4}, 10.2 \mathrm{mmol} / \mathrm{L} \mathrm{Na}{ }_{2} \mathrm{HPO}_{4}, 4 \mathrm{mmol} / \mathrm{L}$ EDTA, $0.5 \%$ formaldehyde) after exactly 20 min of incubation at $37^{\circ} \mathrm{C}$. Flow cytometry was used to 
distinguish between platelets and other cells on forward and sideward scatter pattern and by gating on the CD42b positive cells. Fluorescent intensity in the FITC gate and PE gate was selected to determine activated allbB3 and P-selectin density, respectively, and results are expressed as median fluorescent intensity (MFI).

\section{Rotational thromboelastometry (ROTEM)}

Thrombus formation was measured by ROTEM (Tem International GmbH c/o Dutch Affiliate, Tilburg, The Netherlands). Standard assays were used according to the manufacturer's recommen-dations: EXTEM (ref.: 503-05, Tem International GmbH c/o Dutch Affiliate, Tilburg, The Netherlands), FIBTEM (ref.: 503-06, Tem International GmbH c/o Dutch Affiliate, Tilburg, The Netherlands), and HEPTEM (ref.: 503-09, Tem International $\mathrm{GmbH}$ c/o Dutch Affiliate, Tilburg, The Netherlands). All samples were measured within $1 \mathrm{~h}$ after blood collection. Furthermore, by means of EXTEM and FIBTEM results, the contribution of platelet count to the thrombus formation was calculated as the PLTEM parameter [22].

\section{Statistical analysis}

Statistical analyses were performed using RapidMiner (7.2, Boston, MA) or GraphPad Prism 5.00. Graphical data are displayed as median with interquartile ranges and the Wilcoxon matched-pairs signed-ranks test for nonparametric variables was used to determine statistical significance $(p<0.05)$.

\subsection{RESULTS}




\section{Study population}

The patients included in this study were aged on average 63 years (range 36-76) with equal gender distribution. Seven patients more were included additional to the 20 patients initially planned in order compensate for potential data or sample losses which was not the case. Patient height and weight were respectively $170 \pm 9$ $\mathrm{cm}$ and $72 \pm 12 \mathrm{~kg}$ (mean \pm SD) with ASA classification $2 \pm 1$ (mean $\pm S D$ ). Five \% of the patients were treated for diabetes mellitus, $40 \%$ for arterial hypertension. A quarter of the patients used nicotine the week before surgery, whereas $55 \%$ described a positive smoking history. About a third (35\%) of the patients consumed alcohol in the week before the HIPEC procedure. One out of four patients were treated with acetylsalicylic acid. Every patient received a low-molecular-weight heparin (prophylactic dose) the evening before surgery. Postoperative, low-molecular-weight heparin was reinitiated as soon as the surgical drainage stopped (median: day 2 postoperative). The assessment of carcinomatosis extension among the patients revealed a mean $\mathrm{PCl}$ score of 15 (range 3-29) with a mean prior score of 1 (range 1-3). The origin of carcinomatosis consisted of primarily digestive cancer followed by peritoneal carcinomatosis from the ovarian. The median hospital stay was respectively 23 days (range 5-87).

\section{Blood loss}

Per-operative blood loss was $123 \pm 88 \mathrm{ml}$, mean operation theatre time was 493 (range 293-800) minutes. Re-operation to treat bleeding complication within the study period was required in 2 patients. Transfusion during surgery was administered in 15\%, 10 and $0 \%$ of the patients, respectively for packed cells, fresh frozen plasma and platelets. The total average amount of fluid therapy during surgery was 4325 $\pm 2015 \mathrm{ml}$. Postoperative blood transfusion during ICU stay was required in $22.2 \%$ of the patients, FFP in $3.7 \%$ and platelets in $7.4 \%$ of the patients. Results of all measurements are illustrated in Table 1.

\section{Cytoreductive surgery}

The cytoreductive surgical phase was defined as the period from surgical incision until the start of chemotherapy administration. During this phase, we noticed that fibrinogen, $\mathrm{Ca}^{2+}$ concentration and the ROTEM maximum clot firmness of EXTEM, INTEM and FIBTEM significantly decreased ( $p$ values of $0.001,0.010,0.005,0.003$, $<0.001$, respectively). Moreover, a significant decrease was reported for EXTEM A5, A30 and alpha ( $p$ values of $0.004,0.004$ and 0.002 , respectively) for INTEM A5, A30 and alpha ( $p$ values of 0.001, 0.009 and 0.001 , respectively) and for FIBTEM A5, A30 and alpha ( $p$ values of $<0.001,<0.001$ and 0.001 , respectively). On the contrary, white blood cell count and glycemia significantly increased ( $p$ values of 0.004 and 0.001 , respectively). Moreover, CFT values of EXTEM, INTEM and FIBTEM significantly increased with $p$ values of $0.002,0.001$ and 0.005 , respectively. Compared to baseline (before incision), hemoglobin concentration, platelet count, prothrombin time, activated partial thromboplastin time, and both CT and ML of EXTEM, INTEM and FIBTEM did not demonstrate a significant change.

\section{Chemotherapy}

The period of chemotherapy was defined as the phase starting immediately before 
chemotherapy administration until chemotherapy was stopped (the majority of the patients received 30 minutes of chemotherapy. This phase, demonstrated a significant increase in glucose and lactate concentration and FIBTEM alpha ( $p$ value of $<0.001,<0.001$ and 0.017 respectively). A significant decrease was noticed for $\mathrm{pH}$, prothrombin time, fibrinogen, EXTEM CT, FIBTEM A5, A30, alpha and CFT ( $p$ values of $0.004,0.019,0.019,0.043,0.045,0.032$ and 0.028 , respectively). No significant changes were noticed for hemoglobin concentration, white blood cell count, platelet count, activated partial thromboplastin time and ROTEM EXTEM, INTEM and FIBTEM maximum clot firmness values. With only 4 patients that received chemotherapy for 60 minutes and only 3 patients, 90 minutes of chemotherapy, conclusions of chemotherapy were restricted to 30 minutes.

Compared to the moment before incision, CRS and 30 minutes chemotherapy resulted in a significant increase of WBC, glucose concentration, lactate, EXTEM CFT, INTEM CFT and FIBTEM CFT ( $p$ values of $0.001,<0.001,<0.001,<0.001,0.008$ and 0.019 , respectively) and a significant decrease in calcium concentration, $\mathrm{pH}$, prothrombin time, fibrinogen ( $p$ values of $0.026,0.011,0.022$ and $<0.001$, respectively). Moreover, a significant decrease was measured for EXTEM A5, A30, alpha, MCF and $M L$ ( $p$ values of $<0.001,0.002,<0.001,0.013$ and 0.004 , respectively), for INTEM A5, A30, alpha and MCF ( $p$ values of $0.011,0.022,0.009$ and 0.017 , respectively) and FIBTEM A5, A30 and MCF ( $p$ values of $<0.001,<0.001$ and $<0.001$, respectively).

\section{Day 1 postoperative}

The phase defined as the period between incision and the first day postoperative provided values with significant increase for white blood cell count, glucose concentration, $\mathrm{pH}$, lactate, activated partial thromboplastin time, INR, EXTEM ML, FIBTEM CFT and INTEM ML, (p values of <0.001, <0.001, 0.006, 0.003, 0.001, <0.001, $0.001,0.003$ and $<0.001$, respectively). A significant decrease was measured for platelet count, prothrombin time, EXTEM and INTEM maximum clot firmness values ( $p$ values of $0.001,<0.001,0.004$ and 0.004 , respectively). Additionally, EXTEM A30, INTEM A30, FIBTEM ML were significantly decreased ( $p$ values of $0.002,0.003$ and 0.005 , respectively).

Comparing values after 30 minutes of chemotherapy and 1 day postoperative demonstrated a significant increase of white blood cell count, calcium concentration, $\mathrm{pH}, \mathrm{aPTT}$, INR, fibrinogen, EXTEM A5, EXTEM alpha, EXTEM ML, INTEM alpha, INTEM ML, FIBTEM A5, FIBTEM A30 and FIBTEM MCF ( $p$ values of $0.048,0.025,<0.001$, $0.001,<0.001,<0.001,0.027,<0.001,<0.001,0.024,<0.001,<0.001,<0.001$ and $<0.001$, respectively). A significant decrease was measured for platelet count, glucose concentration, lactate, prothrombin time, EXTEM CFT, FIBTEM CFT and FIBTEM ML ( $p$ values of $0.002,<0.001,0.001,<0.001,0.008,<0.001$ and 0.003 , respectively).

\section{Day 3 postoperative}

The phase between incision and the third day postoperative resulted in a significant 
increase of the calcium concentration, glucose concentration, $\mathrm{pH}$, aPTT, fibrinogen, EXTEM alpha, EXTEM ML, INTEM alpha, INTEM ML, FIBTEM A5, FIBTEM A3O, FIBTEM alpha and FIBTEM MCF ( $p$ values of $<0.001,0.010,<0.001,0.014,<0.001,0.001$, $<0.001,0.037,0.001,<0.001,<0.001,0.002$ and 0.001 , respectively). A significant decrease on the other hand was observed for hemoglobin concentration, platelet count, EXTEM A30, INTEM A30 and FIBTEM ML ( $p$ values of $0.041,<0.001,0.040$, 0.041 and 0.005 , respectively).

Comparing the results of day 3 postoperative with day 1 postoperative demonstrated a significant increase of calcium concentration, $\mathrm{pH}$, prothrombin time, fibrinogen, EXTEM A5, EXTEM A30, EXTEM alpha, EXTEM MCF, EXTEM ML, INTEM alpha, FIBTEM A5, FIBTEM alpha, FIBTEM A30 and FIBTEM ML ( $p$ values of $<0.001,0.015$, $0.001,<0.001,0.046,0.030,0.013,0.032,0.041,0.007,<0.001,0.001,<0.001$ and 0.005 , respectively) and a decrease of hemoglobin, platelet count, white blood cell count, glucose concentration, INR, EXTEM CFT, INTEM CFT ( $p$ values of 0.001, 0.004, $<0.001,0.009,<0.001,0.004$, and 0.038 , respectively).

\section{Day 7 postoperative}

By comparing measurements on the 7th day postoperative with before incision values, a significant increase was observed for white blood cell count, glucose, $\mathrm{pH}$, lactate, fibrinogen, EXTEM A5, EXTEM A30, EXTEM alpha, EXTEM CT, INTEM A5, INTEM A30, INTEM alpha, INTEM MCF, FIBTEM A5, FIBTEM A30, FIBTEM alpha, FIBTEM CT and FIBTEM MCF ( $p$ values of $0.014,<0.001,0.001,0.001,0.011,0.016,0.021,0.037$, $0.004,0.003,0.004,0.004,0.044,<0.001,0.002,0.018$ and $<0.001$, respectively). A significant decrease was noticed for EXTEM CFT, INTEM CFT, FIBTEM CFT and FIBTEM ML with $p$ values of $0.021,0.012,0.044$ and 0.001 , respectively.

\section{Platelet activation}

To study the effect of HIPEC on platelets function, we measured the granule release potential and the aggregation potential of the platelets by quantifying P-selectin expression and activation of the allbB3 receptor, respectively, after addition of PAR-1, glycoprotein VI (GPVI) (collagen) or P2Y12 receptor agonists ( $(n=10)$, Figure 2 and Table 2). Chemotherapy resulted in a significant decrease of allb $\beta 3$ receptor activation in response to TRAP, CRP and ADP (significant decrease 30 min after start chemo compared to before chemo with $p$ values of $0.048,0.02$ and 0.01 , respectively). During the days after surgery the allbB3 receptor activation in response to TRAP and ADP decreased even more, however, a large variation was observed between patients.

In contrast to the decrease in allb $\beta 3$ receptor activation during chemotherapy, no difference in P-selectin expression was measured in response to the 3 agonists. Only a significant decrease in P-selectin expression in response to ADP was observed after 30 min of chemotherapy compared to before incision, however, here also a large variation was detected between patients. 


\section{Thrombin generation}

To study the effect of HIPEC on the coagulation system, thrombin generation was performed in PPP with 1 pM of TF and quantitatively assessed by ETP (endogenous thrombin potential), LT (lag time), TP (thrombin peak) and TTP (time-to-thrombinpeak) ( $n=27$, Figure 3). For each patient, data retrieved before chemotherapy, after 30 minutes of chemotherapy, at day 1 , day 3 and day 7 postoperative were normalized to preoperative values (Table 3).

During surgery, the LT and TTP reduced (significant shortening after 30 minutes of chemotherapy with $p$ values of 0.0003 and 0.002 , respectively) and the TP and ETP increased (significant higher after 30 minutes of chemotherapy with $p$ values of 0.004 and 0.02 , respectively). Subsequently, after surgery, the LT and TTP increased and ETP and TP decreased in time (Figure 3). Interestingly, the LT and TTP were prolonged on day 7 compared to before incision ( $p$ values of 0.0005 and 0.0007 , respectively).

\section{Discussion}

CRS and HIPEC is a therapeutic modality for patients with abdominal malignancies responsible for inducing hemostatic disruption, both on platelet and on coagulation level. To our knowledge, this is the first study demonstrating the combined use of ROTEM, PACT and CAT assays during CRS and HIPEC with a follow-up of 7 days postoperative. This approach demonstrated changes in coagulation much earlier than noticed by standard coagulation tests (PT and aPTT).

Platelet reactivity (relative to before incision values) to CRP and TRAP seems to be slightly reduced during CRS and HIPEC with regard to allbB3 activation, while P-selectin expression was not affected. The decline in allb $\beta 3$ activation is most likely a consequence of impact of CRS and HIPEC. Furthermore, we observed a strong interindividual variation in platelet reactivity, as previously demonstrated by others [25]. Certain drugs as used during anesthesia (e.g. aprotinin) also exert a different impact on the granule release potential and the aggregation potential [26].

Moreover, it has been known that in this population, activated leukocytes and endothelial cells express adhesion molecules on their luminal surfaces, and inflammatory mediators (cytokines, chemokines, nitric oxide, and reactive oxygen species) are secreted into the microenvironment, ultimately leading to either a positive platelet response (an enhancement of inflammation) or a negative one (an inhibition of inflammation) [27].

Thrombin generation measurements (CAT assay) demonstrate time dependent changes. Lag time values and time to peak values, resembling the clotting time, decreased early during surgery (30 minutes of chemotherapy) but ended up with significant higher values than before incision, which might be related with the LMWH prophylaxis initiated early in the postoperative phase. Additionally, thrombin peak values progressively increased until day 1 post-operative which could be expected as elevated thrombin generation following surgical trauma is indicative for elevated plasma procoagulants (tissue factor, FVIII) and decreased anti-coagulants [28]. However, thrombin peak values decreased from day 1 to values measured preoperative. The endogenous thrombin potential initially increased after 30 minutes of chemotherapy but decreased in the postoperative period which was not found in trauma patients where measurements indicate that the capacity to generate thrombin was not altered [28]. 
Maximum clot firmness decreased during surgery but significantly increased at day 7. ROTEM EXTEM MCF, INTEM MCF and FIBTEM MCF decreased during CRS as mentioned by others [29,30]. These findings are considered a nonspecific consequence of surgical aggression, with MCF FIBTEM deterioration as a consequence of the decrease in the concentration of plasmatic fibrinogen or a deterioration of its function. At day 7, INTEM and FIBTEM MCF values were significantly higher than before surgery.

No considerable changes in platelet count and hemoglobin concentration and absence of leukopenia.

Platelet dynamics were previously described by Perez Ruixo, indicating a model based time course of platelet counts, which simultaneously accounts for the acute-immediate thrombocytopenia response induced by the CRS and the hyperthermic intraperitoneal oxaliplatin effects in bone marrow, as well as the subsequent thrombocytosis due to the natural defence mechanism to prevent major bleedings [31]. Our measurements revealed that during CRS and 30 minutes of chemotherapy, platelet count did not significantly change, however it decreased to non-critical levels on day 1 and 3 . Hereafter platelet counts were normalized at day 7. In this context, a correlation between oxaliplatinum exposure and thrombocytopenia has been described with thrombocytopenia related to chemotherapeutic agents, caused by a mild bone marrow suppression (toxicity to megakaryocytic progenitors) occurring in $45-77 \%$ of the cases $[32,33]$. Additionally, oxaliplatin has also been related with drug-induced, immune mediated thrombocytopenia (DITP) and splenic sequestration of platelets due to portal hypertension based on sinusoidal injury [34-37].

5-FU (Fluorouracil), on the other hand, has been related to infection, bleeding and thromboembolism [38, 39]. Also, 5-FU is known to produce a significant reduction in platelet aggregation and platelet factor-3 (PF(3)) availability without being associated with thrombocytopenia [40]. 5-FU does contribute to a potentially pro-thrombotic environment through the depletion of protein $\mathrm{C}$ and increased thrombin activity [41]. Furthermore, animal models and human endothelial cell cultures exposed to 5-FU demonstrated endothelial cell damage with the potential to promote thrombus formation [42]. Another chemotherapeutic agent, cisplatin causes only mild hematological toxicity to all 3 blood lineages [43]. The use of mitomycin however results in a high incidence of bone marrow suppression, particularly thrombocytopenia and leukopenia occurring within 8 weeks after onset of therapy and recovery after cessation within 10 weeks which is beyond the scope of our measurements. [44-46]

With respect to hemoglobin concentrations, significant changes during and after surgery were not noticed in this study. This was partially explained by the minimal blood loss we measured during surgery $(123 \pm 88 \mathrm{ml})$ for a mean operation theatre time of 493 (range 293-800) minutes, even when the total amount of peri-operative fluid therapy was $4325 \pm 2015 \mathrm{ml}$ and by blood transfusion as was required in $15 \%$ of the patients.

The white blood cell count significantly increased early in the process (from incision to the start of chemotherapy). On day 1 and 7 post-operative, the white blood cell count was still significantly higher than before incision which has been reported by others [7-10]. These findings are in contrast with the leukopenia mentioned by others [47]. In our population, only $20 \%$ of the patients underwent a splenectomy. Moreover, no relationship was noticed between patients with or without splenectomy on the white blood cell or platelet count variations postoperatively. Preoperative leukopenia related 
to preoperative chemotherapy is considered an argument to delay the CRS and HIPEC intervention. Although white blood cell counts increased as noticed after any major surgery, immunosuppression counteracted a more significant rise which could be misleading in case of a postoperative infection.

Potential hemostatic interference in CRS and HIPEC is phase dependent. Disturbance in hemostatic physiology related to extensive surgery and HIPEC can be caused by a combination of factors including: hemodilution, tumor burden effect, consumption lysis, significant protein losses which, alongside with albumin diffusion into extravascular spaces, blood loss, early activation of protein C and FX, direct effect of intra-peritoneal chemotherapy and hyperthermia which all potentially account for the early impact on coagulation. Considerable postoperative fluid volume shifts, hepatic toxicity due to anti-neoplastic agents and direct hepatic trauma potentially account for later effects [7-10]. Volume shifts can result in cellular hypoxia by increasing the tissular diffusion distance for oxygen which might promote a pro-thrombotic state [48].

\section{Hyperthermia as independent feature influences hemostatic function.}

Worel et al. and Ludgate demonstrated a temporal correlation between hemostatic alterations and elevation in liver enzymes leading to the assumption that liver impairment might play a crucial role in coagulation disturbances observed during extra-corporeal circulation induced whole body hyperthermia (sarcoma treatment) which is followed by liver sequestration of platelets. [49,50] Bull et al. on the other hand recorded no clotting disorders following whole body hyperthermia [51]. Others concluded that whole body hyperthermia was associated with a consumption coagulopathy [52]. Oglesbee et al. concluded that the induction of whole body hyperthermia by extracorporeal circulation resulted in a coagulopathy characterized by thrombocytopenia, increased plasma fibrin degradation products, prolonged clotting times, and evidence of spontaneous bleeding [53]. Boldt et al. reported that hyperthermic immersion $(\mathrm{HI})$ lead to a shortening of aPTT $(\mathrm{P}<0.05)$ [54]. Fibrinogen concentration decreased immediately after $\mathrm{HI}(\mathrm{P}<0.05)$ but increased during recovery $(\mathrm{P}<0.05)$. Plasminogen activator inhibitor (PAI) activity decreased during $\mathrm{HI}(\mathrm{P}<$ O.05), D-dimer concentration was not found to change. Platelet count increased ( $P<$ 0.05) during $\mathrm{HI}$. The increases in tissue-type plasminogen activator concentration as well as leucocyte count during HI were related to hemoconcentration. PT, PAl-activity and granulocyte count decreased during thermoneutral immersion $(P<0.05)$. Meyer et al. hypothesized that elevated body temperature and reduced central blood volume contributes to hypercoagulability, possibly related with a moderate sympathetic activation, in critically ill patients [55].

\section{Hyperglycemia affects thrombin generation.}

Oxaliplatin is unstable in chloride-containing media, resulting in the use of $5 \%$ dextrose as the carrier solution in these procedures. However, the use of chloride-containing carrier solutions for oxaliplatin does not relevantly affect its concentrations under tested in-vitro conditions. Chloride seems to promote formation of the active cytotoxic drug form of oxaliplatin and therefore could enhance its cytotoxic effect [56]. In this study, glucose concentration increased during surgery, peaked during chemotherapy (related to the dextrose $5 \%$ solution used for chemotherapy instillation) but continued to be increased on day 3 and 7 postoperative [14]. In diabetic patients, the hyperglycemic byproduct methylglyoxal impairs anticoagulant activity through co-valent adduction of antithrombin III [57]. Acute hyperglycemia has been related with a transient increase in thrombin generation [58]. 
Fibrinogen decreased initially during surgery but continued to increase postoperatively from day 7 until day 7.

CRS-HIPEC initially decreases fibrinogen but significantly rises from day 3 postoperative. There are at least three mechanisms responsible for the reduction in fibrinogen concentration during major surgery: hemodilution, consumption, and degradation. Volume replacement with crystalloids and colloids, and blood transfusions containing low levels of fibrinogen can result in hemodilution. Second, excessive activation of the hemostatic system, owing to, for example, blood contact with the surface of the HIPEC circuit and operation trauma, occasionally instigate a disseminated intravascular coagulation process with consumption of platelets, fibrinogen, and other coagulation factors. Other mechanisms leading to fibrinogen loss during surgery are fibrinogenolysis or fibrinogen degradation, caused by plasmin-mediated proteolysis after activation of plasminogen through tissue plasminogen activator (t-PA). It is currently unknown to which extent these different mechanisms contribute to the decrease in fibrinogen concentration during CRS/HIPEC [59]. In our study, we observed an increase of ROTEM $M L$ values postoperative which suggests increased fibrinolysis but simultaneously, fibrinogen values already revealed an increasing trend. The increase of fibrinogen in the postoperative period is related to the prominent role for fibrinogen and degradation products in regulating the inflammatory response in several target tissues [60].

The strengths associated with this study is related to the combined ROTEM, PACT and CAT measurements up to 7 days after surgery which is the first time reported in HIPEC literature. Araña et al. limited the measurements only during the surgery [30]. Moreover, the patient populations consisted only of female patients and only ROTEM, but no PACT and CAT assays were used. They concluded that FIBTEM MCF changes were most relevant.

Although this combination of assays covers a broad spectrum of hemostasis testing, the assays are not able to fully quantify and reveal the hemostatic condition in vivo at the site of surgery. Moreover, from the 27 patients enrolled in this study, only 10 patients were tested by the PACT assay. Only patients not treated with acetylsalicylic acid. The inter-individual variations as noticed both in the PACT and CAT assays suggest considerable individual difference in platelet activation and the potential of thrombin generation, which could not be clarified based on the available data. Additionally, adding other tests such as quantifying coagulation factors, tissue factor expression, plasmin generation, etc is considered an opportunity for a follow-up study. Also, TG was only measured in platelet poor plasma whereas a defect in platelet activation requires testing in platelet rich plasma. More research is required to reveal the influence of age, gender and cancer type on the results presented in this paper. Patients scheduled for CRS and HIPEC have considerable variations in oncological histories, therefore we are interested in the interaction of inflammatory functions and the immune response in general on thrombocytes and coagulation in this context. All patients received a prophylactic LMWH dose the evening before surgery which could have altered our findings (prolongation of the LT and reduction of ETP).

This study does however provide an extra argument to widen the spectrum of tests used to quantify different aspects of hemostasis and interfere where necessary (e.g. administration of LMWH based on LT and TTP values) 


\subsection{CONCLUSION}

Based on this study, the impact of CRS-HIPEC on high precision coagulation measurements ( $T G$ and high precision platelet function measurements (PACT)) is quantitatively illustrated from the moment of incision up to 7 days after surgery. This study demonstrated that PT, aPTT and platelet count insufficiently demonstrated the impact of surgical stress, hyperthermia, chemotherapy and considerable fluid shifts on the overall hemostatic physiology of CRS and HIPEC. This study suggests a decreased platelet reactivity and an altered thrombin generation pattern.

Longer follow-up in a larger patient cohort will be required to clarify the interindividual variations of postoperative bleeding or thrombosis (DVT/PE) in patients treated with CRS and HIPEC.

\subsection{ACKNOWLEDGEMENTS}

All authors contributed equally to this manuscript. The authors disclose there was no writing assistance. 


\subsection{REFERENCES}

1. Sugarbaker PH: Peritonectomy procedures.Ann Surg 1995; 221:29-42.

2. Elias DM, Ouellet JF: Intraperitoneal chemohyperthermia: rationale, technique, indications, and results. Surg Oncol Clin N Am 2001;10:915-33.

3. Speeten K Van Der, Govaerts K, Stuart OA, Sugarbaker PH: Pharmacokinetics of the perioperative use of cancer chemotherapy in peritoneal surface malignancy patients.

Gastroenterol Res Pract 2012;2012:378064.

4. Urano M, Ling CC: Thermal enhancement of melphalan and oxaliplatin cytotoxicity in vitro. Int J Hyperthermia 2002;18:307-15.

5. Perez-Ruixo C, Valenzuela B, Peris JE, et al.: Population pharmacokinetics of hyperthermic intraperitoneal oxaliplatin in patients with peritoneal carcinomatosis after cytoreductive surgery. Cancer Chemother Pharmacol 2013;71:693-704.

6. Hahn GM: Potential for therapy of drugs and hyperthermia. Cancer Res 1979;39:2264-8.

7. Schmidt C, Creutzenberg M, Piso P, et al.: Peri-operative anaesthetic management of cytoreductive surgery with hyperthermic intraperitoneal chemotherapy. Anaesthesia 2008;63:389-95.

8. Desantis M, Bernard JL, Casanova V, et al.: Morbidity, mortality, and oncological outcomes of 401 consecutive cytoreductive procedures with hyperthermic intraperitoneal chemotherapy (HIPEC). Langenbeck's Arch Surg 2014;400:37-48.

9. Kajdi M-E, Beck-Schimmer B, Held U, et al.: Anaesthesia in patients undergoing cytoreductive surgery with hyperthermic intraperitoneal chemotherapy: retrospective analysis of a single centre three-year experience. World J Surg Oncol 2014;12:136.

10. Bell JC, Rylah BG, Chambers RW, et al.: Perioperative management of patients undergoing cytoreductive surgery combined with heated intraperitoneal chemotherapy for peritoneal surface malignancy: a multi-institutional experience. Ann Surg Oncol 2012;19:4244-51.

11. Cooksley TJ, Haji-Michael P: Post-operative critical care management of patients undergoing cytoreductive surgery and heated intraperitoneal chemotherapy (HIPEC). World J Surg Oncol 2011;9:169.

12. Korakianitis O, Daskalou T, Alevizos L, et al.: Lack of significant intraoperative coaulopathy in patients undergoing cytoreductive surgery and hyperthermic intraperitoneal chemotherapy (HIPEC) indicates that epidural anaesthesia is a safe option. Int J Hyperthermia 2015:1-6.

13. Falcon Arana L, Fuentes-Garcia D, Roca Calvo MJ, et al.: Alterations in hemostasis during cytoreductive surgery and hyperthermic intraperitoneal chemotherapy in patients with peritoneal carcinomatosis. Cir Esp 2015;93:496-501.

14. Raytis JL, Lew MW: Hyperthermic Intraperitoneal Chemotherapy (HIPEC) and Intraoperative Electrolyte Disturbances-Implications for Anesthetic Management. Open J Anesthesiol 2009;4:240-3.

15. Kusamura S, Moran BJ, Sugarbaker PH, et al.: Multicentre study of the learning curve and surgical performance of cytoreductive surgery with intraperitoneal chemotherapy for pseudo-myxoma peritonei. Br J Surg 2014;101:1758-65.

16. Canda AE, Sokmen S, Terzi C, et al.: Complications and toxicities after cytoreductive surgery and hyperthermic intraperitoneal chemotherapy. Ann Surg Oncol 2013;20:1082-7. 
17. Newton AD, Bartlett EK, Karakousis GC: Cytoreductive surgery and hyperthermic intraperitoneal chemotherapy : a review of factors contributing to morbidity and mortality. J Gastro-intest Oncol 2016;7:99-111.

18. Hemker HC, Giesen P, AIDieri R, et al.: The calibrated automated thrombogram (CAT): a universal routine test for hyper- and hypocoagulability. Pathophysiol Haemost Thromb 2002; 32: 249-53.

19. Hemker HC, Giesen P, Al Dieri R, et al.: Calibrated automated thrombin generation measurement in clotting plasma. Pathophysiol Haemost Thromb 2003; 33: 4-15.

20. Hemker HC, Kremers R: Data management in thrombin generation. Thromb Res 2013; 131: 3-11.

21. Roest M, van Holten TC, Fleurke G-J et al.: Platelet Activation Test in Unprocessed Blood (Pac-t-UB) to monitor platelet concentrates and whole blood of thrombocytopenic patients. Transfus Med Hemother 2013;40(2):117-25.

22. Ninivaggi M, Feijge, MAH, Baaten C, Kuiper G et al.: Additive roles of platelets and fibrinogen in whole-blood fibrin clot formation upon dilution as assessed by thromboelastometry. Thrombosis and Haemostasis 2014; 111: 381-564.

23. Romlin BS, Wåhlander $H$, Synnergren, Baghaei $F$, Jeppsson A: Earlier detection of coagulopathy with thromboelastometry during pediatric cardiac surgery: a prospective observational study. Pediatric Anesthesia 2013;23(3):222-7.

24. Choi J, Li S, Han J: Platelet function tests: a review of progresses in clinical application. BioMed Research International 2014; 2014:456569

25. Hochholzer W, Ruff CT, Mesa RA, et al.: Variability of individual platelet reactivity over time in patients treated with clopidogrel: insights from the ELEVATE-TIMI 56 trial. J Am Coll Cardiol 2014;64:361-8.

26. Kozek-Langenecker SA: The effects of drugs used in anaesthesia on platelet membrane receptors and on platelet function. Curr Drug Targets 2002;3:247-58.

27. Etulain J, Lapponi MJ, Patrucchi SJ, et al.: Hyperthermia inhibits platelet hemostatic functions and selectively regulates the release of alpha-granule proteins. J Thromb Haemost 2011;9:1562-71.

28. Cardenas JC, Rahbar E, Pommerening MJ, et al.: Measuring thrombin generation as a tool for predicting hemostatic potential and transfusion requirements following trauma. J Trauma Acute Care Surg 2014;77:839-45.

29. Olde Engberink R, Kuiper G, Wetzels R, et al.: Rapid and correct prediction of thrombocytopenia and hypofibrinogenemia with rotational thromboelastometry in cardiac surgery. J Cardiothorac Vasc Anesth 2014;28(2):210-6.

30. Araña LF, Fuentes-garcı D, Martı G, Jose F: Alterations in Hemostasis during Cytoreductive Surgery and Hyperthermic Intraperitoneal Chemotherapy in Patients with Peritoneal. Cirugía Española 2015;3:5-10.

31. Pérez-Ruixo C, Valenzuela B, Peris JE, et al:. Platelet Dynamics in Peritoneal Carcinomatosis Patients Treated with Cytoreductive Surgery and Hyperthermic Intraperitoneal Oxali-platin. AAPS J 2016;18:239-50.

32. Jardim DL, Rodrigues CA, Novis YAS, et al.: Oxaliplatin-related thrombocytopenia. Ann Oncol 2012;23:1937-42.

33. Teng C-J, Hsieh Y-Y, Chen K-W, et al.: Sudden-onset pancytopenia with intracranial hemorrhage after oxaliplatin treatment: a case report and literature review. Jpn J Clin Oncol 2011;41:125-9. 
34. Chong BH, Young-III Choi P, Khachigian L, Perdomo J: Drug-induced immune thrombocytopenia. Hematol Oncol Clin North Am 2013;27:521-40.

35. Suzuki K, Oda H, Sugawara Y, et al.: Oxaliplatin-induced Acute Thrombocytopenia: A Case Report and Review of the Literature. Intern Med 2013;52:611-5.

36. Mittal K, McNamara MJ, Curtis BR, McCrae KR: Antiplatelet antibodies in oxaliplatininduced immune thrombocytopenia. JRSM open 2014;5:2054270414531126.

37. Arnold DM, Nazi I, Warkentin TE, et al.: Approach to the diagnosis and management of drug-induced immune thrombocytopenia. Transfus Med Rev 2013;27:137-45.

38. Kadoyama K, Miki I, Tamura T, et al.: Adverse Event Profiles of 5-Fluorouracil and Capecitabine: Data Mining of the Public Version of the FDA Adverse Event Reporting System, AERS, and Reproducibility of Clinical Observations. Int J Med Sci 2012;1:33-9.

39. Kogo M, Watahiki M, Sunaga T, et al.: Analysis of the risk factors for myelosuppression after chemoradiotherapy involving 5-fluorouracil and platinum for patients with esophageal cancer. Hepatogastroenterology 2011;58:802-8.

40. Kumar A, Kumar R, Sandilium A, Shukla J, Pradhan S: 5-Fluorouracil induces defects in platelet function. Platelets 1999;10:137-40.

41. Feffer SE, Carmosino LS, Fox RL: Acquired protein C deficiency in patients with breast cancer receiving cyclophosphamide, methotrexate, and 5-fluorouracil. Cancer 1989;63(7):1303-7

42. Cwikiel M, Eskilsson J, Wieslander JB, Stjernquist U, Albertsson M: The appearance of endothelium in small arteries after treatment with 5-fluorouracil. An electron microscopic study of late effects in rabbits. Scanning Microsc 1996;10(3):805-18

43. McKeage MJ: Comparative Adverse Effect Profiles of Platinum Drugs. Drug Saf 1995;13:228-44.

44. Jacquet P, Averbach A, Stephens AD, et al.: Heated intraoperative intraperitoneal mitomycin C and early postoperative intraperitoneal 5-fluorouracil: Pharmacokinetic studies. Oncology 1998;55:130-8.

45. Votanopoulos K, Ihemelandu C, Shen P, et al.: A comparison of hematologic toxicity profiles after heated intraperitoneal chemotherapy with oxaliplatin and mitomycin C. J Surg Res 2013;179.

46. Verweij J, Pinedo HM: Mitomycin C: mechanism of action, usefulness and limitations. Anticancer Drugs 1990;1:5-13.

47. Horvath P, Beckert S, Struller F, Königsrainer A, Königsrainer I: Incidence of leukopenia after intraperitoneal vs combined intravenous/intraperitoneal chemotherapy in pseudomyxoma peritonei. World J Gastrointest Pharmacol Ther 2016;7:434.

48. Ninivaggi M, Laat M De, Lancé MMD, et al.: Hypoxia induces a prothrombotic state independently of the physical activity. PLoS One 2015;10.

49. Ludgate CM, Webber RG, Pettigrew Smith, A N RT: Coagulation defects following whole body hyperthermia in the treatment of disseminated cancer: A limiting factor in treatment. Clin Oncol 1976;2:219-25.

50. Worel N, Knöbl P, Karanikas G, et al.: Hepatic dysfunction contributes to coagulation disturbances in patients undergoing whole body hyperthermia by use of extracorporeal circulation.The Int J Artif Organs 2014; 09/2014.

51. Bull JM, Lees D, Schuette W, et al.: Whole body hyperthermia: A phase-1 trial of a potential adjuvant to chemotherapy. Ann Intern Med 1979;90:317-23. 
52. Vance Strother S, Bull JMC, Branham SA: Activation of coagulation during therapeutic whole body hyperthermia. Thromb Res 1986;43:353-60.

53. Oglesbee MJ, Diehl K, Crawford E, Kearns R, Krakowka S: Whole body hyperthermia: Effects upon canine immune and hemostatic functions. Vet Immunol Immunopathol 1999;69:185-99.

54. Boldt LH, Fraszl W, Röcker L, et al.: Changes in the haemostatic system after thermoneutral and hyperthermic water immersion. Eur J Appl Physiol 2008;102:547-54.

55. Meyer MAS, Ostrowski SR, Overgaard A, et al.: Hypercoagulability in response to elevated body temperature and central hypovolemia. J Surg Res 2013;185.

56. Mehta AM, Hoven JM Van den, Rosing H, et al.: Stability of oxaliplatin in chloridecontaining carrier solutions used in hyperthermic intraperitoneal chemotherapy. Int J Pharm 2015;479:23-7.

57. Jacobson R, Mignemi N, Rose K, et al.: The hyperglycemic byproduct methylglyoxal impairs anticoagulant activity through covalent adduction of antithrombin III. Thromb Res 2014;134:1350-7.

58. McGovern KF, Lascola KM, Smith SA: Assessment of acute moderate hyperglycemia on traditional and thromboelastometry coagulation parameters in healthy adult horses. J Vet Emerg Crit Care 2012;22:550-7.

59. Gielen CLI, Grimbergen J, Klautz RJM, Koopman J, Quax PHA: Fibrinogen reduction and coagulation in cardiac surgery: an investigational study. Blood Coagul Fibrinolysis 2015:613-20.

60. Davalos D, Akassoglou K: Fibrinogen as a key regulator of inflammation in disease. Semin Immunopathol 2012;34:43-62. 


\section{Figure 1. Consort Flow Diagram}

Thrombin generation and platelet activation in cytoreductive surgery combined with hyperthermic intraperitoneal chemotherapy.

Enrollment

Allocation

Follow-Up
Assessed for eligibility $(n=28)$

Patients scheduled for CRS-HIPEC April 2015-July 2016

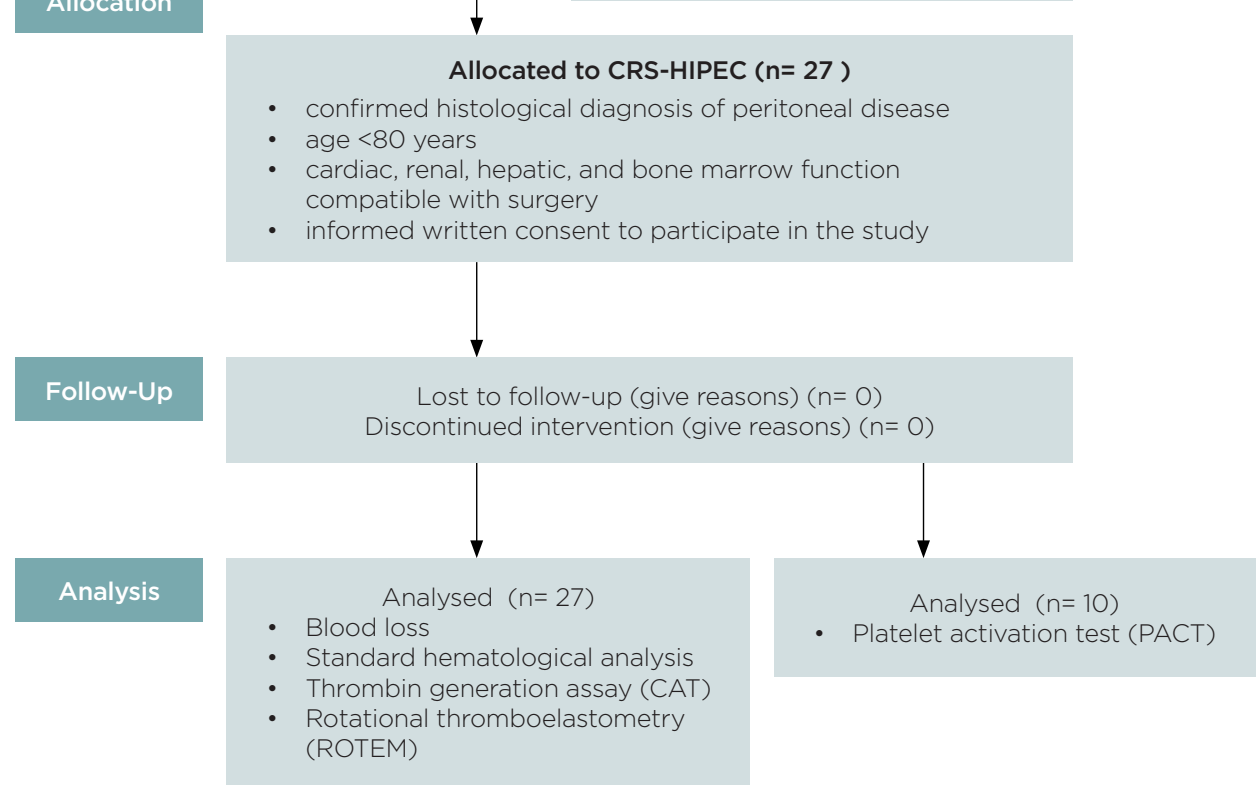


Figure 2. Effect of HIPEC on platelet function: TRAP, CRP and ADP were used to activate platelets via PAR-1 (panel A), GPVI (panel B) and P2Y12 receptor (panel C), respectively. Data of allbß3 activation (left) and P-selectin expression (right) are presented as medians with IQR. Significance was tested with the Wilcoxon matched-pairs signed rank test between two consecutive time points, between before incision and 30 minutes after chemotherapy, between day 1 and day 7 and between before incision and day $7 .{ }^{*} p<0.05,{ }^{* *} p<0.01$.

A
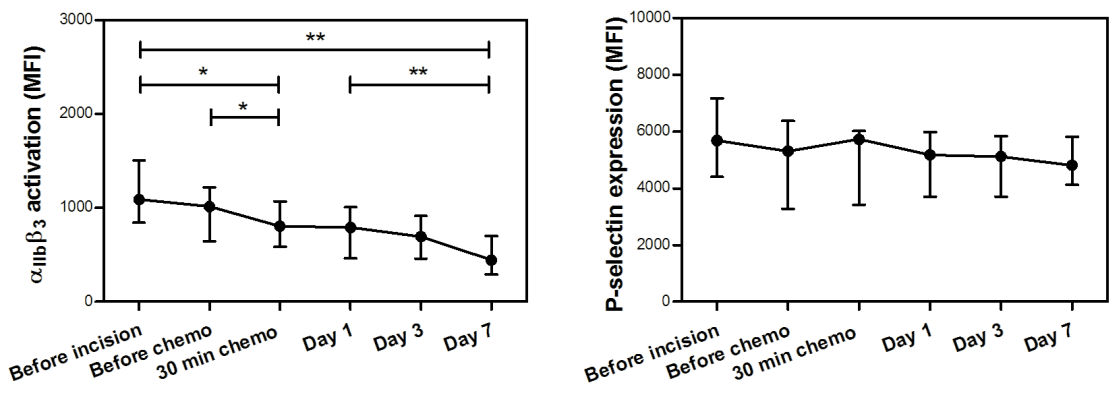

B
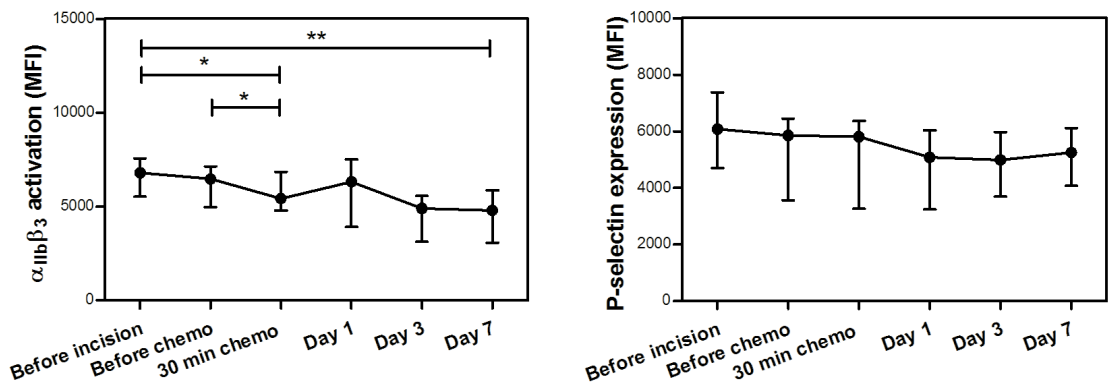

C
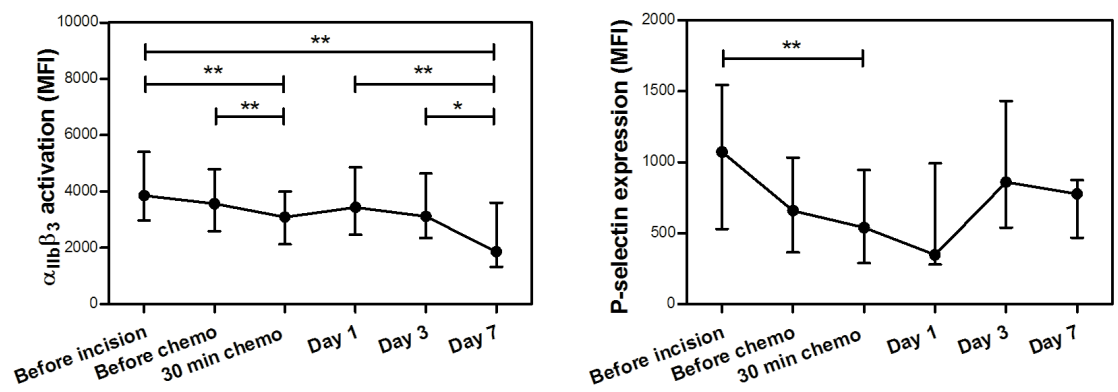
Figure 3. Effect of HIPEC on thrombin generation: TG was determined in PPP and, for each patient, ttPeak (TTP), thrombin peak (TP) and ETP values of the resulting thrombograms were calculated. Data are presented as median with IQR. Significance was tested with the Wilcoxon matched-pairs signed rank test between two consecutive time points, between before incision and 30 minutes after chemotherapy, between day 1 and day 7 and between before incision and day $7 .{ }^{*} p<0.05,{ }^{* *} p<0.01,{ }^{* * *} p<0.001$.
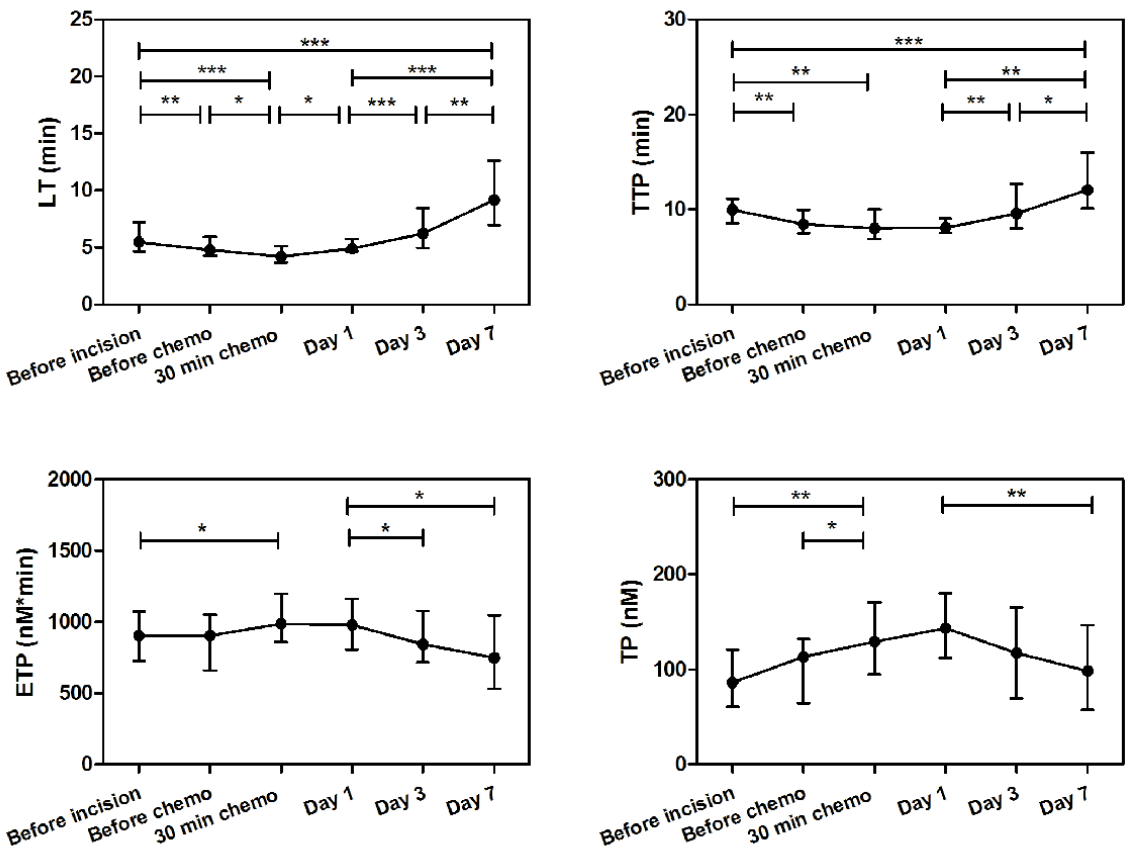


\section{CHAPTER 7}

\section{NORMALIZATION \\ METHODS IN TIME SERIES \\ OF PLATELET FUNCTION \\ ASSAYS: A SQUIRE \\ COMPLIANT STUDY.}

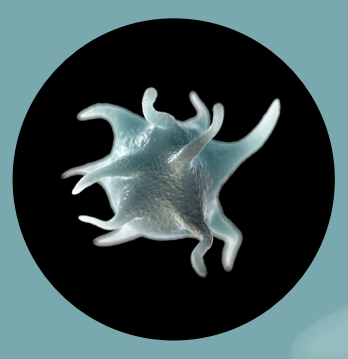

Sven Van Poucke, Zhongheng Zhang, Mark Roest, Milan Vukicevic, Maud Beran, Bart Lauwereins, Ming-Hua Zheng, Yvonne Henskens, Marcus Lancé, Abraham Marcus. Medicine 2016;95:28(e4188) 


\subsection{INTRODUCTION: FROM SAMPLE TO BIG DATA...}

Biological data in general and data generated from platelet research in particular are exploding, both in size and complexity, as been demonstrated by the different assays used to assess platelet function and hemostasis. In this context, the curse of dimensionality refers to the phenomena that arise when analyzing and organizing data in high-dimensional spaces (often with hundreds or thousands of dimensions) that do not occur in low-dimensional settings such as the three-dimensional physical space of everyday experience [1]. The common theme related with these issues is that by increasing the dimensionality, the volume of the space increases so quickly that the available data become sparse. This sparsity is problematic for any method that requires statistical significance. In order to obtain a statistically sound and reliable result, the amount of data needed to support the result often grows exponentially with the dimensionality. With a fixed number of training samples, the predictive power reduces as the dimensionality increases, and this is known as Hughes phenomenon [2].

In the previous chapters, data was generated from relatively small samples and were analyzed in different contexts and by various assays. In terms of analytics, all data was analyzed following the principles of descriptive analytics providing clinical intelligence attached to the samples size and the context the samples were taken. Additionally, groups of samples were compared in order to quantitatively assess different measurements in various contexts.

A more advanced level of analytics (predictive analytics) requires trained and tested models essential to make predictive analysis. This form of analytics is based on Big Data which in the context of platelet research can be generated by multivariate time series combining different assays over time. Big Data is traditionally defined by 4 V's (Volume: sampling becomes observing, measuring and tracking; Velocity: Big Data is often available in real-time; Variety references the different types of structured and unstructured data that organizations can collect; Veracity is an indication of data integrity and the ability to trust the data and be able to confidently use it to make crucial decisions.

In a next level of analytics (prescriptive analytics), Big Data is automatically synthesized resulting in predictions and suggestion for decision options to take advantage of the predictions.

With the accumulation of more platelet function and hemostasis measuring assays, the methods for therapeutic effect quantification evolve and are driven by recent innovations in statistics, machine learning, and Big Data analytics. In Chapter 7 different normalization methods in time series of platelet function assays are compared.

1. Bellman RE, Kalaba RE. Dynamic Programming and Feedback Control. RAND Corp 1959:1778.

2. Hughes G. On the mean accuracy of statistical pattern recognizers. IEEE Trans Inf Theory 1968;14:55-63. 


\section{NORMALIZATION METHODS IN TIME SERIES OF PLATELET FUNCTION ASSAYS. A SQUIRE COMPLIANT STUDY.}

\subsection{ABSTRACT}

Background: Platelet function can be quantitatively assessed by specific assays such as light-transmission aggregometry, multiple-electrode aggregometry measuring the response to ADP, arachidonic acid, collagen, and thrombin-receptor activating peptide and viscoelastic tests such as rotational thromboelastometry (ROTEM).

Local problem: The task of extracting meaningful statistical and clinical information from high-dimensional data spaces in temporal multivariate clinical data represented in multivariate time series, is complex. Building insightful visualizations for multivariate time series demands adequate usage of normalization techniques.

Methods: In this paper various methods for data normalization (z-transformation, range transformation, proportion transformation and interquartile range) are presented and visualized discussing the most suited approach for platelet function data series.

Interventions/ Results: Normalization was calculated per assay (test) for all time points and per time point for all tests.

Conclusions: Interquartile range, range transformation and z-transformation demonstrated the correlation as calculated by the Spearman's correlation test, when normalized per assay (test) for all time points. When normalizing per time point for all tests, no correlation could be abstracted from the charts as was the case when using all data as one dataset for normalization. 


\subsection{INTRODUCTION}

Alterations in platelet function are a common finding in surgical procedures involving cardiopulmonary bypass (CPB). Routine laboratory assays such as activated clotting time, activated partial thromboplastin time, prothrombin time, or platelet count do not provide sufficient specificity and/or sensitivity to assess coagulation and platelet disorders related to the surgical intervention. Platelet function can be quantitatively assessed by more specific assays such as light-transmission aggregometry, multipleelectrode aggregometry measuring the response to ADP, arachidonic acid, collagen, and thrombin-receptor activating peptide and viscoelastic tests such as rotational thromboelastometry (ROTEM). With more data involved, the task of extracting meaningful statistical and clinical information from high-dimensional data spaces, wherein each patient at a certain point in time is defined by hundreds or thousands of measurements, becomes more complex. The massive growth of data set size in health care, in number of records and attributes, has triggered the development of various Big Data platforms that employ parallel data analytics algorithm with a high potential for revealing meaningful clinical information through pattern discovery [1]. Similarly, a high number of attributes triggers the "curse of dimensionality" phenomenon that often prevents building of predictive models and meaningful patterns with good generalization performance (predictions on new data). As such, the use of data dimensionality reduction procedures becomes a necessity for employment of Big Data analytics in medical practice [2]. Selection of important attributes and samples is especially difficult in temporal multivariate clinical data represented in multivariate time series. This task, most often cannot be adequately addressed only by data driven methods and demands deep understanding and involvement of clinical knowledge. Because of that it is of critical importance to provide comprehensible and robust visualizations of the insights obtained by data driven methods, so they could be complemented with clinical knowledge and serve as in decision support. Building insightful visualizations for multivariate time series demands adequate usage of normalization techniques, because different natural scales of original attributes can hide important correlations or temporal trends [3]. However, in current state-of-the-art scientific output, researchers often do not address this problem (adequate normalization of data at hand) in a rigorous manner, potentially leading to biased conclusions.

Optimal implementation of current and new hemostasis and coagulation assays requires quantitative analysis of the involvement of all useful attributes. In this paper several methods for data normalization are presented discussing the most suited approach for platelet function data series [4]. Additionally, a visualization was created, enabling examining multivariate patient data over time more accurately and efficiently than current tabular visualizations [5]. 


\subsubsection{MATERIAL AND METHODS STUDY DESIGN AND PATIENTS}

From January 2013 until January 2014, a single-centre, longitudinal observational study collected data from 20 patients at the Maastricht University Medical Centre, after approval by the local medical ethics committee (NTR 4238). Adult patients scheduled for elective CABG with CPB, and a preoperative PlatCt (platelet count) of $\geq 250 \times 10^{\%} / L$ were included. Exclusion criteria consisted of emergency surgery, chronic thienopyridine APT, not discontinued at least 5 days prior to surgery, the use of any other anticoagulation drug other than prophylactic low-molecular-weightheparins, congenital disorders of the haemostatic system, and detection of an infection prior to surgery. Eligible patients were recruited on the medical ward the day prior to surgery where they provided written informed consent. Data collection was covered for three consecutive days, starting on the day prior to surgery until $24 \mathrm{~h}$ postoperatively. The dataset used in this paper consisted of 20 patients and 171 attributes from 3 time points: S1 (before surgical incision), S2 (after weaning from CPB) and S3 (24h postoperative).

\section{BLOOD COLLECTION \& LABORATORY ANALYSES}

Blood samples were collected in vacuum tubes, using a VenoJect ${ }^{\oplus}$ Quick Fit luer adapter (XX-MN2000Q, Terumo Medical, Europe). Following discarding $10 \mathrm{~mL}$ of blood at each time point, $4 \mathrm{ml}$ whole blood was collected in a $\mathrm{K}_{2}$ EDTA $7.2 \mathrm{mg}$ BD Vacutainer $^{\oplus}$ (Ref.: 368861, Becton, Dickinson \& Company, Plymouth, UK), 4,5 ml whole blood in a sodium citrate 3.2\% BD Vacutainer ${ }^{\circledR}$ (Ref.: 367714, Becton, Dickinson \& Company, Plymouth, UK), and $3 \mathrm{ml}$ whole blood in a hirudin $15 \mu \mathrm{g} / \mathrm{mL}$ Vacutainer (Ref.: MP0600, Verum Diagnostica GmbH, Munich, Germany). Blood samples were directly transported to the laboratory and analyzed within 2-4 h after collection to allow for minimal necessary resting time for PF tests.

\section{STANDARD HAEMATOLOGICAL ANALYSES}

EDTA-anticoagulated blood was used for cytometric analysis using a whole blood counter Sysmex XE 2100 (Sysmex, Kobe, Japan) to obtain a whole blood count.

\section{LIGHT TRANSMISSION AGGREGOMETRY (LTA)}

Citrate-anticoagulated whole blood was centrifuged $10 \mathrm{~min}$ at $170 \mathrm{~g}$ to obtain PRP. The remaining blood was centrifuged twice more, $5 \mathrm{~min}$ at $2.500 \mathrm{~g}$ followed by 10 min at $10.000 \mathrm{~g}$, providing platelet-poor plasma (PPP) as reference material. Platelet aggregation was subsequently measured in test cuvettes (ref.: HB-5538-FG, Hart Biologicals Ltd., Hartlepool, UK) filled with non-adjusted PRP, using the Platelet Aggregometer PAR-4 (ref:: 50.000.1070, Hart Biologicals Ltd., Hartlepool, UK), after addition of platelet agonists: AA (ref.: LS101297, Bio/Data Corporation, Pennsylvania, USA), ADP (ref.: HB-5502-FG, Hart Biologicals Ltd., Hartlepool, UK), COL (ref.: CH 385, CHRONO-LOG Corporation, Pennsylvania, USA) and TRAP (ref.: H-8105.0001, BACHEM, Bubendorf, Switzerland) in final concentrations of $1 \mathrm{mM}$ AA, $5 \mu \mathrm{M}$ ADP, $2 \mu \mathrm{g} /$ $\mathrm{ml} \mathrm{COL}$ and $20 \mu \mathrm{M}$ TRAP respectively. 


\section{MULTIPLE ELECTRODE IMPEDANCE AGGREGOMETRY (MEIA)}

Platelet aggregation was measured by MEIA principle using the Multiplate ${ }^{\circledast}$ multiple electrode aggregometer (Roche Diagnostics, Almere, The Netherlands). Similar to LTA measurements, platelet aggregation was analyzed using the following agonists: AA at a final concentration of 0.5 mM (ASPI-Test; ref.: MPO210, Dynabyte Medical, Munich, Germany), ADP at a final concentration of $6.4 \mu \mathrm{M}$ (ADP-Test; Ref.: MPO220, Dynabyte Medical, Munich, Germany), COL at a final concentration of $3.2 \mu \mathrm{g} / \mathrm{ml}$ (ref:: 385 , Chronolog-PAR, Stago BNL, Leiden, The Netherlands) and TRAP at a final concentration of 32 HM (TRAP-Test; ref:: MPO250, Dynabyte Medical, Munich, Germany). All samples were measured after a resting period of 30 min following blood collection.

\section{ROTATIONAL THROMBOELASTOMETRY (ROTEM)}

Thrombus formation was measured by ROTEM (Tem International GmbH, München). Standard assays and reagents (Tem International $\mathrm{GmbH}$, München) were used according to the manufacturer's recommendations: EXTEM, FIBTEM, and HEPTEM. All samples were measured within $1 \mathrm{~h}$ after blood collection. Furthermore, by means of EXTEM and FIBTEM results, the contribution of platelet count to the thrombus formation was calculated as the PLTEM parameter.

\section{STATISTICAL ANALYSIS}

Analysis was performed by RapidMiner (7.0, Boston, MA). RapidMiner (previously: Rapid-I, YALE) became popular in recent years and is supported by a large scientific community (http://www.kdnuggets.com/2016/02/rapidminer-leader-2016-gartnermq-advanced-analytics-platforms.html). RapidMiner provides multiple extensions suited for dimensionality reduction. Furthermore the tool enables seamless parameter optimization, being a necessary step for many cutting edge algorithms (e.g. PCA). Data was displayed by Tableau (9.2, Seattle, WA) (https://www.tableau. com/about/press-releases/2016/gartner-positions-tableau-leader-magic-quadrantbi-and-analytics-platforms). The dashboard developed for this study is publicly accessible on Tableau Public: https://public.tableau.com/views/LineChart_8/ Dashboard1?:embed=y\&:display_count=yes\&:showTabs=y

\section{NORMALIZATION}

Normalization is as preprocessing step used to rescale attribute values to fit in a specific range. In data analysis, normalization is a type of data transformation referring to the replacement of a variable by a function of that variable: for example, replacing a variable $x$ by the square root of $x$ or the logarithm of $x$. In a stronger sense, a transformation is a replacement that changes the shape of a distribution or relationship.

Normalization of the data is of particular importance when dealing with attributes of different units and scales. In some data mining algorithms like K-NN, the input attributes are expected to be numeric and normalized because the algorithm compares values of different attributes and calculates distance between data points. Data normalization methods enable to bring all of the variables into proportion with one another [6]. Finding an appropriate method to deal with time series normalization is not an easy task because most of the traditional normalization methods make assumptions that do not hold for most time series. The first 
assumption is that all time series are stationary, i.e., their statistical properties, such as mean and standard deviation, do not change over time. The second assumption is that the volatility of the time series is considered uniform [7].

In this study, normalization is calculated by four normalization methods. Each method calculated normalization on the complete dataset, by test for the 3 points in time and by time point for all the tests.

Results of this paper were based on the following normalization methods:

\section{Z_TRANSFORMATION}

This is also called statistical normalization. The purpose of statistical normalization is to convert a data into Normal (Gaussian) distribution with mean $=0$ and variance $=1$. The formula of statistical normalization is $Z=(X-u) / s$. Attribute values are considered as vector $X$ which are subtracted by the mean of the attribute values, $u$, and the difference is divided by the standard deviation, resulting in a vector $Z$ with normal distribution (with zero mean and unit variance), also called Standard Normal distribution, N(0,1). However, the range of the standard Normal distribution is not limited to [0,1]. Limiting the range to -3 and +3 captures $99.9 \%$ of the data. This scaling method is useful when the data follows normal distribution, if the data does not follow normal distribution the method is less suitable.

\section{PROPORTION TRANSFORMATION}

Each attribute value is normalized as proportion of the total sum of the respective attribute i.e. each attribute value is divided by the total sum of the attribute values.

\section{RANGE TRANSFORMATION}

Range transformation normalizes all attribute values in the user specified range [min,max]. Consider the min-max and the decimal scaling methods, for instance. Their applicability depends on the knowledge of the minimum and/or maximum values of a time series, which is not always possible.

\section{INTERQUARTILE RANGE}

Since normalization by range_transformation (described above) only takes into account max and min values for each feature, it may be heavily influenced by outliers in the data. Therefore, another criterion - the interquartile range - is commonly used. It is the distance between the 25th and 75th percentiles (Q3 - Q1). The interquartile range is essentially the range of the middle $50 \%$ of the data. Because it uses the middle $50 \%$, the interquartile range is not affected by outliers or extreme values.

Normalized values are represented by polynomial trend lines (polynomial trends in Tableau, have model degrees of freedom of 1 plus the degree of the polynomial). 


\subsubsection{RESULTS}

Guided by the CRoss-Industry Standard Process for Data Mining (CRISP-DM), the initial dataset (20 patients, 154 attributes) was imported in RapidMiner for data preparation.

The variables (attributes) from standard haematological testing, rotational thromboelastometry, light transmission aggregometry and multiple electrode aggregometry (units) are: i) Laboratory tests: $\mathrm{Hb}$ (mmol/L); Hct (\%); PlatCt ( $\left.\times 10^{9} / \mathrm{L}\right) ; \mathrm{MPV}(\mathrm{fL})$ ii) ROTEM (Rotational Thromboelastometry): A5 EXTEM (mm); A5 EXTEMtPA (mm); A5 FIBTEM (mm); A5 HEPTEM (mm); A5 PLTEM (mm); A10 EXTEM (mm); A10 EXTEMtPA $(\mathrm{mm}) ;$ A10 FIBTEM $(\mathrm{mm}) ;$ A10 HEPTEM $(\mathrm{mm}) ;$ A10 $\operatorname{PLTEM}(\mathrm{mm}) ; \mathrm{A} 20$ EXTEM $(\mathrm{mm}) ;$ A2O EXTEMtPA $(\mathrm{mm}) ; \operatorname{A} 20$ FIBTEM $(\mathrm{mm}) ;$ A2O $\operatorname{HEPTEM}(\mathrm{mm}) ;$ A2O PLTEM (mm); Alpha EXTEM (mm); Alpha EXTEMtPA (mm); Alpha FIBTEM (mm); Alpha HEPTEM (mm); Alpha PLTEM (mm); MCF EXTEM $(\mathrm{mm})$; MCF EXTEMtPA $(\mathrm{mm})$; MCF FIBTEM $(\mathrm{mm})$; MCF HEPTEM $(\mathrm{mm}) ; \operatorname{MCF}$ PLTEM $(\mathrm{mm})$; ML EXTEM (\%); ML EXTEMTPA (\%); ML FIBTEM (\%); ML HEPTEM (\%); ML PLTEM (\%); CT EXTEM (s); CT EXTEMtPA (s); CT FIBTEM (s); CT HEPTEM (s); CT PLTEM (s); CFT EXTEM (s); CFT EXTEMtPA (s); CFT FIBTEM (s); CFT HEPTEM (s); CFT PLTEM (s);

iii) LTA (Light Transmission Aggregometry): MA AA (\%); MA ADP (\%); MA COL (\%); MA TRAP (\%); iv) MEA (Multiple Electrode Aggregometry): AUC ASP (U); AUC ADP $(U)$; AUC COL (U); AUC TRAP (U) AggrRate AA (na); AggrRate ADP (na); AggrRate COL (na); AggrRate TRAP (na).

\section{CORRELATION}

Correlations between LTA/MEIA/ROTEM and PlatCt or Hct, were analyzed using Spearman's correlation test. (Table 1) The Spearman correlation is nonparametric with the exact sampling distribution obtained without requiring knowledge of the joint probability distribution of the parameters. Correlation analysis using Spearman's correlation coefficients (Table 1) identified a strong ( $r>0.40$ or $r<-0.40$ ) correlation between MEIA results and PlatCt for respectively ADP- $(r=0.741, p<0.01), C O L-(r$ $=0.494, p<0.01)$ and TRAP-induced $(r=0.551, p<0.01)$ platelet aggregation. With respect to ROTEM measurement, EXTEM MCF $(r=0.749, p<0.01)$ demonstrated a strong correlation with PlatCt.(Fig. 1) No moderate $(0.30<r<0.39$ or $-0.30>r>-0.39)$ or strong correlations were found between LTA measurement and PlatCt intrinsic to LTA methodology. Further, strong correlation is observed $(r>0.40$ or $r<-0.40)$ between MEIA results and Hct for respectively AA- $(r=0.492, p<0.01$ and ADP-induced $(r=0.405$, $p<0.01)$ platelet aggregation. Additionally, ROTEM values were correlated with Hct results (FIBTEM MCF $r=0.374, p<0.01$ ). Correlation analysis between LTA and Hct was not performed since this assay is performed in PRP. 
Table 1: Spearman rank test and p-values of correlation analyses between LTA, MEIA and ROTEM versus PlatCt and Hct $n=20$.

\begin{tabular}{|c|c|c|c|c|}
\hline & & PlatCt & & \\
\hline & $r$ & $p$ value & $r$ & $p$ value \\
\hline LTA - AA & 0.135 & 0.338 & a & $a$ \\
\hline LTA - ADP & 0.317 & *0. 022 & a & a \\
\hline LTA - COL & 0.338 & *0. 014 & a & $a$ \\
\hline LTA - TRAP & 0. 359 & ${ }^{* *} 0.009$ & a & a \\
\hline MEIA - AA & 0.318 & *0. 019 & 0. 492 & $* * 0.000$ \\
\hline MEIA - ADP & 0. 741 & $* * 0.000$ & 0.405 & $* * 0.003$ \\
\hline MEIA - COL & 0. 494 & ${ }^{* *} 0.000$ & 0.301 & $* 0.030$ \\
\hline MEIA - TRAP & O. 551 & ${ }^{* *} 0.000$ & 0.328 & *0.018 \\
\hline ROTEM - PLTEM MCF & 0.067 & 0.629 & -0.066 & 0.640 \\
\hline ROTEM - EXTEM MCF & O. 749 & ${ }^{* *} 0.000$ & 0.302 & $* 0.030$ \\
\hline ROTEM - FIBTEM MCF & $\mathrm{b}$ & $\mathrm{b}$ & 0. 374 & **0.006 \\
\hline
\end{tabular}

*p value $<0.05$

**p value $<0.01$

a. Correlation analysis was not performed for LTA versus Hct because the assay is performed in PRP.

b. Correlation analysis was not performed for FIBTEM versus PlatCt because the assay is performed in presence of cytochalasin D, which completely inhibits platelet action.

(LTA light transmission aggregometry; MEIA multiple electrode impedance aggregometry; AA arachidonic acid; ADP adenosine diphosphate; TRAP thrombin-receptor activating peptide; COL collagen; ROTEM rotational thromboelastometry; PlatCt platelet count; Hct haematocrit; PRP platelet rich plasma; MCF maximum clot firmness) 


\section{Figure 1}

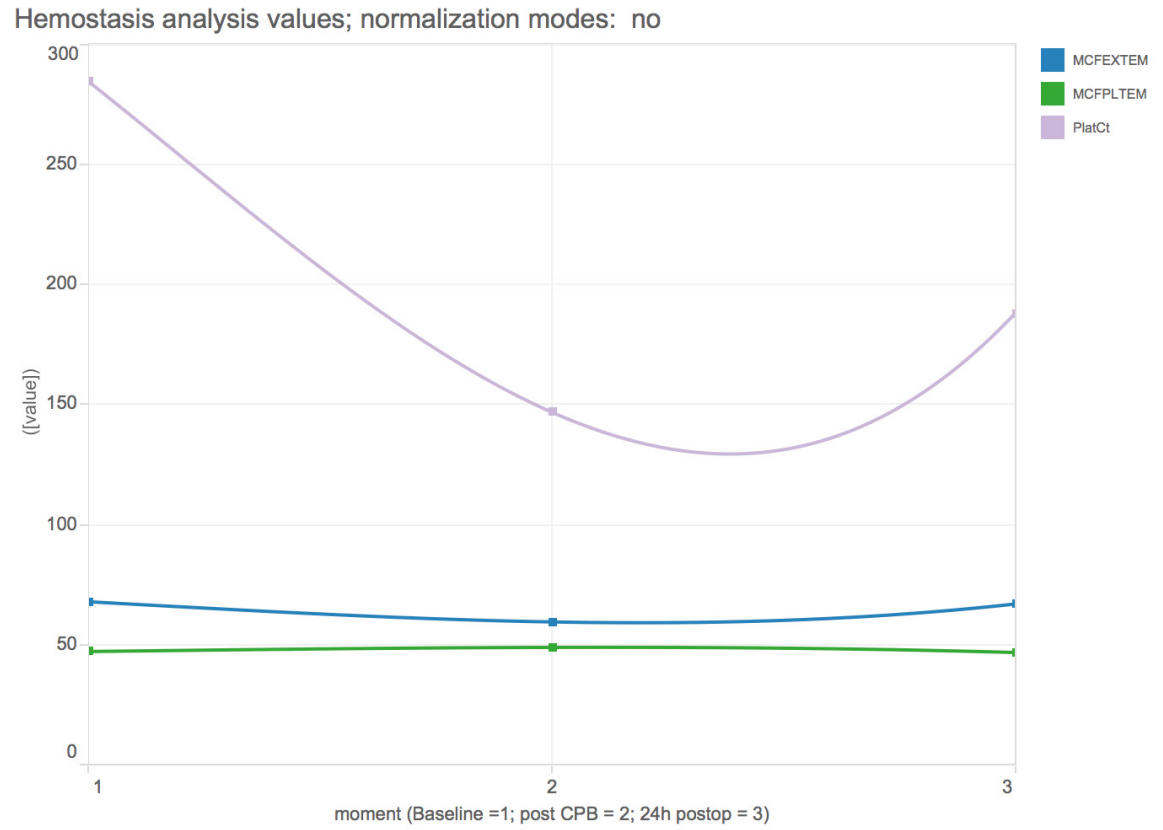

Data of PlatCt, MCFEXTEM, MCFPLTEM for Baseline, post-CPB, postop. No normalization.

Charts generated by Tableau and available from: https://public.tableau.com/views/ LineChart_8/Dashboard1?:embed=y\&:display_count=yes\&:showTabs=y.

Normalization modes: no: without normalization;

(MCF maximum clot firmness; PlatCt platelet count; CBP cardiopulmonary bypass; postop postoperative)

In order to illustrate different normalization methods the correlation of PlatCt and ROTEM EXTEM MCF $(r=0.749 p=0.000)$ and ROTEM PLTEM MCF $(r=0.067 ; p=0.629)$ is studied (Table 1). Each method calculated normalization, on the complete dataset, by test for the 3 points in time and by time point for all the tests. With a strong and significant correlation of PlatCt with ROTEM EXTEM MCF, and a weak, non significant correlation of PlatCt with ROTEM PLTEM MCF, the difference between the 2 features should be clearly to illustrate. With platelet count (PlatCt) expressed as $\times 10^{9} / \mathrm{L}$ (normal range: 150-450) and ROTEM maximal clot formation (MCF) as mm (normal range ROTEM EXTEM MCF: 49-71 \& ROTEM PLTEM MCF: 35-45 ). PLTEM, was calculated by subtracting FIBTEM from EXTEM to distinguish thrombocytopenia from hypofibrinogenemia [8]. 
Polynomial trend lines of PlatCt, ROTEM EXTEM MCF, ROTEM PLTEM MCF values, illustrated without any normalization (Fig 1), was not able to illustrate correlation of PlatCt and ROTEM EXTEM MCF (Fig 1). Additionally, differences in unit and scale of PlatCt values compared to ROTEM EXTEM MCF, ROTEM PLTEM MCF values impede a clear display of the time related changes of ROTEM EXTEM MCF, ROTEM PLTEM MCF values (Fig 2,3,4)Similar observations are noticeable, although with different scaling, with normalization of all data by z-transformation (Fig 4d), range transformation (Fig 4b), proportion transformation (Fig 4c) and interquartile range (Fig 4a).

Analyzing normalization by test for all time points only reveals correlation of PlatCt and ROTEM EXTEM MCF by interquartile range (Fig 2a), range transformation (Fig 2b) and z-transformation (Fig 2d). No correlation is abstracted from visualization by proportion normalization (Fig 2c).

Analyzing normalization by time point for all tests did not demonstrate correlation of PlatCt and ROTEM EXTEM MCF in any chart (Fig 3 a,b,c,d).

\subsubsection{DISCUSSION}

In biomedical environments, it is desirable to compare dynamical systems based on their behavior [9]. Similarity of behavior often implies similarity of internal mechanisms or dependency on common extrinsic factors (e.g. LTA and MEIA agonists). Although methods for comparing univariate time series are generally adopted, most dynamical systems in biomedicine are characterized by multivariate time series. Comparison of multivariate time series has been limited to cases where a common dimensionality is shared [10].

Normalization is a generally employed preprocessing technique used to rescale attribute values to fit in a specific range. Normalization of the data is critical when dealing with attributes with different units and scales because certain data mining techniques (e.g the ones based on distance/similarity calculations) require normalization. However, normalization of biomedical data is often ignored, and this can lead to misinterpretation of the results and ultimately wrong decisions [11].

Finding an appropriate method for time series normalization is not a clear cut task. Most of the traditional normalization methods make assumptions that are lacking in time series. A first assumption is related with the non-stationary property of time series. Stationary processes assume that their statistical properties (e.g. mean and standard deviation), do not fluctuate over time. The second assumption is related with the volatility of the time series which is considered uniform. It is proposed to normalize time series by Adaptive Normalization [7]. In Adaptive Normalization, the original nonstationary time series is transformed into a stationary sequence. This transformation is based on the concepts of moving averages. In this paper, moving averages were not implemented because only 3 time points were included. The authors attempted to find the adequate normalization technique(s) illustrating the correlations as calculated for the different features. 
When feature values cover a large range, the use of the logarithms of the values rather than the actual values reduces the wide range to a more manageable size. This approach might be suitable for visualization, when using certain analytical methods, normalization becomes essential. Basically, normalization is performed to obtain the same range of values for data mining and machine learning techniques like support vector machine, neural network, etc). This can guarantee stable convergence of weight and biases and speed of the optimization process.

We developed an online dashboard (Tableau) enabling to measure similarity for multivariate time series representations of physiological and laboratory data allowing physicians to identify patients with similar events and/or phenotypes for the purpose of predicting patient outcomes [12].

Polynomial trend lines of PlatCt, ROTEM EXTEM MCF, ROTEM PLTEM MCF values with normalization (by z-transformation, range transformation, proportion transformation and interquartile range) or without normalization on all values of the dataset, was not able to illustrate correlation of PlatCt and ROTEM EXTEM MCF (Fig 1). This approach is also not suitable for time series considering the non-stationary property of the data. When normalization was performed for each test separately but for all time points, correlation of PlatCt and ROTEM EXTEM MCF was illustrated by interquartile range (Fig 2a), range transformation (Fig 2b) and z-transformation (Fig 2d). No correlation is abstracted from visualization by proportion normalization (Fig 2c). Analyzing normalization separately for each time point but for all tests, correlation of PlatCt and ROTEM EXTEM MCF could not be abstracted in any chart (Fig 3 a,b,c,d). Besides correlation analysis of features, temporal trend should be considered. The chart illustrating no normalization (Fig 1) and the chart illustrating normalization performed for each test separately but for all time points (Fig 2 a,b,c,d), both ROTEM EXTEM MCF and ROTEM PLTEM MCF have a negative correlation, but on the chart illustrating no normalization (Fig 1), no clear temporal change of ROTEM EXTEM MCF and ROTEM PLTEM MCF is observed.

\subsubsection{CONCLUSION}

There is no unique assay to quantitatively assess platelet function. Tools as been provided by this study enable clarification of the complex relationship between the various features measured in clinical medicine. Results of multivariate time series are often represented without normalization. Because of different scales of original features, such visualizations most often cannot reveal significant correlations between variables, nor temporal trends. Additionally, many machine learning and data mining algorithms require normalization as preprocessing step in order to provide valid models (i.e. k-means or k-NN) or to allow fast and stable convergence to the optimal solution (i.e. logistic regression). However, there is a multitude of available normalization techniques, and not all of them are suitable for each type of data. In this study, we examined the value of several normalization techniques (z-transformation, range transformation, proportion transformation and interquartile range) for visualizing correlations and temporal trends of temporal tests. Interquartile range, range transformation and z-transformation demonstrated correlation when normalized per assay (test) for all time points; when normalizing per time point for all tests, no correlation could be abstracted from the charts as was the case when using all data as one dataset for normalization. 
These conclusions might provide a tool for deeper investigation of potential correlations. Different normalization techniques lead to different views on data.

\subsubsection{REFERENCES}

1. Van Poucke S, Zhang Z, Schmitz M, et al. Scalable predictive analysis in critically ill patients using a visual open data analysis platform. PLOSONE 2016;11.

2. Cunningham JP, Yu BM. Dimensionality reduction for large-scale neural recordings. Nat Neurosci 2014;17:1500-1509.

3. Peña D, Poncela P. Advances in Distribution Theory, Order Statistics, and Inference. In: Balakrishnan N, Sarabia JM, Castillo E, eds. Statistics for Industry and Technology. Boston, MA: Birkhauser Boston, 2006:433-458.

4. Min Zhu, Jing Xia, Molei Yan, et al. Dimensionality Reduction in Complex Medical Data: Improved Self-Adaptive Niche Genetic Algorithm. Computational and Mathematical Methods in Medicine. 2015; Article ID 794586, 12 pages, 2015.

5. Ordóñez P, DesJardins M, Feltes $C$, et al. Visualizing multivariate time series data to detect specific medical conditions. AMIA Annu Symp Proc 2008:530-534.

6. Goldin DQ, Kanellakis PC. On Similarity Queries for Time-Series Data: Constraint Specification and Implementation. Princ Pract Constraint Program 1995:137-153.

7. Ogasawara E, Martinez LC, Oliveira D De, et al. Adaptive Normalization: A novel data normalization approach for non-stationary time series. IEEE Proc Int Jt Conf Neural Networks 2010.

8. Olde Engberink RHG, Kuiper GJAJM, Wetzels RJH et al. Rapid and correct prediction of thrombocytopenia and hypofibrinogenemia with rotational thromboelastometry in cardiac surgery. J Cardiothorac Vasc Anesth 2014;28:210-216.

9. Chuah MC, Fu F. ECG Anomaly Detection via Time Series Analysis. In: Proceedings of the 2007 International Conference on Frontiers of High Performance Computing and Networking. ISPA'07. Berlin, Heidelberg: Springer-Verlag, 2007:123-135.

10. Tapinos A, Mendes P. A Method for Comparing Multivariate Time Series with Different Dimensions. PLoSONE 2013:8(2): e54201.

11. Wu Y, Li L. Sample normalization methods in quantitative metabolomics. J Chromatogr A 2016:1430:80-95.

12. Keogh E, Kasetty S. On the Need for Time Series Data Mining Benchmarks: A Survey and Empirical Demonstration. Data Min Knowl Discov 2003;7:349-371.

\subsubsection{ABBREVATIONS}

CPB cardiopulmonary bypass; ROTEM rotational thromboelastometry;

ADP adenosine diphosphate; CABG coronary artery bypass grafting; PlatCt platelet count; APT anti-platelet therapy; K2EDTA dipotassium ethylenediaminetetraacetate; PPP platelet-poor plasma; PRP platelet-rich plasma; PF platelet function; AA acetylsalicylic acid; COL collagen; TRAP thrombin receptor-activating peptide; MEIA multiple electrode impedance aggregometry; LTA light transmission aggregometry; PCA principal component analysis; K-NN k-Nearest Neighbors; CRISP-DM CRoss-Industry Standard Process for Data Mining; Hb haemoglobin; Hct haematocrit; MCF maximum clot firmness; ML maximum lysis; CT clotting time; CFT clot formation time. 


\section{Figure 2}

Data of PlatCt, MCFEXTEM, MCFPLTEM for Baseline, post-CPB, postop. Normalization by test for the 3 points in time (moments: Baseline, post-CPB, postop).

Charts generated by Tableau and available from: https://public.tableau.com/views/ LineChart_8/Dashboard1?:embed=y\&:display_count=yes\&:showTabs=y.

Normalization mode: test: normalization by test for the 3 points in time (moments: Baseline, post-CPB, postop);

Hemostasis analysis values; normalization modes: test_interQ

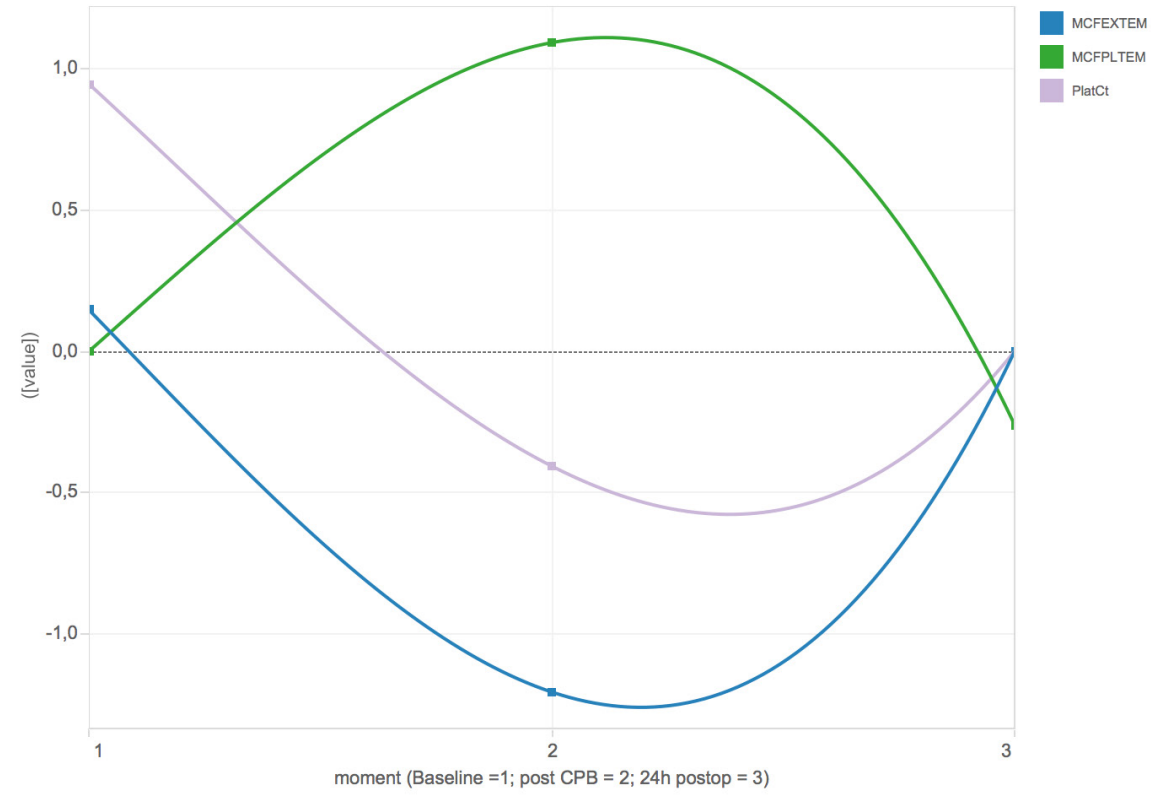


Figure 2a InterQ: interquartile range;

Hemostasis analysis values; normalization modes: test_range

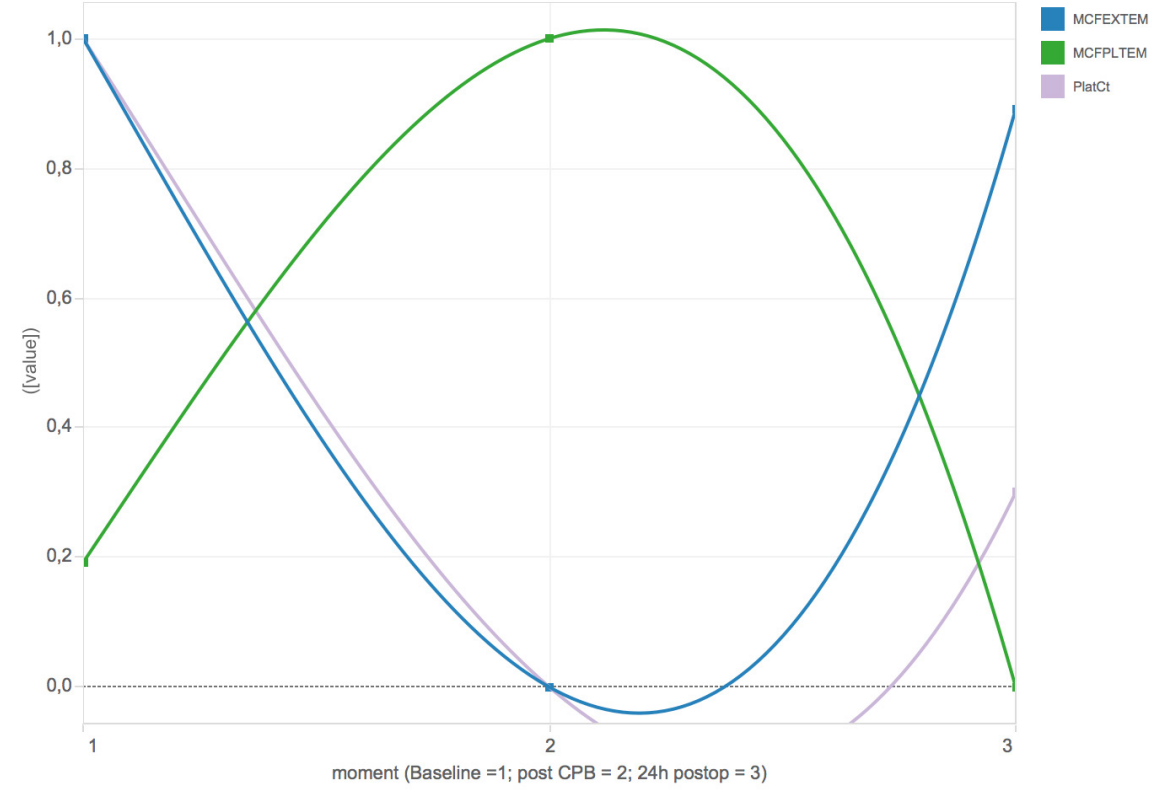

Figure $\mathbf{2 b}$ range: range transformation;

Hemostasis analysis values; normalization modes: test_prop

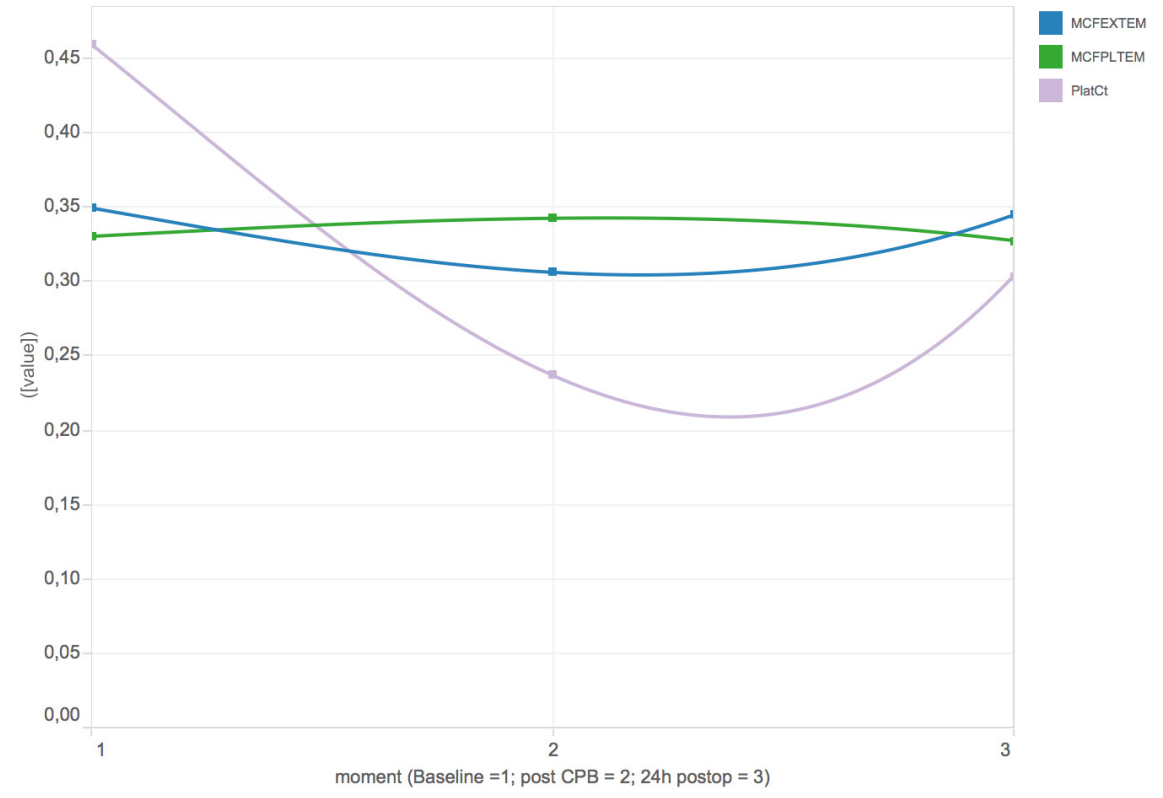


Figure 2c prop: proportion transformation;

Hemostasis analysis values; normalization modes: test_Z

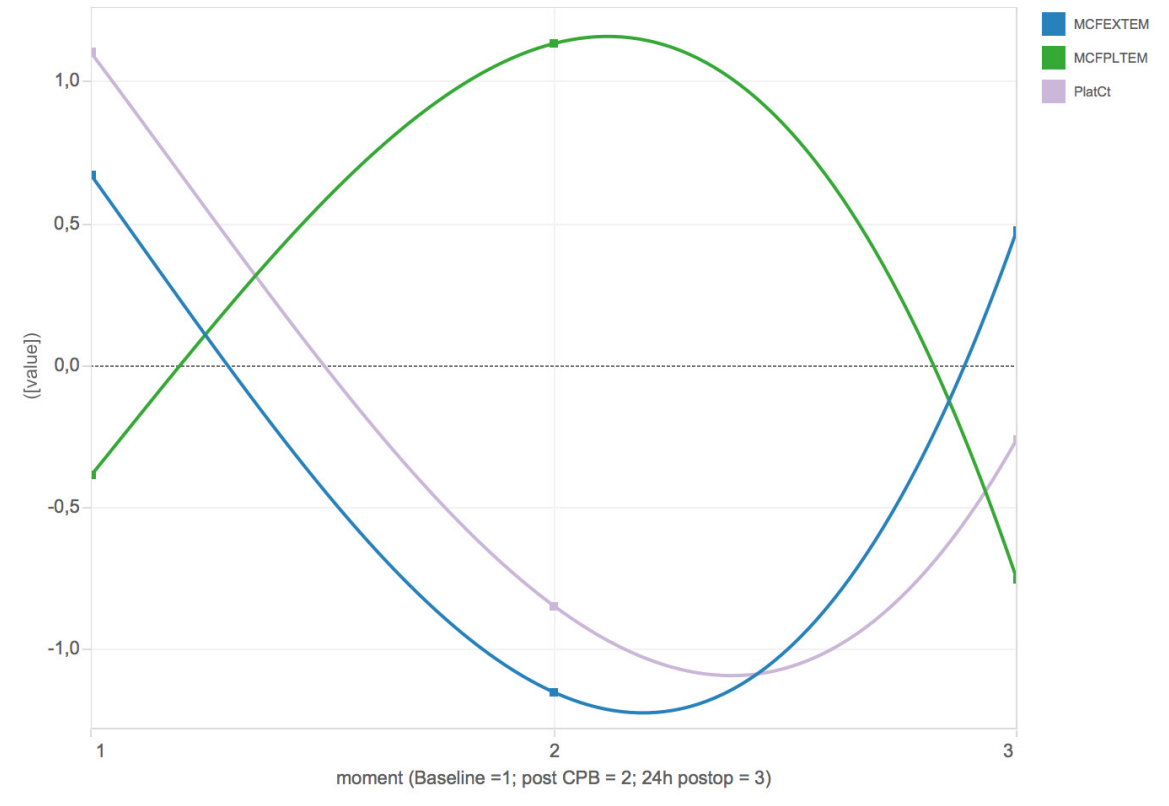


Figure 2d Z: z-transformation.

(MCF maximum clot firmness; PlatCt platelet count; CBP cardiopulmonary bypass; postop postoperative)

\section{Figure 3:}

Data of PlatCt, MCFEXTEM, MCFPLTEM for Baseline, post-CPB, postop. Normalization by time point for all tests (MCFEXTEM, MCFPLTEM and PlatCt).

Charts generated by Tableau and available from: https://public.tableau.com/views/ LineChart_8/Dashboard1?:embed=y\&:display_count=yes\&:showTabs=y.

Normalization mode: time: normalization by time point for all tests (MCFEXTEM, MCFPLTEM and PlatCt);

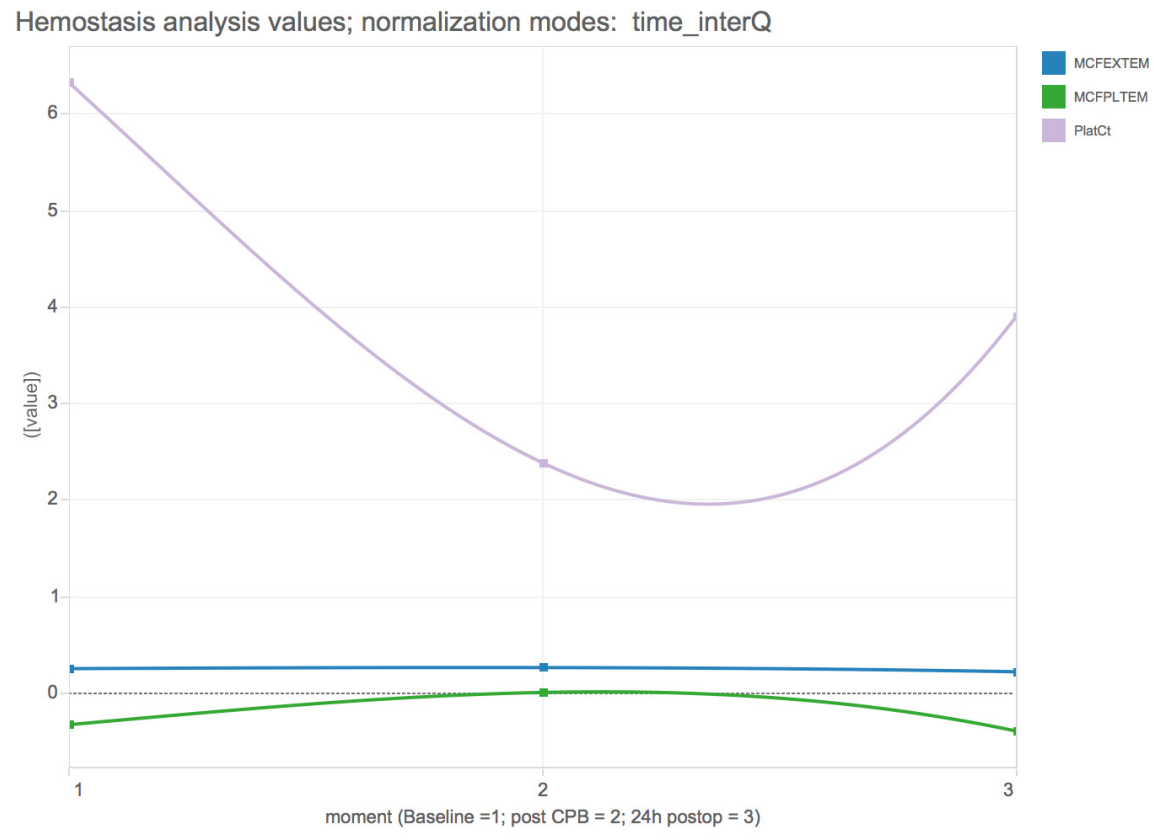


Figure 3a InterQ: interquartile range;

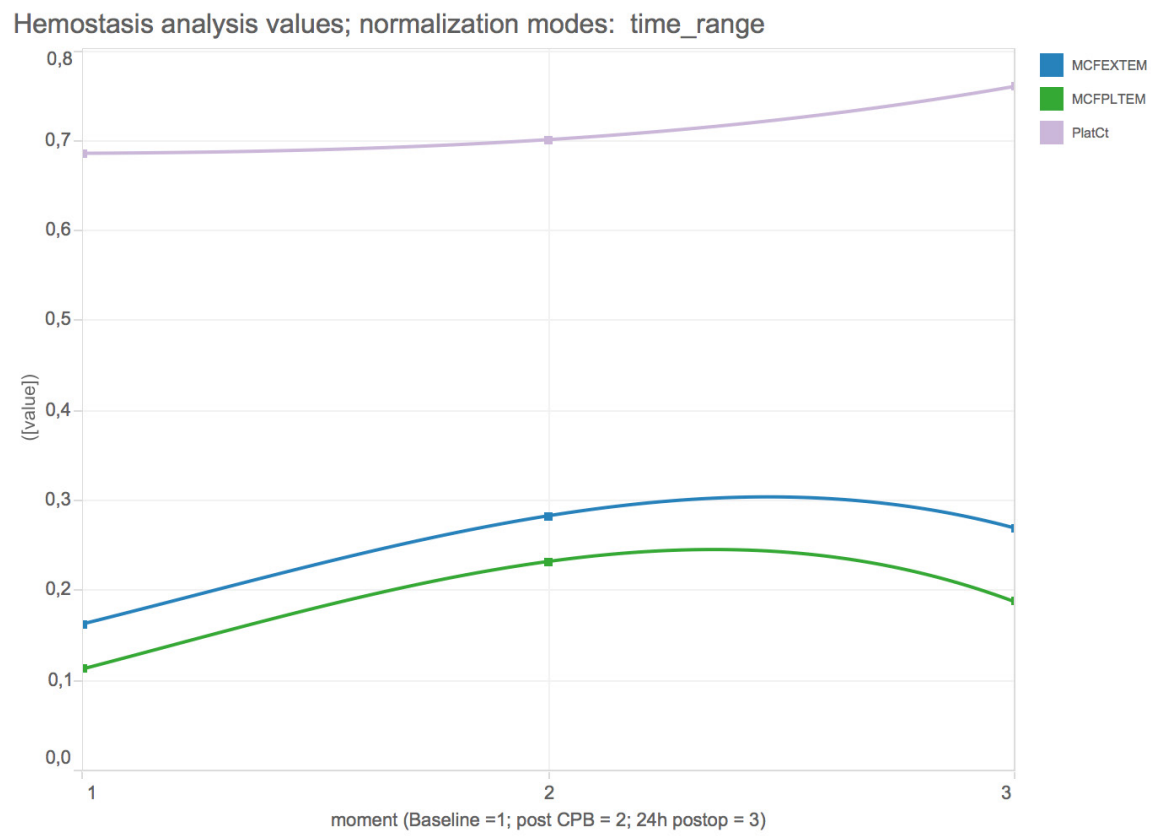

Figure $3 b$ range: range transformation;

Hemostasis analysis values; normalization modes: time_prop

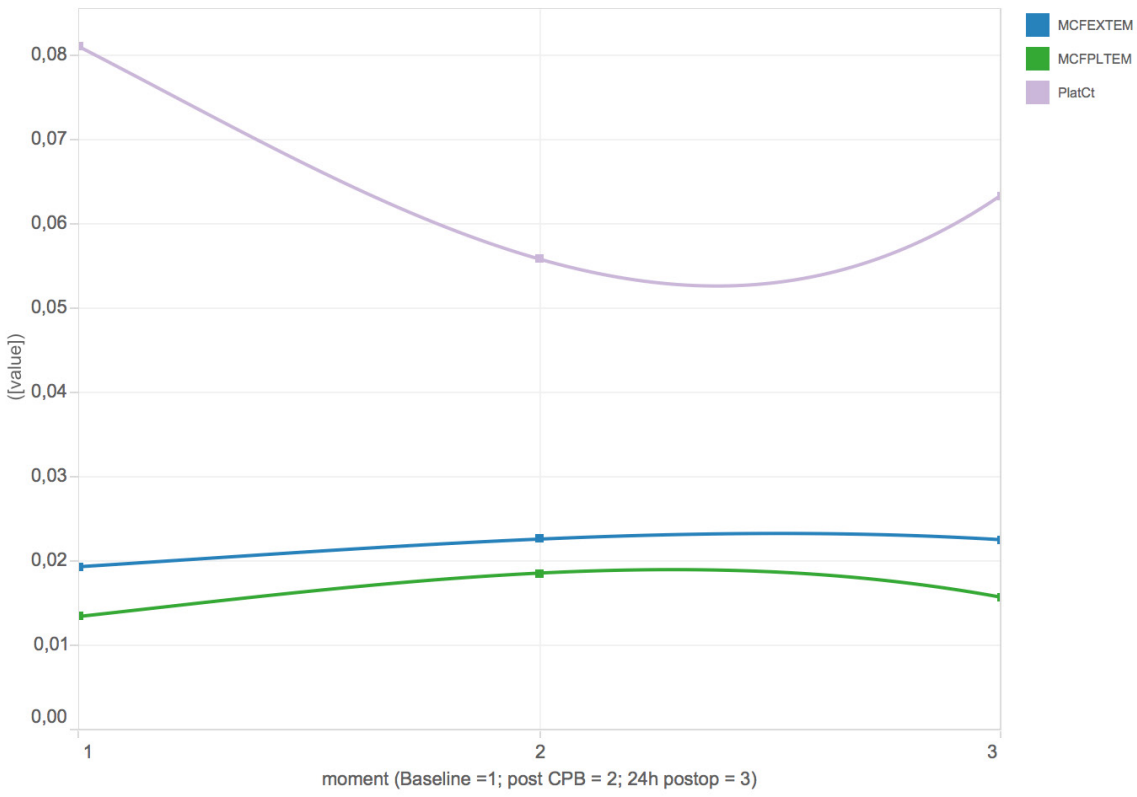


Figure 3c prop: proportion transformation;

Hemostasis analysis values; normalization modes: time_Z

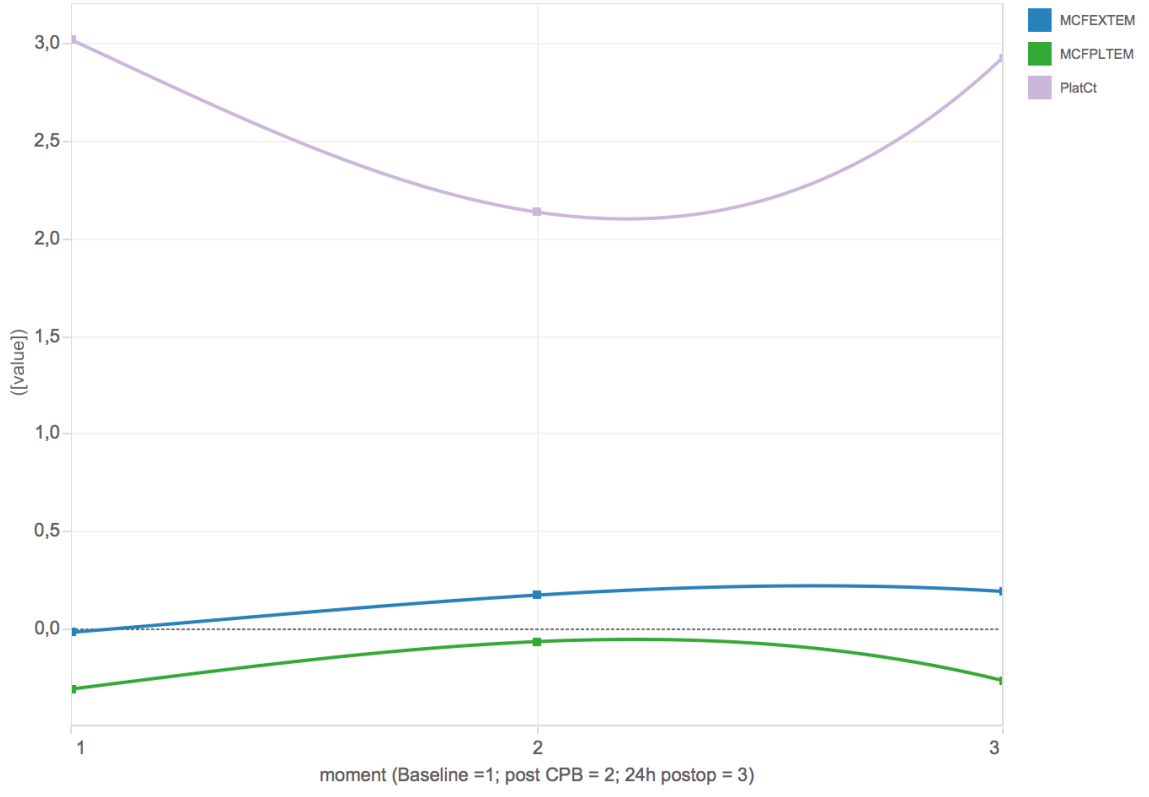




\section{Figure 3 b range: $z$-transformation}

(MCF maximum clot firmness; PlatCt platelet count; CBP cardiopulmonary bypass; postop postoperative)

\section{Figure 4:}

Data of PlatCt, MCFEXTEM, MCFPLTEM for Baseline, post-CPB, postop. Normalization on the complete dataset.

Charts generated by Tableau and available from: https://public.tableau.com/views/ LineChart_8/Dashboard1?:embed=y\&:display_count=yes\&:showTabs=y.

Normalization mode: all: normalization on the complete dataset;

Hemostasis analysis values; normalization modes: all_interQ

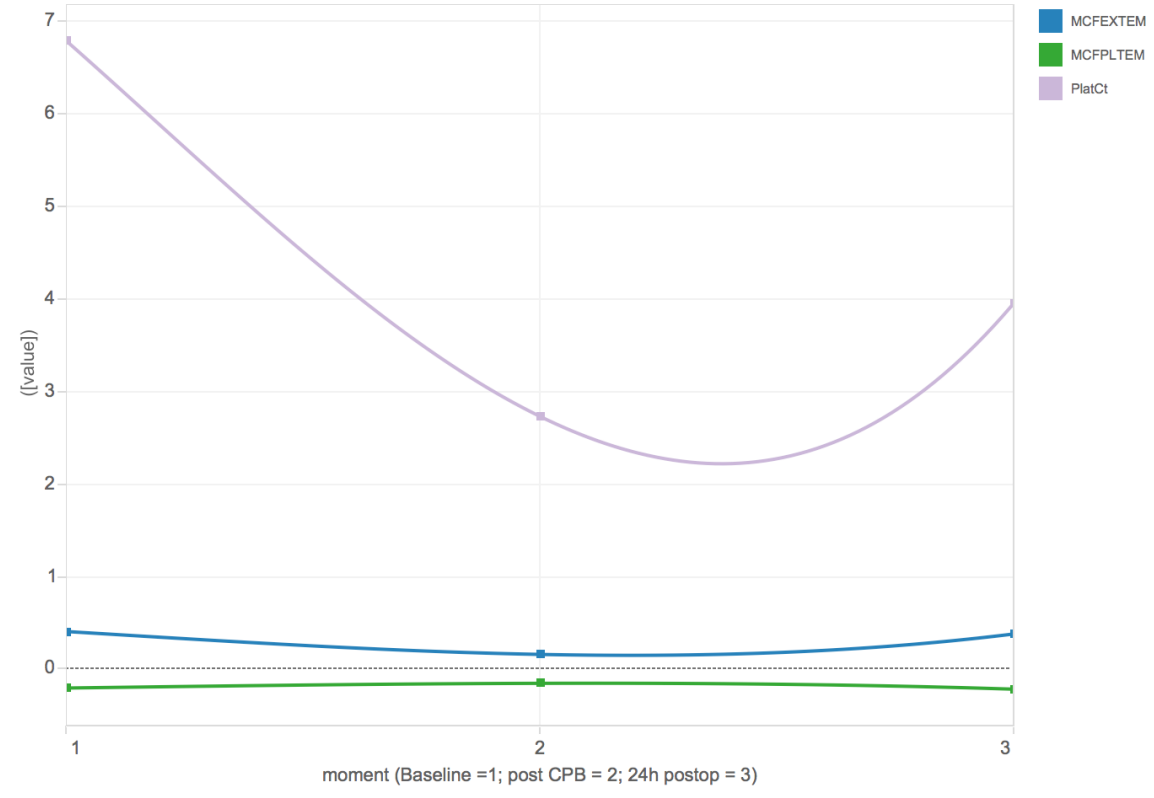


Figure 4a InterQ: interquartile range;

Hemostasis analysis values; normalization modes: all_range

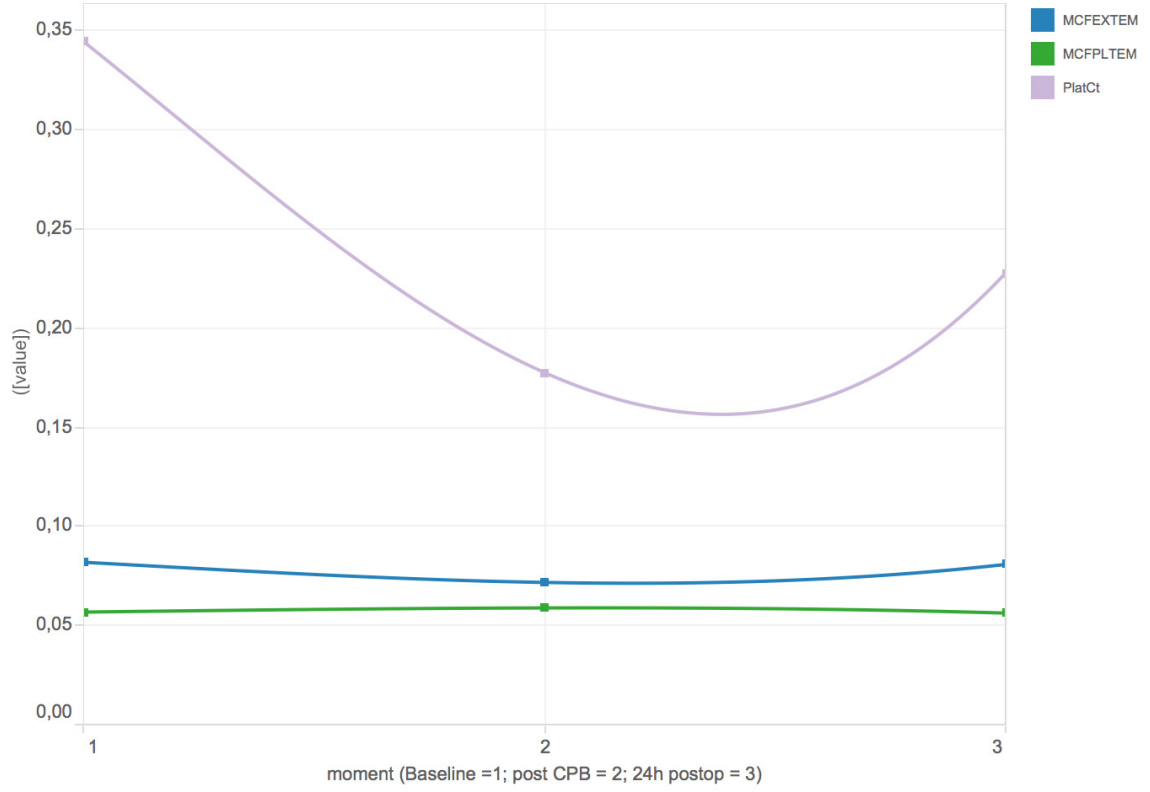

Figure 4b range: range transformation;

Hemostasis analysis values; normalization modes: all_prop

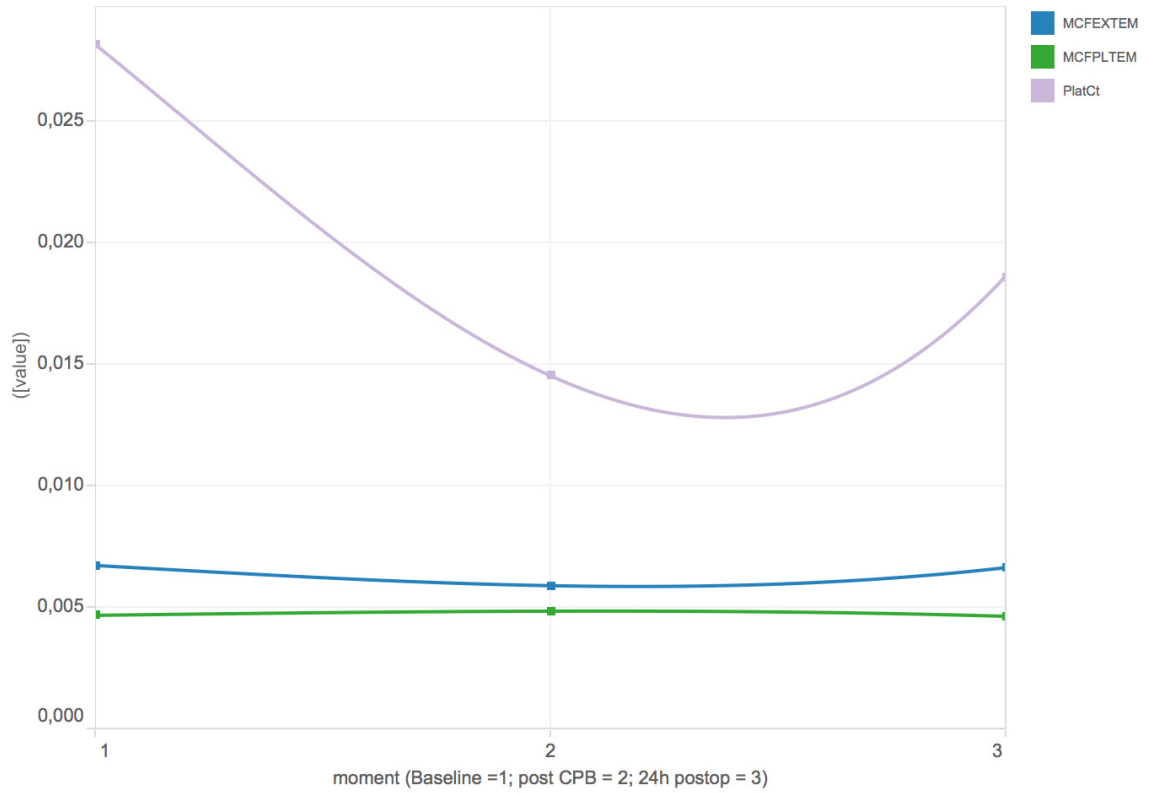


Figure 4c prop: proportion transformation;

Hemostasis analysis values; normalization modes: all_Z

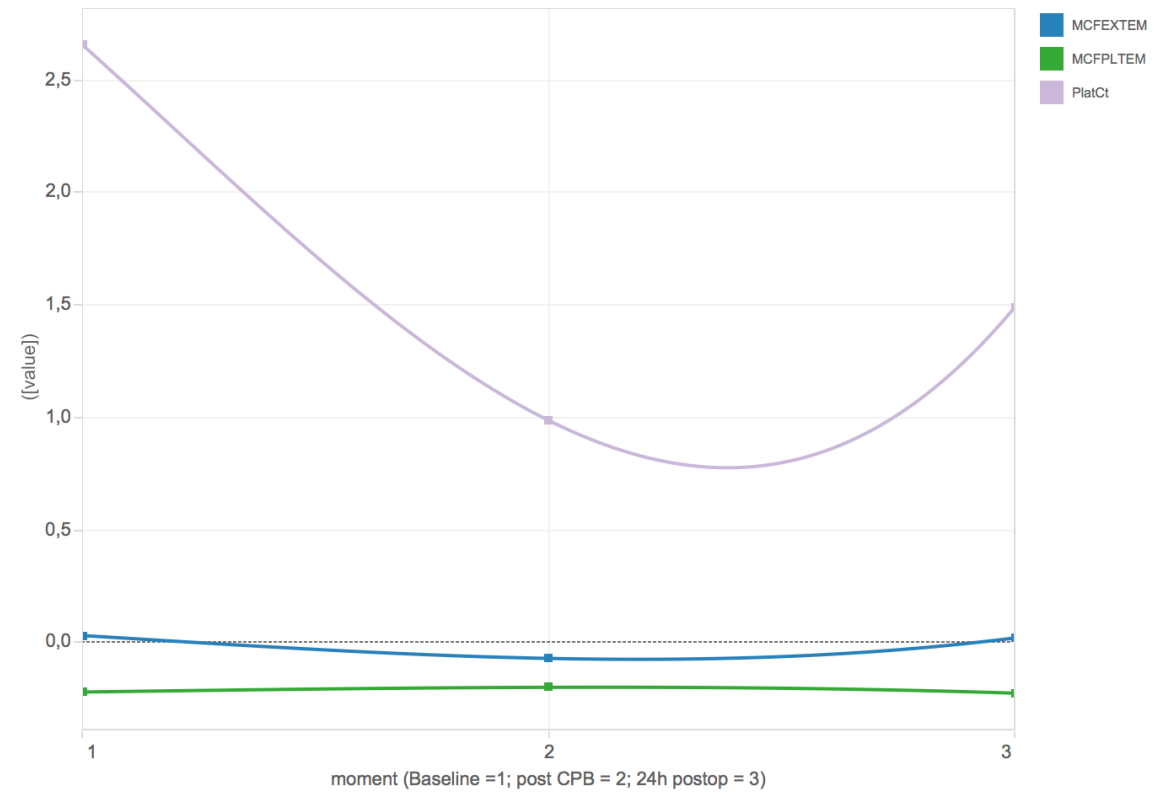

Figure 4d Z: z-transformation.

(MCF maximum clot firmness; PlatCt platelet count; CBP cardiopulmonary bypass; postop postoperative) 


\section{SQUIRE GUIDELINES}

(Standards for QUality Improvement Reporting Excellence)

Final revision - 4-29-08

$>$ These guidelines provide a framework for reporting formal, planned studies designed to assess the nature and effectiveness of interventions to improve the quality and safety of care.

$>$ It may not be possible to include information about every numbered guideline item in reports for original formal studies, but authors should at least consider every item in writing their reports.

$>$ Although each major section (i.e., Introduction, Methods, Results, and Discussion) of a published original study generally contains some information about the numbered items within that section, information about items from one section (for example, the Introduction) is often also needed in other sections (for example, the Discussion).

\begin{tabular}{|c|c|c|}
\hline $\begin{array}{c}\text { Text section; } \\
\text { Item number and name }\end{array}$ & Section or Item Description & $\begin{array}{l}\text { Reported } \\
\text { on Page }\end{array}$ \\
\hline Title and Abstract & \multicolumn{2}{|l|}{$\begin{array}{l}\text { Did you provide clear and accurate information for finding, } \\
\text { indexing, and scanning your paper? }\end{array}$} \\
\hline 1. Title & $\begin{array}{l}\text { a. Indicates the article concerns the improvement of quality } \\
\text { (broadly defined to include the safety, effectiveness, patient- } \\
\text { centeredness, timeliness, efficiency, and equity of care) } \\
\text { b. States the specific aim of the intervention } \\
\text { c. Specifies the study method used (for example, } \\
\text { "A qualitative study," or "A randomized cluster trial") }\end{array}$ & 1 \\
\hline 2. Abstract & $\begin{array}{l}\text { Summarizes precisely all key information from various sections } \\
\text { of the text using the abstract format of the intended publication }\end{array}$ & 2 \\
\hline Introduction & \multicolumn{2}{|l|}{ Why did you start? } \\
\hline $\begin{array}{l}\text { 3. Background } \\
\text { knowledge }\end{array}$ & $\begin{array}{l}\text { Provides a brief, non-selective summary of current knowledge } \\
\text { of the care problem being addressed, and characteristics of } \\
\text { organizations in which it occurs }\end{array}$ & 4 \\
\hline 4. Local problem & $\begin{array}{l}\text { Describes the nature and severity of the specific local problem } \\
\text { or system dysfunction that was addressed }\end{array}$ & 4 \\
\hline 5. Intended improvement & $\begin{array}{l}\text { a. Describes the specific aim (changes/improvements in care } \\
\text { processes and patient outcomes) of the proposed intervention } \\
\text { b. Specifies who (champions, supporters) and what (events, } \\
\text { observations) triggered the decision to make changes, and why } \\
\text { now (timing) }\end{array}$ & $4-5$ \\
\hline 6. Study question & $\begin{array}{l}\text { States precisely the primary improvement-related question and } \\
\text { any secondary questions that the study of the intervention was } \\
\text { designed to answer }\end{array}$ & 5 \\
\hline Methods & \multicolumn{2}{|l|}{ What did you do? } \\
\hline 7. Ethical Issues & $\begin{array}{l}\text { Describes ethical aspects of implementing and studying the } \\
\text { improvement, such as privacy concerns, protection of participants' } \\
\text { physical well-being, and potential author conflicts of interest, and } \\
\text { how ethical concerns were addressed }\end{array}$ & 5 \\
\hline 8. Setting & $\begin{array}{l}\text { Specifies how elements of the local care environment considered } \\
\text { most likely to influence change/improvement in the involved site } \\
\text { or sites were identified and characterized }\end{array}$ & $5,6,7$ \\
\hline
\end{tabular}




\section{Planning the} intervention

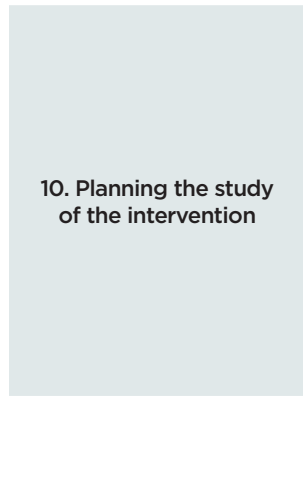

11. Methods of evaluation

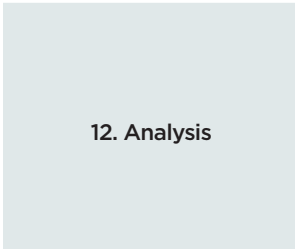

Results a. Describes the intervention and its component parts in sufficient detail that others could reproduce it

b.Indicates main factors that contributed to choice of the specific intervention (for example, analysis of causes of dysfunction; matching relevant improvement experience of others with the local situation)

c. Outlines initial plans for how the intervention was to be implemented: e.g., what was to be done (initial steps; functions to be accomplished by those steps; how tests of change would be used to modify intervention), and by whom (intended roles, qualifications, and training of staff)

a. Outlines plans for assessing how well the intervention was implemented (dose or intensity of exposure)

b. Describes mechanisms by which intervention components were expected to cause changes, and plans for testing whether those mechanisms were effective

c. Identifies the study design (for example, observational, quasiexperimental, experimental) chosen for measuring impact of the intervention on primary and secondary outcomes, if applicable d. Explains plans for implementing essential aspects of the chosen study design, as described in publication guidelines for specific designs, if applicable (see, for example, www.equator-network.org) e. Describes aspects of the study design that specifically concerned internal validity (integrity of the data) and external validity (generalizability)

a. Describes instruments and procedures (qualitative, quantitative, or mixed) used to assess a) the effectiveness of implementation,

b) the contributions of intervention components and context factors to effectiveness of the intervention, and c) primary and secondary outcomes

b. Reports efforts to validate and test reliability of assessment instruments

c. Explains methods used to assure data quality and adequacy (for example, blinding; repeating measurements and data extraction; training in data collection; collection of sufficient baseline measurements)

a. Provides details of qualitative and quantitative (statistical) methods used to draw inferences from the data

b. Aligns unit of analysis with level at which the intervention was implemented, if applicable

c. Specifies degree of variability expected in implementation, change expected in primary outcome (effect size), and ability of study design (including size) to detect such effects

d. Describes analytic methods used to demonstrate effects of time as a variable (for example, statistical process control)

What did you find?

a) Nature of setting and improvement intervention

i) Characterizes relevant elements of setting or settings

(for example, geography, physical resources, organizational culture, history of change efforts), and structures and patterns of care (for example, staffing, leadership) that provided context for the intervention

ii) Explains the actual course of the intervention (for example, sequence of steps, events or phases; type and number of participants at key points), preferably using a time-line diagram or flow chart

iii)Documents degree of success in implementing intervention components

iv)Describes how and why the initial plan evolved, and the most important lessons learned from that evolution, particularly the effects of internal feedback from tests of change (reflexiveness) b)Changes in processes of care and patient outcomes associated with the intervention

i) Presents data on changes observed in the care delivery process

ii) Presents data on changes observed in measures of patient outcome (for example, morbidity, mortality, function, patient/staff satisfaction, service utilization, cost, care disparities)

iii) Considers benefits, harms, unexpected results, problems, failures iv)Presents evidence regarding the strength of association between observed changes/improvements and intervention components/context factors

v) Includes summary of missing data for intervention and outcomes 


\begin{tabular}{|c|c|c|}
\hline Discussion & \multicolumn{2}{|l|}{ What do the findings mean? } \\
\hline 14. Summary & $\begin{array}{l}\text { a. Summarizes the most important successes and difficulties } \\
\text { in implementing intervention components, and main changes } \\
\text { observed in care delivery and clinical outcomes } \\
\text { b. Highlights the study's particular strengths }\end{array}$ & 13,14 \\
\hline $\begin{array}{l}\text { 15. Relation to other } \\
\text { evidence }\end{array}$ & $\begin{array}{l}\text { Compares and contrasts study results with relevant findings } \\
\text { of others, drawing on broad review of the literature; use of a } \\
\text { summary table may be helpful in building on existing evidence }\end{array}$ & 13,14 \\
\hline 16. Limitations & $\begin{array}{l}\text { a. Considers possible sources of confounding, bias, or imprecision } \\
\text { in design, measurement, and analysis that might have affected } \\
\text { study outcomes (internal validity) } \\
\text { b. Explores factors that could affect generalizability (external } \\
\text { validity), for example: representativeness of participants; } \\
\text { effectiveness of implementation; dose-response effects; features } \\
\text { of local care setting } \\
\text { c. Addresses likelihood that observed gains may weaken over } \\
\text { time, and describes plans, if any, for monitoring and maintaining } \\
\text { improvement; explicitly states if such planning was not done } \\
\text { d. Reviews efforts made to minimize and adjust for study } \\
\text { limitations } \\
\text { e. Assesses the effect of study limitations on interpretation and } \\
\text { application of results }\end{array}$ & 13 \\
\hline 17. Interpretation & $\begin{array}{l}\text { a. Explores possible reasons for differences between observed and } \\
\text { expected outcomes } \\
\text { b. Draws inferences consistent with the strength of the data } \\
\text { about causal mechanisms and size of observed changes, paying } \\
\text { particular attention to components of the intervention and context } \\
\text { factors that helped determine the intervention's effectiveness (or } \\
\text { lack thereof), and types of settings in which this intervention is } \\
\text { most likely to be effective } \\
\text { c. Suggests steps that might be modified to improve future } \\
\text { performance } \\
\text { d. Reviews issues of opportunity cost and actual financial cost of } \\
\text { the intervention }\end{array}$ & 13,14 \\
\hline 18. Conclusions & $\begin{array}{l}\text { a. Considers overall practical usefulness of the intervention } \\
\text { b. Suggests implications of this report for further studies of } \\
\text { improvement interventions }\end{array}$ & 15 \\
\hline Other information & Were other factors relevant to conduct and interpretation of the study? & \\
\hline 19. Funding & $\begin{array}{l}\text { Describes funding sources, if any, and role of funding organization } \\
\text { in design, implementation, interpretation, and publication of study }\end{array}$ & 16 \\
\hline
\end{tabular}




\section{CHAPTER 8}

\section{FROM SAMPLE TO BIG DATA}

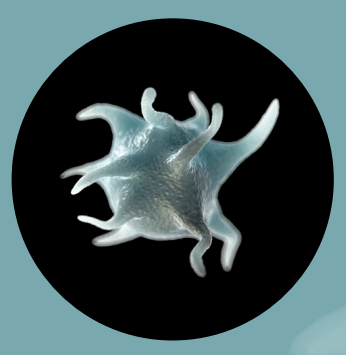

Scalable Predictive Analysis in Critically III Patients Using a Visual Open Data Analysis Platform. Van Poucke S, Zhang Z, Schmitz M, Vukicevic M, Vander Laenen M, Celi LA, De Deyne C. PLoS One 2016;11:e0145791 


\title{
8.1 SCALABLE PREDICTIVE ANALYSIS IN CRITICALLY ILL PATIENTS USING A VISUAL OPEN DATA ANALYSIS PLATFORM.
}

\begin{abstract}
With the accumulation of large amounts of health related data, predictive analytics could stimulate the transformation of reactive medicine towards Predictive, Preventive and Personalized (PPPM) Medicine, ultimately affecting both cost and quality of care. However, high-dimensionality and high-complexity of the data involved, prevents data-driven methods from easy translation into clinically relevant models. Additionally, the application of cutting edge predictive methods and data manipulation require substantial programming skills, limiting its direct exploitation by medical domain experts. This leaves a gap between potential and actual data usage. In this study, the authors address this problem by focusing on open, visual environments, suited to be applied by the medical community. Moreover, we review code free applications of big data technologies. As a showcase, a framework was developed for the meaningful use of data from critical care patients by integrating the MIMIC-II database in a data mining environment (RapidMiner) supporting scalable predictive analytics using visual tools (RapidMiner's Radoop extension). Guided by the CRoss-Industry Standard Process for Data Mining (CRISP-DM), the ETL process (Extract, Transform, Load) was initiated by retrieving data from the MIMIC-II tables of interest. As use case, correlation of platelet count and ICU survival was quantitatively assessed. Using visual tools for ETL on Hadoop and predictive modeling in RapidMiner, we developed robust processes for automatic building, parameter optimization and evaluation of various predictive models, under different feature selection schemes. Because these processes can be easily adopted in other projects, this environment is attractive for scalable predictive analytics in health research.
\end{abstract}

\section{Keywords}

predictive analytics, critical care, data mining, platelet count, feature selection, ensemble methods 


\subsubsection{INTRODUCTION}

The critical care sector generates bountiful data around the clock, which can paradoxically complicate the quest for information, knowledge, and 'wisdom' [1]. The accumulation of clinical data has outpaced the capacity for effective aggregation and analysis aiming to support clinical quality, patient safety and integrated patient care. Intelligent data analysis promises a more efficient representation of the complex relations between symptoms, diseases and treatment [2]. Additionally intelligent data analysis hopes for a reduction of cost of care and faster design and implementation of clinical guidelines [3]. In this respect, the secondary use of clinical and operational data could support comparative effectiveness research, data mining, and predictive analytics. Commonly used data analysis platforms in clinical practice, frequently only provide support for data integration and monitoring, leaving all the analysis and decision taking to the clinical end-users. The clinical end-user is not in the position to constantly monitor and process the large amounts of data generated by patient monitoring and diagnostics. The potential of predictive analytics is to provide the clinical end-user with validated medical decision support and ultimately leading to more Predictive, Preventive and Personalized Medicine (PPPM) [4]. PPPM is an integrative concept in health care that enables to predict individual predisposition before onset of the disease, to provide targeted preventive measures and create treatment algorithms tailored to the person. PPPM relies on the potential of large amounts of heterogeneous data collected in medical environments (electronic health records, medical texts and images, laboratory tests etc), but also from external data of increasingly popular wearable devices, social media etc. Data driven predictive algorithms often fail to provide self explanatory models due to high-dimensionality and high-complexity of the data structure leading to unreliable models. Also, successful predictive analytics and application of cutting edge machine learning algorithms often demands substantial programming skills in different languages (e.g. Python or R). This migrates modeling from the domain expert to the data scientist, often missing the necessary domain expertise, and vice versa, domain experts are not able to perform ad hoc data analyses without the help of experienced analysts. This leads to slow development, adoption and exploitation of highly accurate predictive models, in particular in medical practice, where errors have significant consequences (for both patients and costs). In this paper, we address this problem by exploring the potential of visual, code free tools for predictive analytics. We also review the potential of visual platforms (RapidMiner, Knime and Weka) for big data analytics. As a showcase, we integrated the MIMIC-II database in the RapidMiner data analytics platform. Data extraction and preparation was performed on a Hadoop cluster, using RapidMiner's Radoop extension. Further, we used RapidMiner Studio in order to develop several processes that allow automatic feature selection, parameter optimization and model evaluation. The process compared several learning methods (Decision Stump, Decision Tree, Naive Bayes, Logistic Regression, Random Forest, AdaBoost, Bagging, Stacking, Support Vector Machine) in association with feature weighting and selection quantitatively assessed in terms of Correlation, Gini Selection, Information Gain and ReliefF. 


\subsubsection{SCALABLE PREDICTIVE ANALYTICS AND VISUAL OPEN PLATFORMS}

The need for scalable and efficient frameworks, accessible to users with various levels of expertise, was recently emphasized by Koliopoulos et al. [5]. These frameworks allow data analysts and domain experts to focus on effective knowledge extraction and model tuning instead of learning new programming languages. There are multiple tools supporting open-source development with highly involved communities. This leads to faster implementation and deployment of cutting edge methods provided in the literature. The authors only address open-source, visual tools in this paper. Reviews covering open, visual tools for data analyses have been previously published, identifying RapidMiner, Knime and Weka as platforms with the highest potential for scalable big data analytics [6,7]. Furthermore, Gartner identified RapidMiner and Knime as leaders in advanced analytics platforms [8].

Furthermore, we briefly describe the available open technologies for predictive analysis of big data supported by visual tools, followed by an overview of the visual tools allowing code free big data analytics [9].

First, Google introduced MapReduce allowing big data processing on clusters with Mapping (parallel processing of dataset partitions) and Reducing (aggregation of the results), assuring fault-tolerance computation through replication [10].

Further, Yahoo developed Hadoop as an open source implementation of MapReduce [11]. The Hadoop Distributed File System (HDFS) is a disk-based file system that spans across the nodes of a distributed system. HDFS encapsulates distributed local storage into a single logical unit and allows automatic division of data into blocks and replication on local disks, allowing fault-tolerance computations. Map/reduce jobs on Hadoop can be developed on Hive software enabling querying and managing large data on distributed storage [12]. It provides a mechanism to project structure on this data and query the data using an SQL-like language called HiveQL. It also allows definition and execution of map/reduce map reduce jobs in other languages when required. Vavilapalli et al. noticed that the major disadvantage of Hadoop for general purpose analytics is the tight coupling of a specific programming model with the resource management infrastructure [13]. In order to overcome this, a new architecture was developed, called YARN (Yet Another Resource Negotiator) that decouples the programming model from the resource management infrastructure and delegates many scheduling functions (e.g., task fault tolerance) to per-application components. Vavilapalli et al. provided experimental evidence of improved efficiency of running YARN on production environments and many projects in the Hadoop ecosystem support work on YARN with almost the same feature set as on Hadoop: e.g. Hive [12], or Pig [14].

In order to exploit the potentials of Hadoop for predictive analytics, Mahout was developed providing scalable data mining libraries [15]. Even though Mahout is widely used for scalable predictive analytics, it is also criticized, as its libraries do not provide a general framework for building algorithms, the quality of the provided solutions varies significantly being dependent on the contributor expertise $[5,16]$. Mahout also focuses on implementing specific algorithms, rather than building execution models for algorithm methods.

Hadoop and its ecosystem gain high popularity over the years, but processing data from disk made it inefficient for many data mining applications that often require iteration, which is not easily performed in MapReduce [5, 9]. 
In order to tackle these insufficiencies, Spark, was developed allowing in-memory and iterative computation [17]. Spark also implements the MapReduce paradigm and is Java-based (as is Hadoop). These features enable users to deploy existing Hadoop application logic in Spark via its Scala API. It is based on abstractions called Resilient Distributed Datasets (RDD), which store data in-memory and provide fault tolerance without replication [17]. RDDs can be understood as read-only distributed shared memory [18]. Spark has been shown to outperform Hadoop by up to two orders of magnitude in many cases.

MLlib is the machine learning library for Spark covering the same range of learning categories as Mahout, but also adds regression models, which is lacking in Mahout $[9,19]$. MLlib's reliance on Spark, in-memory computations and iterative batch and streaming approaches, enable jobs to run significantly faster than those using Mahout [20]. However, the fact that it is tied to Spark may present a problem for performing machine learning on multiple platforms [21]. MLlib is still relatively young compared to Mahout.

SparkR [22] and PySpark [23] provide R and Python users a lightweight front-end to a Spark system, by compiling the declarative scripts to low-level MapReduce jobs which is considered valuable taking into account the popularity of R and Python in the data science community.

RapidMiner (previously: Rapid-I, YALE) became very popular in recent years and is supported by a large community. Its visually appealing, user friendly GUI (graphical user interface) and wiki-based contextual help (with process examples for each operator), allow ease of use and a fast learning curve. This is also supported by the "Wisdom of crowds" which provides suggestions (which operator should be used next) based on the community experience. Additionally, there are multiple extensions providing data and pre-defined processes suited for specific application areas (e.g. marketing, finance etc.) and a community is very active in sharing processes on the RapidMiner "Marketplace". One of the important strengths of RapidMiner is its flexibility in process design through "Process/Sub-process" structures and "Macros" that represent global variables of the environment. This enables a visual design of complex processes, and a high level of automation (as presented in our experiments) which is usually possible only by programing (e.g. in R or Python). Furthermore this allows seamless parameter optimization, being a neccessery step for many cutting edge algorithms (e.g. SVMs). This technique allows simple maintenance of data flows (in comparison with pure coding environments). RapidMiner also provides a large number of machine learning algorithms, tools for pre-processing and visualization, including wrappers for most of the Weka operators and simple tools for incorporation of custom-built R and Python scripts. Considering all this makes RapidMiner a powerful predictive analytics environment for data analysts and/or domain experts with variable levels of expertise. On the down side, the support for deep learning methods and some of the more advanced specific machine learning algorithms (e.g. extremely randomized trees, various inductive logic programming algorithms) is currently limited [7] but can be solved by incorporation of $\mathrm{R}$ and Python scripts. Additionally, the current version of Rapidminer [6.5] has a free license [7] with very few constraints compared to the commercial version (e.g. SQL database support) and provides some of the previous versions free of charge (currently, version 5.3 is available). 
RapidMiner supports scalable predictive analytics on Big data through its Radoop extension. It allows code free, visual analytics on Hadoop, Spark, Hive, MapReduce, Pig and Mahout through series of specialized operators that can be used with standard RapidMiner operators within the used workflows. Additionally, Radoop enables incorporation of SparkR, PySpark, Pig and HiveQL scripts within predictive analytics workflows. This allows seamless combination of data preparation on Spark and Hadoop with predictive analytics using Spark's machine learning library MLlib or Radoop's Mahout.

Weka (Waikato Environment for Knowledge Analysis) is a very powerful and versatile data analytics tool, also largely supported by a community and very popular in the academic world [25]. The success of Weka is related to the availability of a wide range of well implemented machine learning algorithms and model evaluation procedures and metrics. Weka also provides an API (application programming interface) for integration of its algorithms and procedures resulting in a frequent adoption in other visual environments such as RapidMiner and Knime. Even more interesting, Weka's algorithms are also used in coding environments like R and Python through API's. As RapidMiner and Knime, Weka allows implementation of extensions independent of the used core system resulting in a fast increasing number of Weka features provided by their community. In contrast, Weka's GUI is not as visually appealing and extendable as RapidMiner or Knime, it lacks many data survey and visualization methods and it has the tendency to be more oriented towards classification and regression problems and less towards descriptive statistics and clustering methods [7]. This probably explains why Weka didn't make it to the leaders quadrant in Gartners report on advanced analytics platforms [8]. Still, Weka offers a completely free and very powerful environment for code-free predictive analytics. Weka also supported R scripting for a long time and recently a "wekaPython" extension provided Python scripting within dataflows defined through GUI.

Regarding big data tools, Weka does not have an integral environment for both Hadoop and Spark, but it supports big data analytics through several extensions. It allows work with Hadoop through DistributedWekaBase and DistributedWekaHadoop packages [25]. These packages provide both base "map" and "reduce" tasks that are not tied to any specific distributed platform and Hadoop-specific wrappers and jobs for these base tasks. These packages allow different data pre-processing, modeling and evaluation tasks on big data (e.g. computing correlation and covariance matrices, PCA, training, scoring and evaluation of classifiers and regressors). In case of learning models, classifiers and regressors are divided into "aggregatable" and "non-aggregatable". Aggregatable, produce a single model, that is learned in parts on a cluster and aggregated in a Reduce job while models that cannot be aggregated in a Reduce job allow making of ensemble models (e.g. Bagging) built separately on a cluster.

Recently DistributedWekaSpark, a distributed framework for in-memory cluster computation in Weka is proposed (5) allowing similar functionalities as previously described for MapReduce and Hadoop. Weka extensions for big data do not offer wrappers for machine learning algorithms already developed in Mahout or MLlib, but rather adapt its own algorithms to work with MapReduce. This makes learning more difficult for entry level analysts (5]. 
KNIME (Konstanz Information Miner) is also considered a visual open-source tool, based on the Eclipse project, but also offers commercial licenses for companies requiring professional technical support [26]. It shares good features with RapidMiner allowing a fast learning curve for entry level analytics: visually appealing and intuitive GUI, good documentation and community support, ease of development through core system and extensions and a large repository of example workflows is available facilitating efficient learning of the tool. KNIME also integrates Weka, allows scripting for $\mathrm{R}$ and Python and provides commercial extensions for more specific functionalities.

Similar to RapidMiner, Knime provides support for big data analytics. The KNIME Big Data Extension, which provides a set of nodes for accessing Hadoop/HDFS via Hive from inside KNIME can be easily installed and used of the shelf. Still, it lacks the support for direct usage of Mahout and in-memory cluster analytics (like Spark), but this can be expected soon as an update of Big Data extension.

\subsubsection{MATERIAL AND METHODS}

\subsubsection{DATA SOURCE AND EXPERIMENTAL ENVIRONMENT}

The MIMIC II (version 2.6) clinical database consists of 32,536 ICU patients (medical, surgical, coronary care and neonatal), admitted to Beth Israel Deaconess Medical Center (Boston, MA) from 2001 to 2008 [27, 28]. The establishment of the database was approved by the Institutional Review Boards of the Massachusetts Institute of Technology (Cambridge, MA) and Beth Israel Deaconess Medical Center (Boston, MA). The data in the MIMIC-II database is available to other researchers. The contents of the MIMIC-II Clinical Database are derived from original data that contained protected health information $(\mathrm{PHI})$, as defined by HIPAA. The providers of the data have given scrupulous attention to the task of locating and removing all PHI, so that the remaining data can be considered de-identified and therefore not subject to the HIPAA Privacy Rule restrictions on sharing PHI. Because of the richness and detail of the database, the data is released only to legitimate researchers under the terms and conditions as described by Physionet.org [28]. All data and related metadata is available after successful completion of the NIH web-based training course named "Protecting Human Research Participants" enabling access to the entire MIMIC-II database. Accessing the database was approved for authors S.V.P \& Z.Z. (certification number: 1712927 \& 1132877). Informed consent was waived due to observational nature of the study.

The MIMIC-II clinical database includes data related to patient demographics, hospital admissions \& discharge dates, room tracking, death dates (in or out of the hospital), ICD-9 codes, health care providers and types. All dates were surrogate dates but time intervals were preserved. Additionally, physiological data (hourly vital sign metrics, SAPS score, SOFA score, ventilator settings, etc.), medications consumption, laboratory investigations, fluid balance calculations and notes \& reports (discharge summary, nursing progress notes, cardiac catheterization, ECG, radiology, and echo reports) were included. The SAPS-I score (Simplified Acute Physiology Score) was calculated using the method outlined earlier [29]. A New Simplified Acute Physiology Score (SAPS II) based on a European/North American Multicenter Study was later published [30]. 
The SOFA score (Sequential Organ Failure Assessment) was used to assess the incidence of organ dysfunction [31]. The MIMIC-II database contained patients from five ICU types: medical (MICU), surgical (SICU), cardiac (CCU), cardiac surgery recovery (CSRU) and neonatal (NICU).

The initial size of the dataset was identical to the size of the MIMIC-II Clinical Database. All data for a given patient were contained in a set of 33 flat files for each patient. The data archives contained the flat files for about 1000 subjects each. The decompressed flat files occupied about 31 GB in all. The process presented in this paper consisted of only a third of the number of patients from the MIMIC-II database.

In order to enable a scalable environment for future research and to demonstrate seamless usage of big data technologies within a code free environment, the MIMIC-II Clinical Database flat files were integrated in a dedicated Hadoop cluster with Hive server [32, 33] (Fig 1). RapidMiner 6.5 was installed following the instructions provided by RapidMiner. RapidMiner provided data mining and machine learning procedures visualization, predictive analytics and statistical modeling, evaluation, and deployment [34]. RapidMiner Radoop 2.3.0 was installed through the extension manager of RapidMiner and used to connect to the Hadoop cluster and to perform data loading and transformation (Extract, Transform, Load (ETL) and initial preprocessing. RapidMiner Radoop pushed down visually designed workflows for analytics into Hadoop environments for processing the workflows - integrating with core Hadoop technologies HDFS, MapReduce/ YARN and Hive. The MIMIC-II database was initially imported in a PostgreSQL database and consequently converted to Hive. For the implementation of security, a 4-layer security model for Hadoop was used. The first level is responsible for authenticating a user (Perimeter Security). The second level is responsible for authorizing access to data (Data Access Security), i.e. granting access to users only to data, services and resources that they are specifically entitled to use. The common goal of the third security level is to foster accountability by allowing administrators to monitor and audit data access on Hadoop. The fourth level of security covers data-at-rest encryption, on-the-wire encryption, data masking, etc. The hardware used in this research consisted of a local machine (MacBookPro 11.1; Intel Core i5; 2,4 GHz; 1 processor, 2 cores; L2-cache (per core): 256 KB; L3-cache: 3 MB Memory 8 GB) and a Hadoop cluster (5 nodes; 8GB/node; version 2.4.1; configured capacity 7.1 TB)

In the following text we present the algorithms used for the analysis. First we focus on the classification algorithms, then feature selection algorithms are covered. 


\subsubsection{PREDICTIVE ALGORITHMS}

Naive Bayes (NB) - The Naive Bayesian learning uses Bayes theorem with "Naive" assumption of independence between predictors [35]. Examples are classified based on the posterior probability that an example should be assigned to class $\mathrm{c}$.

$$
y=\underset{k \in\{1 . . K\}}{\arg \max } P\left(C_{k}\right) \prod_{i=1}^{n} p\left(x_{i} \mid C_{i}\right)
$$

Even though, independence assumption is violated in most real world applications, Naive Bayes often demonstrated satisfactory performance in practice [36], and was classified as one of the top 10 algorithms in data mining [37]. Additionaly, Naive Bayes are easy to construct, without any setting or adjusting of complex parameters, computational and time effectiveness. Naive Bayes have the ability to work with large datasets (big data) and provide good interpretability, which is a must in real world bio-medical applications [38].

Decision trees (DT) are predictive algorithms based on "greedy", top-down recursively partitioning of data. DT algorithms perform an exhaustive search over all possible splits in every recursive step. The attribute (predictor) demonstrating the best split by some evaluation measure is selected for branching the tree. Regularly used are information theoretic measures (e.g. Information Gain, Gain Ratio, Gini etc.) or statistical tests quantifying significance of association between predictors and class. The procedure is recursively iterated, until a stop criterion is met. Greedy strategy for DT building is often criticized, but the ability to build strait forward and the highly interpretable rules on massive data, led to many successful applications in medical applications [39,40]. In this research we used J48 algorithms which is the Java implementation of the C4.5 algorithm [41].

Logistic regression (LR) is a widely used linear classifier modeling the probability of a dependant binary variable y given a vector of independent variables $X$. For the estimation of the probability the example belongs to the positive class, a logit model is used:

$$
\log \left(\frac{p}{1-p}\right)=\theta_{0}+\theta_{1} x_{1}+\ldots+\theta_{n} x_{n}
$$

Support Vector Machines (SVMs) construct hyperplanes between the examples (represented as points in high-dimensional space), in such a way that examples of the separate categories are divided by a clear gap that is as wide as possible [46,47]. New examples are subsequently mapped into the same space and predicted to belong to a category based on the side of the gap they fall in. SVMs are considered as one of the state-of-the-art classification models, with the ability to handle large feature spaces and to 
avoid over-fitting. Still, unlike NB, DTs and LR they are not widely used in medical research because of the lack of interpretability (examples represented in highly dimensional feature spaces), but also because of their model-fitting nature, where hyperparameters have to be optimized without clear theoretical guidance.

In this research we used a radial basis function (rbf) and linear (lin) SVM models. In case of rbf- SVM, two parameters are crucial to quantify the performance of a classifier: the softmargin penalty or cost (C) represents the amount of errors allowed during the training and evaluation steps and the $\gamma$ (gamma) representing the width of the SVM radial function.

Ensemble (meta-learning) methods combine multiple models in order to provide more accurate or more stable predictions. Ensemble models can aggregate the same model that is built on different sub-samples of data, different models built on the same sample or a combination of the previous two techniques. Ensemble methods are often used to improve the individual performance of algorithms that constitute ensembles [48] by exploiting the diversity among the models produced. Next a short explanation of the ensemble methods used in this paper is provided: Random Forest [49], Boosting [50], Bootstrap Aggregating (Bagging) [51] and Stacking [52].

Random Forest (RF) is an ensemble classifier that evaluates multiple decision trees and aggregates their results, by majority voting, in order to classify an example [49]. There is a two level randomization in building these models. First, each tree is trained on a bootstrap sample of the training data and second, in each recursive iteration of building a DT (splitting data based on information potential of features), a subset of features for evaluation is randomly selected. This strategy allows efficient model building, and despite its random nature often provides highly accurate predictive models. In this research we grew and evaluated Random Forest (RF) with 10 trees (with the default parameters of Weka's implementation of Random Forest).

Boosting is an ensemble meta-algorithm developed in order to improve supervised learning performance of weak learners (models whose predictive performance is only slightly better than random guessing). Boosting algorithms are built on a principle that subsequent classifiers are adapted to improve predictive performance on those instances that are misclassified by previous classifiers. In this study, the Adaptive Boosting (AdaBoost) algorithm was used [50]. The AdaBoost algorithm builds and applies multiple classifiers over a user defined number of iterations. In each iteration, the weights of each incorrectly classified example by the previous classifier are increased, and the weights of each correctly classified example are decreased in order the new classifier is adapted to the data that is misclassified by previous ones.

Bagging algorithm builds and applies a series of models that are built on different data sub-samples (with replacement) from the initial dataset, and apply, for example, a tree classifier (e.g., CHAID) to the successive samples [51]. In practice, this method is often used in order to address the instability of models often the case in small data sets. The final prediction of an ensemble could be derived by simple or weighted voting.

Stacking (Stacked generalization) builds several different models (in contrast to bagging that builds one type of model on different subsamples] [52]. Similar to Boosting, the final decision is made by simple or weighted voting. In this research we used the J48 algorithm and Naive Bayes as basis for building a stacked classifier. 


\subsubsection{FEATURE WEIGHTING AND SELECTION}

In this study we evaluated several Filter and Wrapper feature selection schemes.

Filter Selection (FS) methods rely on the evaluation of the information potential of each input feature in relation to the label. Filter Selection methods are very fast and scalable, but since they are not relating a feature subset selection with the algorithm performance, they can underperform when applied for specific predictive algorithms. Additionally, most of these techniques are based on weighting (providing a list of weights on output). Consequently, a threshold search and selection of the "right" number of features is needed. In this study, several schemes for filter feature weighting and selection were implemented. The first is based upon Correlation returning the absolute or squared value of the correlation as attribute weight. Furthermore we applied Information Gain and Gini index, two weighting schemes that are based on information theoretic measures, frequently used with decision trees for evaluation of potential splits [41]. The t-test calculated, for each attribute, a p-value for 2-sided, 2-sample t-test. Finally, the ReliefF evaluated the impact of an attribute by repeatedly sampling an instance and considering the value of the given attribute for the nearest instance of the same and different class [53].

Instead of relying on the evaluation of each feature independently (as is the case in filter feature selection methods), Wrapper methods evaluate the usefulness of feature sets based on the predictive performance of the algorithms. This means that they provide a better estimation of the final model performance [54]. Wrappers are much more computationally expensive than filter techniques (since they build and evaluate the entire predictive model in each iteration). This is the reason wrappers are usually not used in association with computationally demanding models such as SVMS.

In this study we used two popular and diverse strategies from this class Forward Selection and Backward elimination [55]. The Forward Selection operator starts with an empty selection of attributes and, in each round, it adds each unused attribute and evaluates it based on algorithm performance. Only the attribute giving the highest increase of performance is added to the selection. Then a new round is started with the modified selection. Backward elimination is based on the same strategy, but in opposite direction. It starts with the full set of attributes and, in each round, it removes each remaining attribute of the given ExampleSet.

Evolutionary Search (ES) for parameter optimization: is a generalization of a genetic algorithm inspired by the adaptation of many species to new-come problems. This adaptation searches for adequate solutions over a huge number of genotypes [56]. It is considered population-based, meta-heuristic using mechanisms inspired by biological evolution, such as reproduction, mutation, recombination, and selection. Solutions of the optimization problem, called candidates, represents individuals of a population, and the fitness function determines the quality of the solutions. Evolutionary algorithms often perform well in various types of optimization problems because they do not make any assumption about the underlying search space. Because of prior mentioned advantages and successful applications in many areas, Evolutionary Search (ES) is often used for SVM parameter optimization [57]. Basic parameters are: number of units in population, number of generations, crossover and selection scheme. As mentioned before, for the purpose of this study, ES for SVM parameter optimization was used (with default values provided by RapidMiner). 


\subsubsection{EXPERIMENTS AND RESULTS}

In this section, the process of data extraction, pre-processing and exploratory analysis are described. Furthermore, RapidMiner processes for automatic building of multiple predictive models, parameter optimization and feature selection are illustrated. Finally the results of the feature selection and classification models are evaluated.

\subsubsection{DATA EXTRACTION, PRE-PROCESSING AND EXPLORATORY ANALYSES}

Guided by the CRoss-Industry Standard Process for Data Mining (CRISP-DM), the ETL process started by retrieving data from the MIMIC-II tables of interest [34]. The database was accessed within RapidMiner by a running connection to the Hive server. The relational database of MIMIC-II consisted of of 38 tables. In this pilot, data was extracted from the following tables: LABEVENTS,D_LABITEMS, COMORBIDITY_ SCORES, ICUSTAY_DETAIL resulting in 3 data sets (Platelet Count, ICUdetail, Comorbidity) (Fig 1). Considering the entire database as baseline, the initial query reduced the data to a selection of 11944 admissions. For this purpose, RapidMiner Radoop was used for extracting the data from the cluster.

Attribute roles were defined (id, regular, label, etc) and example sets were joined using id attributes as key. The dataset used for modeling and feature weighting consisted of 70 attributes with icustay_expire_flg as label (Table 1). All data was filtered returning a data set including rows that fulfilled a predefined condition (ICU admission age $=$ adult; laboratory test: platelet count (itemid= 50428)) (Fig 1). Platelet count values were mapped to classes according to the following thresholds: normal platelet count 150-450 $\times 10^{9} / \mathrm{L}$; mild, moderate, severe and extreme thrombocythemia, respectively for platelet count values: $450-700 \times 10^{9} /$ L, $700-900 \times 10^{9} /$ L, $900-1000 \times 10^{9} /$ L, $>1000 \times 10^{9} / \mathrm{L}$; grade

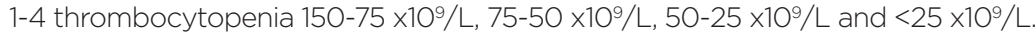

A total of 11944 ICU admissions satisfied our inclusion criteria. From the 11944 patients (age $>15$ years) admitted to ICU, ICU mortality was $11.5 \%(n=1378)$. Patients who survived ICU stay were significantly younger $(63.9 \pm 18.4$ years vs $70.3 \pm 16.2$ years; $\mathrm{p}<0.001)$ and and significantly more male patients survived ICU stay (57.0\% vs $50.7 \%$; $\mathrm{p}<0.0001)$. SAPS-1 and SOFA scores were significantly higher in the non-survivor group, respectively (13.9 \pm 4.7 vs $19.3 \pm 5.6$ and $5.4 \pm 3.4$ vs 9.6 \pm 4.5 ) (Table 2 ).

In the non-survivor group, significantly more patients suffered from renal failure, complicated diabetes, coagulopathy and liver disease. Mortality was higher for patients admitted on MICU and SICU. The prevalence of normal platelet count on ICU admission was $73.8 \%$. Low platelet count was observed in $12.5 \%, 2.3 \%, 1.2 \%$, $0.6 \%$ of the cases on admission, respectively for grade 1, 2, 3 and 4 thrombocytopenia. High platelet count was observed in 9.0\%, 0.3\%, 0.0\%, 0.3\% of the cases on admission respectively for mild, moderate, severe and extreme thrombocythemia. Mean platelet count on admission was $255.2 \pm 127.2 \times 10^{\%} / \mathrm{L}$. PLTO was significantly lower in nonsurvivors than in survivors $\left(238,2 \pm 132.4 \times 10^{9} / L ; 257.4 \pm 126.4 \times 10^{9} / L, p<0.001\right)$. Maximum and mean platelet count during ICU stay were significantly lower in non-survivors vs 
survivors, respectively $344.1 \pm 206.5 \times 10^{9} / L$ vs $469.3 \pm 227.4 \times 10^{9} / L$ and $212.4 \pm 117.0 \times 10^{\%} / L$ vs $249.8 \pm 111.6 \times 10^{9} / \mathrm{L}$. In the survivors, $74.4 \%$ of the patients had a normal platelet count. Low platelet count was observed in $11.9 \%, 2.2 \%, 1.0 \%, 0.5 \%$ of the cases on admission, respectively for grade 1, 2, 3 and 4 thrombocytopenia. High platelet count was observed in $9.4 \%, 0.3 \%, 0.0 \%, 0.3 \%$ of the cases on admission respectively for mild, moderate, severe and extreme thrombocythemia. The non-survivors, $68.6 \%$ of the patients resulted in a normal platelet count. Low platelet count was observed in $16.6 \%, 3.5 \%, 3.0 \%, 1.6 \%$ of the cases on admission, respectively for grade $1,2,3$ and 4 thrombocytopenia. High platelet count was observed in $6.4 \%, 0.6 \%, 0.0 \%$, $0.0 \%$ of the cases on admission respectively for mild, moderate, severe and extreme thrombocythemia.

\subsubsection{AUTOMATIC MODEL BUILDING, PARAMETER OPTIMIZATION AND EVALUATION}

The process for automatic building, parameter optimization and evaluation of multiple predictive models is illustrated in Fig 2. The upper left part of the figure illustrates the main process. In the main process, the data (Fig 1.) was extracted from the 3 data sets (Platelet count, Comorbidity, ICUdetail) and basic pre-processing was performed in a Sub-process operator. The final operator in the main process (Loop) was defined by a global variable (macro) iterating over a user defined interval. This allowed looping through multiple algorithms resulting in model building and evaluation in a single process execution. The inner operators of the Loop consisted of a Select Subprocess, Performance and Log. The Apply model took as an input the model provided from the Select Sub-process and holdout data that were forwarded from a previous process level.

When the model was applied, AUPRC (Area Under the Precision Recall Curve) values were calculated. Since currently RapidMiner does not provide AUPRC calculation within its Performance operator, we used the RapidMiner-R extension allowing incorporation of R scripts within the Execute-R operator, based on the PRROC R package [58]. In order to enable building and evaluation of multiple models in one process execution, the Select Sub-process operator, consisted of an inner operator structure that could be iteratively executed for user defined number of times. For the purpose of this paper, we defined 17 subprocesses, containing one predictive algorithm (middle layer of Fig 2). The execution order is controlled by the iteration macro, provided from the Loop operator.

Additionally, this process structure allowed parameter optimization if needed (e.g. for SVMs). As described before we implemented an Evolutionary algorithm for parameter optimization of SVMs (Fig 2: 2nd sub-process from left, layer 2).

Additionally to the first process, described in Fig 2, we developed two processes as an extension allowing automatic feature selection, model building and evaluation under various feature selection schemes (described in the Materials and Methods section) (Fig 3). 
In case of Wrapper techniques, the only difference with the previously described process is that we used ForwardSelection and BackwardElimination and embeded the part for model learning and evaluation (Select Sub-process, ApplyModel and Execute R) into them. On the output this resulted in one "optimal" feature set for each algorithm, which is further evaluated on the test-set.

In case of Filter techniques we wrapped the previously described process in an additional Loop operator (allowing automatic learning of each algorithm over each selected feature set). As mentioned before, the problem with Filter selection is the determination of the right (most adequate) threshold of feature weights and selection of number of features. So, for each algorithm and feature selection technique, we evaluated AUPRC performance based on thresholds that select from 5 to 45 attributes (variables) with step of $5[59,60]$. This was achieved by usage of the OptimizeParameters operator with Grid strategy, that evaluated all algorithms in the described range and returned the optimal number of parameters. This process demonstrated the robustness and ease of implementation of a relatively complex experimental setups in RapidMiner (this process automatically executes 672 experiments: 14 algorithms $X 6$ feature selection schemes $X 8$ thresholds). Since optimization of parameters for SVM model fitting is computationally very demanding, we excluded them from the experiments with different feature selection techniques (they are evaluated only on the complete set of features). In case rbf-SVM we optimized $\gamma$ (kernel width) in range between 0.001 to 2 and $C$ between $10^{-9}$ to 105 as suggested in [61]. In case of linear SVMs, only C is optimized in the same parameter range. As an optimization technique, we used Evolutionary Search for parameter optimization (part of standard RapidMiner package) with 10 generations and 10 population size. All other parameters were fixed to their default values.

\section{Evaluation}

All evaluations reported in this paper are based on holdout (test) set created by stratified sampling meaning that the initial distribution of positive and negative classes of the target attribute are preserved. Experiments including some type of optimization (parameters or feature sets), sensitive for overfitting and reduced generalization of predictive models, are cross-validated on training sets (70\% of initial data). Because of the unbalanced nature of data we calculated AUPRC (Area Under the Precision Recall Curve) values as evaluation parameter for model comparison. Other parameters, frequently published in this respect, such as AUC (Area Under the ROC Curve) and Accuracy are independent of class size ratios, but often provide misleading results in unbalanced data scenarios $[59,60]$. AUPRC measured the fraction of negatives misclassified as positives and resulting in a plot representing precision (TP/(TP+FP)) vs. recall ratio (this is TPR, sometimes referred to as sensitivity)(TP: True Positive, FP: False Positive, TPR: True Positive Ratio). By varying the threshold, the precision can be calculated at the threshold that achieves that recall ratio. AUPRC is a less forgiving measure, and a high value indicates that a classification model makes very few mistakes. 


\section{Performance and Feature Selection}

All experimental results are summarized in Table 3. AUPRC performance and the number of features involved in model building (in brackets) are showed for each model (rows) and feature selection technique (columns). In bold, the best AUPRC performances for each row are provided, revealing the best feature selection method for each model. Based on these results, the Random Forest (RF) was the dominant modeling technique (provided by the best performance for each feature selection schema and for the entire feature set). The best result in terms of AUPRC (AUPRC $=0.764$ ) was achieved associating Random Forest (RF) and Backward Elimination (BE) technique (Fig 4). It is interesting to observe that BE removed only one feature (icustay_first_service $=$ CSRU) resulting in an increased model performance from 0.743 to 0.764 . Further inspection of the results revealed that all other feature selection techniques put this feature above the 30th rank (in a total of 70 features). Furthermore, it should be noticed that by using Random Forest, there are three other, valuable feature selection techniques with respect to AUPRC values and the number of features. Namely, in association with Forward selection (FS), Random Forest (RF) resulted in AUPRC values of 0.744 (with 8 features). Random Forest in association with Correlation and Gini Selection resulted in AUPRC values of 0.734 with only 5 features. (sofa_max, sofa min, sapsi max, sofa first, sapsi min). From a medical perspective, the selection of these 5 features is no surprise because SOFA and SAPS values, as severity of disease classification, are intrinsic related to other parameters [30, 31]. Forward Selection resulted in similar features (except for sapsi_max) but added diabetes_uncomplicated, icustay_first_careunit=CSRU, weight_min and PLTmean to its selection.

Precision (the number of selected attributes that are relevant) and recall (the number of relevant attributes that are selected) have an inverse relationship providing the option to increase one at the cost of reducing the other (Fig 4).

In terms of feature selection, all methods provided similar performance over the models, except for the t-test resulting in a maximum AUPRC in association with Random Forest (RF) of 0.341 with all others values below 0.19 .

Closer inspection of the 5 most important features based on the filter selection methods, the sofa max score was ranked first (3 times) and ranked second (once). Only the t-test method provided a very low ranking for the sofa_max score (63rd rank). As already mentioned, this test resulted in an overall poor performance. Congestive heart_failure and diabetes_complicated were also first ranked once (congestive_heart failure was also ranked on a 4th place once). On second place, popularly ranked were sofa min (3 times), sofa_max, hypertension, on the third place: hypertension (once), sapsi_max, icustay_last_service=FICU, sapsi_max (3 times), on the fourth place: icu stay_lastservice $=C C U$, sofa first (twice), weight_first and finally on fifth place: chronic_ pulmonary, reumathoid_arthritis, sapsi_min (twice) and weight max.

Since this paper identified patients based on survival, it is preferable for the determination of thresholds, to keep recall high (Fig 4), taking in to account not to make most of the predictions false alarms. Based on our results, with recall values on $>=0.8$ the model providing the best precision values for that recall value could be recommended. 


\subsubsection{DISCUSSION}

This pilot study, is the first report presenting the integration of the MIMIC-II database in RapidMiner data mining technology (Fig 1) and demonstrated the modalities of a code free environment for building complex, automated processes in scalable environment.

Data selection from the MIMIC-II database resulted in 70 attributes which covered basically the features previously validated as relevant in relation to outcome survival on ICU. Moreover, platelet counts were added to this selection. Based on the modeling and feature selection processes, the associating of Random Forest (RF) and Backward Elimination (BE) resulted in the best AUPRC values. Additionally, the combination of Random Forest (RF) with Correlation, Gini Selection and Forward Selection resulted in higher AUPRC values. It was no coincidence finding SAPS and SOFA scores highly ranked as they were already validated as disease severity scores. Interestingly, Random Forest (RF) and Forward Selection also retained PLTmean in its selection. In the future, a similar modeling and feature selection procedure could be used implementing features with no, unknown or minimal interdependency. This technique could then provide medical and financial liability for the use of existing and the implementation of new features resulting from laboratory tests or monitoring devices. Additionally, this approach could provide more understanding how important certain features are in relation to the clinical context they are used in.

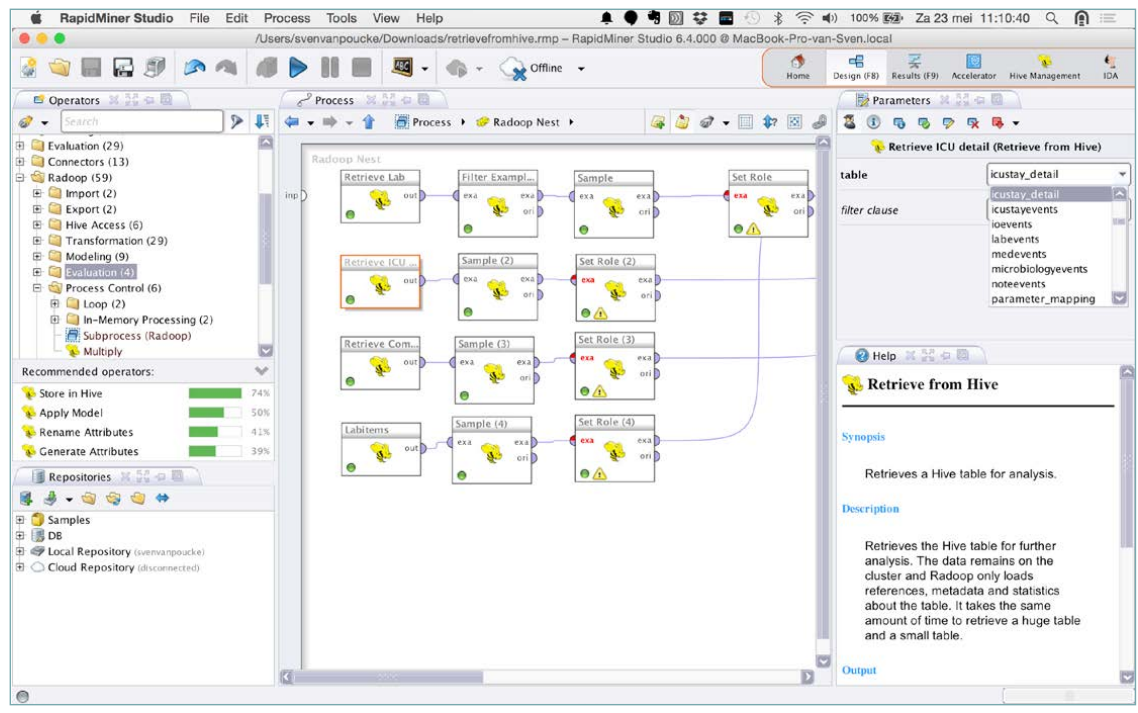

Figure 1: illustration of integration of the MIMIC-II database in a Hadoop/RapidMiner computer cluster: data retrieval and preprocessing. 
The presented deployment offered an access to all MIMIC-II data, also for the noncoding scientist community. Our results demonstrated the predictive value of platelet count in the survival of ICU patients. Additionally, changing data input by selecting data from tables of interest and changing modeling and feature selection operators result in other survival predictions.

Although there are other clinical databases available for research in critical care medicine, the MIMIC-II and recently the MIMIC-III database, is currently one of the largest clinical databases able to provide high resolution clinical information [61]. Recently, the MIMIC-III database is introduced with an update of patient data and a more efficient database architecture.

\begin{tabular}{|c|c|c|c|c|}
\hline Characteristics & $\begin{array}{l}\text { Population } \\
(n=11944)\end{array}$ & Survivors $(n=10566)$ & $\begin{array}{l}\text { Non-survivors } \\
\quad(n=1378)\end{array}$ & $p$ \\
\hline Age (years) & $63.2 \pm 18.6$ & $63.9 \pm 18.4$ & $70.3 \pm 16.2$ & $<0.0001$ \\
\hline Sex (male, \%) & - & 6025 (57.0\%) & $578(50.7 \%)$ & $<0.0001$ \\
\hline SAPS-1 on admission & $14.7 \pm 4.5$ & $13.9 \pm 4.7$ & $19.3 \pm 5.6$ & $<0.0001$ \\
\hline SOFA on admission & $6.0 \pm 3.6$ & $5.4 \pm 3.4$ & $9.6 \pm 4.5$ & $<0.0001$ \\
\hline \multicolumn{5}{|l|}{ Comorbidity $(n, \%)$} \\
\hline Congestive heart failure & - & 3263 (30.9\%) & $420(30.5 \%)$ & $=0.766$ \\
\hline Paralysis & - & $115(1.1 \%)$ & $13(0.9 \%)$ & $=0.672$ \\
\hline Renal failure & - & $1738(16.4 \%)$ & $131(9.5 \%)$ & $<0.0001$ \\
\hline Uncomplicated diabetes & - & $2258(21.4 \%)$ & $258(13.7 \%)$ & $=0.015$ \\
\hline Complicated diabetes & - & $2658(25.2 \%)$ & $59(4,2 \%)$ & $<0.0001$ \\
\hline Coagulopathy & - & $765(7.2 \%)$ & $144(10.4 \%)$ & $<0.0001$ \\
\hline AIDS & - & $80(0.8 \%)$ & $9(0.7 \%)$ & $=0.667$ \\
\hline $\begin{array}{l}\text { Chronic pulmonary } \\
\text { disease }\end{array}$ & - & $2437(23.1 \%)$ & $262(19,0 \%)$ & $=0.008$ \\
\hline Obesity & - & $92(0.9 \%)$ & $8(0.6 \%)$ & $=0.269$ \\
\hline Liver disease & - & $471(4.5 \%)$ & $103(7.5 \%)$ & $<0.0001$ \\
\hline \multicolumn{5}{|l|}{ Types of care unit (n, \%) } \\
\hline $\mathrm{CCU}$ & - & $2054(19.4 \%)$ & $304(22.1 \%)$ & $=0.751$ \\
\hline CSRU & - & $2804(26.5 \%)$ & $306(22.2 \%)$ & $=0.02$ \\
\hline $\mathrm{MICU}$ & - & $63.9 \pm 18.4$ & $528(38.3 \%)$ & $<0.0001$ \\
\hline SICU & - & $181(1.7 \%)$ & $56(4.1 \%)$ & $<0.0001$ \\
\hline \multicolumn{5}{|l|}{ Platelet count (x 10\%/L) } \\
\hline PLTO & $255.2 \pm 127.2$ & $257.4 \pm 126.4$ & $238,2 \pm 132.4$ & $<0.0001$ \\
\hline PLTmax & $454.9 \pm 228.6$ & $469.3 \pm 227.4$ & $344.1 \pm 206.5$ & $<0.0001$ \\
\hline PLTmin & $122.9 \pm 84.8$ & $122.4 \pm 83.9$ & $126.9 \pm 91.7$ & $=0,666$ \\
\hline PLTmean & $245.5 \pm 112.9$ & $249.8 \pm 111.6$ & $212.4 \pm 117.0$ & $<0.0001$ \\
\hline
\end{tabular}

Table 2: Characteristics of intensive care units survivors and non-survivors. 
The advantage of using this type of databases is the representation of a "real world" setting in which no strict study protocol has been performed in collecting data. Indeed, many interventional trials have been criticized for its strict inclusion and exclusion criteria [61]. Although a web-based QueryBuilder and Virtual Machine image of the MIMIC-II database are available, with clinical researchers rarely achieving the required expertise in SQL [62], the database is underemployed. The RapidMiner platform has a code-free $\mathrm{UI}$ and is available both in the cloud and as an open-source client/server platform. With a platform including more than 1,500 methods across all stages of the predictive analytics life cycle, RapidMiner has the breadth and flexibility adapted to the researchers' need to consume data. RapidMiner helps reduce timeto-insights and guide best practices for data analysts, analyzing the behavior of their users to create "wisdom of the crowds" guidance. A report by Gartner, reviewed 16 analytics and data science firms over 10 criteria, based on completeness of vision and ability to execute data [8]. SAS, IBM, KNIME, and RapidMiner lead in Gartner 2015 Magic Quadrant for Advanced Analytics Platforms.

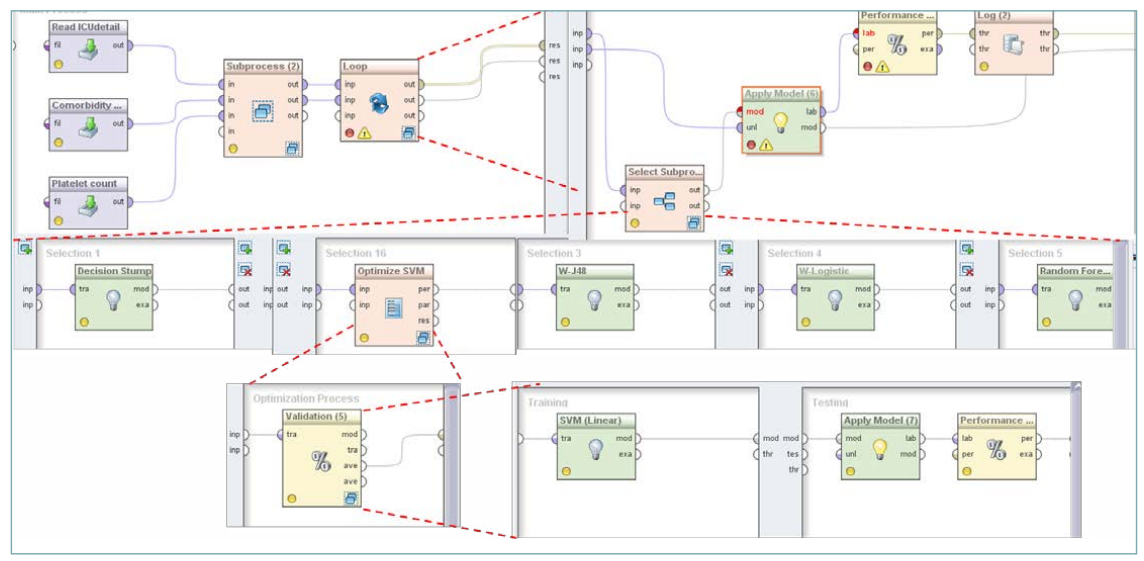

Figure 2: Basic process for automatic building, parameter optimizaton and evaluation of multiple predictive models as displayed in RapidMiner. 
Data mining on ICU-patient data opens opportunities enabling modeling with classification, evaluating predictive accuracy of models, visualizing the performance of models using lift charts and ROC charts, and finally ranking patients by the predicted confidence for a clinical decision in order to select the best candidates for a therapy. Several limitations need to be acknowledged. First, the study is retrospective and bears potential limitations of such design. For instance, patients without platelet count measured during ICU stay were excluded from the analysis, this may be responsible for bias because the included cohort does not represent the whole study population. However, included and excluded cohorts are similar in many clinical characteristics (data not shown), making our cohort representative of the target population. Second, ICU patients were heterogeneous including medical, surgical and cardiac surgical patients, whether narrowing study population will improve the prognostic value of platelet count for survival requires further investigations. Third, although every effort has been made to adjust for the confounding factors by using multivariate analysis, other unknown factors may still exist to confound the prognostic value of platelet count. The authors used ICU mortality instead of the more commonly used ones such as 28-day and 90-day mortality as the study endpoint. This is because data after ICU discharge are not directly available in the MIMIC-II database [63].

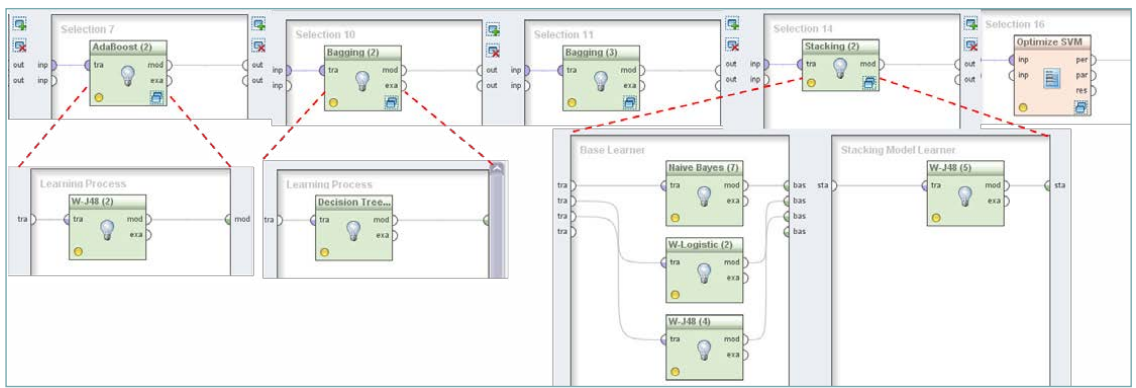

Figure 3: illustration of the ensemble learning methods as displayed in RapidMiner (Decision Stump, AdaBoost, Random Forest, Bagging, W-J48, Decision Tree, Naive Bayes, Stacking, Logistic Regression, Support Vector Machine) 


\subsubsection{CONCLUSION}

This paper reports the integration of the MIMIC-II database in RapidMiner, enabling scalable predictive analysis of clinical data from critically ill patients in a visual, code free environment. The major benefit from the proposed integration is seamless manipulation, data extraction, preprocessing and predictive analytics of huge amounts of data, using visual tools without the need for writing a single line of code. As such this system has the potential to put cutting edge analytical tools into the hands of medical domain experts, eventually bridging the gap between potential and actual usage of medical data. This approach enables the development of Digital Research Environments (DRE) including data lakes (large object-based storage repositories that holds data in its native format until it is needed) becoming attractive platforms in research facilities around the world. As a showcase of the proposed environment we demonstrated a prognostic value of platelet count in critically ill patients, by defining several processes for automatic building of multiple models, parameter optimization, feature selection and model evaluation. These processes are robust and flexible enough to provide fast and effective research in a variety of clinical research questions with minimal adoptions. The authors did not have the intention to provide any clinical relevance of the value of platelet counts on admission in relation to survival on ICU.
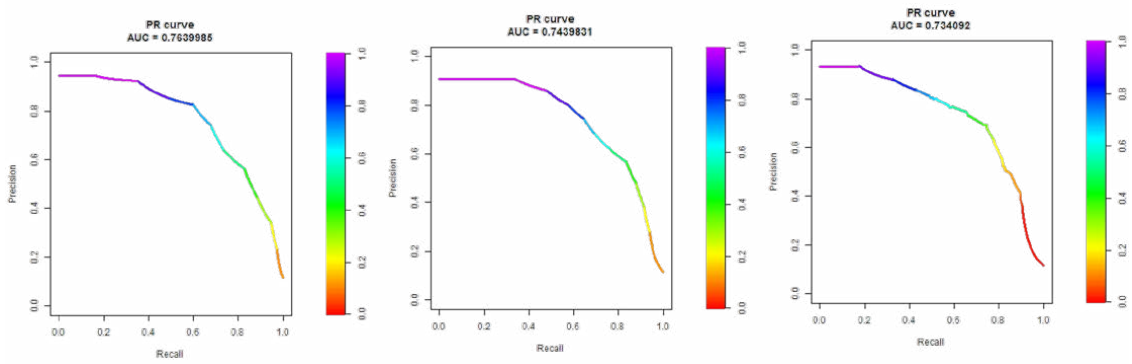

Figure 4: AUPRC curves for the 3 best models as discussed in this paper. Random Forest (RF) in association with Backward Selection (BS) and 69 features (left), with Forward Selection (FS) and 8 features (middle) and Gini Selection (GS) and 5 features. 


\subsubsection{REFERENCES}

1. Van Poucke S, Thomeer M, Hadzic A. 2015, Big data in healthcare: for whom the bell tolls? Crit Care. 2015;19(1): 2013-4.

2. Ghassemi M, Celi LA, Stone DJ. State of the art review: the data revolution in critical care. Crit Care. 2015;19(1).

3. Mohammadzadeh N, Safdari R, Baraani A, Mohammadzadeh F. Intelligent data analysis: the best approach for chronic heart failure (CHF) follow up management. Acta Inform Med. 2014; 22(4): 263-7.

4. Golubnitschaja O, Kinkorova J, Costigliola V. Predictive, Preventive and Personalised Medicine as the hardcore of "Horizon 2020": EPMA position paper. EPMA J. 2014;5(1):6.

5. Koliopoulos AK, Yiapanis P, Tekiner F, Nenadic G, Keane J. A Parallel Distributed Weka Framework for Big Data Mining using Spark. Big Data (BigData Congress), 2015 IEEE International Congress on. IEEE. 2015: 9-16.

6. Wimmer H, Powell LM. A comparison of open source tools for sentiment analysis. 2015;1-9. Available from: http://fotiad.is/blog/sentiment-analysis-comparison/

7. Jovic, A, Brkic K, Bogunovic N. An overview of free software tools for general data mining. Information and Communication Technology, Electronics and Microelectronics (MIPRO), 2014 37th International Convention on. IEEE. 2014: 1112-1117.

8. Herschel G, Linden A, Kart L. Magic quadrant for advanced analytics platforms. Available from: http://www.gartner.com/technology/reprints.do?id=1-2A881DN\&ct=150219\&st=sb

9. Landset S, Khoshgoftaar TM, Richter AN, Hasanin T. A survey of open source tools for machine learning with big data in the Hadoop ecosystem. J Big Data [Internet]. Springer International Publishing; 2015;2(1):24.

10. Dean J, Ghemawat S. MapReduce : Simplified Data Processing on Large Clusters. Commun ACM [Internet]. 2008;51(1):1-13.

11. Apache Hadoop. http://hadoop.apache.org/

12. Thusoo A, Sarma JS, Jain N, Shao Z, Chakka P, N. Z. O002, Anthony S, Liu H, Murthy R. Hive - a petabyte scale data warehouse using Hadoop. In F. Li, M. M. Moro, S. Ghandeharizadeh, J. R. Haritsa, G. Weikum, M. J. Carey, F. Casati, E. Y. Chang, I. Manolescu, S. Mehrotra, U. Dayal, and V. J. Tsotras, editors, Proceedings of the 26th International Conference on Data Engineering, ICDE 2010, March 1-6, 2010, Long Beach, California, USA, pages 996-1005. IEEE. 2010.

13. Vavilapalli VK, Murthy AC, Douglas C, Agarwali S, Konar M, Evans R, et al. Apache Hadoop YARN : Yet Another Resource Negotiator. ACM Symp Cloud Comput [Internet]. 2013;16.

14. Olston C, Reed B, Srivastava U, Kumar R, Tomkins A. Pig Latin: A Not-So-Foreign Language for Data Processing. Proc 2008 ACM SIGMOD Int Conf Manag data - SIGMOD '08. 2008;1099.

15. Apache Mahout. http://mahout.apache.org/.

16. Sparks ER, Talwalkar A, Smith V, Kottalam J, Pan X, Gonzalez J, et al. MLI: An API for Distributed Machine Learning. 13th IEEE International Conference on Data Mining [Internet]. 2013. p. 1187-92.

17. Zaharia M, Chowdhury M, Das T, Dave A. Fast and interactive analytics over Hadoop data with Spark. USENIX Login. 2012;37(4):45-51. 
18. Ni Z. Comparative Evaluation of Spark and Stratosphere. Thesis, KTH Royal Institute of Technology; 2013

19. MLib. https://spark.apache.org/mllib/

20. Zheng J, Dagnino A. An initial study of predictive machine learning analytics on large volumes of historical data for power system applications. In: 2014 IEEE International Conference on Big Data. 2014. 952-59.

21. Katsipoulakis NR, Tian Y, Reinwald B, Pirahesh H. A Generic Solution to Integrate SQL and Analytics for Big Data. In: 18th International Conference on Extending Database Technology (EDBT). 2015. 671-6.

22. SparkR. http://amplab-extras.github.io/SparkR-pkg/.

23. PySpark. https://spark.apache.org/docs/0.9.0/python-programming-guide.html.

24. Ritthoff $O$, Klinkenberg R, Fisher S, Mierswa I, Felske S. YALE: Yet Another Learning Environment. LLWA'O1 - Tagungsband der Gl-Workshop-Woche Lernen- Lehren Wissen Adaptivitat. University of Dortmund, Dortmund, Germany. Technical Report 763. 2001: 84-92.

25. Hall M. Weka and Hadoop. 2013. Available: http://markahall.blogspot.co.uk/2013/10/weka-and-hadooppart-1.html/

26. Berthold MR, Cebron N, Dill F, Gabriel TR, Kötter T, Meinl T, et al. KNIME: The Konstanz Information Miner. In Preisach C, Burkhardt H, Schmidt-Thieme L, Decker R, editors. Data Analysis, Machine Learning and Applications (Studies in Classification, Data Analysis, and Knowledge Organization). Berlin Heidelberg: Springer.2008. 319-326.

27. Saeed M, Villarroel M, Reisner AT, Clifford G, Lehman L, Moody GB, Heldt T, Kyaw TH, Moody TE, Mark RG. Multiparameter intelligent monitoring in intensive care II (MIMIC-II): A public-access ICU database. Crit Care Med. 2011;39(5): 952-960.

28. Goldberger AL, Amaral LAN, Glass L, Hausdorff JM, Ch P, Mark RG, et al. PhysioBank, PhysioToolkit, and PhysioNet. Circulation. 2000;101(23): E215-20.

29. Le Gall JR, Loirat P, et al. A simplified acute physiology score for ICU patients. Crit Care Med. 1984;12: 975-977.

30. Le Gall JR, Lemeshow S, Saulnier F. A new Simplified Acute Physiology Score (SAPS II) based on a European/North American Multicenter Study. JAMA. 1993;270: 2957-2963

31. Vincent JL, de Mendonça A, Cantraine F, Moreno R et al. Use of the SOFA score to assess the incidence of organ dysfunction/failure in intensive care units: results of a multicenter, prospective study. Working group on "sepsis-related problems" of the European Society of Intensive Care Medicine. Crit Care Med. 1998; 26:1793-1800.

32. Dean J, Ghemawat S. MapReduce : Simplified data processing on large clusters. Communications of the ACM - 50th anniversary issue: 1958 - 2008 [Internet]. 2008;51(1): 1-13.

33. Mohammed EA, Far BH, Naugler C. Applications of the MapReduce programming framework to clinical big data analysis: current landscape and future trends. BioData Min [Internet]. 2014;7(1): 1-23.

34. Shearer C. The CRISP-DM model: the new blueprint for data mining. J Data Warehousing. 2000; 5:13-22.

35. Russell S, Norvig P. Artificial intelligence: a modern approach. 2nd ed. Prentice Hall Series; 2003. 
36. Rish I. An empirical study of the naive bayes classifier. In: IJCAI 2001 Workshop on empirical methods in artificial intelligence; 2001: 41-66.

37. Wolfson J, Bandyopadhyay S, Elidrisi M, Vazquez-Benitez G, Musgrove D, Adomavicius $G$, et al. A Naive Bayes machine learning approach to risk prediction using censored, time-to-event data. ARXIV [Internet]. 2014; Apr 8.

38. Hand DJ, Yu K. Idiot's Bayes - not so stupid after all? International Statistical Review. 2001; 69 (3): 385-398.

39. Chao CM, Yu YW, Cheng BW, \& Kuo YL. Construction the model on the breast cancer survival analysis use support vector machine, logistic regression and decision tree. J Med Syst. 2014; 38(10): 1-7.

40. Ting H, Mai YT, Hsu HC, Wu HC, \& Tseng MH.. Decision tree based diagnostic system for moderate to severe obstructive sleep apnea. J Med Syst. 2014;38(9):1-10.

41. Quinlan JR. Induction of Decision Trees. Machine Learning. 1986; 1: 81-106.

42. Hastie T, Tibshirani R, Friedman J, Franklin J. The elements of statistical learning: data mining, inference and prediction. Math Intell. 2005;27:83-5.

43. Druss BG, Marcus SC, Rosenheck RA, Olfson M, Tanielian T, \& Pincus HA. Understanding disability in mental and general medical conditions. Am J Psychiatry. 2000;157(9):1485-91.

44. Radovanovic, S, Vukicevic, M, Kovacevic, A, Sliglic, G, Obradovic, Z (2015) Domain knowledge based hierarchical feature selection for 30-day hospital readmission prediction. Proceedings of the 15th Conference on Artificial Intelligence in Medicine; 2015 June 17-20; Pavia, Italy.

45. Post RM, Altshuler L, Leverich, GS, Frye MA, Suppes T, McElroy SL et al. Relationship of clinical course of illness variables to medical comorbidities in 900 adult outpatients with bipolar disorder. Compr Psychiatry. 2015; 56: 21-28.

46. Chang CC, Lin CJ. LIBSVM : a library for support vector machines. ACM TIST. 2011;2(3):1-27.

47. Cortes C, Vapnik V. Support vector networks. Machine Learning. 1995;20: 273-297.

48. Kuncheva LI, Whitaker CJ. Measures of diversity in classifier ensembles. Machine Learning. 2003;51: 181-207.

49. Breiman L. Random Forests. Machine Learning. 2001;45:5-32. Available from: http://link.springer.com/article/10.1023\%2FA\%3A1010933404324

50. Freund Y, Schapire R, Abe N. A short introduction to boosting. Journal of JSAl.1999; 14(5): 771-780. Available from: http://cseweb.ucsd.edu/ yfreund/papers/IntroToBoosting.pdf

51. Breiman L. Bagging predictors. Machine Learning. 1999;24(2):123-140. Available from: http://link.springer.com/article/10.1023\%2FA\%3A1018054314350

52. Breiman, L. Stacked regressions. Machine learning. 1996;24(1):49-64. Available from: http://link.springer.com/article/10.1007\%2FBF00117832

53. Kononenko I. Estimating Attributes: Analysis and Extensions of RELIEF. In: European Conference on Machine Learning, 171-182, 1994. Available from: http://link.springer.com/chapter/10.1007\%2F3-540-57868-4_57.

54. Kohavi R, John GH. Wrappers for feature subset selection. Artificial Intelligence. 1997; 97(1): 273-324. DOI=http://dx.doi.org/10.1016/S0004-3702(97)00043-X.

55. Mao KZ. Orthogonal forward selection and backward elimination algorithms for feature subset selection. Systems, Man, and Cybernetics, Part B: Cybernetics, IEEE Transactions on. 2004; 34(1): 629-634. 
56. Goldberg DE. Genetic algorithms in search, optimization, and machine learning.1st Ed.Boston: Addison-Wesley Longman; 1989.

57. Friedrichs F, Igel C. Evolutionary tuning of multiple SVM parameters. Neurocomputing. 2005; 64:107-117.

58. Grau J, Keilwagen J. Precision-Recall and ROC Curves for Weighted and Unweighted Data; 2015. Repository: CRAN package repository [Internet].

Available from: https://cran.r-project.org/web/packages/PRROC/PRROC.pdf

59. Riley, RD, Ahmed I, Debray TPA, Willis BH, Noordzij JP, Higgins JPT, Deeks J. Summarising and validating test accuracy results across multiple studies for use in clinical practice. Statist. Med. 2015;34(13):1097-0258.

60. Davis J, Goadrich M. The relationship between Precision-Recall and ROC curves. In Proceedings of the 23rd international conference on Machine learning (ICML 2006). ACM, New York, NY, USA, 233-240.

61. Kamkar I, Gupta SK, Phung D, Venkatesh S. Stable feature selection for clinical prediction: Exploiting ICD tree structure using Tree-Lasso. J Biomed Inform. 2015;53: 277-290.

62. Zhang Z, Xu X, Ni H, Deng $\mathrm{H}$. Predictive value of ionized calcium in critically ill patients: An analysis of a large clinical database MIMIC II. PLoS ONE. 2014;9(4): e95204.

63. Scott DJ, Lee J, Silva I, Park S, Moody GB, Celi LA, et al. Accessing the public MIMIC-II intensive care relational database for clinical research. BMC Med Inform Decis Mak [Internet]. 2013 Jan;13(1): 9.

\section{Acknowledgments}

LAC is funded by the National Institutes of Health (NIH) through National Institute of Biomedical Imaging and Bioengineering grant R01 EB017205-01A1. This research is partially funded by SNSF Joint Research project (SCOPES), ID: IZ73ZO_152415. Access, licenses and support for Hadoop/Hive are provided by Vancis B.V. (Amsterdam, NL) and Xomnia B.V. (Amsterdam, NL).

Licenses for RapidMiner/Radoop are provided by RapidMiner (Cambridge, MA, USA).

RapidMiner (RapidMinerAcademia) provided a free use of the commercial version of its platform to researchers and other academics at educational institutions. 
Table 1: Attributes selected for modeling and feature selection (weighting)

\section{Attributes (alphabetical order)}

aids

alcohol_abuse
blood_loss_anemia
cardiac_arrhythmias
chronic_pulmonary
coagulopathy
congestive_heart_failure
deficiency_anemias
depression
diabetes_complicated
diabetes_uncomplicated
drug_abuse
fluid_electrolyte
gender = F
gender = M
height

hypertension

hypothyroidism
icustay_first_careunit $=\mathrm{CCU}$
icustay_first_careunit $=\mathrm{CSRU}$
icustay_first_careunit $=\mathrm{FICU}$
icustay_first_careunit $=\mathrm{MICU}$
icustay_first_careunit $=\mathrm{NICU}$
icustay_first_careunit $=\mathrm{SICU}$
icustay_first_service $=\mathrm{CCU}$
icustay_first_service $=\mathrm{CSRU}$
icustay_first_service $=\mathrm{FICU}$
icustay_first_service $=\mathrm{MICU}$
icustay_first_service $=\mathrm{NICU}$
icustay_first_service $=$ SICU
icustay_last_careunit $=\mathrm{CCU}$
icustay_last_careunit $=\mathrm{CSRU}$
icustay_last_careunit $=\mathrm{FICU}$
icustay_last_careunit $=\mathrm{MICU}$
icustay_last_careunit $=\mathrm{NICU}$

icustay last careunit $=\mathrm{SICU}$

icustay_last_service $=\mathrm{CCU}$

icustay_last_service $=$ CSRU

icustay_last_service $=$ FICU

icustay_last_service $=$ MICU

icustay_last_service $=$ NICU

icustay_last_service $=$ SICU

liver_disease

Iymphoma

metastatic_cancer

obesity

other_neurological

paralysis

peptic_ulcer

peripheral_vascular

PLTO

PLTmax

PLTmean

PLTmin

psychoses

pulmonary_circulation

renal_failure

rheumatoid_arthritis

sapsi_first

sapsi_max

sapsi_min

sofa_first

sofa_max

sofa_min

solid_tumor

valvular_disease

weight_first

weight_loss

weight_max

weight_min 
Table 2: Characteristics of intensive care units survivors and non-survivors.

\begin{tabular}{|c|c|c|c|c|}
\hline Characteristics & $\begin{array}{l}\text { Population } \\
(n=11944)\end{array}$ & Survivors (n=10566) & $\begin{array}{c}\text { Non-survivors } \\
\quad(n=1378)\end{array}$ & $p$ \\
\hline Age (years) & $63.2 \pm 18.6$ & $63.9 \pm 18.4$ & $70.3 \pm 16.2$ & $<0.0001$ \\
\hline Sex (male, \%) & - & $6025(57.0 \%)$ & $578(50.7 \%)$ & $<0.0001$ \\
\hline SAPS-1 on admission & $14.7 \pm 4.5$ & $13.9 \pm 4.7$ & $19.3 \pm 5.6$ & $<0.0001$ \\
\hline SOFA on admission & $6.0 \pm 3.6$ & $5.4 \pm 3.4$ & $9.6 \pm 4.5$ & $<0.0001$ \\
\hline \multicolumn{5}{|l|}{ Comorbidity (n, \%) } \\
\hline Congestive heart failure & - & 3263 (30.9\%) & $420(30.5 \%)$ & $=0.766$ \\
\hline Paralysis & - & $115(1.1 \%)$ & $13(0.9 \%)$ & $=0.672$ \\
\hline Renal failure & - & $1738(16.4 \%)$ & $131(9.5 \%)$ & $<0.0001$ \\
\hline Uncomplicated diabetes & - & $2258(21.4 \%)$ & $258(13.7 \%)$ & $=0.015$ \\
\hline Complicated diabetes & - & $2658(25.2 \%)$ & $59(4,2 \%)$ & $<0.0001$ \\
\hline Coagulopathy & - & $765(7.2 \%)$ & $144(10.4 \%)$ & $<0.0001$ \\
\hline AIDS & - & $80(0.8 \%)$ & $9(0.7 \%)$ & $=0.667$ \\
\hline $\begin{array}{l}\text { Chronic pulmonary } \\
\text { disease }\end{array}$ & - & $2437(23.1 \%)$ & $262(19,0 \%)$ & $=0.008$ \\
\hline Obesity & - & $92(0.9 \%)$ & $8(0.6 \%)$ & $=0.269$ \\
\hline Liver disease & - & $471(4.5 \%)$ & $103(7.5 \%)$ & $<0.0001$ \\
\hline \multicolumn{5}{|l|}{ Types of care unit $(n, \%)$} \\
\hline $\mathrm{CCU}$ & - & $2054(19.4 \%)$ & $304(22.1 \%)$ & $=0.751$ \\
\hline CSRU & - & $2804(26.5 \%)$ & $306(22.2 \%)$ & $=0.02$ \\
\hline MICU & - & $63.9 \pm 18.4$ & $528(38.3 \%)$ & $<0.0001$ \\
\hline SICU & - & $181(1.7 \%)$ & $56(4.1 \%)$ & $<0.0001$ \\
\hline \multicolumn{5}{|l|}{ Platelet count (x 10\%/L) } \\
\hline PLTO & $255.2 \pm 127.2$ & $257.4 \pm 126.4$ & $238,2 \pm 132.4$ & $<0.0001$ \\
\hline PLTmax & $454.9 \pm 228.6$ & $469.3 \pm 227.4$ & $344.1 \pm 206.5$ & $<0.0001$ \\
\hline PLTmin & $122.9 \pm 84.8$ & $122.4 \pm 83.9$ & $126.9 \pm 91.7$ & $=0,666$ \\
\hline PLTmean & $245.5 \pm 112.9$ & $249.8 \pm 111.6$ & $212.4 \pm 117.0$ & $<0.0001$ \\
\hline
\end{tabular}


Table 3: AUPRC (Area Under the Precision Recall Curve) performance and the number of features involved in model building (in brackets) are showed for each model (rows) and feature selection technique (columns). In bold, the best AUPRC performances for each row are illustrated, revealing the best feature selection method for each model.

\begin{tabular}{|c|c|c|c|c|c|c|c|c|}
\hline $\begin{array}{l}\text { Algorithm/ } \\
\text { Feature } \\
\text { selection }\end{array}$ & $\begin{array}{c}\text { No } \\
\text { feature } \\
\text { selection }\end{array}$ & $\begin{array}{l}\text { Information } \\
\text { gain }\end{array}$ & ReliefF & Correlation & Gini & T-test & $\begin{array}{l}\text { Forward } \\
\text { selection }\end{array}$ & $\begin{array}{l}\text { Backward } \\
\text { selection }\end{array}$ \\
\hline $\begin{array}{l}\text { RM- Decision } \\
\text { Stump }\end{array}$ & 0.275 & $0.282(5)$ & $0.282(5)$ & $0.282(5)$ & $0.282(5)$ & $0.115(30)$ & $0.358(1)$ & 0.275 (69) \\
\hline$J 48$ & 0.448 & $0.537(5)$ & $0.484(5)$ & $0.593(5)$ & $0.593(5)$ & $0.115(15)$ & $0.575(8)$ & $0.454(67)$ \\
\hline Naïve Bayes & 0.435 & $0.593(5)$ & $0.553(10)$ & $0.573(5)$ & $0.569(5)$ & $0.125(35)$ & $0.588(20)$ & $0.623(26)$ \\
\hline $\begin{array}{l}\text { Logistic } \\
\text { Regression }\end{array}$ & 0.687 & 0.607 (5) & $0.664(15)$ & $0.629(5)$ & $0.629(5)$ & $0.19(45)$ & $0.664(32)$ & 0.692 (57) \\
\hline Random Forest & 0.743 & $0.707(5)$ & $0.732(15)$ & $0.734(5)$ & $0.734(5)$ & $0.341(45)$ & $0.744(8)$ & $0.764(69)$ \\
\hline AdaBoost-J48 & 0.668 & $0.628(5)$ & $0.500(5)$ & $0.654(5)$ & $0.654(5)$ & $0.127(5)$ & $0.637(6)$ & $0.661(69)$ \\
\hline AdaBoost-NB & 0.555 & $0.515(10)$ & $0.519(20)$ & $0.499(20)$ & $0.475(10)$ & $0.142(40)$ & $0.433(4)$ & $0.661(69)$ \\
\hline AdaBoost-LR & 0.432 & $0.575(20)$ & $0.571(25)$ & $0.565(15)$ & $0.555(15)$ & $0.174(45)$ & $0.384(16)$ & $0.534(68)$ \\
\hline Bagging-J48 & 0.494 & $0.501(5)$ & $0.511(10)$ & $0.530(5)$ & $0.530(5)$ & $0.115(10)$ & $0.525(5)$ & $0.436(67)$ \\
\hline Bagging-NB & 0.460 & $0.592(5)$ & $0.554(10)$ & $0.569(5)$ & $0.568(5)$ & $0.146(45)$ & $0.594(12)$ & $0.483(68)$ \\
\hline Bagging-LR & 0.681 & $0.605(5)$ & $0.66(15)$ & $0.628(5)$ & $0.628(5)$ & $0.187(45)$ & $0.659(34)$ & $0.686(58)$ \\
\hline $\begin{array}{c}\text { Stacking } \\
(\mathrm{DS}, \mathrm{J} 48, \mathrm{NB})\end{array}$ & 0.570 & $0.486(30)$ & $0.511(30)$ & $0.51(20)$ & $0.496(25)$ & $0.157(45)$ & 0.327 (3) & $0.397(68)$ \\
\hline SVM - linear & 0.465 & - & - & - & - & - & - & - \\
\hline SVM - rbf & 0.588 & - & - & - & - & - & - & - \\
\hline
\end{tabular}


CHAPTER 9

DISCUSSION

AND VALORIZATION

\section{(n)




\subsection{INTRODUCTION}

With the implementation of novel technologies, the agile availability of information on hemostasis in critically ill and peri-operative patient care, has set an exciting new trend in more pro-active and personalized interaction of the anesthesiologist with respect to hemostasis and thrombosis.

Moreover, population-based data-driven knowledge systems that generalizes experiences from patient's life, disease and treatment, enable the imputation of the best course of action for the diagnosis, prognosis and treatment of future patients. Both, the combined use of novel technologies related to hemostasis and early explorations towards "precision" medicine were presented in this thesis.

\subsection{RESEARCH MOTIVATION}

Peri-operative care demands an attitude to make rapid, quick-fire decisions in complex, time-pressured situations that are potentially susceptible for decisional errors with significant impact. Strategies to improve the decision making process, basically triggered our research driven by personal formalized curiosity. On a daily basis, anesthesiologists are confronted with thrombosis and hemorrhage.
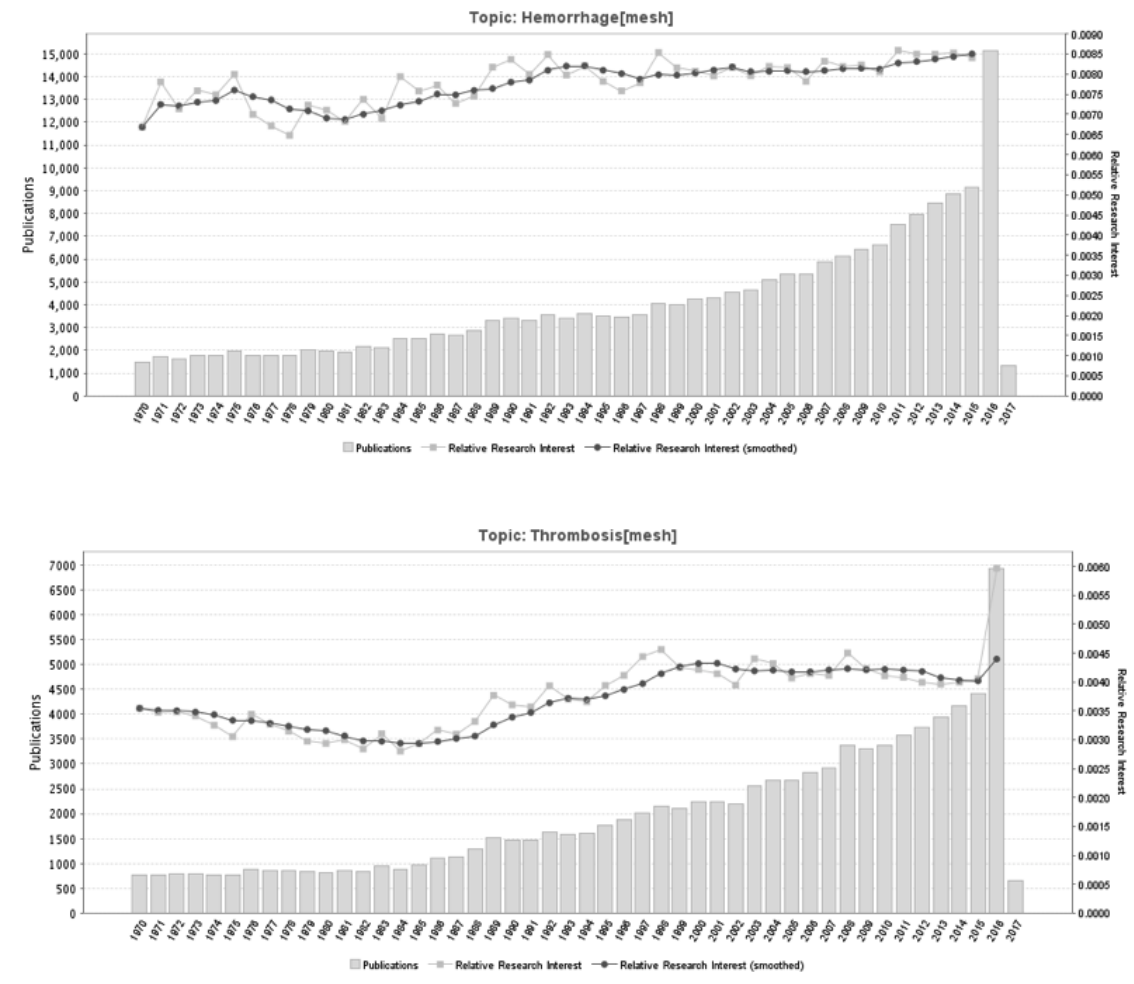

Fig. 1 GoPubMed ${ }^{\oplus u b l i c a t i o n s ~ o v e r ~ t i m e ; ~ e x p r e s s e d ~ a s ~ n u m b e r ~ o f ~ p u b l i c a t i o n s ~ a n d ~}$ relative research interest; subject: "hemorrhage", "thrombosis". 
Ontology-based literature search (Doms 2005), revealed that "hemorrhage" and "thrombosis" as research topics continue to be popular, both in absolute number of scientific publications as compared to the all scientific output (Fig. 1). On the contrary, a search for "hemostasis" or "coagulation" suggested a growing unpopularity until very recently (Fig. 2).
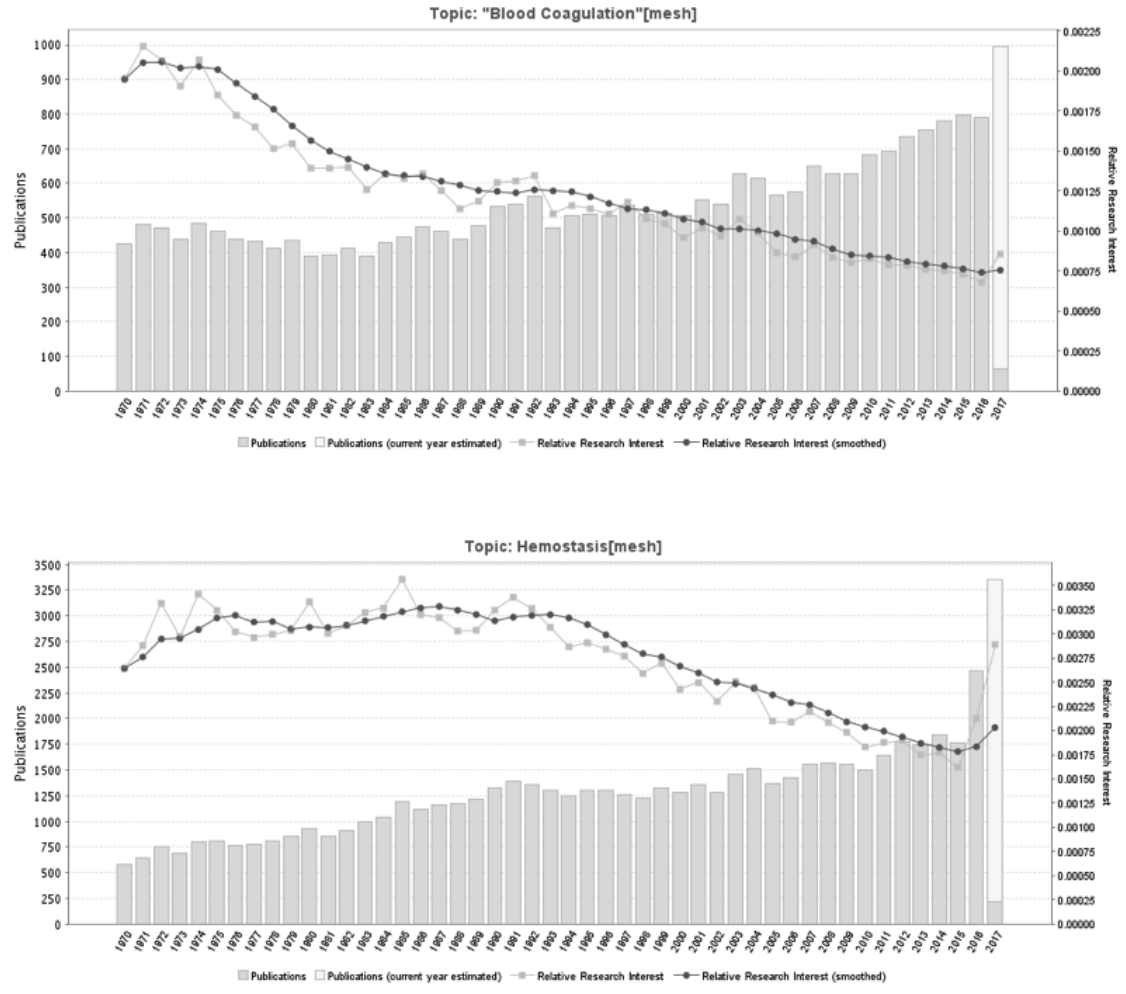

Fig. 2 GoPubMed ${ }^{\circledast}$ publications over time; expressed as number of publications and relative research interest; subject: "blood coagulation", "hemostasis". 
Anticoagulants" and "platelet aggregation inhibitors" demonstrated a fast growing interest, most probably related to novel drug developments, in absolute number of publications, the latter however with a reduced relative research interest (Fig. 3).
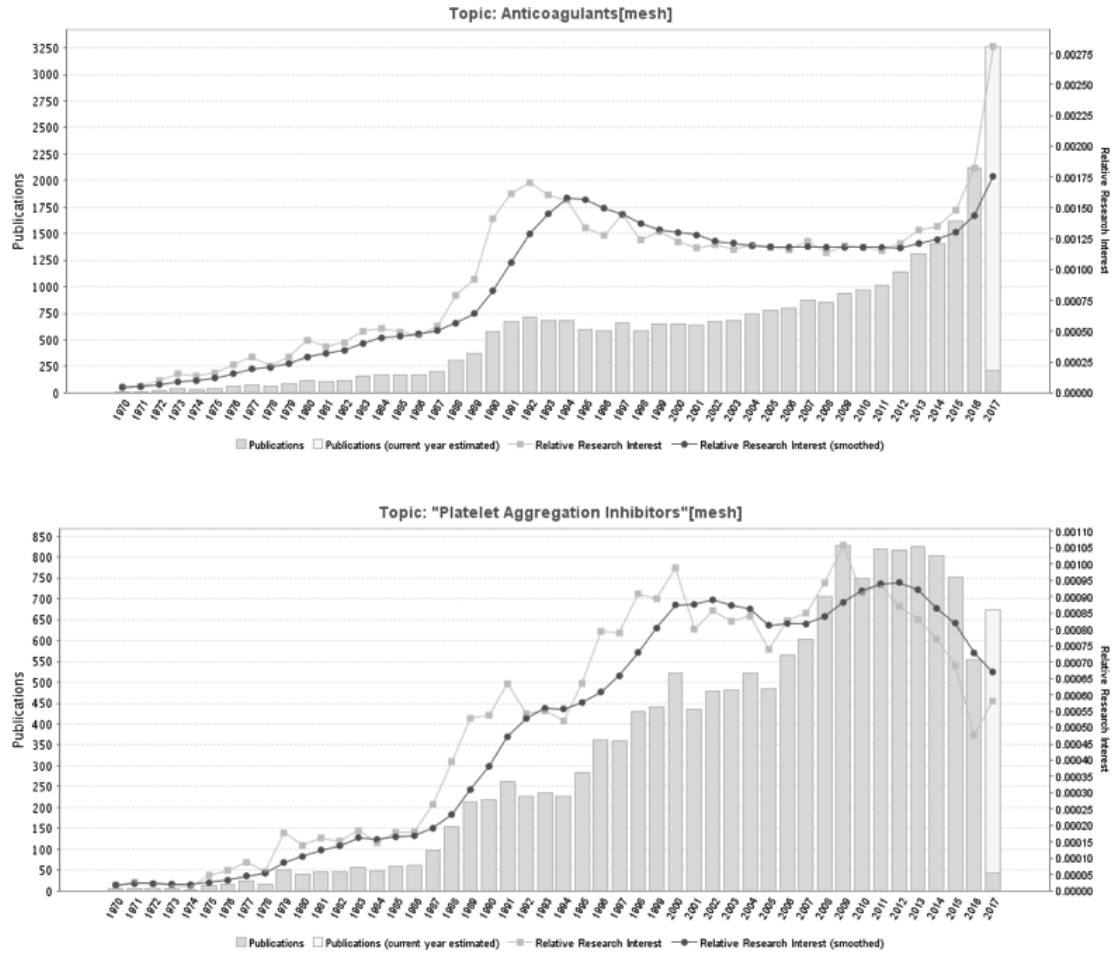

Fig. 3 GoPubMed ${ }^{\circledast}$ publications over time; expressed as number of publications and relative research interest; subject: "anticoagulants", "platelet aggregation inhibitors".

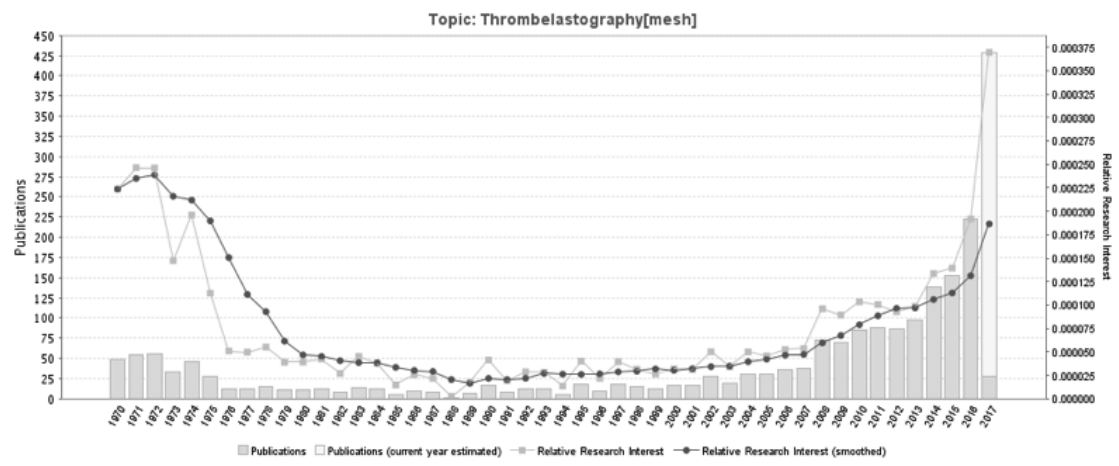



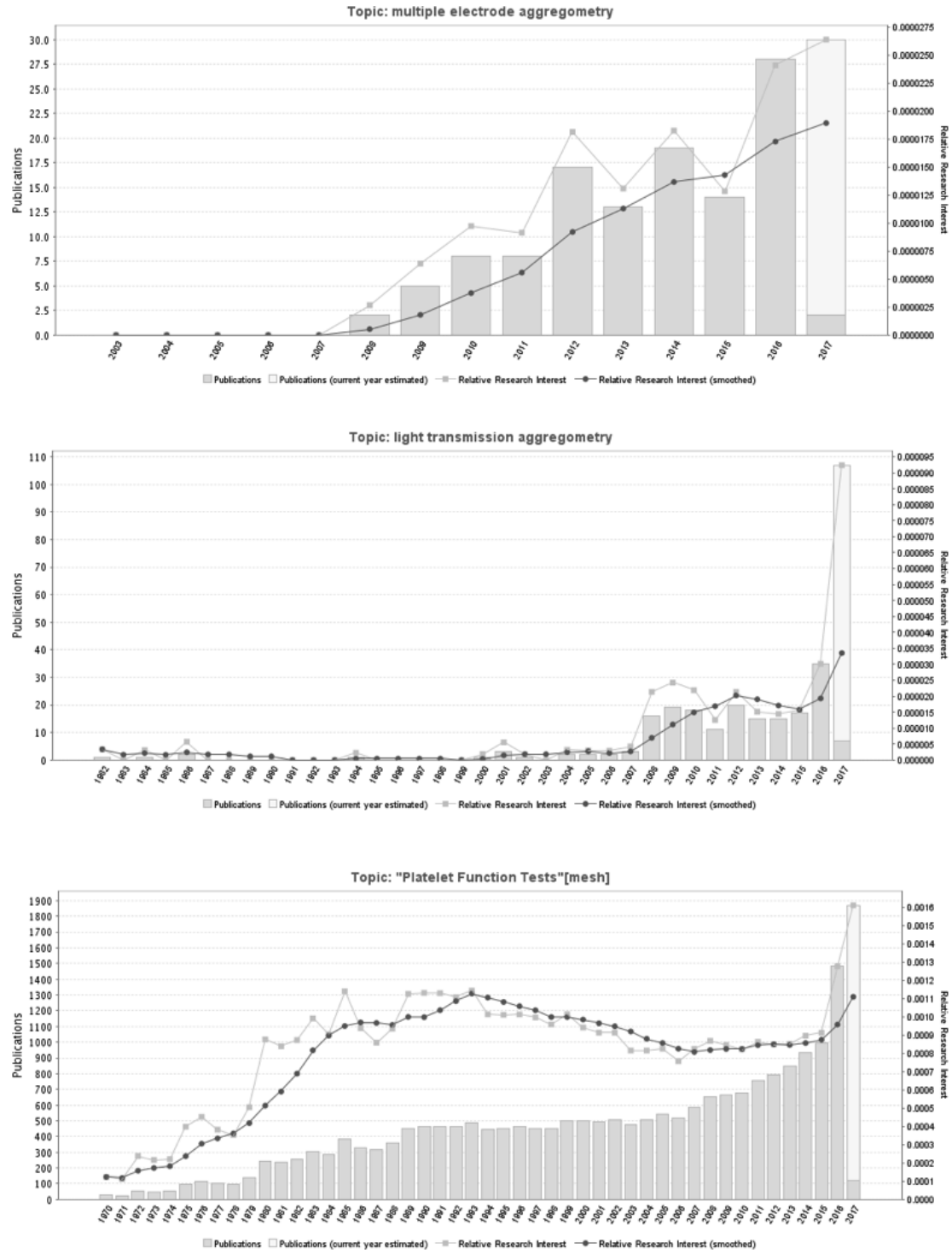

Fig. 4 GoPubMed ${ }^{\circledR}$ publications over time; expressed as number of publications and relative research interest; subject: "thromboelastography", "multiple electrode aggregometry", "platelet function tests", "light transmission aggregometry". 
In the context of this thesis, the scientific output of the mentioned assays demonstrated a growing popularity (Fig. 4).

In a search for the improvement of quality and safety of care, by identifying and reducing the causes of sub-optimal care, by minimizing variability and by the conscientious, explicit and judicious use of the current best evidence for the individual patient, the following research questions were proposed:

\section{RESEARCH QUESTION 1}

What is the measurable impact of temperature and/or pressure changes on platelet function (Ch2, Ch6), in in-vitro context (Ch3), during experimental mock circulation (Ch4) and during two different in-vivo extracorporeal circulation techniques (Ch5, Ch6)?

\section{RESEARCH QUESTION 2}

Which technological, computational and epistemological (the study of knowledge and justified belief) challenges are faced by studying platelets in a big data context? (Ch7, Ch8)?

\subsection{METHODOLOGY}

In Chapter 2, a review of current literature of hypothermia and its effects on platelet function and hemostasis were guided by the PRISMA guidelines as the evidence-based minimum set of items for reporting systematic reviews (Moher 2009).

The study presented in Chapter 3 aimed to quantitatively assess in-vitro platelet function after pneumatic tube transport followed by warmed and/or pressure-aided mock transfusions. The use of the pneumatic tube transport and pressure-aided mock transfusions were reported by other researchers of the Maastricht University (Lancé 2012, Kicken 2014).

Chapter 4 described the use of mock circulation loops (MCLs) as an in vitro flow model for research on coagulation and platelet function. Although limited by the absence of an endothelial layer in the circulating system but compared to the Chandler loop model without blood-air contact susceptible for inducing leukocyte and platelet aggregation and protein denaturation, mock circulation loops have been used in several experimental settings and different purposes (Timms 2011, Slee 2012, van Oeveren 2012).

Chapter $\mathbf{5}$ focused on patients exposed to in-vivo extracorporeal circulation following cardiac surgery with cardiopulmonary bypass in a prospective observational study. 
Chapter 6 assessed the impact of cytoreductive surgery, chemotherapy and hyperthermia on hemostasis in a prospective observational study population with peritoneal carcinomatosis.

Chapter $\mathbf{7}$ assessed normalization methods in time series of platelet function assays guided by SQUIRE compliance (Standards for QUality Improvement Reporting Excellence, Ogrinc 2015).

In Chapter 8, predictive analysis in critically ill patients using a visual open data analysis platform was explored based on the most recent trends in data mining and artificial intelligence technology. Data mining was performed guided by the CRoss-Industry Standard Process for Data Mining (CRISP-DM).

\section{ASSAYS}

LTA, light transmission aggregometry, (the reference method for the measurement of platelet function in patients with suspected platelet function disorders) as introduced by O'Brien and Born. With a reproducibility and the intra-individual variability of in vitro platelet aggregation described as relatively high, the Platelet Physiology Subcommittee of the Scientific and Stand-ardization Committee (SSC) of the International Society on Thrombosis and Hemostasis formed a working party of experts with the aim of producing a series of consensus recommendations for standardizing LTA based on a formal consensus method (the RAND methodology). (Mezzano, Cattaneo)

These recommendations revealed:

\section{LTA is clinically useful for the study of subjects with bleeding disorders}

2. LTA should not be used for the identification of subjects at risk of thrombosis, except in research

\section{LTA should not be used for monitoring subjects on anti-platelet therapy, except in research}

\section{Multiple electrode aggregometry (MEA)}

Multiple electrode impedance aggregometry (MEIA) using whole blood and similar agonists as LTA, has the potential to become an alternative point-of-care platelet function test (although MEIA seems more sensitive to variations in platelet count). All samples were analyzed according to the manufacturers recommendations and according to CE marked tests.

\section{Platelet activation test (PACT)}

The platelet activation test (PACT) (adjusted from Roest 2013) is based on platelet activation induced by addition of a specific agonist to whole blood reflecting the granule release capacity and the aggregation potential of platelets. The test contained three agonists to activate the platelets: (1) the protease activated receptor (PAR-1) agonist thrombin receptor activator peptide, (2) the glycoprotein VI (GPVI) agonist collagen-related peptide, and (3) the P2Y12 agonist ADP. 


\section{Thrombin generation (CAT)}

The ability to generate thrombin is essential for the overall success of the coagulation system to rapidly provide sufficient hemostasis during bleeding. Thrombin generation in plasma was measured with the calibrated automated thrombogram (CAT) assay as developed by Hemker and co-workers. Measuring TG (thrombin generation) may provide an exquisitely sensitive tool for detecting disturbances in the enzymatic phases of coagulation in critically injured patients. In particular, the CAT (calibrated automated thrombogram) is highly sensitive to elevated antithrombin levels, as it potently degrades thrombin, FIX, FX, FXI, and FXII. CAT is not approved for or convenient for use in emergency settings since the current machine uses a 96-well plate, making it inconvenient and extremely costly to measure TG on a patient-by-patient basis. Finally, CAT is only moderately sensitive to fibrinogen levels and thus, the contribution of fibrinogen as a determinant of bleeding should be measured separately.

\subsection{MAJOR FINDINGS}

The major findings are represented here as a short collection of bullet points that convey the core findings and provide readers with a quick textual overview of this PhD research.

\section{RESEARCH QUESTION 1}

- Platelet concentrate transport by pneumatic tube systems and pressure-aided/ warmed transfusion might be a safe modality for patients requiring rapid platelet concentrate transfusion (Ch3).

- Pneumatic tube system transport markedly reduces the ADP response in fresh platelet concentrate, an effect more pronounced after 7 days storage (ADP and collagen response) (Ch3).

- A mock circulation loop is an alternative experimental environment for consistent measurement of platelet function (e.g. thermophysiology, biorheology) using minimal sample volumes of fresh human blood (Ch4).

- Based on a mock circulation loop investigation analyzing the impact of hypothermia on platelet aggregation both LTA and MEA, demonstrated a reduced platelet aggregation during hypothermic mock circulation with only partial recovery during rewarming (Ch4).

- ROTEM (EXTEM, FIBTEM, PLTEM) reflected a uniform decreased thrombus formation as measured in terms of MCF in a mock circulation loop investigation (Ch4).

- LTA and MEIA analysis demonstrated significant platelet dysfunction after CPB, with partial recovery within $24 \mathrm{~h}$ after surgery (Ch5).

- AA-induced platelet aggregation increased to higher levels within $24 \mathrm{~h}$ after CABG compared to baseline values as measured by LTA (Ch5). 
- Correlation analyses revealed that MEIA and ROTEM, but not LTA, were dependent on platelet count and hematocrit in CABG patients (Ch5).

- MEIA as point of care test is able to detect platelet dysfunction during cardiac surgery with a $P C$ of $\geq 150 \times 10^{9} / L$ (Ch5).

- During CRS/HIPEC procedures, platelet reactivity (relative to before incision values) to CRP and TRAP are slightly reduced with regard to allbß3 activation, while P-selectin expression is not affected (Ch6).

- During CRS, CAT assay demonstrated that LT and TTP values decrease while and TP and ETP increase. Subsequently, after surgery, LT and TTP increase and ETP and TP decrease in time (Ch6).

- ROTEM EXTEM MCF, INTEM MCF and FIBTEM MCF decreased during CRS. At day 7, post CRS/HIPEC surgery, INTEM and FIBTEM MCF values were significantly higher than before surgery (Ch6).

\section{RESEARCH QUESTION 2}

- Normalization of data is critical when dealing with attributes with different units and scales in particular for certain data mining techniques (e.g. distance/similarity calculations, k-NN), requiring normalization (Ch7).

- Interquartile range, range transformation and z-transformation demonstrated the correlation between LTA and MEA findings in CABG patients as calculated by the Spearman's correlation test, when normalized per assay (test) for all time points but not when normalizing per time point for all tests or when using all data as 1 dataset for normalization (Ch7).

- Guided by the CRoss-Industry Standard Process for Data Mining (CRISP-DM) and based on the MIMIC-II tables of interest. Correlation of platelet count and ICU survival was quantitatively assessed (Ch8).

- Robust processes for automatic building, parameter optimization and evaluation of predictive models, based on different feature selection schemes using the presented platform (RapidMiner) are attractive for scalable predictive analytics in health research (Ch8). 


\subsection{VALORIZATION}

The valorization or knowledge exchange, as a result of this $\mathrm{PhD}$ research, is demonstrated on different levels. Although in general terms, valorization is required "to meet the needs of society", this research resulted in actual and future interactions with specific stakeholders or users. Considering academical users, field experts and clinicians as a first target group, each chapter of this PhD research was published in scientific journals as mentioned in the publications section. As such the scientific output was monitored by several key metrics (e.g. Altmetric score, Web of Science citations) which enabled measurement of general interest positively affecting the communication strategies of the Maastricht University, the Maastricht UMC+/azM, the Ziekenhuis Oost-Limburg and Synapse BV.

Considering the valorization with respect to the relation of research and practice, this thesis aimed to improve existing habits and practices. The research findings stimulated our knowledge regarding the added value but also the limitations of different assays. Additionally, the general interest in thrombosis prevention in the post-surgical phase potentially increased in particular in future research associated with inflammation.

The research results also opened opportunities for new research projects in a different context, e.g. research of platelet function in (pre-)eclampsia directly profiting from the logistical experience of this research and because of the constructive relation we created with the Maastricht University, the Maastricht UMC+/azM and Synapse BV. Additionally, the expertise and knowledge we shared and built during this PhD trajectory was noticed by researchers from the Chinese Wenzhou Medical University, Institute of Hepatology resulting in a growing scientific output as mentioned in the publications section.

The collaboration with the laboratories for the purposes of development and testing of the assays enabled expansion and quality improvement of the quantitative assessment of hemostasis and thrombosis in our hospital. The combination of knowledge from various disciplines (e.g. oncologic surgery, central laboratory) improved the collaboration potentially affecting the care of critically ill patients and patients admitted for surgical interventions in particular for CABG and CRS/HIPEC.

As target populations subdivide along combinations of co-morbidities and countless genetic polymorphisms, as diagnostic and monitoring devices including become more ubiquitous, it is clear that the traditional approach to knowledge discovery cannot scale to match the exponential growth of medical complexity (Ghassemi 2015). Also this part in research was explored, thanks to the kind and constructive cooperation with the Beth Israel Deaconess Medical Center (Boston USA), the Laboratory for Computational Physiology at the Massachusetts Institute of Technology, the Faculty of Organizational Sciences at the University of Belgrade which opened new opportunities for future research in thrombosis and hemostasis research based on large medical databases (MIMIC-III). 


\subsection{FUTURE PERSPECTIVES}

- Future research will require a substantial focus on the effectiveness and quality assurance of new technologies ultimately leading to diagnostic accuracy and evidence. Although we have attractive, promising tools available, we have not reached the point to cry of victory. More research efforts, focused on specific patient populations are required to minimize any possible bias and to define universally accepted reference standards (Hunt 2015). Technological advances such as in ROTEM sigma and TEG 6 s, being fully automated, not requiring pipetting and test preparation, might reduce bias by minimizing operator involvement. Additionally whole blood thrombin generation monitored with a calibrated automated thrombogram-based assay is increasingly being recognized as a versatile diagnostic tool in the field of thrombosis and hemostasis (Ninivaggi 2015). Probably this year, a fully automated device for thrombin generation measurement will be launched.

- The vascular endothelium and shear stress are critical determinants of physiological hemostasis and platelet function in-vivo, yet current diagnostic and monitoring devices do not fully incorporate endothelial function under flow in their assessment. Utilization of 3D bio-printing technology for the construction of a highly biomimetic thrombosis-on-a-chip models and micro-fluidic devices have a potential to disrupt the current diagnostics in hemostasis (Jain 2016). Future developments could be based on computationally simulation of the microscopic process of thrombosis (Chessnutt 2015). It is the author's opinion that future research of thrombosis and hemostasis quantification will be focused on miniaturizing devices with decreasing turnaround times. The design of a specific technology will be focused on a particular clinical question (e.g. drug monitoring, thrombotic potential measurement). As such, the interaction of domain experts in the clinical and engineering field requires new attention (e.g. closed loop solutions for DVT prophylaxis).

- From a clinical perspective, there is a daily need to translate trial results into diagnostic and therapeutic decisions for our patients. The current clinical research enterprise does not fully address daily clinical questions such as "what is the most adequate course of action for a particular patient, under these conditions, in this phase of the illness?" Classically, deductive science begins with a hypothesis or theory and proceeds to derive possible conclusions and statements. With the introduction of precision medicine as an emerging approach for disease treatment and prevention, the question arises whether simple and logical theoretical systems are the only choice for predictive analysis of complex, high-dimensional data from a multi-morbidity patient population? Consequently, this PhD project, in particular Chapter 8, provided a platform to stimulate predictive modeling in health care by explaining the concepts of predictive modeling. Finally, data scientists need to create familiarity with data visualization as a channel for information sharing. Data-driven research incorporates artificial intelligence and machine learning into statistics and supports the recognition of patterns within massive datasets. Validation and interpretation of results is an essential step preceding data visualization. As data dimensionality continues to make big leaps, interpretability of results, visualization of data (correlation), as part of artificial intelligence gain a central interest at Google, Facebook, Apple and others, and graphics processing units (GPUs) make it possible to create the neural nets and server systems that back machine learning, image recognition and other technologies 
under the broad artificial intelligence umbrella.

- The scenario best predicting platelet function (and hemostatic capacity) requires redefining the terminology used in clinical practice and research. Therefore, in the case of research and prior to write any study protocol, the terminology and its relations should be used following the latest standards in ontology research. An ontology is in this context a dictionary of terms formulated in a canonical syntax and with commonly accepted definitions designed to yield a lexical or taxonomical framework for knowledge-representation which can be shared by different information system communities (Smith 2007). Applicable in this context are the Human Disease Ontology (doid), Ontology for Biomedical Investigations (obl), Adverse Event Reporting Ontology (aero), as proposed by the OBO Foundry which mission is to develop a family of interoperable ontologies that are both logically well-formed and scientifically accurate (http://www.obofoundry.org/)

- Optimal prediction of platelet function (and hemostatic capacity) should be guided by the principles of Evidence Based Medicine as defined by the late Dr. David Sackett (Sackett 1996): "the conscientious, explicit and judicious use of the current best evidence in making decisions about the care of the individual patient. This means integrating individual clinical expertise with the best available external clinical evidence from systematic research." Based on this definition, clinical expertise and the best available external clinical evidence from systematic research are essential. The "best" available external clinical evidence from systematic research should delivered by the result of all our scientific efforts, as far as they are ethically and scientifically sound.

- To conclude, synchronizing evolutions in biomedical science, engineering and data science ultimately will lead to more personalized healthcare better predicting the most adequate therapy with the least side effects for individual patients. It should improve the quality of care and decrease cost at the same time. Inevitable, the research on platelet function and coagulation will evolve in the direction that proposes the customization of healthcare, with medical decisions, practices, and/or products being tailored to the individual patient.

\subsection{REFERENCES}

Doms A, Schroeder M. GoPubMed: Exploring PubMed with the GeneOntology. Nucleic Acid Research 2005; 33: W783-W786.

Moher D, Liberati A, Tetzlaff J, Altman DG, The PRISMA Group (2009). Preferred Reporting Items for Systematic Reviews and Meta-Analyses: The PRISMA Statement. PLoS Med 2009; 6(7): e1000097.

Lancé MD, Marcus MAE, van Oerle R, Theunissen HMS and Henskens YMC. Platelet concentrate transport in pneumatic tube systems - does it work?. Vox Sanguinis 2012; 103: 79-82.

Kicken C, Lancé MD, van Egmond LT, van Oerle R, Henskens YMC. Rapid platelet concentrate 
delivery by pneumatic tube system and pressured transfusion is a feasible option. Journal of Thrombosis and Haemostasis 2014;12:78-78

Timms DL, Gregory SD, Stevens MC, Fraser JF. Haemodynamic modeling of the cardiovascular system using mock circulation loops to test cardiovascular devices.

Annu Int Conf IEEE Eng Med Biol Soc 2011;4301-4.5.

Slee JB, Alferiev IS, Levy RJ, Stachelek SJ. The use of the ex-vivo Chandler Loop Apparatus to assess the bio-compatibility of modified polymeric blood conduits. JoVE 2014;90:e51871.6. van Oeveren W, Tielliu IF, de Hart J. Comparison of modified Chandler, roller pump, and ball valve circulation models for in-vitro testing in high blood flow conditions: application in thrombogenicity testing of different materials for vascular applications. Int J Biomater 2012; 673163.

Ogrinc G, Davies L, Goodman D, Batalden P, Davidoff F, Stevens D.SQUIRE 2.0 (Standards for QUality Improvement Reporting Excellence): revised publication guidelines from a detailed consensus process. BMJ Qual Saf 2015;0:1-7

O'Brien JR. The adhesiveness of native platelets and its prevention. J Clin Pathol 1961;14:140-149.

Born GV. Aggregation of blood platelets by adenosine diphosphate and its reversal. Nature. 1962;194:927-929.

Mezzano D, Quiroga T, Pereira J. The level of laboratory testing required for diagnosis or exclusion of a platelet function disorder using platelet aggregation and secretion assays. Semin Thromb Hemost 2009;35:242-54.

Cattaneo M, Cerletti C, Harrison P, Hayward CPM, Kenny D, Nugent D, Nurden P, Rao AK, Schmaier AH, Watson SP, Lussana F, Pugliano MT, Michelson AD. Recommendations for the standardization of light transmission aggregometry: A consensus of the working party from the platelet physiology subcommittee of SSC/ISTH. J Thromb Haemost 2013;11:1183-9.

Ghassemi M, Celi LA, Stone DJ. State of the art review: the data revolution in critical care. Crit Care 2015;19.

Hunt H, Stanworth S, Curry N, Woolley T, Cooper C, Ukoumunne O, Zhelev Z, Hyde C. Thromboelastography (TEG) and rotational thromboelastometry (ROTEM) for trauma-induced coagulopathy in adult trauma pa-tients with bleeding. Hunt $\mathrm{H}$, ed. Cochrane Database Syst Rev 2015;16:CD010438.

Ninivaggi M, Apitz-Castro R, Dargaud Y, Laat B de, Hemker HC, Lindhout T. Whole-blood thrombin generation monitored with a calibrated automated thrombogram-based assay. Clin Chem 2012;58:1252-9.

Jain A, Meer AD van der, Papa AL, Barrile R, Lai A, Schlechter BL, Otieno MA, Louden CS, Hamilton GA, Mi-chelson AD, Frelinger AL, Ingber DE. Assessment of whole blood thrombosis in a microfluidic device lined by fixed human endothelium. Biomed Microdevices 2016;18:1-7.

Chesnutt JKW, Han HC. Simulation of the microscopic process during initiation of stent thrombosis. Comput Biol Med 2015;56:182-91.

Smith B, Ashburner M, Rosse C, Bard J, Bug W, Ceusters W, Goldberg LJ, Eilbeck K, Ireland A, Mungall CJ, Leontis N, Rocca-Serra P, Ruttenberg A, Sansone S-A, Scheuermann RH, Shah N, Whetzel PL, Lewis S. The OBO Foundry: coordinated evolution of ontologies to support biomedical data integration. Nat Biotechnol 2007;25:1251-5.

Sackett DL, Rosenberg WMC, Gray JAM, Haynes RB, Richardson SW. Evidence based medicine: what it is and what it isn't. BMJ 1996;312:71-72 


\section{NEDERLANDSE SAMENVATTING}

met betrekking tot het proefschrift van Sven Van Poucke 2017

Platelets, from sample to big data Exploring granularity in platelet research

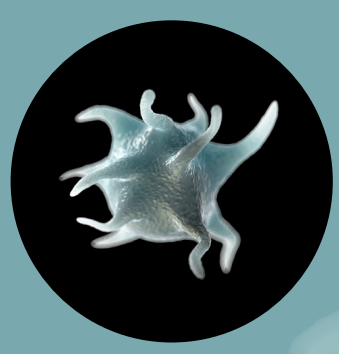


Dit proefschrift heeft zich als doel voorgenomen de modaliteiten te onderzoeken waarmee bloedplaatjes veranderen wanneer ze onderhevig zijn aan onnatuurlijke omstandigheden.

In hoofdstuk 1 wordt de achtergrond geschetst horende bij dit proefschrift. In een notendop wordt toegelicht dat het onderzoek naar plaatjes zowel in de diepte als in de breedte kan uitgevoerd worden. Diepgaand onderzoek gaat na welke verschillende testen de functies van bloedplaatjes kunnen kwantificeren in diverse omstandigheden. Onderzoek in de breedte onderzoekt de mathematische achtergrond nodig om bloedplaatjes onderzoek te kunnen uitvoeren op massale hoeveelheden data (Big Data). Hoofdstuk 1 vermeldt kernachtig wat bloedplaatjes zijn en op welke wijze ze deelnemen in het stollingsproces en andere processen. Vervolgens gaat dit hoofdstuk in op de testen welke aan bod zullen komen in het verdere onderzoek van dit proefschrift. Dit hoofdstuk rechtvaardigt tevens het uitgevoerde onderzoek op een gestructureerde wijze gebruik makende van de FINER criteria. Eindigen doet dit inleidende hoofdstuk met het stellen van 2 onderzoeksvragen:

RQ1: What is the measurable impact of temperature and/or pressure changes on platelet function (Ch2, Ch6), in in-vitro context (Ch3), during experimental mock circulation (Ch4) and during two different in-vivo extracorporeal circulation techniques (Ch5, Ch6)?

Onderzoeksvraag 1: Wat is de meetbare impact van temperatuur- en of drukveranderingen op de functies van bloedplaatjes (Hfst 2, Hfst 6), in een in-vitro omgeving (Hfst 3), tijdens een experimentele circulatie (Hfst 4) en tijdens 2 verschillende extracorporele circulatietechnieken (Hfst 5, Hfst 6)?

RQ2: Which technological, computational and epistemological (the study of knowledge and justified belief) challenges are faced by studying platelets in a big data context? (Ch 7, Ch8)?

Onderzoeksvraag 2: Met welke technologische, rekenkundige en epistemologische (kennistheorie) uitdagingen worden we geconfronteerd tijdens het onderzoek van bloedplaatjes in een big data context (Hfst7, Hfst8)?

Hoofdstuk 2 behandelt een overzicht van de actuele literatuur met betrekking tot de impact van hypothermie op de biologie van bloedplaatjes. De modaliteit waarmee bloedplaatjes in hypothermie omstandigheden worden gebracht, bepaalt in belangrijke mate de invloed op het (dis)functioneren van bloedplaatjes. Wijzigingen in temperatuur hebben een invloed op de vorm van de bloedplaatjes, maar ook de prikkelbaarheid van de bloedplaatjes wordt door een daling van de temperatuur beschreven. In koude omstandigheden zien we de bloedplaatjes uit de circulatie verdwijnen, een kenmerk welke bijzonder ingenieus ontwikkeld is bij winterslapers. Koude zorgt naast gewijzigde prikkelbaarheid ook voor een minder efficiënte deelname in het stollingsproces. Daarenboven zijn bloedplaatjes omgeven door andere cellen en weefsels die tevens door een daling van de temperatuur worden beïnvloed. 
Hoofdstuk 3 onderzoekt of het transport van bloedplaatjes concentraat via een pneumatische buis systeem (PTS) samen met verwarmde en of verhoogde druk transfusie een schadelijke invloed uitoefent in situates waar versnelde transfusie vereist is. Hoewel bij een enkelvoudig transport door het PTS systeem, de respons van verse bloedplaatjes van adenosine difosfaat (ADP) doet dalen, heeft stockage van bloedplaatjes gedurende 7 dagen een meer uitgesproken effect op de ADP en collageen respons. De klinische relevantie van deze bevindingen dienen verder bepaald te worden, in het bijzonder binnen bepaalde patiëntenpopulaties. Het aanbrengen van druk of druk en warmte heeft geen verdere nefaste invloed op de functie van bloedplaatjes. Verder onderzoek zal verhelderen of bloedplaatjes via een versnelde toediening kunnen aangeboden worden aan patiënten in een realistische klinische setting.

Hoofdstuk 4 heeft zich als doel voorgenomen de bruikbaarheid van een kunstmatige circulatielus te toetsen om de impact van hypothermie op bloedplaatjes na te gaan. De studie toont aan dat plaatjes aggregatie, met verscheidene agonisten, zowel door licht transmissie aggregometrie (LTA) als door multiple electroden aggregometrie (MEA), daalt onder deze omstandigheden. Daarenboven wordt voor beide essays slechts een gedeeltelijk herstel in bloedplaatjes aggregatie vastgesteld. Tevens observeert men een daling in het aantal bloedplaatjes welke gerelateerd kan zijn aan de binding van de bloedplaatjes aan de circulatielus, aan een aggregatie van bloedplaatjes met andere cellen en aan bloedplaatjes destructie.

Hoofdstuk 5. In dit hoofdstuk wordt de functie van bloedplaatjes gemeten voor, tijdens en na overbruggingschirurgie van het hart onder kunsthart. Het doel van dit onderzoek was na te gaan welke tijdsafhankelijke wijzigingen geïnduceerd werden bij overbruggingschirurgie onder kunsthart. Bloed bij 20 patiënten met pre-operatieve bloedplaatjes aantal van meer dan $250 \times 10^{\%} / \mathrm{L}$ werden afgenomen net voor de heelkundige incisie, na het spenen van het kunsthart en 24 uur postoperatief. De functie van de bloedplaatjes werd gekwantificeerd met multiple electrode impedance aggregrometry (MEIA) in vol bloed en met licht transmissie aggregrometrie (LTA) in bloedplaatjes-rijk plasma, na stimulate met arachidonzuur, adenosine difosfaat, collageen en thrombine-receptor-activerend-peptide. LTA en MEIA analysis resulteerden in een significante daling van de bloedplaatjes aggregatie, met slechts gedeeltelijk herstel binnen de 24 uur na heelkunde. Arachidonzuur geïnduceerde bloedplaatjes aggregatie steeg zelfs tot hogere waarden dan de beginwaarden gemeten met LTA. Een correlatie analyse toonde aan dat MEIA en ROTEM, maar niet LTA, afhankelijk zijn van het aantal bloedplaatjes en het hematocriet. Hieruit concludeerden wij dat een reversibele disfunctie van bloedplaatjes plaatsvindt bij deze ingreep, zich herstellende binnen de $24 \mathrm{u}$ na het stoppen van het kunsthart. Het feit dat arachidonzuur geïnduceerde bloedplaatjes aggregatie met hogere waarden eindigden in de eerste 24 u postoperatief zou het argument voor meer vroegtijdig opstarten van plaatjes remmende medicatie kunnen ondersteunen.

Hoofdstuk 6 analyseert de impact van cytoreductieve chirurgie (CRS) met hypertherme intraperitoneale peroperatieve chemotherapie (HIPEC), geïndiceerd voor patiënten met peritoneale metastasen van het spijsverteringsstelsel of van gynaecologische oorsprong. Deze ingreep, blijk van een aanzienlijke invloed op het hemostase metabolisme uit te oefenen, zowel op bloedplaatjes als op coagulatie niveau. De hemostatische wijzigingen in CRS en HIPEC zijn fase afhankelijk. Deze studie illustreert het gecombineerde gebruik van ROTEM (rotatie thromboelastometry), PACT (bloedplaatjes activering test) en CAT (trombine generatie test) testen tijdens CRS en HIPEC met een follow-up van 7 dagen na de ingreep. 
Plaatjesreactiviteit (ten opzichte van de pre-incisie waarden) door CRP (collageengerelateerd peptide) en TRAP (trombine receptor activator peptide) lijkt enigszins te dalen bij CRS en HIPEC wat allbß3 activatie betreft, terwijl P-selectine-expressie niet wordt beïnvloed. Tijdens de operatie toont CAT aan dat de LT (Lag Time) en TTP (time-to-trombin-peak) waarden verlagen terwijl de TP (trombin peak) en ETP (endogenous trombin potential) toenemen. Vervolgens, na de operatie, ziet men LT en TTP verhogen en terwijl ETP en TP afnemen in de tijd. ROTEM EXTEM MCF, INTEM MCF en FIBTEM MCF (maximal clot firmness) daalde tijdens CRS. Op dag 7 waren de INTEM en FIBTEM MCF waarden aanzienlijk hoger dan voor de operatie. Een afwezigheid van grote veranderingen in de bloedplaatjes aantal en hemoglobine concentratie en de afwezigheid van leukopenie werden vastgesteld. Deze aanpak detecteert veranderingen in bloedstolling veel eerder dan opgemerkt door standaard coagulatietests (PT en aPTT).

Hoofdstuk 7. Dit hoofdstuk beschrijft het gebruik van normalisatie technieken bij de analyse van de functie van bloedplaatjes gebruik makende van visco-elastische testen zoals de ROTEM technologie, licht transmissie aggregometrie en multiple elektroden aggregometrie. De data afkomstig van dit onderzoek kan beschouwd worden als hoog-dimensioneel, multivariabel en als tijd serie. Grafische voorstellingen om dergelijke resultaten met elkaar visueel te vergelijken behoeven voorafgaandelijk normalisatie. In deze studie worden diverse methoden voor data normalisatie gehanteerd: (z-transformatie, range transformatie, proportionele transformatie en interquartiele range). Normalisaties werden berekend per test over alle tijdspunten, en per tijdspunt voor alle testen. De interquartiele range, range transformatie en z-transformatie illustreerden best de correlatie berekend door de Spearman's correlatie test, wanneer genormaliseerd werd per test en voor alle tijdspunten. Anderzijds bij normalisatie per tijdspunt maar voor alle testen kon geen correlatie gevisualiseerd worden evenals wanneer alle data in zijn geheel genormaliseerd werden.

Hoofdstuk 8. In dit hoofdstuk wordt de overstap gemaakt van diepgaand onderzoek van bloedplaatjesfunctie naar data analyse in de breedte. Hoofdstuk 8 sluit aan bij wat men actueel predictieve, preventieve, en gepersonaliseerde geneeskunde noemt. De hoge dimensionaliteit en complexiteit van deze data weerhoudt het opmaken van eenvoudige data gestuurde modellen. Daarenboven is het opmaken van dergelijke modellen weggelegd voor dataspecialisten. De afwezigheid van voldoende expertise in de medische opleiding als onvoldoende medische kennis bij de dataspecialisten zorgt voor een leemte tussen het huidig en het potentieel gebruik van data ter onze beschikking. Voor dit deel van het proefschrift werd een framework ontwikkeld. Data afkomstig van de MIMIC databank welke alle parameters en gegevens bevat van meer dan 50000 intensieve zorgen opnames over een periode van 2001 en 2012. Deze data werd vervolgens geïntegreerd in de data mining toepassing RapidMiner welke schaalbare predictive analyse ondersteunt via de RapidMiner's Radoop extensie. Geleid door de industrie standaard (CRISP-DM) voor data mining, werd de data geëxtraheerd en voorbereid voor verder analyse. In dit onderzoek werd nagegaan in welke mate het aantal bloedplaatjes in gerelateerd was met de overleving na een opname op een intensieve zorgen afdeling. Daarbij werden parallelle computer technieken (Hadoop) gebruikt voor de aanmaak, de parameter optimalisatie en evaluatie van verschillende predicatieve modellen. Daarbij werd gebruik gemaakt van verschillende variabel selectie schema's. Aan de hand van technieken zoals Random Forest (RF) en Backward Elimination (BE) werden de beste resultaten qua modeling 
beschreven met de beste AUPRC waarden. Daarenboven werd aangetoond dat de combinatie van Random Forest (RF) met Correlation, Gini Selection en Forward Selection resulteerde in de hoogste AUPRC waarden. Het was niet toevalling dat SAPS en SOFA scores een hoge ranking kregen als predicatieve instrumenten vermits zij reeds gevalideerd werden als scoring systeem. Verassend bleek wel dat, gebruik makende van Random Forest (RF) en Forward Selection, het gemiddeld aantal bloedplaatjes tijdens het verblijf op intensieve zorgen weerhouden werd in de top tien predicatieve parameters bepalend voor de overleving van de patiënt.

Hoofdstuk 9. In dit hoofdstuk wordt, op basis van het uitgevoerde onderzoek getracht antwoord te bieden op de gestelde onderzoeksvragen en wordt de potentiële valorisatie aangehaald.

Onderzoeksvraag 1: Wat is de meetbare impact van temperatuur- en of drukveranderingen op de functies van bloedplaatjes (Hfst 2, Hfst 6), in een invitro omgeving (Hfst 3), tijdens een experimentele circulatie (Hfst 4) en tijdens 2 verschillende extracorporele circulatietechnieken (Hfst 5, Hfst 6)?

Onderzoeksvraag 2: Met welke technologische, rekenkundige en epistemologische (kennistheorie) uitdagingen worden we geconfronteerd tijdens het onderzoek van bloedplaatjes in een big data context (Hfst7, Hfst8)? 


\section{ENGLISH SUMMARY}

of the thesis authored by

Sven Van Poucke

2017

Platelets, from sample to big data

Exploring granularity in platelet research

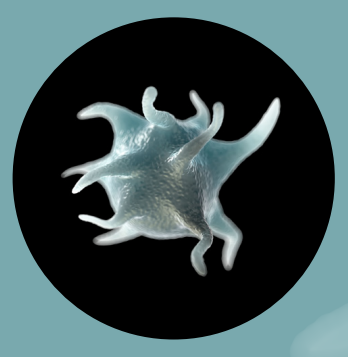


This thesis aimed to examine the modalities by which platelets change when exposed to unnatural conditions.

Chapter 1 outlines the background related to this thesis. In a nutshell, the chapter explains that research of platelets can be performed both both in depth and width. In depth studies examine the different tests with the potential to quantify platelet functions in various conditions. Width research examines the mathematical requirements to carry out research on platelet in a context of massive amounts of data (Big Data). Chapter 1 explains concisely what platelets are and how they participate in the clotting process and other processes. Then, this chapter mentions the tests which will be discussed in each research paper of this thesis. This chapter also justifies the research of this thesis based on the FINER criteria. This introductory chapter ends by asking two questions:

\section{RQ1: What is the measurable impact of temperature and/or pressure changes on platelet function (Ch2, Ch6), in in-vitro context (Ch3), during experimental mock circulation (Ch4) and during two different in-vivo extracorporeal circulation techniques (Ch5, Ch6)?}

\section{RQ2: Which technological, computational and epistemological (the study of knowledge and justified belief) challenges are faced by studying platelets in a big data context? (Ch7, Ch8)?}

Chapter 2 describes a survey of the current literature related to the impact of hypothermia on the biology of blood platelets. The modality in which platelets are placed in conditions of hypothermia, determines to a large extent, the impact on the functioning of platelets. Temperature changes influence the shape of blood platelets, as well as variations in excitability are described by a drop in temperature. In cold conditions, we observed that platelets temporarily disappear from circulation, a feature which becomes advantageous in hibernating animals. Cold causes also a reduced efficiency of platelets in the participation of hemostasis. In addition, platelets are surrounded by other cells and tissues which are also affected by a decrease of the temperature.

Chapter 3 examines the effects of transport of platelet concentrate through a pneumatic tube system (PTS) in association with heated and or elevated pressure transfusion revealing an adverse influence in clinical cases where accelerated transfusion is required. Although a single transport through the PTS system, reduces the response of fresh platelets by adenosine diphosphate (ADP), storage of platelets for 7 days, demonstrates a more pronounced effect on their ADP and collagen response. The clinical relevance of these findings should be determined in more depth in particular in certain patient populations. The application of pressure or pressure and heat has no further adverse impact on the function of blood platelets. More research will be required to determine whether platelets can be provided through accelerated infusion in a realistic clinical setting. 
Chapter $\mathbf{4}$ aimed to test the usefulness of an artificial circulation loop in ex-vivo research dealing with the impact of hypothermia on platelets. The study illustrates that platelet aggregation, with various agonists, measured both by light transmission aggregometry (LTA) as by multiple electrodes aggregometry (MEA), is reduced. Additionally, only a partial recovery in platelet aggregation for both assays is observed. In addition, a decrease in the number of platelets is measured which may be related to the binding of the platelets to the circulation loop, in a platelet aggregation with other cells and on platelet destruction.

Chapter 5. In this chapter, platelet function is measured before, during and after coronary bypass surgery with cardiopulmonary bypass. The aim of this study was to examine the time-dependent changes of platelet function during this procedure. Blood samples of 20 patients with preoperative platelet count of $>250 \times 10^{\%} / \mathrm{L}$ were taken just before the surgical incision, after weaning of the cardiopulmonary bypass, and 24 hours postoperatively. The function of the platelets was quantified with multiple electrode impedance aggregrometry (MEIA) in whole blood and with light transmission aggregrometry (LTA) in platelet-rich plasma, after stimulation with arachidonic acid, adenosine diphosphate, collagen, and thrombin receptor activating peptide. LTA and MEIA analysis demonstrated a significant decrease in platelet aggregation, with only partial recovery within 24 hours after surgery. Arachidonic acid induced platelet aggregation increased even to values higher than the initial values measured by LTA. A correlation analysis showed that MEIA and ROTEM, but not LTA, are dependent on platelet count and hematocrit. From this we concluded a reversible platelet dysfunction occurs following this operation, recovering within the $24 \mathrm{hrs}$ after the end of the cardiopulmonary bypass. The fact that arachidonic acid-induced platelet aggregation ended up with higher values in the first 24 hours post-operatively, triggers the argument for an earlier re-initiation of platelets inhibiting drugs.

Chapter 6 analyses the impact of cytoreductive surgery (CRS) with hyperthermic intraperitoneal peroperative chemotherapy (HIPEC), indicated for patients with peritoneal metastases from digestive or gynecological malignancies alike, demonstrating a considerable impact on hemostatic metabolism, both on platelet and on coagulation level. The potential hemostatic interference in CRS and HIPEC is phase dependent. This study demonstrates the combined use of ROTEM (rotational thromboelastometry), PACT (platelet activation test) and CAT (thrombin generation test) assays during CRS and HIPEC with a follow-up of 7 days postoperative.

Platelet reactivity (relative to before incision values) to CRP (collagen-related peptide) and TRAP (thrombin receptor activator peptide) seems to be slightly reduced during CRS and HIPEC with regard to allb $\beta 3$ activation, while P-selectin expression is not affected. During surgery, CAT demonstrates that, the LT (lag time) and TTP (timeto-thrombin-peak) values decrease while and the TP (thrombin peak) and ETP (endogenous thrombin potential) increase. Subsequently, after surgery, the LT and TTP increase and ETP and TP decrease in time. ROTEM EXTEM MCF, INTEM MCF and FIBTEM MCF (maximum clot firmness) decrease during CRS. At day 7 INTEM and FIBTEM MCF values are significantly higher than before surgery. No considerable changes in platelet count and hemoglobin concentration and absence of leukopenia are noticed. This approach detects changes in coagulation much earlier than noticed by standard coagulation tests (PT and aPTT) 
Chapter $\mathbf{7}$ describes the use of normalization techniques in the analysis of platelets function using viscoelastic tests such as the ROTEM technology, light transmission aggregometry and multiple electrodes aggregometry. The data from this study can be considered as high-dimensional, multivariate and as time serie. Graphical representations in order to visually compare results from each test requires normalization. This study used a variety of methods for data normalization (z-transform, range transformation, proportional transformation and interquartile range). Normalization was calculated for each test over all time points, and each time point for all tests. The interquartile range, range transform and z-transform illustrated best the correlation calculated by the Spearman's correlation test when normalized for each test and for all time points. On the other hand normalization per time point but for all the tests, provided no visual correlation as was the case when all the data were normalized as a whole.

In chapter $\mathbf{8}$, the transition is made from in-depth investigation of platelet function to wide data analysis. Several topics are covered in this chapter. Chapter 8 is consistent with what is known to date as predictive, preventive, and personalized medicine. The high dimensionality and complexity of these data prevents the preparation of simple data-driven models. Moreover, the preparation of such models is most frequently reserved for data specialists. The absence of sufficient expertise in medical training as insufficient medical knowledge by the data specialists creates a gap between the current and potential use of available data. A framework has been developed for this part of the thesis. Data from the MIMIC database with patients data from more than 50,000 ICU admissions between 2001 and 2012 is used. These data were then integrated into a data mining application (RapidMiner) which provided scalable predictive analysis support through the RapidMiner's Radoop extension. Led by the industry standard (CRISP-DM) for data mining, data was extracted and prepared for further analysis. This study examined the extent to which the number of platelets was related to survival after admission at an intensive care unit. It integrates parallel computer techniques (Hadoop) used for the production, the parameter optimization and evaluation of different predictive models. In addition, different variable selection schemes were used. By means of techniques such as Random Forest (RF) and Backward Elimination (BE), the best results in terms of modeling have been described providing the best AUPRC values. In addition, it was shown that the combination of Random Forest (RF) with Correlation, Gini Selection and Forward Selection resulted in the highest AUPRC values. It was no coincidence that SAPS and SOFA scores delivered high rankings as predictive tools since they have already been validated as scoring systems. Surprisingly, it was found that using random forest (RF) and Forward Selection, the average number of platelets during intensive care unit stay was retained in the top ten predictive parameters decisive for the survival of the patient.

In chapter 9, the research questions are used as guide to find answers related to valorization related to this thesis

RQ1: What is the measurable impact of temperature and/or pressure changes on platelet function (Ch2, Ch6), in in-vitro context (Ch3), during experimental mock circulation (Ch4) and during two different in-vivo extracorporeal circulation techniques (Ch5, Ch6)? 
RQ2: Which technological, computational and epistemological (the study of knowledge and justified belief) challenges are faced by studying platelets in a big data context? (Ch7, Ch8)?

Additionally, future perspectives are provided related to multiple technological and medical opportunities ultimately leading to a paradigm shift from reactive to proactive medicine. 


\section{PUBLICATIONS}

\section{स्थ

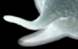 1}




\section{THESIS PUBLICATIONS}

1. Hypothermia: effects on platelet function and hemostasis. Poucke S Van, Stevens K, Marcus AE, Lancé M. Thromb J 2014;12:31.

2. Response of platelet concentrates to pressure and temperature changes without impairment of the in vitro function. Kicken C, Poucke S Van, Marcus AE, Lancé MD. Henskens Y. Thromb Res 2015;135:1-5.

3. Platelet function during hypothermia in experimental mock circulation. Poucke S Van, Stevens K, Kicken C, Simons A, Marcus A, Lancé M. Artif Organs 2016;40:288-93.

4. Early platelet recovery following cardiac surgery with cardiopulmonary bypass. Poucke S Van, Stevens K, Wetzels R, Kicken C, Verhezen P, Theunissen M, Kuiper G, Oerle R van, Henskens Y, Lancé M. Platelets 2016;7104:1-7.

5. 2015, Big Data in Healthcare: for Whom the Bell Tolls? Poucke S Van, Thomeer M, Hadzic A. Crit Care 2015;19:2013-4.

6. Scalable predictive analysis in critically ill patients using a visual open data analysis platform. Poucke S Van, Zhang Z, Schmitz M, Vukicevic M, Laenen M Vander, Celi LA, Deyne C De. PLoS One 2016;11.

7. Normalization methods in time series of platelet function assays.

A SQUIRE compliant study. Poucke S Van, Zhang Z, Roest M, Vukicevic M, Maud B, Lauwereins B, Zheng M-H, Henskens Y, Lancé M, Marcus A. Medicine (Baltimore) 2016;95:e4188.

8. Thrombin generation and platelet activation in cytoreductive surgery combined with hyperthermic intraperitoneal chemotherapy. Sven Van Poucke, Dana Huskens, Kurt Van der Speeten, Mark Roest, Bart Lauwereins, Ming-Hua Zheng, Seppe Dehaene, Joris Penders, Abraham Marcus, Marcus Lancé. PLOS One, submitted

\section{ADDITIONAL PAPERS}

1. Quinidine induced ventricular fibrillation: diagnosis and management by prehospital emergency medical care units. S. Van Poucke, N. Benameur, L. Besnard, R. Joly, P. Goldstein. JEUR (European Journal of Emergency Medicine) 1998; 11(3):150.

2. Hémorragie cérébrale et modifications électrocardiographiques. Cerebral hemorrhage and ECG modifications. L. Besnard, S. Van Poucke, N. Benameur, R. Joly, P. Goldstein. JEUR (European Journal of Emergency Medicine) 1998; 11 (3): 150.

3. Zur Hyperbaren Sauerstofftherapie am Diabetischen Fuss. Hyperbaric Oxygen in Diabetic Foot Ulcers. S. Van Poucke, L. Beaucourt. Podologie 22, L, Heft 6, 1999.

4. Hyperbaric Oxygen as useful, adjunctive therapeutic modality in Acute Traumatic Peripheral Ischemias. S. Van Poucke, T. Leenders, V. Saldien, J. Verstreken, L. Beaucourt, H. Adriaensen Acta Chir Belg. 2001 Mar-Apr;101(2):73-4.

5. Hyperbaric Oxygen Therapy. Sven Van Poucke, Luc Beaucourt. BHL (Vessels, Heart, Lungs) 2000; 5 (6):164-167.

6. The Release of Dissolved Gases from Solution during Decompression after Hyperbaric Treatment: Effervescent Tables and Henry's Law. Poucke S Van, Hans G, Hens P. Anesthesiology 2001;95:816. 
7. Pyoderma gangrenosum: a challenging complication of bilateral mastopexy.

Poucke S Van, Jorens PG, Peeters R, Jacobs W, Beeck BO de, Lambert J, Beaucourt L. Int Wound J 2004;1:207-13.

8. Successful use of posaconazole in a pediatric case of fungal necrotizing fasciitis Decker K De, Poucke S Van, Wojciechowski M, leven M, Colpaert C, Vogelaers D, Jorens PG. Pediatr Crit Care Med 2006;7:482-5.

9. Automatic colorimetric calibration of human wounds. Poucke S Van, Haeghen Y Vander, Vissers K, Meert T, Jorens P. BMC Med Imaging 2010;10:7.

10. Comparative analysis of two methods for wound bed area measurement. Poucke S Van, Nelissen R, Jorens P, Haeghen Y Vander. Int Wound J 2010;7:366-77.

11. Acetaminophen in critically ill patients, a therapy in search for big data analytics. Poucke S Van, Boer W. J Thorac Dis 2016;8:E109-10.

12. Building interpretable predictive models for pediatric hospital readmission using TreeLasso logistic regression. Jovanovic M, Radovanovic S, Vukicevic M, Poucke S Van, Delibasic B. Artif Intell Med 2016;72:12-21.

13. National incidence of autoimmune liver diseases and its relationship with the human development index. Pan H, Dai Y, Zheng J, Shi K, Poucke S Van. Oncotarget 2016;7:46273-82.

14. Are randomized controlled trials the (G)old Standard? From clinical intelligence to prescriptive analytics. Sven Van Poucke, Michiel Thomeer, John Heath, Milan Vukicevic. J Med Internet Res 2016;18(7):e185

15. Eye lens dosimetry in anesthesiology: a prospective study. Vaes B, Keer K van, Struelens L, Schoonjans W, Nijs I, Vandevenne J, Poucke S van. J Clin Monit Comput 2016:1-6.

16. Targeting endoplasmic reticulum stress in liver disease. Wu F-L, Liu W-Y, Poucke S Van, Braddock M, Jin W-M, Xiao J, Li X-K, Zheng M-H. Expert Rev Gastroenterol Hepatol 2016;4124:1-12.

17. Comparative efficacy of oral nucleotide analogues for the prophylaxis of hepatitis B virus recurrence after liver transplantation: a network meta-analysis. Zheng J-N, Zou T-T, Zou H, Zhu G-Q, Ruan L-Y, Cheng Z, Poucke S Van, Zheng M-H. Expert Rev Anti Infect Ther 2016;7210:14787210.2016.1220831.

18. Is an elevated hemoglobin concentration a novel risk factor for metabolic syndrome in the Chinese population ? a large- scale study. Zhou X, Wu S, Wang L, Liu W,

Zheng J, Shi K-Q, Poucke S Van, Zhang D-C, Huang W-J, Zheng M-H. Oncotarget 2016. (Advanced Publication)

19. Successful treatment of scrub typhus-associated hemophagocytic lymphohistiocytosis with chloramphenicol. Zhou Y-H, Xia F-Q, Poucke S Van, Zheng M-H.. Medicine (Baltimore) 2016;95:e2928.

20. AME evidence series 001-The Society for Translational Medicine: clinical practice guidelines for diagnosis and early identification of sepsis in the hospital. Zhang Z, Smischney NJ, Zhang H, Poucke S Van, Tsirigotis P, Rello J, Honore PM, Kuan W Sen, Ray JJ, Zhou J, Shang Y, Yu Y, Jung C, Robba C, Taccone FS, Caironi P, Grimaldi D, Hofer S, Dimopoulos G, Leone M, Hong S-B, Bahloul M, Argaud L, Kim WY, Spapen HD, Rocco JR. $J$ Thorac Dis 2016;3.

21. Personalized Treatment of Patients with very Early Hepatocellular Carcinoma. Vitale A, Peck-Radosavljevic M, Giannini EG, Vibert E, Sieghart W, Poucke S Van, Pawlik TM. J Hepatol 2016. 
22. Causal mediation analysis in the context of clinical research. Zhang Z, Zheng C, Kim C, Poucke S Van, Lin S, Lan P. Ann Transl Med 2016.

23. Establishment and Validation of GV-SAPS II Scoring System for Non-Diabetic Critically III Patients. Liu W-Y, Lin S-G, Zhu G-Q, Poucke S Van, Braddock M, Zhang Z, Mao Z, Shen F-X, Zheng M-H. PLOS One 2016;11:e0166085.

24. Serum alkaline phosphatase, a risk factor for non-alcoholic fatty liver, but only for women in their 30s and 40s: evidence from a large cohort study. Zhou Y-J, Zou H, Zheng J-N, Zou T-T, Vitale A, Miele L, Poucke S Van, Liu W-Y, Shen S, Zhang D-C, Shi K-Q, Zheng M-H. Expert Rev Gastroenterol Hepatol 2017; 0:17474124.2017.1283984.

25. Citations for Randomized Controlled Trials in Sepsis Literature : The Halo Effect Caused by Journal Impact Factor. Zhang Z, Van Poucke S. PLOSOne 2017: 12(1):e0169398.

26. Hierarchical cluster analysis in clinical research with heterogeneous study population: highlighting its visualization with R. Zhang Z, Murtagh F, Van Poucke S, Lin S, Lan P. Ann Transl Med 2017;5.

27. AKI-CLIF-SOFA: a novel prognostic score for critically ill cirrhotic patients with acute kidney injury. Sun D-Q, Zheng C-F, Liu W-Y, Poucke S Van, Mao Z, Shi K-Q, Wang X-D, Wang J-D, Zheng M-H. Aging (Albany NY) 2017. DOI: 10.18632/aging.101161.

28. Acute circulatory failure-chronic liver failure-sequential organ failure assessment score. Zhou X-D, Chen Q-F, Wang Z-X, Liu W-Y, Poucke S Van, Mao Z, Wu S-J, Huang W-J, Zheng M-H. Eur J Gastroenterol Hepatol 2016:1. DOI: 10.1097/MEG.0000000000000817.

29. Stratified Platelet-to-Lymphocyte Ratio: A Novel Target for Prognostic Prediction of Hepatocellular Carcinoma after Curative Liver Resection. Huang GQ, Zheng JN, Zou TT, Chen YR, Shi KQ, Van Poucke S, Zhang C, Ruan LY, Zheng MH. J Clin Transl Hepatol 2017; XX:1-8.

30. Early management of sepsis with emphasis on early goal directed therapy: AME evidence series 002. Zhang Z, Hong Y, Smischney NJ, Kuo H-P, Tsirigotis P, Rello J, Kuan W Sen, Jung C, Robba C, Taccone FS, Leone M, Spapen H, Grimaldi D, Van Poucke S, Simpson SQ, Honore PM, Hofer S, Caironi P. J Thorac Dis 2017;9:392-405.

31 Impact of platelet-lymphocyte ratio and metabolic syndrome on the prognosis of colorectal cancer patients. You J, Zhang H, Shen Y, Chen C, Liu W, Zheng MH, Van Poucke S, Guo G, Huang ZH. OncoTargets and Therapy accepted March 122017.

32 Nucleos(t)ide analogues for preventing HBV reactivation in immunosuppressed patients with hematological malignancies: a network meta-analysis. Zhang MY, Zhu GQ, Zheng JN, Cheng Z, Van Poucke S, Shi KQ, Huang HH, Chen FY, Zheng MH. Expert Review Of Anti-Infective Therapy. 2017;15(5): DOI: 10.1080/14787210.2017.1309291.

\section{RESEARCH FUNDING}

1. Specialisation Grant of the Fondation Médicale Mathilde E. HORLAIT DAPSENSE (Brussels, December 7 2000) Evaluation of Chronic Wound Care in Centres of Excellence $(16200,-\$)$

2. Funding from Institute for the promotion of Innovation by Science and Technology in Flanders (IWT-Flanders) (Brussels, March 2004): Peopleware Project: Clinical Analysis Software for Chronic Wound Care (174.536,-EUR) 
3. Funding EmUrgency (www.emurgency.eu). Project combines medical expertise with expertise from technology-enhanced learning and computer science.The project is led by the Centre for Learning Sciences and Technologies of the Open University of the Netherlands. Other consortium members are: Universitätsklinikum Aachen, RWTH Aachen, Maastricht University, Ziekenhuis Oost-Limburg (ZOL), K.U.Leuven, CHR Citadelle (CHR) and CECOTEPE ASBL. The project is financed by the European Regional Development Funds, regions from the Euregio Rhine-Meuse and the participating institutions.

\section{ACTIVITIES}

1. Co-worker of ASSENT II study (Boehringer Ingelheim) (Assessment of the Safety and Efficacy of a New Thrombolytic Agent) Phase 3 study, SAMU Lille, 12/97-12/98

2. Member of Surgical Team Earth Quake Turkey 1999 Member of Surgical Team Earth Quake India 2001

3. CANVAS (OVERLEVEN) TV Program on Scientists and Scientific Topics (45 min) May 6 2001: Oxygen under Pressure: Dr. Sven Van Poucke and his links with hypoxia, hyperoxia, hyperbaric and hypobaric environments. (https://youtu.be/U2-xHjkVH4g?list=LLaweOp8_3E25jx2eW8EsBpA)

4. RADIO 1 (National Radio Channel Belgium) Jongens en Wetenschap: Discussion on the Physiology of Freediving, Sept 2003

5. RADIO1 (National Radio Channel Belgium) Peeters en Pichal: Discussion on oxygen bars. Febr. 2008

6. Clinical Investigator: HAO08: Phase 3, Multicenter, Multi-national, Open-Label Study to Evaluate the Safety and Efficacy of Alfimeprase in Subjects with Occluded Central Venous Access Devices. (Nuvelo, Inc 2001 Industrial Road, Suite 310, San Carlos, CA 94070; Genk Belgium 2007

7. Clinical Investigator: A Multi-center, Randomized, Double-blind, Controlled Phase III Study of the Efficacy and Safety of an Oxygen-carrying colloid and Plasma Expander, Hemospan, compared with Colloid (Voluven) for Treatment of Perioperative Hypotension in Patients undergoing Primary Hip Arthroplasty with Spinal Anaesthesia. Genk Belgium 2007 (Protocol No 6090)

8. Principle Investigator: A Multi-center, Randomized, Double-blind, Controlled Phase III Study of the Efficacy and Safety of an Oxygen-carrying colloid and Plasma Expander, Hemospan, compared with Colloid (Voluven) for Treatment of Perioperative Hypotension in Patients undergoing Primary Hip Arthroplasty with Spinal Anaesthesia. Genk Belgium 2007 (Protocol No 6084)

9. Clinical Investigator: Evaluation of MP4OX for prevention of perioperative hypotension in patients undergoing primary hip arthroplasty with spinal anesthesia: a randomized, double- blind, multicenter study. Olofsson Cl, Górecki AZ, Dirksen R, Kofranek I, Majewski JA, Mazurkiewicz T, Jahoda D, Fagrell B, Keipert PE, Hardiman YJ, Levy H; Study 6084 Anesthesiology. 2011 May;114(5):1048-63.

10. Study Investigator: A double-blind, randomized, multicenter study of MP4OX for treatment of perioperative hypotension in patients undergoing primary hip arthroplasty under spinal anesthesia. van der Linden P, Gazdzik TS, Jahoda D, Heylen RJ, Skowronski JC, Pellar D, Kofranek I, Górecki AZ, Fagrell B, Keipert PE, Hardiman YJ, Levy H; 6090 Anesth Analg. 2011 Apr;112(4):759-73. 
11. Coordinator Woundontology Consortium (an international organization whose purpose is to create a standard vocabulary for studying chronic wounds.)

12. External Expert Belgian Healthcare Knowledge Centre: De Laet C, Obyn C, Ramaekers D, Van De Sande S, Neyt M. Hyperbare Zuurstoftherapie: Rapid Assessment. Health Technology Assessment (HTA). Brussel: Federaal Kenniscentrum voor de Gezondheidszorg (KCE); 2008. KCE Reports 74A (D/2008/10.273/13).

13. RADIO 1 Interview on Shortage of Emergency Physicians. (http://deredactie.be/cm/1.386363?view=popupPlayer)

14. Clinical Investigator Kingfisher Healthcare NV. Protocol Number KFH-2007-001-site Nr 12 (B32220083450)

15. Project Manager PHL Limburg Department Healthcare.(2008-present)

16. Founding Member Ontology Outreach Advisory (http://www.ontology-advisory.org/ node/29) 2008-2012

17. Member of RapidMiner Academy (2015-present)

18. RapidMiner Alpha/Beta tester 


\section{BIOGRAPHY}

\section{स्थ

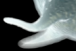 1}


Born on March 18, 1969, in St. Amandsberg, Belgium. In 1995, Sven Van Poucke graduated "magna cum laude" in medicine from the Ghent University. Before and during his life as a student he was passioned about submarine excavations which at that time first required the approval of his parents but rapidly ended up in various underwater projects where his father being shanghaied and his mother used everything in her power to hope for a save return. The "high tech" environment of submarine excavations and the introduction to a hyperbaric facility (naval base in Ostend, Belgium) convinced Sven Van Poucke that the human physiology exerted by extreme environments would be the first reason to become a medical doctor. During medical school Van Poucke noticed that the monoplace hyperbaric chamber at the University Hospital of Ghent (Belgium) was managed by Prof. Dr. Georges Rolly, head of the anesthesiology department. Anesthesiology became the discipline which would bring him closer to his initial interest. With the monoplace chamber at the University Hospital of Ghent mainly used for the treatment of carbon monoxide intoxications, Van Poucke changed his plans to be nearer to the center of excellence, Le Centre Hyperbare (Centre du Hospitalier Régional Universitaire de Lille (France)) by Prof. Dr. Daniel Mathieu and Prof. Dr. Francis Wattel where he was trained to use hyperbaric oxygen for the treatment of critically ill patients. During his stay in France, the University Hospital of Antwerp, Belgium (Prof. Dr. Luc Beaucourt) had the ambition to start a hyperbaric facility. The final part of his anesthesiology fellowship (Prof. Hugo Adriaensen) and his early years as anesthesiologist, Van Poucke dedicated, aside of his duties as anesthesiologist, to the development of this facility focusing on the treatment of critical care patients and severe scuba diving accidents. A few years later, Van Poucke had the opportunity to become anesthesiologist at the Ziekenhuis Oost-Limburg, Genk, Belgium, where a new multi-place hyperbaric chamber was installed. Related to his interest for extreme environments, the call of the North, his interest to quantitatively assess the effects of hypothermia in his PhD project seemed obvious. Sven Van Poucke demonstrated another passion, computational biology, from early in his professional life. When computing and software turned into commodity services, big data processing seems to be forging a technology revolution for the community which could not easily bypass Van Poucke's interest. Initially, he quantitatively analyzed medical images of chronic wounds by calibrated colorimetry which was a gentle introduction to the world of predictive analytics and big data use in medicine. Currently, Van Poucke is engaged in various international projects dealing with predictive analytics of patient related data.

Researchgate: https://www.researchgate.net/profile/Sven_Van_Poucke

Publons: publons.com/a/445759/

ORCID: 0000-0001-8070-8786 


\section{THANKS AND ACKNOWLEDGEMENTS}

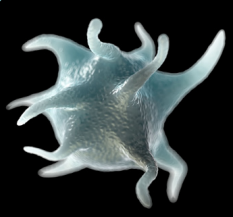


This work is primarily dedicated to the growing group of people demonstrating their interest in analytics. In general, this project is dedicated to all the members of my research network and communities of practice, who connected, inspired, collaborated, interacted, challenged, and shared with me personally and professionally. I am thankful for your passion.

I am deeply touched to notice that from the day it all the started until the end I didn't give my promotor, co-promoters, colleagues and family anything except, from time to time, the worst part of myself and after all the years it took to finish this thesis, we are still good friends.

My special thanks goes to all the members of the Department of Anesthesiology, Emergency Medicine, Critical Care and Pain Therapy both to the colleagues inspiring me with their critical feedback (in particular Dr. Luc Van Keer, Prof Dr. Raf De Jongh, Prof Dr. Cathy De Deyne) as the colleagues who facilitated my temporary focus on this research project while they were providing continued care for the patients we are responsible for.

I also would like to thank the Reading Committee for the time spending to evaluate my efforts: Prof. dr. Hugo te Cate (voorzitter), Prof. dr. Christa Boer, Prof. dr. Steven Olde Damink, Prof. dr. Dieter Mesotten, Dr. Bas de Laat

In particular I would like to thank:

\section{Prof. Dr. Wolfgang Bühre}

Department of Anesthesiology \& Pain Treatment, Maastricht University Medical Centre, Maastricht, The Netherlands.

To the captain: The wind and the waves are always on the side of the ablest navigator!

\section{Prof. Dr. Abraham Marcus}

Department of Anesthesiology, ICU and Perioperative Medicine, HMC, Doha, Qatar.

Professor, our relationship by distance coaching is the best demonstration that geographical distance is without any relevant importance in the world today.

\section{Dr. Marcus Lancé}

Department of Anesthesiology, ICU and Perioperative Medicine, HMC, Doha, Qatar. Without your incompatible background on platelet physiology and hemostasis and the way you thought me into this domain was extra-ordinary! Thank you.

\section{Dr. René Heylen}

Department of Anesthesiology, Emergency Medicine, Critical Care and Pain Therapy, Genk Belgium

We cannot become what we want to be by remaining what we are. The challenge I received from you gave me sometimes headaches, but resulted in who and what I am today, therefore my special thanks.

\section{Prof. Dr. Michiel Thomeer}

Department of Pneumology, Ziekenhuis Oost-Limburg, Genk, Belgium 


\section{Mr. John Heath}

RapidMiner, Shanghai, China

\section{Prof. Milan Vukicevic}

Faculty of Organizational Sciences, University of Belgrade, Belgrade, Serbia

\section{Dr. Zhongheng Zhang}

Department of Critical Care Medicine, Jinhua Hospital of Zhejiang University, Zhejiang, P.R. China

\section{Dr. Bas de Laat}

Synapse Research Institute, Maastricht, The Netherlands

\section{Prof. Dr. Ming-Hua Zheng}

Department of Infection and Liver Diseases, Liver Research Center, Wenzhou Medical University, Wenzhou, China

\section{Dr. Yvonne Henskens}

Central Diagnostic Laboratory, Maastricht University Medical Centre, Maastricht, The Netherlands

\section{Dr. Kris Stevens}

Department of Anesthesiology \& Pain Treatment, Maastricht University Medical Centre, Maastricht, The Netherlands

\section{Dhr. Rick Wetzels}

Central Diagnostic Laboratory, Maastricht University Medical Centre, Maastricht, The Netherlands

\section{Dr. Cécile Kicken}

Department of Anesthesiology \& Pain Treatment, Maastricht University Medical Centre, Maastricht, The Netherlands

\section{Dhr. Paul Verhezen}

Central Diagnostic Laboratory, Maastricht University Medical Centre, Maastricht, The Netherlands

\section{Dhr. Maurice Theunissen}

Department of Anesthesiology \& Pain Treatment, Maastricht University Medical Centre, Maastricht, The Netherlands

\section{Dhr. Gerhardus Kuiper}

Department of Anesthesiology \& Pain Treatment, Maastricht University Medical Centre, Maastricht, The Netherlands 


\section{Dhr. Rene van Oerle}

Central Diagnostic Laboratory, Maastricht University Medical Centre, Maastricht,

The Netherlands

\section{Dr. Martin Schmitz}

RapidMiner GmbH, Dortmund, Germany

\section{Dr. Margot Vander Laenen}

Department of Anesthesiology, Intensive Care, Emergency Medicine and Pain Therapy, Ziekenhuis Oost-Limburg, Genk, Belgium

\section{Dr. Leo Anthony Celi}

MIT Institute for Medical Engineering and Science,Massachusetts Institute of Technology, Cambridge, Massachusetts, United States

\section{Prof. Dr. Cathy De Deyne}

Limburg Clinical Research Program, Faculty of Medicine, University Hasselt UH, Hasselt, Belgium

Department of Anesthesiology, Intensive Care, Emergency Medicine and Pain Therapy, Ziekenhuis Oost-Limburg, Genk, Belgium

\section{Prof. Dr. Admir Hadzic}

Department of Anesthesiology, Intensive Care, Emergency Medicine and Pain Therapy, Ziekenhuis Oost-Limburg, Genk, Belgium \& New York School of Regional Anesthesia, New York, United States

\section{Dr. Antoine Simons}

Cardiovascular Research Institute, Maastricht University, Maastricht, The Netherlands

\section{Prof. Dr. Kurt Vanderspeeten}

Department of Surgery, ZOL, Genk, Belgium

\section{Dr. Dana Huskens}

Synapse Research Institute, Maastricht, The Netherlands

\section{Dr. Mark Roest}

Synapse Research Institute, Maastricht, The Netherlands

\section{Dr. Maud Beran}

Department of Anesthesiology, Intensive Care, Emergency Medicine and Pain Therapy, Ziekenhuis Oost-Limburg, Genk, Belgium

\section{Dr. Bart Lauwereins}

Department of Anesthesiology, Intensive Care, Emergency Medicine and Pain Therapy, Ziekenhuis Oost-Limburg, Genk, Belgium 


\section{Dr. Seppe Dehaene}

Department of Anesthesiology, Intensive Care, Emergency Medicine and Pain Therapy, Ziekenhuis Oost-Limburg, Genk, Belgium

\section{Dr. Kristien Van Pelt}

Central Diagnostic Laboratory, Ziekenhuis Oost-Limburg, Genk, Belgium

\section{Prof. Dr. Joris Penders}

Central Diagnostic Laboratory, Ziekenhuis Oost-Limburg, Genk, Belgium

\section{Albert Van Poucke \& Rosine De Clercq}

I am unable to express all the intellectual and emotional background I am so grateful to have been offered by my dear parents during my life time.

\section{Dr. Sylvie Offeciers}

My lifelong mentor, competitor, the mother of my children, you supported me over en over again. The symbol embedded in the white gloves you received years ago in a different context should best explain the position you take in my life.

\section{Sam, Senne, Seb Van Poucke}

The 3 different mirrors of myself. Thank you for finding everything exterior to my personal boundaries.

\section{Mr. Patrick De Graeve† 22/05/2003}

Patrick, as expert Borland specialist at Microsoft you were tragically paralyzed by a car accident early in life. How grateful I am to have spent the last years with you developing algorithms for color calibration of digital wound images while discussing the different approaches of developing software applications in contrast with medical reasoning. The night I attempted to resuscitate you, will be tattooed in my brain forever. The 2 million lines of code we wrote together will always be in my memory. 




